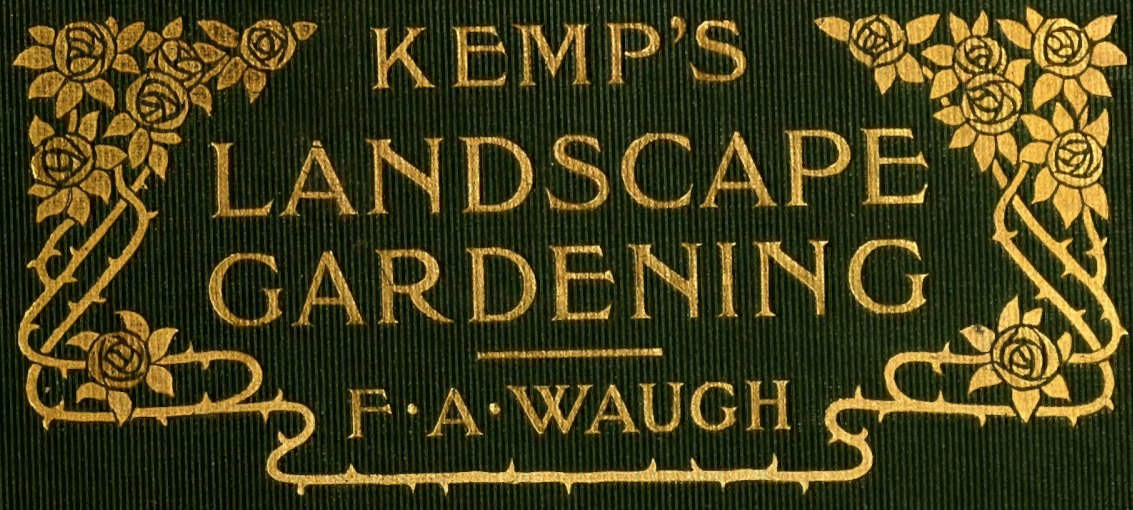



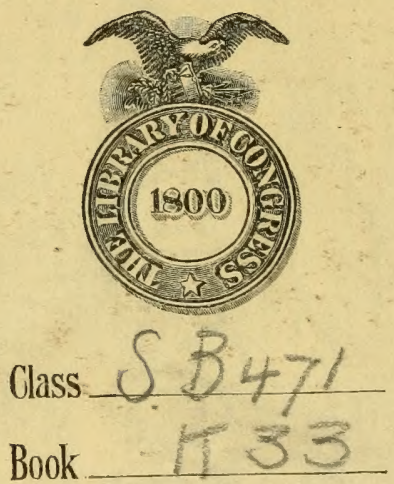

Copyrightt $\mathrm{N}^{0}$

COPYRIGIIT DEPOSIT. 
:

, 






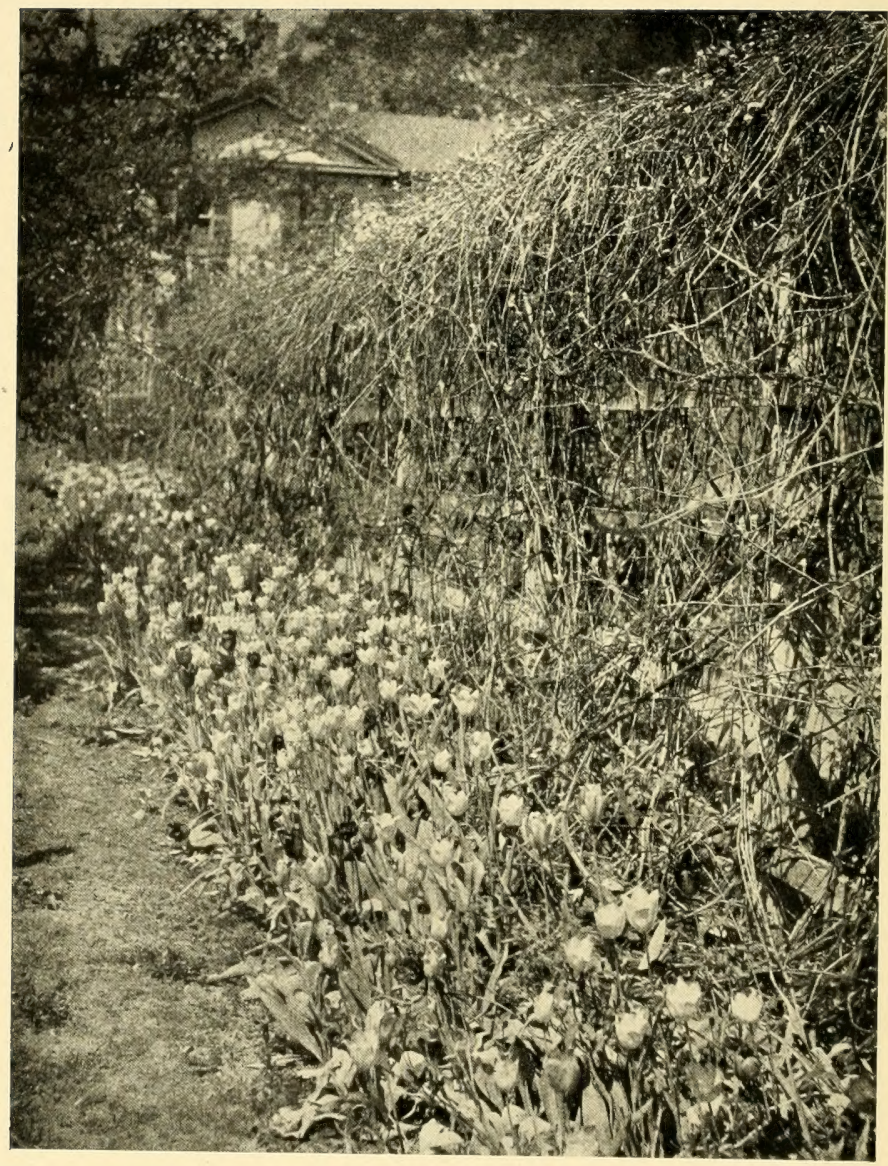

Springtime in the Garden. 


\title{
LANDSCAPE GARDENING
}

\section{HOW TO LAY OUT A GARDEN}

\author{
BY \\ EDWARD KEMP \\ LANDSCAPE GARDENER \\ EDITED, REVISED AND ADAPTED TO \\ NORTH AMERICA \\ BY \\ F. A. WAUGH \\ Professor of Landscape Gardening, Massachusetts \\ Agricultural College
}

FOURTH EDITION

FIRST THOUSAND

NEW YORK

JOHN WILEY \& SONS

LONDON : CHAPMAN \& HALL, LIMITED

1911 


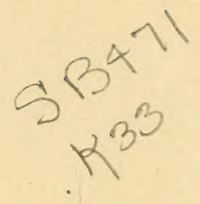

COPYRIGHT, I9I I

BY

F. A. WAUGH

$\because \vdots \vdots$

Stanbope IPress

F. H. GILSON COMPANY BOSTON. U.S.A.

(C) Cl.A280395 


\section{TABLE OF CONTENTS}

PReFACE TAGE

Preface to the First Edition.................. vii

Preface to the American Edition................ xii

Brographical Note....................... xv

CHAPTER I

The Chorce of a Place.................... I

CHAPTER II

What to Avoid........................... 28

CHAPTER III

General Princtples..................... 46

CHAPTER IV

The Several Styles...................... IO 7

CHAPTER V

Practical Considerations................... I 27

CHAPTER VI

Particular Objects........................... I75

CHAP'TER VII

Spectal Features........................ I 94

CHAPTER VIII

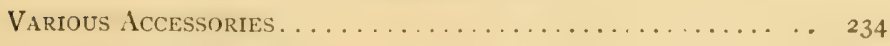

CHAPTER IX

Practical Directions. . . . . . . . . . . . . . 257 



\section{PREFACE TO THE FIRST EDITION}

IT is a salutary axiom, especially in this book-making age, that no volume should be sent before the public without something beyond a private reason for its appearance. It requires to be shown that other people have an interest to be served by it, and that the author's own pleasure or advantage is not alone consulted.

But even this plea, however well made out, will not be a sufficient or satisfactory excuse for publication, unless the work be very erudite or far in advance of the times and calculated to benefit future generations. For an ordinary volume, on a common subject, the additional justification of being adapted and required for the use of large numbers of the people is demanded.

How far, then, these requirements can be substantiated in reference to the present unassuming little essay the reader will easily be able to judge when its origin and purport are explained.

Having spent a good deal of time in passing through the suburbs of large towns, the author, in common with many others whom he has had the opportunity of conversing with, has been very much impressed with the incongruity and dullness observable in the majority of small gardens, and been led strongly to wish that the general appearance of such districts were more gratifying to the passers-by, and the arrangement of individual gardens more productive of pleasure to the several occupants. There is such a humanizing and elevating influence about everything that is really beauti- 
ful, whether in Art or in Nature, that it is almost impossible for the observant wayfarer to stumble upon such objects without being cheered and benefited, while their effect on those who have them daily beneath their eye is of a still deeper kind.

From the author's every-day intercourse with gentlemen who are either laying out new grounds or are seeking to amend errors in design formerly committed, he is also enabled to perceive that sound and useful information is greatly wanted on the subject of landscape gardening, and that to this defect are mainly attributable the deformities so lamentably frequent. He feels certain, moreover, that other landscape gardeners will bear him out in the assertion, that their services are more employed to remedy irregularities which have been fallen into for want of due consideration and enlightenment, than to furnish entirely new designs. And the difficulty and expense of rectifying such errors can scarcely be overestimated. It is wisely ordained that while a truly beautiful object will yield permanent and increasing delight, everything of a contrary nature is nearly sure, at some period or other, to pall and disgust the mind.

As far as the writer's own observation has extended, - and he has reason to believe that is a fair criterion of the real facts of the case, - there is no want of appreciation, among the classes for whom this work is intended, of what is tasteful and elegant in gardening. Most persons are able to admire a chaste and beautiful garden when they see it. What is rather required is something or some one to develop and guide their tastes and direct them to fitting objects.

On all these accounts, then, and as a humble but earnest effort to supply these demands, the book now submitted has been written. It is clearly required by the multitude, for how few there are among the middle classes who do not possess a 
small garden! And the very extreme of smallness will not exclude a place from the beneficent influence of art, which is, perhaps, all the more necessary and powerful in proportion as the limits become more contracted. Still, a garden varying in extent from a quarter of an acre to four or five acres, and either wholly without an accompanying field, or having one that comprises from one to twenty-five acres, is what has been chiefly kept in view.

Nor will places of greater size and more pretension than have been actually contemplated in the outline of the work be altogether beyond its range. Unambitious as it is in its title and leading object, it may not be without interest or use to the proprietor of a large domain. In its radical principles art is essentially the same, whether it apply to a great or a little object; and, relieved of whatever is peculiar in its reference to small places (this being distinctly pointed out, where it is requisite to do so) the points of which the book prominently treats are such as embrace both extensive and limited estates indiscriminately. The author's hope is, consequently, while writing for a large and particular section of the community, not entirely to shut out a smaller but higher or more wealthy class.

The work of the late indefatigable Mr. Loudon, on Suburban Gardening, being somewhat of the nature of the present more restricted production, may be mentioned with the greatest respect, as a voluminous and ample treatise on everything relating to the subject. The book now submitted covers but a fragment of the same field, without, it is believed, at all trenching on the province of its predecessor, it having been the aim to avoid, as far as possible, traveling over beaten and frequented ground. The price and portableness of this volume will further place it at an immense distance from whatever has preceded it. 
Such being, in brief, the nature, object, and occasion of the essay which follows, a few words only remain to be said on its materials and execution. There is nothing of egotism (certainly nothing intentional) in the remark that these pages have sprung out of the author's own reflection and observation, and have often been jotted down of an evening, or during a journey, as the result of daily experience. It is very likely that a more finished and comprehensive and readable book might have been produced by the use of frequent quotation and copious illustration from other and less easily attainable works. This, however, was no part of the original plan; though it should be added, that since its completion the best books on the art have been glanced over, and a few valuable hints, which have been mostly acknowledged, gleaned from Sir Uvedale Price, Mr. Repton, and Mr. Loudon. The work of Sir U. Price on "The Picturesque" is probably the most valuable thing of the kind in our language. To have collected more from these, or Mr. Gilpin, or any other authority, would have entirely altered the limits and intention of the essay.

At the outset of his task, it was the author's purpose to have illustrated the volume with a number of woodcuts, showing how the various suggestions might be actually carried out, and supplying designs for a few gardens of different sizes in the two principal styles. Well-selected lists of the several tribes of plants suitable for gardens of limited dimensions were likewise to have been inserted. But it was soon found that the first of these would have materially increased the price without adding greatly to the efficiency of the book, while the catalogues in question would also have seriously enlarged its bulk. Mere lists of plants, too, are of such common occurrence in other publications, that they do not seem to be wanted; and general designs for places, or sketches of 
particular objects, are seldom capable of being applied, without much modification, to individual gardens.

With regard to the style and manner of the work, the author confesses some little fear lest it should be deemed too elaborate or dogmatical. The first of these faults, if it have any palpable existence, has originated in the wish to render the matter as expressive, as dense, and as serviceable as possible. It is mainly due to the aim at obtaining brevity and force, without omitting anything. And on so comprehensive a theme it is hardly surprising that the matter should have accumulated to an extent by no means originally contemplated, so that the object indicated by the title may even seem to be unduly departed from. This will, however, be more than justified by the fact that there are yet a great many things, not without interest or importance, unavoidably omitted.

For the second defect, which appears more manifest and serious, a similar excuse may in part be alleged, with the additional plea that practical information can hardly be made altogether suggestive, and must, to some extent, become dogmatical, unless it be conveyed in a very circuitous form. At any rate, it is hoped that this will be considered simply as a fault of manner, and not as indicating a positive or presumptuous disposition, which is utterly foreign to the author's purpose.

With these frank admissions he now submits his little volume to the test of public opinion, assured that, whatever may be its fate, it will be judged by the substance of what it contains, and not by the mere accidents of manner and composition.

BirkenheAd Park, LtVerpool.

\section{EDWARD KEMP.}




\section{PREFACE TO THE AMERICAN EDITION}

When it was first proposed that I undertake the American revision of this work I accepted the opportunity with high anticipations. Kemp's Landscape Gardening was one of the first books on the subject I had ever read, and one of the most delightful. I had used it for years as a reference book in my classes. I expected that the work of revision would be easy and entertaining.

So far as the simplicity of the task was concerned I was soon better informed. Though I have not ceased to enjoy the work, I have found it a much greater task than I had supposed. On hundreds of pages it has been almost impossible to separate the gist of good advice from the detail of old English practice in which it was imbedded. Oftener than I had expected I found myself in disagreement with the recommendations of the author. In such cases it became very difficult to decide whether the author's methods had been outgrown in the general improvement of landscape gardening since his day, whether his methods were simply unfashionable at this moment in America, or whether it was merely a difference of opinion between author and reviser. In cases of the first kind I have not hesitated to eliminate outgrown methods and to substitute the rules of more modern practice. In those of the second kind, where merely a changing fashion is involved, I have usually retained the author's views, adding some note of present American ideas. In cases of the third kind, where there appeared to be only a difference of opinion, it is hardly necessary to say that I have allowed 
the author's text to stand intact, reserving the expression of my own views for some more appropriate opportunity.

The reader will readily understand, therefore, that where the personal pronoun, first person, occurs in the text it always means Edward Kemp.

The work of Kemp will be better understood and more enjoyed if it is studied in connection with the work of his contemporaries, particularly Repton, Milner, Loudon and Downing; for America, the comparison with Dorning is most natural and most instructive. There is, of course, no space in this book for a critical comparison of these various workers, but a slight introduction to such a study will be found in the biographical note on Kemp included herewith. There is every reason to believe that, with the remarkable popularization and no less remarkable liberalization of landscape art now going on in America, there will be more interest than ever before in the work of those great men who established the English (and therefore the American) style of landscape gardening.

\section{F. A. WAUGH.}

Massachusetts Agricultural College,

January, I9II. 



\section{BIOGRAPHICAL NOTE}

EDWARD Kemp was born at Streatham, Surrey, England, September 25, I8I7, and died at Birkenhead, Liverpool, England, March 2, ISgI, in his seventy-fourth year. Even at this early date, less than twenty years since his death, there are very few details of his life and work to be learned.

His technical training was gained in the gardens of the Royal Horticultural Society at Chiswick, under Dr. Lindley, and subsequently in private work under Sir Joseph Paxton. In September, I843, at the age of twenty-five, he was made superintendent of Birkenhead Park, Liverpool, and the remainder of his life was closely connected with that particular enterprise. He designed a number of private places, several of which are illustrated and described in the various editions of his books.

His debut as a writer came in 1850 , when he put out a small volume under the title "How to Lay out a Small Garden," which was really the germ of the present book. A second edition, illustrated and much enlarged, was issued in 1858 . A third and yet larger edition appeared in 1864 . The chronological list of his principal writings is as follows: r850. "How to Lay out a Small Garden"; intended as a guide to amateurs in choosing, forming or improving a place, with reference to both design and execution. London, Bradbury \& Evans. 2I 2 pp., 8vo.

I850. Editor, "The Handbook of Gardening," tenth edition. 
I85 . . "Parks, Gardens, etc., of London and its Suburbs." London. I $2 \mathrm{mo}$.

I858. "How to Lay out a Small Garden," 2 d ed., enlarged and illustrated. London. I2mo., about $400 \mathrm{pp}$.

I858. Same. First American edition, Wiley \& Halstead. New York. 403 pp., I 2 mo.

I864. Same. Third Edition (English) again revised and enlarged. London, Bradbury \& Evans. 428 pp., 8 vo.

I880. Same, Second American Edition, John Wiley \& Sons, New York. 403 pp. I 2 mo.

At his death Mr. Ke mp was buried in Flaybrick Hill Cemetery, Birkenhead, of which he had been the designer. At a meeting of the Burial Board for the Parish of Liverpool held at their offices, Anfield Park Cemetery, on Thursday the $2 \mathrm{~d}$ of April, r8gr, it was unanimously

"Resolved, That the Board has heard with much regret of the recent death of Edward Kemp, Esq., the eminerit Landscape Gardener and Garden Architect to whose genius Liverpool and its Burial Board are indebted for the Anfield Park Cemetery. Mr. Kemp furnished the Design, also zealously and faithfully attended to the laying out and embellishment of the Grounds.

"Through his strict integrity and dignified conduct the Burial Board soon after its origin escaped many evils, and, prompted by his solicitude for the future good management and reputation of the Cemetery (at the request of the Board and in its interest) he induced his Draughtsman, Assistant and Friend, Mr. Wm. Wortley to undertake the Superintendence of the Estate, which he has so ably managed for the period of twenty-eight years.

"Further, that this Resolution be recorded upon the Minutes as a tribute of high respect to the memory of the departed, and that this expression of the Board's sincere 


\section{Biographical Note}

regret and condolence be conveyed to the Relatives of the Late Mr. Kemp."

\section{Extracted from the Proceedings, ELEAZOR ROBERTS, Clerk to the Burial Board.}

A memorial card circulated at the time of his death had, according to the then prevailing fashion, a tribute in verse, which read:

"He made the Landscape meet the eye With Beauty: and turned the barren wastes To noble Parks and Gardens of the Lord. Thus Nature's rugged face By Art he wreathed with winsome smiles That woo'd the Children of the City, and the Sons Of grimy toil and gave delight to all."

$$
\text { J. C. P. }
$$

Although I have employed two expert English antiquarians for the search, and though I have myself visited the scene of his principal labors for the same purpose, it has not been possible to add any important facts to this meager biography of an able and useful man. His most enduring memorial will certainly be his book on "Landscape Gardening; or How to Lay out a Garden."

F. A. WAUGH. 



\section{LIST OF PLATES}

Springtine in the Garden.......................... Frispiece Plate

Or. Page

I. Stone Steps with Plantings............... Io

II. Shores of the Charles River.............. 26

III. On the Biltmore Estate, North Carolina....... 42

IV. Lawn Vista from House Veranda........... 58

V. Lawn Vista and Groupings............... 74

VI. Old-fashioned Garden................. 9 90

ViI. Rustic Bridge in Rock Creek Park........... Io 6

VIII. Wistarias and Subtropical Plants........... 122

IX. Entrance and Drive, Biltmore Estate......... 138

X. Plantings along a Drtveway............... I54

XI. A Pleasant Winter Walk. ................. 170

XII. Excellent Water Surface with Background and SKY LINE. . . . . . . . . . . . . . . . . . . . I 86

XIII. Vista across a POND .................... 202

XIV. Effective Grouping of Trefs............. 218

XV. Wide Road with Border and Screen.......... 234

XVI. Entrance to a Ten-acre Private Place......... 250

XVII. Effective. Water Surface and Grouping........ 258

XVIII. Pleasant Naturalistic Lawn on a Georgia Estate. . 266

XIX. Good Water Surface, Good Borders, Good BackGROUND, GoOD SKY LINE................ 274

XX. IN the Wild Garden.................. 282 



\section{LIST OF ILLUSTRATIONS}

Figure $\quad$ Pagk

I. Improper Grade for a Lawn . . . . . . . . . . . . . . . . 16

2. Convex-Concave Grade for a Lawn.................. I6

3. Plan of a House with Reference to the Grounds........... I9

4. Arrangement of an American House... . . . . . . . . . . 22

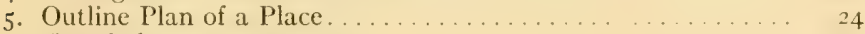

6. Tree Belt - Monotonous. . . . . . . . . . . . . . . 36

7. Same as Fig. 6 - Improved . . . . . . . . . . . . . . 36

8. Monotonous Belt on Rolling Land ............... 37

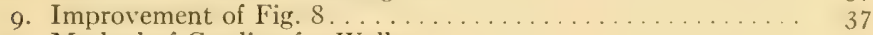

I0. Method of Grading for Walks. . . . . . . . . . . . . . . 57

Ix. Practical Perspective........................ 60

I2. Vista Showing Distant Views....................... 62

13. Treatment of Flat Foreground .................... 64

I4. Treatment of Foreground with Water View ............ 66

15. Treatment of Curved Walk ................... 7o

16. Grouping Shrubs along a Walk . . . . . . . . . . . . . 7 I

I7. Typical Group........................... 7 I

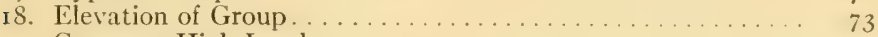

I9. Group on High Land . . . . . . . . . . . . . . 74

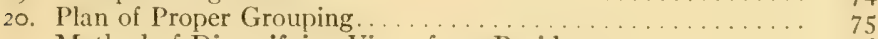

21. Method of Diversifying Views from Residence.......... 76

22. Vistas with Cross-Views. . . . . . . . . . . . . . . 79

23. Treatment of Boundary ..................... S

24. Location of Group on a Knoll ................. $\delta_{2}$

25. Treatment of Grades. . . . . . . . . . . . . . . . . . . $8_{3}$

26. Branching of Straight Walk.................. I Io

27. Various Treatments of Formal Walks................. I I 3

$2 \mathrm{~S}$. Various Forms of Flower Beds. . . . . . . . . . . . . . I 6

29. Other Forms of Flower Beds.................. I Is

30. Terrace Treatment of Rising Ground............... I 2 I

3I. Grades about a House . . . . . . . . . . . . . . . . . . . I 22

32. A Type of the Picturesque .................... I . 25

33. Oblique Turn-in from Public Road . . . . . . . . . . . . . . . I 133

34. Turn-in at Right Angles. . . . . . . . . . . . . . . . . . . 134

35. Carriage Turn for Small Grounds . . . . . . . . . . . . . . . . I $_{3} 8$

36. Carriage Turn with Embellishment. . . . . . . . . . . . . . . $\quad$ I 39

37. Branching of a Walk. ................... I

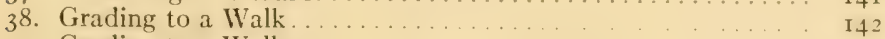

39. Grading to a Walk . . . . . . . . . . . . . . . . . . . 143

40. Sunken Wall or Fence.................... 144 
41. Sloping Invisible Iron Fence. . . . . . . . . . . . . . . . . 144

42. Common Wire Fence Sunken................... I45

43. Boundary Wall with Planting.................. 146

44. Rustic Fence.............................. I4

45. Simple Protector for Tree. . . . . . . . . . . . . . . . 148

46. Tree Protected by Undergrowth.................. I 49

47. Proper Form for Border Planting. . . . . . . . . . . . . . . I $_{5}$ I

48. Two Groups which look like One................. ${ }{ }_{53}$

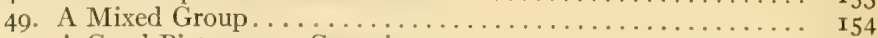

50. A Good Picturesque Grouping. . . . . . . . . . . . . . I 54

51. How to Plant a Hill. ........................ I 55

52. Terrace Disguised by Plantings. . . . . . . . . . . . . . 169

53. Plan of an Architectural Garden. ................. I I I

54. How to Manage a Hedge. . . . . . . . . . . . . . . . . . I89

55. Plan of a Home Park........................ 201

56. Design of Residence Grounds. . . . . . . . . . . . . . . . 205

57. A Secluded Flower Garden...................... 207

58. Design for a Rose Garden...................... 2 I 5

59. The Arrangement of a Collection................ 2 I8

60. Design for a Bowling Green ................... 22 I

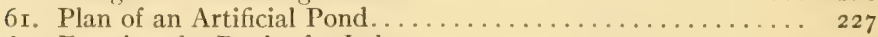

62. Forming the Bank of a Lake................... 229

63. Lake Shore Planting. . . . . . . . . . . . . . . . . . 230

64. Rustic Bridge on Simple Lines................... $23 \mathbf{I}$

65. Design of a Summer House. . . . . . . . . . . . . . . . . 236

66. Gate Lodge and Entrance....................... 247

67. Simple Lodge and Entrance.................... 249

68. Imposing Recessed Entrance. . . . . . . . . . . . . . . 250

69. An Unusual Type of Entrance................... 25 I

70. Plan of a Seaside Garden...................... 254

7 I. Section through Garden Shown in Fig. $70 \ldots \ldots \ldots \ldots \ldots .255$

72. Cross Section of Drain..................... 260

73. Cross Section of Drain......................... 260

74. Excavation for Walk....................... 262

75. Different Forms of Walks.................... ${ }_{2} 67$

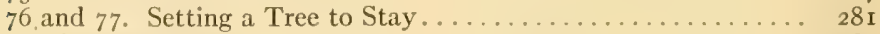

78. Staking a Tree. . . . . . . . . . . . . . . . . . . ${ }_{2} 8_{2}$

79. Staking a Large Tree. .................... 282 


\section{LANDSCAPE GARDENING}

\section{CHAPTER I}

\section{The Chorce of a Place}

From that beautiful variety of taste which brings the commonest persons into association with the more cultivated, and secures for objects that many would regard as inferior a certain amount of approbation and patronage, scarcely any two individuals will be disposed to select, where there is a full latitude of choice and a thorough knowledge of every peculiarity, precisely the same spot for a residence. What would perfectly satisfy one might be displeasing to another. The conditions that some would even detest others might actually covet. And this it is, united to the fact that few can obtain exactly all they desire, and that the alternative must generally lie between situations which comprise a greater or less proportion of the required capabilities, that distributes the population of our towns pretty equally over the suburbs, and brings districts into use that would otherwise remain entirely waste or be devoted only to the farmer or the grazier.

Railways, however, with their annual contracts for conveyance, and the rapidity, ease, and certainty of transit, are now gradually bringing other parts of the country within the range of selection, and enabling the town merchant or man of business to locate himself from ten to twenty, or even forty or fifty miles from the town, and thus get the benefit of country air and rural pleasures. And from the greater abundance 
and cheapness of land in such districts a wider field of choice is afforded, and more scope for the exercise of judgment and taste.

Although, therefore, every person will necessarily have his own peculiar inclinations, and the opportunities of gratifying a refined feeling may be very limited, it is right that a book like the present, which professes merely to be suggestive, should point out those characteristics most generally desirable in a place, and which might not be thought of, or would possibly be but lightly regarded, if not thus specifically presented, leaving every one to the exercise of his individual wishes.

I. Accessibility. - The question which first arises in the mind of an inquirer after a site for a residence is determined is, how it will be accessible. There may be different opinions as to the kind of road preferable for getting at a dwellingplace, but an actual necessity exists that there should be some convenient mode of access. Many would desire to fix themselves near a well-frequented road, while some would rather be situated on the side of a more retired and private thoroughfare. It will be obvious however, that the road by which a place is approached should be a sound one, likely to be kept in good repair and capable of being used at all times. A bad road that has to be frequently traveled, is not merely an inconvenience and a nuisance, but gives a most unfavorable impression of a place to visitors; and a private road, that is closed at night, may occasion a good deal of trouble and discomfort.

To settle in a place to which there is no good road already formed, or where one cannot be built, will seldom be otherwise than productive of misery. A mere expectation that a road will be made should never be held sufficient, for a house may stand in a state of isolation several years, cut off, as it were, from all proper connection with the world, if the road 
to it or past it be not already in existence or certain to be opened.

It will be well to calculate, further, the length of road or drive which will have to be made and kept in order by the owner or occupant of a place. Road-making is an expensive process in most districts, and the due preservation of roads is always troublesome. While, therefore, the having to provide a considerable length of private drive in order to get at a place will be an advantage in the way of conferring more privacy and retirement, it must be looked upon as a source of increased outlay and additional subsequent labor.

Where there is any possibility of obtaining such a piece of land, it is most important that it should have a public road along one of its sides only, and that this road should be on the north, north-east, or north-west boundary. Access will thus be given to the house at the point which is of least consequence in regard to views, and the warmer and better sides can be kept open and private. Entrance from any other point would always more or less interfere with the lawn and the more ornamental parts of the garden, besides laying bare some of the best windows of the house or involving the necessity of giving these an inferior aspect. This is assuming, however, that the site be chosen with reference to a proper aspect and views for the house.

Comparative nearness to a railway station will, even where a vehicle is kept, be a decided acquisition; for there are certain to be times when either the owner or his friends will want to make use of these conveniences. In wet weather, especially, it will be unpleasant to have to walk far before reaching some kind of conveyance.

Proximity to some seat of business, where at least the necessaries of life can be readily procured, will also be an advantage. To have to send a great distance for articles of food when 
there may be an unexpected demand for them, will generally be a heavy tax upon patience and time. The situation ought likewise to be within reach, by an easy and pleasant walk, of some suitable place of worship.

It should be recollected that roads on which there is much traffic bring a large amount of dust at certain seasons, while they render a house and garden more exposed to observation from the foot-passengers or the travelers on public vehicles. A place on a small and less frequented road, at a little distance from a great highway, will therefore be more comfortable and more secluded than one which lies by the side of a turnpike road. And this view of the case will further serve to show the undesirableness of having a property entirely surrounded by roads. Arable lands, fields, open country, or other gardens and private estates, will be the best possible accompaniments on all the southerly sides of a place.

Anything in the way of a public path crossing a property, and severing it into two parts, or a public road passing across a plot in the same manner, would seriously prejudice its value. When such things are carried through an estate without being fenced off, they lay bare certain portions of it to the public eye, and, what is worse, subject it to continual trespass. And to fence off a path or road of this description would greatly mutilate a place, and give it a small and confined appearance. Nor is it at all easy to get established pathways diverted, unless a more direct route can be prepared for them. The nuisance of having a place thus open to the use of all, in populous districts, can hardly be exaggerated.

In this, as in a variety of similar cases, however, circumstances that would be inconvenient and objectionable to most persons might be altogether unproductive of annoyance to others; for no rule of life is more true or of more universal 


\section{The Choice of a Place}

application than that things are not so much discomforting or pleasurable in themselves, but are just what they are considered to be. So that what would be intolerable to many might become perfectly inoffensive to those who were determined to regard it favorably.

2. Neighborhood Environment. - Besides the advantage of having the property on the best boundaries of a place congenially treated, and appropriated to agricultural or garden purposes, or left to the rudeness and picturesqueness of nature, it is of consequence that the whole of the surrounding property be of a similar character, and that it be not covered with cottage tenements, or crowded with any kind of inferior houses, or the atmosphere darkened by the smoke and polluted by the gases from large manufactories. To live amidst fields and gardens and cultivated or unassisted nature, or to have only the vicinity of kindred or superior places, is a luxury well worth the sacrifice of some trifling conveniences and the traveling a mile or two further from a town. There is so much calculated to offend and to annoy in a closely peopled neighborhood, especially if it be crowded with small cottages, that the majority of persons will gladly shun it.

Not only, however, will it be well to look closely into the character of the surrounding district, and ascertain how it is actually built upon or appropriated, and by what class of persons it is populated, but the probable uses of the neighborhood should likewise be considered. A particular locality may at the time of choosing it appear highly rural, and have every desirable characteristic, whereas in a few years it may become densely covered with small houses or obnoxious manufactories, be cut up into narrow roads, and otherwise be completely spoiled as a place for residence. For all these things, then, due calculation must be made; and though no human foresight can reach anything like certainty in such 
a matter, especially considering the rapid transitions which property is now frequently undergoing, diligent investigation will commonly prove a tolerably safe guide.

Those localities unquestionably offer the greatest security in regard to the preservation of a respectable and partially rural character wherein large tracts are in the hands of one or two proprietors who bind lessees or purchasers to build only a certain number and class of houses on the land and themselves agree to lay it out strictly according to a definite plan. Here there is something approaching to absolute certainty, and a person may settle on a given spot with the full knowledge of what alone can be done by all his neighbors, and the actual pecuniary and social status of those neighbors.

Where several plots of land overlook fine natural scenery, as on the shores of large rivers, lakes, or the sea, that which is nearest the object itself will generally be the most eligible, if other things are about equal. For the view over a natural landscape that is incapable of alteration, and with no intervening space that can ever be used by another party, becomes perfectly safe from interruption at any future period, and may be treated much more liberally and with reference solely to individual wants and tastes. Every position farther from the scenery most worth preserving, however unencumbered the view from it may be, will be liable to have that view more or less intercepted by the uses to which the interposing property may be put, unless the elevation be very considerable and the slope of the ground rapid and almost precipitous.

If, again, land on both sides of a public road commands the same beautiful scenery, that which is on the side nearest the scenery itself will be greatly superior as the site for a house and garden; because, on the opposite plot, a partial plantation will have to be made to screen the place from the road, and this will, to some extent, block out the view, while 


\section{The Choice of a Place}

the owner will be thoroughly dependent, in respect to landscape, on what may be done by his opposite neighbor in the way of both planting and building. It will be most unlikely - almost impossible - that some of this latter should not entirely obstruct every open sight into the country beyond.

3. Historical Considerations. - What has formerly been done upon a place may be by no means an insignificant, and will certainly be an interesting, question. The part which it plays in local histories or legends, and the associations which previous ownership or occupation or uses may fasten upon it, are all worthy of scrutiny, and may help either to endear and enliven a spot or to clothe it with gloomy and repulsive features.

To be able to trace back the possession of a property by one or more families through a long series of years will be almost as pleasing to some minds as haring a lengthened and well-ascertained personal pedigree; and though many would not care to know who have been the former owners and for how long a period the history can be made out, to others such a record will be full of attraction. The very trees and shrubs, if any old ones exist, will be all the more pregnant with interest when it is authentically made out by whom and when they were planted.

In reviving ancient recollections and usages, or searching after mementos of former times, a variety of hints may be gleaned as to the treatment of a place, or objects brought to bear upon the composition of its landscape, which will be exceedingly remunerative. A valuable spring or well may be laid bare; a charming ruin may be contrived from existing fragments; the first step in a train of interesting antiquarian researches may be stumbled on; family histories, which are often the key to greater memorials, may be brought to light; 
and, what is not entirely unimportant, an excellent and characteristic name for the property may be suggested: for, in the prevailing fashion for distinguishing every place, however small, with a separate title, those are usually happiest who have some historical or local circumstance on which to found it. The old and common names of fields are often highly characteristic, and, when sufficiently descriptive or euphonious, there is great propriety in adopting the ancient title of any part of a property intended for a residence, but more particularly of the field on which the house is to be built or the garden founded.

4. Altitude. - The relative elevation of the district, or of the particular site selected in it, will have a great influence on the healthiness, comfort, and scenery of a place. A tract that is low and flat is always damper, and consequently colder. I have often noticed dips in a road along which I have been accustomed to travel in winter evenings, where, by the much greater coldness of the atmosphere in such lower parts (even though no water existed), I could distinguish the arrival at them with closed eyes; and where rivers or streams or other pieces of water exist in hollows, their dampness and coldness are of course increased. Fogs are always more prevalent in valleys or low level tracts, and it is a well-ascertained fact that spring frosts are felt much later, and autumn frosts earlier, in lowland districts and near the course of streams than on the sides or summits of hills.

A rather elevated or hilly tract, though more exposed to winds than a flatter locality, will, if it have a good aspect and slope in the right direction, be drier and warmer in winter and command much finer views of the country. It will be more likely to be free from all kinds of nuisances, to be out of the way of cottage property, and to escape from the gaze of travelers along contiguous roads. Where a house and 


\section{The Choice of a Place}

garden are lower than the outside road, it is extremely diffcult to shut them in effectually. From a gentle eminence, too, it will be easy to conceal all the bad features of the adjoining property and to make use of all the better objects in enhancing the beauty and variety of a scene.

Any extravagant height, however, above the rest of the country will produce an amount of exposure, both for the house and the garden, which will destroy some of the enjoyment derivable from a habitation and prevent the plants in a garden from flourishing luxuriantly. It would, moreover, occasion some inconvenience in regard to the approach. To have constantly to toil up a steep ascent before a place can be reached will neither be agreeable to man nor horse, and will contribute somewhat to lengthen the journey. A very moderate elevation is therefore best, and will be specially appropriate where any member of the family has delicate health and cannot endure much in the way of bracing winds.

5. Soil. - Of almost greater moment than the altitude of a district is the character of the soil, and this, rather as it affects the health and the comfort than with reference to its influence on garden produce and operations, although the latter is far from being a matter of indifference. Scarcely anything will grow well on thoroughly stiff land, and it is very unpleasant and laborious to work it, besides requiring more attention as to the choice of weather for going upon it than can usually be afforded.

Nothing is more unsatisfactory than to have a house and garden on a clay soil. No amount of draining will convert it into an agreeable and open state. And whatever ingredients may be added, or amelioration by working it may be attempted, it will still remain more or less cold and sticky, and in some degree unfit for developing vegetable life perfectly. It will be bad to keep clean, and to dig, and to crop, 
and to walk upon. It will be cold and greasy in wet weather, and cake together and crack during drought. Few vegetable crops will succeed in it, and a still smaller number of flowers. Even grass grown upon it will generally be either very wet or very dry; and the atmosphere above it will be correspondently cold and moist throughout the winter. Unless the utmost care be used to prevent any part of a building from coming into contact with it, a considerable dampness will be communicated from it to the walls, and a house will thus be made exceedingly miserable.

Land of a light and open texture is, on the contrary, conducive to both health and enjoyment and renders a house comfortable and a garden delightful at all times. It never becomes too wet; it is readily worked in almost any weather; it makes a lawn pleasant to walk upon and encourages the growth of the finer grasses; it is the best of soil for flowers, and, with due enrichment, for vegetables and fruit trees; and; in short, for any purpose it will be found either perfectly suitable or capable of quickly being made so.

Nor is the surface soil alone of consequence, for the substratum will continually more or less affect the upper crust. A cold and clayey foundation soil, or a close retentive layer of gravel, will act upon the roots of all the larger growing plants, and tend to produce feebleness and disease after they have once reached it. A rocky, chalky, or sandy bottom will be much the driest, and altogether the most calculated to promote human enjoyment and vegetable health.

It follows, therefore, that a light and porous (though not a very sandy or friable or shallow) soil, on a dry and open, or rocky foundation, will be the best to build upon, so as to secure dryness and warmth in a house, and the fittest to make a garden pleasurable and to supply the conditions most needed by the bulk of vegetables, flowers, and fruits. 


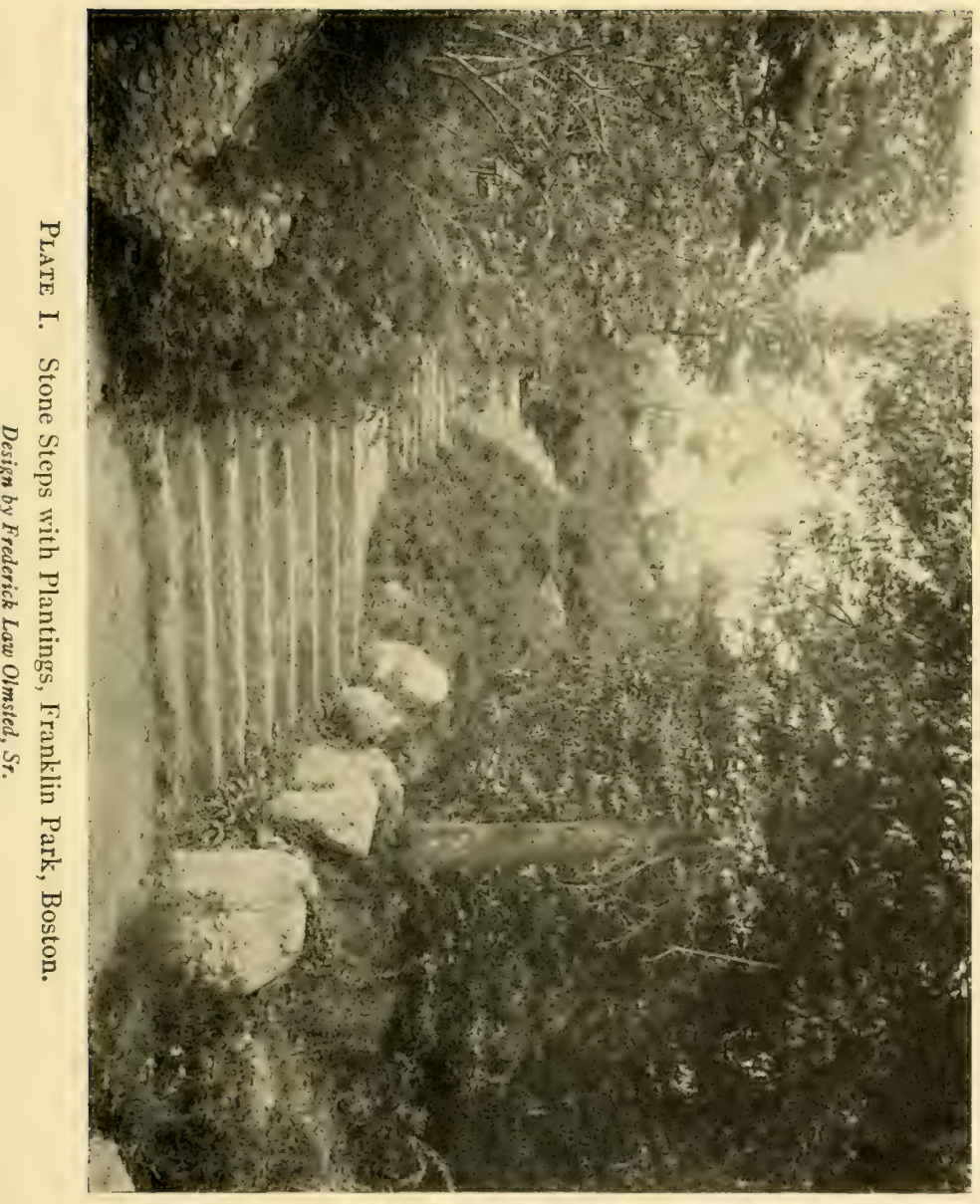



And it will, in point of economy, do away with some, at least, of the necessity for artificial drainage.

Lest this conclusion, however, should be unduly appropriated, it may be well to state that it applies only to garden ground and to the site of a residence; and that, even for the former, any extreme of lightness or sandiness will be apt to occasion withered grass in the summer and the necessity for increased manuring in the kitchen garden. For all farming purposes a moderately heavy land is decidedly preferable, as, if properly drained and carefully worked, it will yield far more abundant crops at a much lighter expense in the way of manure.

6. Boundaries. - With respect to the shape or outline of a small place, that form is most suitable which is simple, free from all acutely angular corners and any great irregularities. A place that has many angles or a very broken outline is less capable of being made either useful or ornamental, and requires a larger amount of fencing, which is always expensive. Very narrow pieces of land are also to be avoided, as affording no scope for variety of treatment and presenting the hard boundary lines too prominently.

That boundary is unquestionably the best which is composed of pretty regular lines and brings the whole into a somewhat oblong figure, of which the greatest length is north and south, or nearly so, the length being about one-third greater than the breadth. Such a shape is particularly adapted for the geometrical style of gardening. In the freer Fnglish manner a little more irregularity of outline might be preferable. If the southerly end of such a plot be the broadest, this will be a decided merit generally, as it will afford a wider range of view and make the whole appear larger from the best windows of the house.

A nearly triangular figure, the narrow end of which is cut 
off and not drawn to a point, and the broader end having a rather southerly aspect, will be a desirable shape for a small piece of land. If there be space enough for the entrances on the northern side, the increased and expanding breadth at the southern part will be of great consequence from an ornamental point of view. At the same time nothing could be more unfortunate than to have a plot gradually narrowing away on the best side of the house; and a shape at all approaching to a triangle, with the narrow part fronting the principal windows of the house, would be one of the worst that could be selected, unless the slope of the land be a very rapid one towards the south, and the property immediately in front be of a decidedly open and park-like character.

On the whole, then, the spot that requires the least quantity of fencing, which gives sufficient room for access on the entrance front, and which widens out towards the extreme verge on the best side of the house, will, by admitting a greater breadth and variety of prospect, and more light and air, as well as by imparting an appearance of extent and rendering the fences cheaper and easier to preserve, be in all respects preferable.

7. Climate. - Where a person is in some measure tied to a particular district by business or other connections, of course there cannot be much latitude of choice in regard to climate. But those who have habituated themselves to observe differences of this kind will know that within the circuit of a few miles around any town there will be found the most striking variations of climate, according as certain winds prevail or particular degrees of elevation or forest growth exist.

In the neighborhood of towns a linowledge of the prevailing winds is of very great moment, for at the opposite point from which they come there will generally be a greater visitation of smoke and other nuisances. But if the parts over 
which smoke would thus frequently travel are elevated, the atmosphere will not be so much polluted as it would were they low and flat. Hilly tracts, again, as previously mentioned, are not so liable to be affected with dense and disagreeable fogs.

Regarding the most desirable aspect for a place, more positive rules can be given. A slope that inclines to the southeast is unquestionably the best for every purpose. It is more healthy, more cheerful, better suited for the growth of plants, drier, and warmer, than any other that can be chosen.

A garden that has not a good aspect is seldom enjoyable. It will usually be damp and cold, the walks mossy, and the plants unhealthy. It will be wanting in the great charm produced by light and shade. Flowers will not develop themselves freely and finely nor will fruits be abundant or good. In fact, with a bad aspect, the beauty of a garden and the pleasure it produces will be greatly marred.

It is true that, in looking over an extensive landscape, the effects are sometimes heightened and improved, and the observer is able to examine them better, when the sun is behind him, and he can stand in the shade to scrutinize a richly illumined scene. Every feature thus becomes more distinct, the eye is not pained or dazzled, and the atmosphere appears clearer. But the benefit obtained by these results would never atone for the great disadvantages of a northerly aspect; and they can, moreover, often be realized from the entrance front of a place, without any sacrifice of outlook.

8. Shelter. - To render a place of residence thoroughly delightful it should not be destitute of shelter; and, where this exists naturally, or is already provided, the spot will be all the more eligible as the site for a house and garden.

If a good range of hills extend along the north, north-east, and north-west sides of a plot and at no great distance from 
it, it will be admirably sheltered. No position could be warmer or more favorable than one on the slope or at a short distance from the base of such a range of hills. They will ward off all the worst and most unhealthy winds to which this country is exposed, without at all interfering with the action of the sun at any time of the day, or during any part of the year.

In hilly countries, there is often a considerable depression or hollow in the face of the hills, caused by the projection of large arms or buttresses on either side; and the basin thus formed, if it front any point near the south, will yield a particularly warm and snug retreat for a house and homestead.

Masses of well-grown trees on the northerly sides of a place would be an excellent substitute for hills, and may occasionally be more pleasant and congenial. Plantations are always highly effective in regard to shelter, and it is a great point to find them already on the ground.

Independently of shelter, however, if trees have not been drawn up and spoiled by neglect, there can scarcely be too many of them on any spot intended for habitation. Nothing is easier than to thin out and remove them, and there is always a great pleasure resulting from the formation of openings through old plantations, to get views of the outside country. If the trees be not unhealthy, therefore, and are well supplied with branches, the more abundantly they exist, the greater will be the capabilities of a place. Large or aged trees and shrubs are also valuable in destroying all semblance of newness or rawness in a garden, in giving an appearance of age and cultivation, in shutting out bad objects, in improving the outlines and grouping of new plantations, and in supplying an increased amount and play of agreeable shadow.

Available outbuildings, or walls, or fences of any kind, should not be wholly disregarded. A good existing fence, 
especially if it be a hedge where such a thing would be wanted, will be of the greatest use, as it would take many years to rear it. But it is better that a plot should be wholly without every description of appurtenance than that things of an improper class or of bad construction or in a wrong position should exist to tempt the purchaser to retain them, as the greatest dissatisfaction is commonly experienced from patching up an old house or other building that is not strictly suitable, and which can never afterwards be made so. It is far more pleasurable, and in the end more economical, to arrange and erect everything anew, than to submit to great inconvenience for the sake of preserving some relic of things that actually exist, because they happen to be ancient.

9. The View. - Whatever kind of view is sought to be obtained from a place can be best compassed where it is situated on a slight eminence; and the rule will hold good whether the view be one of the garden itself, as seen from the house, of natural scenery, of an arable and agricultural district, of other estates, of a river or a lake or the sea, of distant hills, or of good individual objects.

In relation to the garden itself as viewed from the house, some modification of the principle may perhaps seem necessary. Although a place, the ground of which rises as it recedes from the house, appears larger, because more of its surface is seen, yet the reverse of this would be the case when looked at from the outside of the garden or from any point just within its boundary; and a slope from the house gives to the latter an appearance of dryness and importance, and enables one to bring in the exterior landscape more easily. This may be better understood by reference to fig. I, which represents a piece of land the form of which is entirely convex, with the house on its summit. If the ground also rises in a gentle bank, just towards the bound- 
ary, such a slope being more perfectly seen from the house, will enlarge the apparent extent; the general section of such a plot being shown in fig. 2. But any great amount of convexity in the surface of the ground as it slopes from the house would be an evil because it would seriously foreshorten the whole and reduce its apparent size materially as

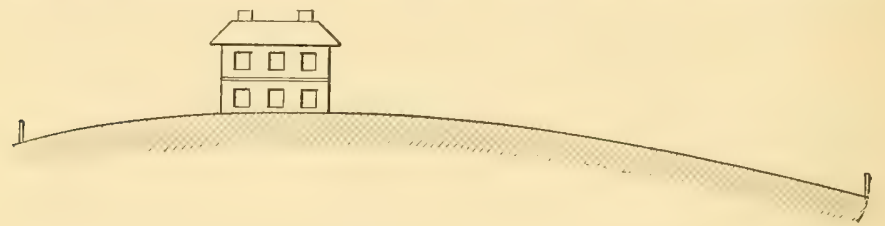

Fig. I. Improper Grade for a Lawn.

seen from the windows. A very gentle slope, with only a small portion of roundness in it, will be preferable.

One of the chief desiderata in regard to the surface levels of a plot of land is to obtain a good platform, which is tolerably level, as a site for the house and garden. This will give the house the appearance of being more naturally placed,

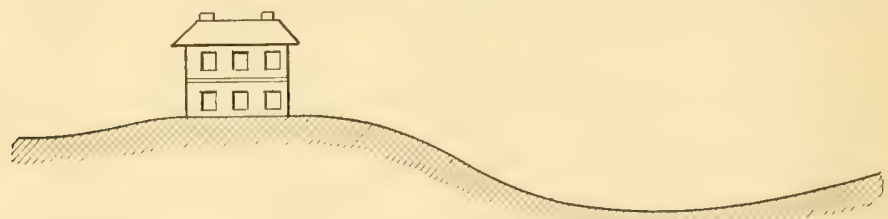

Fig. 2. Convex-Concave Grade for a Lawn.

and will lighten the expense of earthwork and of foundations, while it will, in a hilly country, make the garden more comfortably accessible. As a general rule the summit of a hill, if it be otherwise than a very low one, with a broad piece of table-land at the top, is not so eligible for a house as the face of an easy slope to the south. In the latter case the 
hill itself will afford some degree of shelter and of background, which, with the necessary planting, will soon give a new place a habitable look, such as scarcely any amount of growth in the trees would impart to the crown of a hill.

That the best views of things beyond a garden may be had from a partial elevation will be too obvious to need enfercing. In regard to water however, which forms such a beautiful and interesting addition to a landscape, a point of view considerably above its level will reveal its outline and extent more distinctly, and is therefore better adapted for large and bold sheets of it than for smaller lakes. Still, it will always be more pleasing and comfortable to be a good deal above a piece of water that it may seem in a valley and that the garden may convey the impression of being elevated.

It is far from being desirable that only the features of nature should be seen from a place. The better parts of detached neighboring houses, good public buildings, places of worship, etc., if nicely brought into view, will give an air of habitation and sociality to a district. Rows of houses however, or masses of cottages, unless the latter be pleasing in themselves or picturesquely grouped, will be very unsightly and unsuitable constituents of a landscape. And a spot that overlooks a town, except partially and from a height and so as to catch merely the principal buildings, need never be sought. Still, glimpses of a navigable river, in the immediate vicinity of a large town, may, from the variety and motion of the craft employed upon it, give animation and beauty to a scene. So, likewise, a distant view of a town or of a portion of it where there is any irregularity of surface, or where the principal buildings serve to compose a picture, which is framed by nearer trees and plantations, may occasionally be rendered attractive and even striking.

I0. Aspect. - The principal aspect of a house like that 
of the garden should be as nearly as possible south-east. This will allow of the entrance being on the north-west side, the breakfast-room or library having a south-east aspect, the drawing-room with a south-east and a south-west window, and the dining-room looking north-east or north-west, which is perhaps the best arrangement. If the kitchen and offices be on the ground floor, they can be kept on the north-east side of the house where the yard will also be situated and from which last there should be a communication with the kitchen garden.

A gentle eminence with the ground sloping a little away from it in all directions, especially towards the south, will be the best site for a house. An approach by a rising road and command of the outlying scenery will thus be attained, while the house will be dry and appear to be so. Its dignity and importance will also thus be enhanced. It should be put rather nearer the north-east than the south-west side of a plot that there may be some slight breadth of pleasure garden in front of the side drawing-room window, and that the offices and yard may not be too much obtruded. The center of the house should be about one-third the distance from the entrance to the opposite boundary of the pleasure grounds that two-thirds of the ground may be devoted to the private garden.

I have here introduced the ground-plan of an imaginary house (fig. 3) by way of illustrating generally what would be a desirable arrangement of the rooms, windows, offices, etc., with reference to both aspect and convenience. Not that I would pretend to such a knowledge of architectural detail as would induce me to design a house that should actually be erected. But, having given the subject a good deal of consideration, and having frequently experienced the difficulty of adapting grounds to what would appear to be great defects 
The Choice of a Place

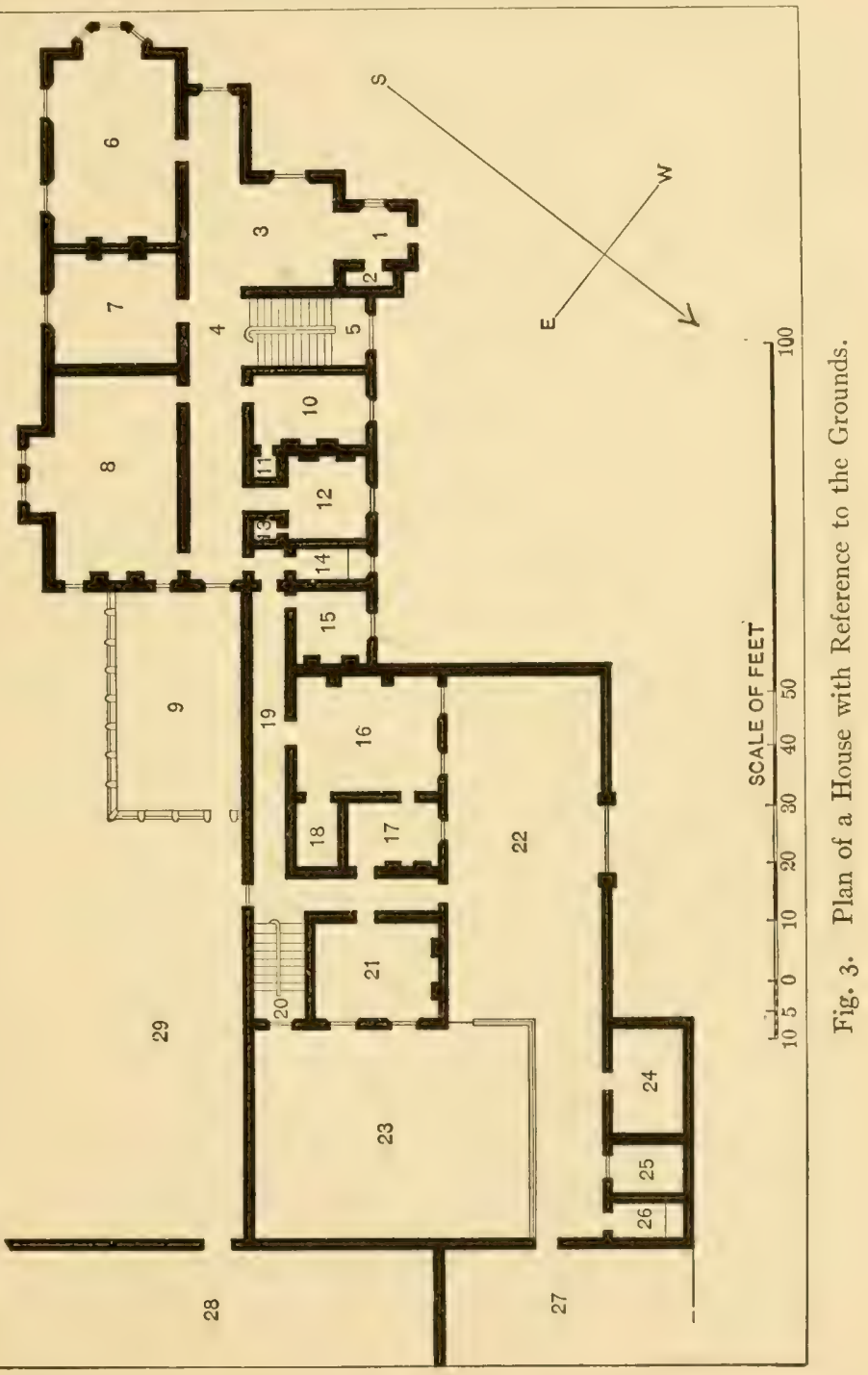


in architectural plans, I venture a hint or two on this point as viewed chiefly in the light of my own profession.

By the sketch it will be seen that the entrance to the house is from the north-west, that no important windows are on that side, and that the vestibule (I) projects sufficiently beyond the main line of the building to allow of an easy approach to the door by a carriage. The vestibule is lighted from the south-west side and has a recess in it (2) for hats, cloaks, etc., and may be separated from the hall (3) by glass doors. The hall is also lighted by a window from the southwest which would render it cheerful and give it more of the character of a room. It might also have a fire-place opposite the entrance or against the wall that divides it from the staircase. It opens on to a corridor (4) connected with all the principal rooms, and has a large window overlooking the garden at the south-west end and a glass door which is the entrance to the conservatory at the other end. From this corridor, at about the center of the house the staircase (5), which is kept separate from the hall although directly connected with it and is opposite the doors of the chief rooms, turns to the north-west and has a broad window on the landing. The drawing-room placed at the south corner of the house, farthest from the offices and nearest the entrance door, has a large bow-window to the south-west, so as to obtain a view of the garden on that side and of the setting sun, and it has likewise two windows on the south-east side. The library or morning room $(7)$ is next to the drawing-room with the window to the south-east; while the dining-room (8) is near the kitchen and offices, farthest from the entrance, and has two doors, one of which, close to the back passage, is for the servants. The principal window of the dining-room is to the south-east. There are two smaller windows to the north-east, one of which looks into the conservatory (9). It 
would thus be a cheerful breakfast or morning room, and the sun will have left it long before the usual dinner hour. The door from the corridor into the conservatory would also serve as a garden door, there being another door opposite to it into the garden.

On the north-west side of the house there is an office, business, or gentleman's room (го), containing a recess for an iron saie (I I), and readily accessible from the servants' apartments. Next there is a butler's pantry (I 2), with a recess for a plate safe (I3), this apartment being placed as near as possible to the entrance door and the entertaining rooms, besides being in the neighborhood of the kitchen and overlooking, by its window, the approach to the house. At I 4, detached alike from the main corridor and from the servants' passage, is a water-closet, and $\mathrm{I} 5$ is the housekeeper's room. The kitchen (I6) has a scullery (I7) and a pantry or storecloset (I8) attached to it, the windows looking into the house-yard. A servants' corridor (I9) is terminated by a back staircase (20), which is close to the servants' hall (2I), the latter having its windows opening to the dryingground and being near the back entrance. None of the office windows look into the garden or pleasure grounds, as the window for lighting the back corridor may be of dulled glass.

In the house-yard (22) there is sufficient space for a cart to turn, and from this yard only is there access to the dryingground $(25)$, which has a hedge on the side next the houseyard. The coal-shed (24), ash-pit (25), and water-closet (26), are placed in a recess of the house-yard, where they are more out of observation, and the yard is thus left clearer, neater, and more compact. The numbers 27,28 , and 29 refer to a compost and rubbish yard, the kitchen garden, and a flower garden, respectively. 


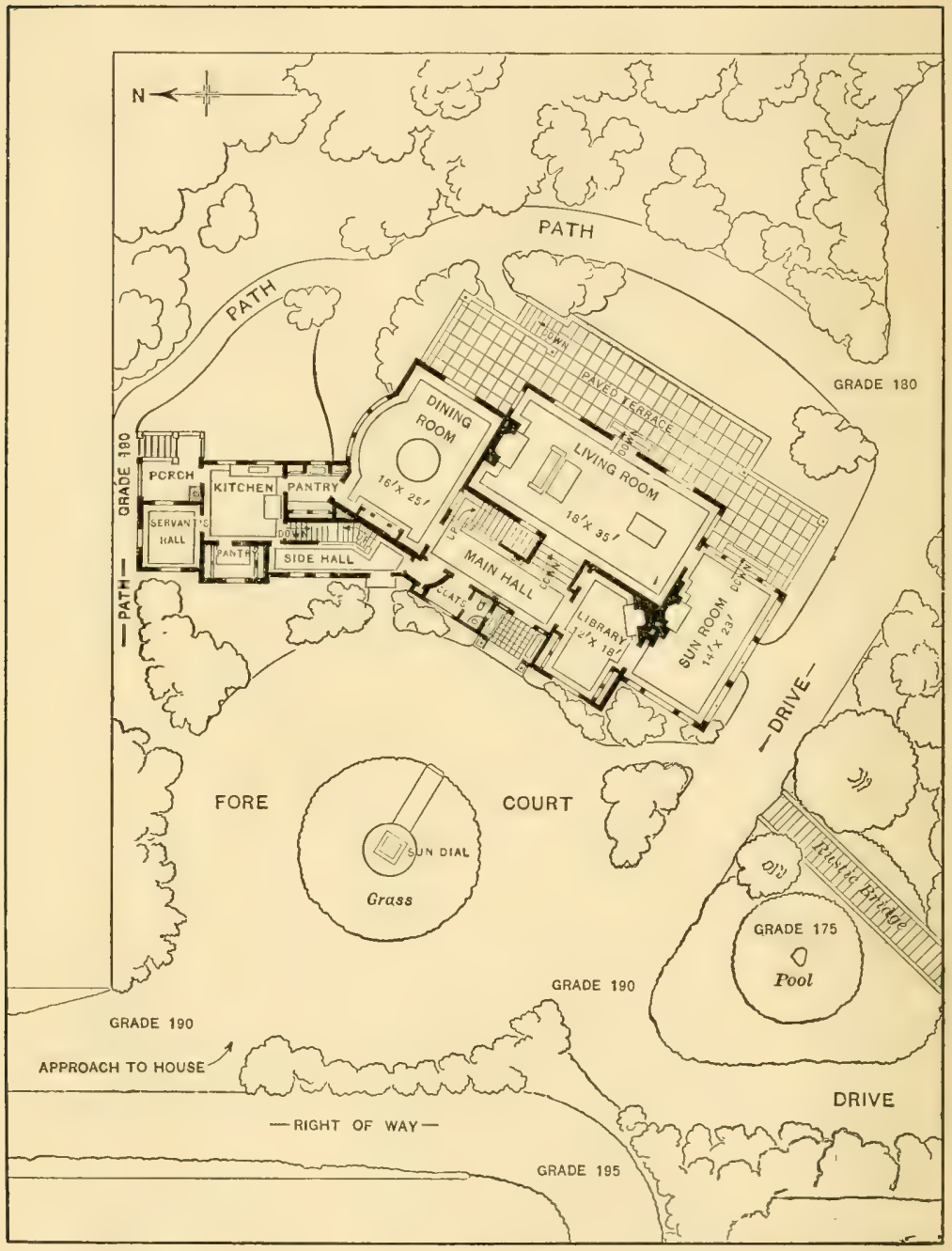

Fig. 4. Arrangement of an American House, Designed by Willcox \& Sayward, Seattle. 
II. Approaches. - In connection with every house there are certain matters of convenience and utility to be transacted, which, if they cannot be carried on apart from the ornamental portion of the garden, would interfere with its privacy and its beauty. Coals, and a variety of other necessaries, have to be brought to a house, and rubbish of several kinds requires to be taken from it. To accomplish this, it is essential to the enjoyment of a place that it should have a back and front approach, and the facilities for affording these ought to be the subject of calculation when the land is obtained.

When the access to a house is from a main road along its northerly side, separate approaches can readily be secured by entering at different points along that boundary. If the approach be only on any side near the south, however, it is difficult to get a second entrance without grievously cutting up the best part of the place. And where one entrance is used on the south side for all purposes, the privacy of the garden will be almost entirely destroyed, and servants, tradesmen, vagrants, etc., will have the use of the best part of the garden, and be able to gaze into the best windows. It is a great nuisance, too, to have coals and similar dirty things conveyed over the principal approach to a house, and possibly deposited close to the front door.

If, therefore, the chief entrance to a place has necessarily to be on the southerly side, it will be desirable to have a small public lane at the back of the land, by which access can be given to the offices of the house, and to the kitchen garden, without intruding upon the better portions of the pleasure grounds.

That some degree of practical bearing may be given to this part of the book, an outline imaginary sketch (fig. 5), embodying some of the principal points which have been discussed, is now presented. The plan of the house, on a 
previous page, is taken as a basis of the arrangement, and the present sketch is intended to exemplify, generally, a good

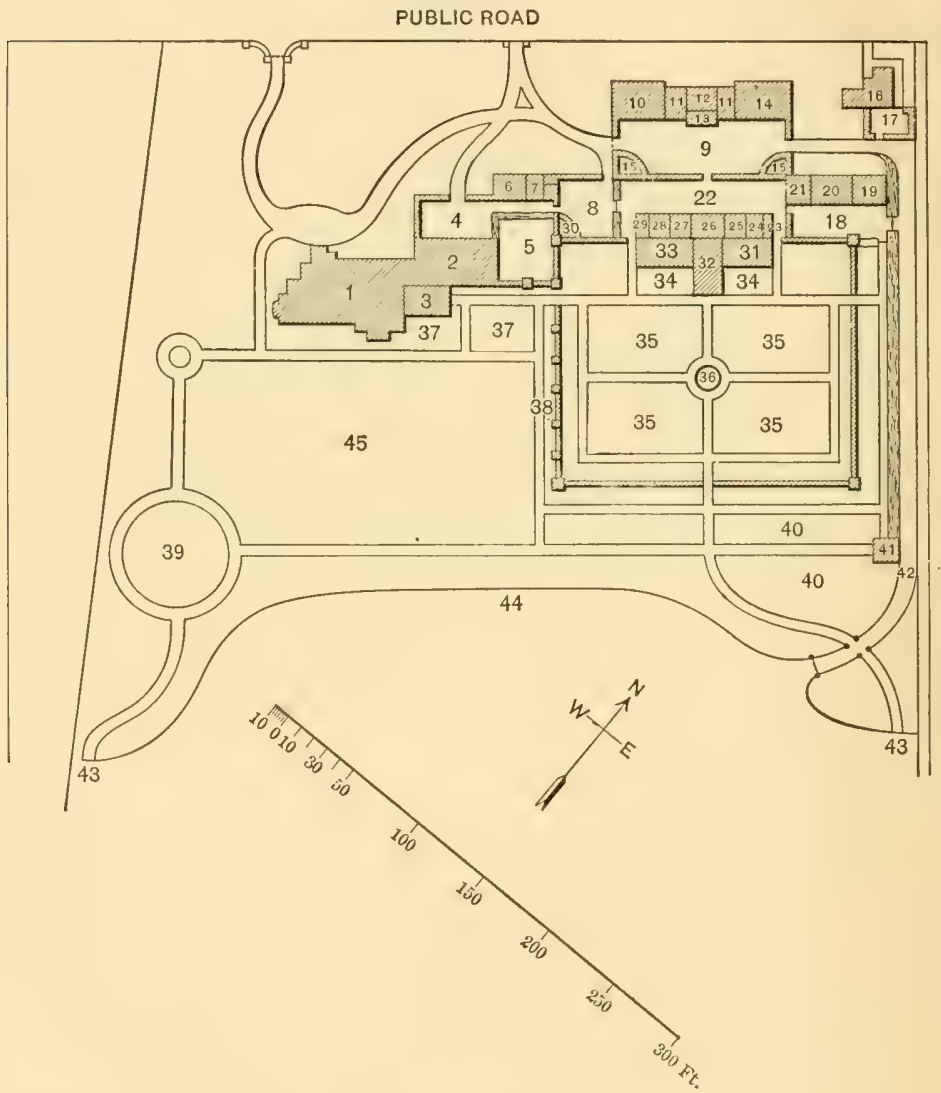

Fig. 5. Outline Plan of a Place.

shape for a small plot of land, with the relative position of the house, offices, approaches, gardens, field, etc., as these 
might appropriately be disposed. It does not purport to be a perfect model of design, but is simply brought forward to show how the various parts of a place may be arranged, and dovetailed into one another. For the sake of additional clearness, all minor details are omitted.

The plot of land represented is supposed to contain about eight acres, having a public road along the north-western margin, the parts about the house being tolerably flat, the field sloping to the south-east, and an open country lying towards the south and east, with similar places to the southwest and the north-east.

It will readily be perceived, from this sketch, that a good deal of accommodation is compressed into a small compass, and that, while each of the departments is kept essentially separate, they are all, where necessary, very thoroughly and directly connected. The principal approach to the house has a branch to the stables, and one back entrance is made to give access to the house-yard, the frame-ground, the stableyard, and, through the latter, to the farm-yard, the yard attached to the gardener's cottage, and the field. The drying-ground is connected only with the house-yard, and has on one side of it a hedge on which linen may be hung to bleach. The frame-ground communicates with the house-yard and the garden-yard, and thus affords a direct way from the kitchen garden to the back entrance door. There is also space enough for pits and frames on the north side of the frame-ground, which will be beyond the shade of walls or buildings, and the separating line between this ground and the garden-yard is merely a hedge. A cart entrance into the frame-ground completes the facilities of communication, by allowing soils or manure to be introduced or rubbish carted away. The pit for rubbish in the corner of this ground would enable the gardener always to keep it clean and tidy. 
The position of the stable-yard, on the north side of the house, is a favorable one, as there is comparatively little wind from that quarter to convey any kind of nuisance, and the stables are conveniently near, without being uncomfortably or obtrusively so. It will be noticed, too, that the stable buildings are opposite the center of the kitchen garden, so that the clock-tower, designed to surmount the former, would be an object from the middle walk; and both the stables and the farm buildings face the south-east, which would render them dry, pleasant, and healthy. The situation of the manure pits is likewise convenient for conveying the manure to the frame-ground, the kitchen garden, or the field; and the manure made in the cow house and pig sties could, by the doors into the garden-yard and into the back road, be removed with similar ease.

In the walls, too, there would be considerable economy of space and material, as most of them are made to answer a double purpose. The wall on the south-east and north-east sides of the kitchen garden is capable of being used for fruit trees on both sides, and that along the south-western margin, as just mentioned, serves for ornamental climbers on the side towards the pleasure grounds.

By placing the gardener's cottage near the north corner of the land the whole property is protected on that side and the gardener is brought into the midst of his more important duties. A path as shown from the high road to the cottage would enable any one to come to it independently without passing into the grounds.

A little architectural skill in the treatment of the various elevations, and the adoption of such details and decorations as would give harmony and consistency to the whole might, I conceive, produce an agreeable effect of grouping from so varied an outline, and by a judicious adaptation of the roofs 

turn even the subordinate offices to advantage. The general picturesqueness and artistic effect of any group of buildings must manifestly depend on the treatment of the roofs with regard to material, pitch, breadth of eaves and diversity of elevation.

To sum up the suggestions offered under this head, though few pieces of land would perfectly fulfill al the several requirements thus set forth, it may safely be affirmed that such as make the nearest approach to them will produce the greatest amount of comfort and satisfaction and be most permanently fertile in the various sources of pleasure. And where two places comprising a fair proportion of some of these capabilities, but wanting in others, should come into competition, the preponderance in either of those particular merits to which most importance is attached by the individual selecting, must determine their relative desirableness.

It is not for a moment supposed that the question has here been fully considered. All that has been pretended to be done is to offer a few leading hints The standing, occupations, pursuits, objects, connections, or tastes of each person choosing a place for residence will all more or less affect his own judgment. 


\section{CHAPTER II}

\section{What to Avord}

When a physician is called in to prescribe for a patient, one of the first things which is commonly found necessary is to advise what the invalid should abstain from taking, and how he should endeavor to escape from injurious influences. This treatment is often found sufficient without the use of any medicine and in all cases greatly aids the application of more active remedies. And thus it is with respect to any one who advises on other subjects. No good foundation can be laid for such works as the present unless all erroneous and prejudicial notions be first cleared away.

In aiming, therefore, to bring the subject fairly before the reader, it will be necessary, at starting, to show what are the things which the amateur should not do, before proceeding to speak of such as should be actually performed. Many a person who has gardened for himself has no doubt for want of such beacons irretrievably spoiled his place before discovering his error, or at least involved himself in a considerably larger outlay, or rendered the whole design patchy and disjointed.

I. Overdoing. - Possibly the greatest and most prevalent mistake of those who lay out gardens for themselves is attempting too much. A mind unaccustomed to generalize or to take in a number of leading objects at a glance finds out the different points embraced in landscape gardening one by one, and, unable to decide which of them can most suitably be applied, determines on trying to compass more than can 
really be attained. One thing after another is at different times observed and liked, in some place visited, and each is successively wished to be transferred to the observer's own garden, without regard to its fitness for the locality or its relation to what has previously been done. A neighbor or a friend has a place in which certain features are exquisitely developed and these are at once sought to be copied. The practice of cutting up a garden into mere fragments, which is unhappily of too frequent occurrence, is the natural result of such a state of things.

There are several ways in which a place may be frittered away, so as to become wholly deficient in character and beauty. It may be too much broken up in its general arrangement; and this is the worst variety of the fault, because least easily mended and most conspicuous. To aim at comprising the principal features proper to the largest gardens in those of the most limited size is surely not a worthy species of imitation, and one which can only excite ridicule and end in disappointment. There is a wide difference between variety which is desirable and the separation into minute parts, or blending of incongruous materials, the former being quite compatible with both unity and simplicity.

A place may be likewise too much carved up into detached portions, or overshadowed or reduced in apparent size by planting too largely. Trees and shrubs constitute the greatest ornaments of a garden, but they soon become disagreeable when a place is overrun with them by contracting the space, shutting out light, rendering the grass imperfect and the walks mossy: Nothing could be more damp, gloomy, and confined than a small place too much cumbered with plantations. Nor is the consideration of its influences on the health of the occupants at all unimportant, for where 
sun and wind cannot get free play a moist and stagnant air, very injurious to all animal life, is necessarily occasioned.

But if this be true with regard to any superfluous vegetation in general, it is much more so in respect to large timber trees. To introduce or retain many of these in a small garden is quite contrary to all the principles of good taste, and conducive only to trouble and discomfort. All the evils which attend a redundancy of the lower forms of plants are greatly aggravated, and carried to their highest point by a similar overgrowth of trees.

In the immediate neighborhood of the house, moreover, it is particularly desirable that trees and shrubs should not abound. Independently of darkening the windows, they communicate great dampness to the walls, and prevent that action of the wind upon the building which alone can keep it dry, comfortable, and consequently healthy. It is almost impossible for any house to be otherwise than damp which is too much and too closely surrounded by plantations. Any portion of these, therefore, which may be necessary to shut out the offices or outbuildings should be placed as far from the walls as practicable, and by no means allowed to be in contact with them.

Another mode in which the effect of a garden may be marred is in the formation of numerous flower beds, or groups of mixed shrubs and flowers on the lawn. This is a very common failing and one which greatly disfigures a place, especially as, where intended only for flowers, such beds usually remain vacant and naked for several months in the year. Flower beds, too, when introduced in any quantity on a small lawn, have an exceedingly artificial appearance, reminding one of the character common to children's gardens. They interfere sadly with all ideas of breadth, harmony, and repose. 
A still more striking interruption to that beautiful continuity, which does so much in the way of producing size and expression, occurs when unnecessary divisions are introduced into a place. These may be employed to detach parts of a very different character; or, as in the old system of hedging in particular portions, may simply be intended to change the scene suddenly, or furnish certain lines which are probably supposed to accord with the general character of the house. Not only, however, are those formal divisions mostly inadmissible in a limited space, but all kinds of separating lines, though varied and broken in the most artful manner, must be condemned, as a rule, unless the place is tolerably large. These remarks of course do not apply to plantations or fences between the kitchen and pleasure garden, or between the latter and the field, nor do they refer to those irregular masses of shrubs or trees which may sometimes be thrown partly across a lawn to occasion a fresh scene behind them. They are simply aimed at such separating lines, whether of fence or plantation, as might be dispensed with or for which there is no real necessity, as well as at the practice of splitting up a place into minute parts instead of making it as spacious and airy as possible.

Partly for the reasons just alleged, and also because they introduce ugly strips of a conspicuously different color on a lawn, a multiplicity of walks, beyond what are absolutely requisite, is very undesirable in a small piece of ground. It is acknowledged that numerous walks conduce to variety, but it is much better to have only that moderate amount of the latter which can be attained without the sacrifice of simplicity. Walks that have no definite or sufficiently important object, and do not serve to reveal features or aspects of a place that would otherwise be imperfectly seen or entirely lost, are always to be avoided. 
A garden may also be overloaded with a variety of things, which, though ornamental in themselves, and not at all out of keeping with the house or the principal elements of the landscape, may yet impart to it an affected or ostentatious character. An undue introduction of sculptured or other figures, vases, seats and arbors, baskets for plants, and such like objects would come within the limits of this description. And there is nothing of which people in general are so intolerant in others as the attempt to crowd within a confined space the appropriate adornments of the most ample gardens. It is invariably taken as evidence of a desire to appear to be and to possess that which the reality of the case will not warrant, and is visited with the reprobation and contempt commonly awarded to ill-grounded assumption. An unpresuming garden, like a modest individual, may have great defects without challenging criticism, and will even be liked and praised because of its very unobtrusiveness. But where a great deal is aimed at, and there is much pretension, whether in persons or things, scrutiny seems invited, incongruities are magnified, and actual merits are passed by unnoticed.

Artificial mounds, though they may be very useful for some objects, and conducive to effect in certain positions, will be exceedingly unsatisfactory if made too high, too conspicuous, or too decidedly indicative of the employment of art in their formation. If the ground of the neighboring country be very flat they will appear all the more out of place and require adapting with the nicest elaboration. Everything in the shape of a large hillock or long line of bank that has no particular meaning and is badly connected with the general surface can never present a pleasing character. Some evidence of a sufficient intention or purpose and a manifest correspondence with the rest of the scene will be absolutely demanded in all such elevations. 
2. Rustic Work. - Among the more specific features to be repudiated in a small garden the employment of rockeries or other rustic objects in connection with the house, or in its immediate neighborhood, may be next mentioned. Every house must be regarded as a work of art whatever may be its class or merit, and there would consequently be a want of harmony in associating it with anything composed of, or resembling, the uncultivated parts of nature. However ingeniously it may be contrived, a rockery near a house must be considered radically wrong, and though great skili be used in adaptation or a variety of fortunate accidents eventually awaken interest, these can never wholly atone for the fundamental error. Nor will the way in which such things are generally managed admit of even this extenuation and excuse. And as a retired corner could almost always be found for cultivating rock-plants if desired, those who would steer clear of the vulgarities and irregularities of mere cockneyism will do well not to permit anything of the kind I have been describing around their houses. When composed of such materials as shells, pieces of old porcelain, scorix, and other small, artificial or manufactured articles and interspersed with grotesque looking busts, heads, etc., as is frequently the case, their use in connection with houses is all the more to be deprecated.

As similarly interfering with the harmony of a place, the employment of conspicuous grottoes, towers, summer houses, or other buildings within a short distance or in open view from the house, cannot be defended on any known principle in landscape arrangement. If very sparingly introduced, and of a quiet appearance and partially concealed, architectural objects though not in the same style as the house may be occasionally admissible. It is against the staring and grossly peculiar forms sometimes met with in suburban gardens that 
the chief objection lies. A castellated grotto, for example, with the greatest and most fantastic variety of outline and numerous turrets is occasionally to be seen from a house either in the Grecian or Italian form, or from one of those square, commonplace erections from which everything like style is expressly omitted.

3. Overplanting. - The practice of planting much immediately around a house is erroneous in other ways than those yet pointed out. It prevents the true proportions, outlines, and details of a building from being properly seen and rightly appreciated. If a house be well designed, it should make a picture of itself and only require the aid of vegetable forms, at a little distance from it, as supports and accompaniments. An occasional tree or plant may be valuable to balance the several parts, to soften abrupt transitions of outline, to sober and break a glare of color, or to impart an air of finish in some cases; and even a mass of trees or shrubs would often be effective in blinding inferior parts of the building, or covering defects of symmetry or enrichment. But where the architect has thoroughly studied his subject and treated it as a picture, aids of this sort will be but little wanted and should be adopted with the utmost care. There is probably no one point in landscape gardening wherein less of the true feeling of art is exhibited than in the choice of accompaniments to a building.

4. Tree Belts. - The planting of tree belts on small places is always quite inappropriate. They consist of strips of trees, either of equal or irregular width, placed just within the boundary, so as to confine the view wholly to the place itself. They serve, in fact, completely to shut it in by a kind of green wall, which effectually excludes a great deal of sunlight and air and all appearance of distance. They make the garden a sort of prison which cannot be seen into by others 
and from which not a glimpse can be obtained of what is passing without. Privacy no doubt they may secure, but it is the privacy of the cell or the cloister, - a sort of monastic seclusion which would better fit the tenant of a hermitage.

Nothing could be more monotonous than a timber belt in which the trees are nearly all of the same age, height and general character. All variety of effect and all ideas of indefiniteness are of course out of the question under such circumstances. To whatever part of the garden we go the same hard and uniform boundary terminates the view. There is no play of outline, none of that beautiful illusion which arises from skillful connection with other property. The cheerfulness of sunlight is curtailed, and the healthy vigor common to plants which have plenty of light and air is not to be found. The walks become green and slimy, and are always more or less damp, while a portion of the grass is made feeble and sickly or gradually dwindles away into mere mossiness.

But the worst feature of all these evils is that they have seldom any origin in necessity, and could usually be obviated. There are extremely few places so thoroughly surrounded by bad objects as to allow of no breaks in the boundary and no peeps into the country beyond. And even where such is the case considerable diversity and interest may be created by the use of plants of different heights and habits to act as the screen. Indeed, a boundary that must necessarily be a barrier to all further view into the outlying country may be so contrived and treated as scarcely to appear like a boundary at all, as I shall hereafter have occasion to show. I need only add here that formal, regular belts, especially where the trees are planted in rows, are in the worst possible taste.

Those masses of trees or shrubs known as clumps, and notorious for their extreme clumsiness, are a part of the same 


\section{$36 \quad$ Landscape Gardening}

system as belts, and alike open to reprobation. They are either roundish, or of no regular figure, nor can they be called irregular. As generally used, they can only be described as large spots or blots in the landscape, having neither beauty in themselves nor connection with anything else. It is probable that they were originally intended as the foundation or nucleus of a scattered group, merely filled up for a time, to

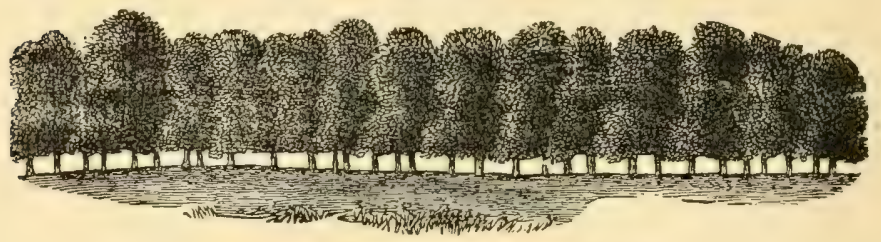

Fig. 6. Tree Belt - Monotonous.

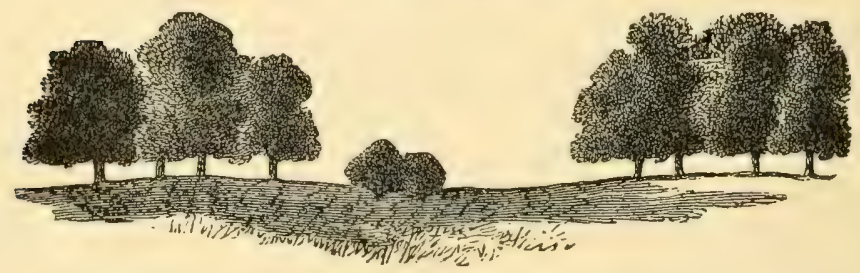

Fig. 7. Same as Fig. 6-Improved.

obtain protection and greater rapidity of growth. But such objects might be just as well fulfilled in conjunction with some more indefinite and pleasing external outline.

Narrow strips or lines of plantation are among the most tasteless forms which belts can assume, and are equally mean and undignified wherever else they may occur. They can so readily be seen through and will frequently present at the lower parts a mere assemblage of bare stems. Their effect is most meager. They want breadth and massiveness. 
Hence, when plantations are necessarily so straitened, they should be composed mainly of such low-growing shrubs and dwarf trees, especially evergreens, as will, by being planted tolerably close and furnished down to the ground, produce a thicket-like character that shall conceal or disguise their actual dimensions.

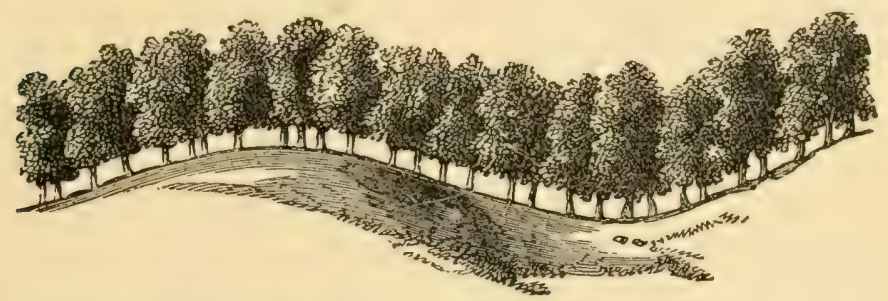

Fig. 8. Monotonous Belt on Rolling Ground.

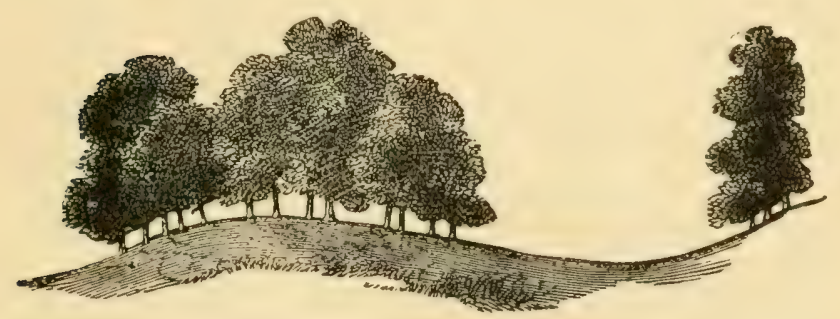

Fig. 9. Improvement of Fig. 8.

In the subjoined sketches, fig. 6 shows a narrow belt of trees, similar in size and character, such as is frequently seen round the margins of small parks, where, if undergrowth of any kind has ever been planted, it has become killed by the density and shade of the larger trees. Fig. 7 will serve as a hint of the way in which such a belt may be broken up and its form still more diversified by the use of a few intermediate bushes, such as thorns or hollies. 
The same defect rendered probably a little more manifest from the superior beauty and variety of the ground line will be apparent in fig. 8 , which exhibits a belt traversing an undulating surface. And the mode of remedying the evil is partially indicated in fig. 9, where the trees are thrown into masses on the slopes and summits of the swells in the ground, the hollow being left unclothed for the purpose of marking the full extent of its depression.

5. Bad Fences. - Any description of high fence that confines a place too much is as faulty in all essential respects as a belt of trees, and in some particulars even more so. It has a harsher, more forbidding, and exclusive appearance, and its upper line will necessarily be stiffer. It gives an unkindly and inhospitable expression to a place. Besides, high close fences keep out air even more than trees, and also produce, for a given distance, a more complete shade. They should never be employed unless they are really indispensable, and then they ought to have the hardness of their lines relieved by trees and shrubs inside, or with ivy or other climbers scrambling irregularly over them. Those sides of a garden where shelter is required must, however, be excepted from the rule, though it will generally be found that trees are a much better screen for gardens than a wall, provided there be breadth enough to admit of a sufficiently dense plantation.

6. Over-exposure. - There is an opposite extreme to that just described, into which some persons are apt to fall by rendering their gardens too exposed. Examples might be found in which from a love of display or a disposition to give others the benefit of whatever enjoyment happens to be possessed, every inch of the garden is bared to public gaze. There is thus no quiet, no retirement, and scarcely any of the pleasure arising from the ownership of property. A lady or gentleman fond of gardening cannot engage in any 
of its pursuits without attracting general notice; dogs and other animals will have the run of the place; and the luxury of cherishing song-birds must be relinquished, for they will not frequent a garden that is so unsheltered.

Nor is this all. Every beautiful flower that unfolds itself, or shrub that spreads out its attractive berries about Christmas time, affords so many temptations to pilfering for the passers-by, among whom there will ordinarily be some, at least, who will be unable to resist the inducement, and the mortification of seeing the choicest and most admired favorites thus stolen will be frequently incurred.

7. Removal of Trees. - Where a garden is to be made on land that has been planted at some previous period, and trees of considerable magnitude exist upon it, especial care should be used in reference to the removal of any of these, so as not to render the place too open and bare; for where fine trees are known to have stood, an air of nakedness and poverty of the higher forms of vegetation will be all the more manifest and displeasing. There is no subject on which greater deliberation is demanded than the cutting down or removal of large trees, as nothing changes the character of a place more.

8. Mixed Styles. - The adoption of too great a mixture of styles in gardens is an error that should be specially guarded against. It is the source of numberless little incongruities and improprieties, and although, where the space is very small, it may be somewhat difficult to attain any style at all, yet a mixture of the formal and the free, the decorated and the simple, the picturesque and the polished is sometimes seen attempted, and with the worst effects. Straight and regular lines can rarely be blended with curved and flowing ones nor can rough and broken forms be fitly associated with such as are smooth and graceful. Things which have no affinity in their character, or expression, should not, except 
in very rare and peculiar instances, be brought into conjunction.

9. Unsuitable ornaments are things which many persons who have only a glimmering of the requirements of art have a great propensity for placing about gardens. These may be of the nature of artificial basins of water, ponds, figures, bridges, flag-poles, prospect-towers, cannon, groups of stones, spar, or roots, with objects of a similar nature, which may or may not be fitting ornaments for a garden in themselves, but which may be so inappropriately disposed, or so entirely unallied to the prevailing characteristics of a particular spot, as to be wholly inadmissible. In some few cases it may happen that the vulgarity or the ugliness of an individual object offends the eye of taste, but a much more common cause for complaint exists in the passion for scraping together all sorts of good or indifferent things without adequate regard being paid to their affinity to each other, or their suitableness for the place in which they are deposited.

10. Cheap Surprises. - The making arrangements in the plan of a place for occasioning to visitors one or more little surprises as they are passing round the garden, is extremely unsatisfactory at best. It is an appeal to the lowest species of admiration, and all the pleasure it may occasion is but momentary, and can never be renewed to the same individual. When on a small scale, too, the machinery by which the effect is produced will be always sadly apparent. Solid merits and substantial beauties are much to be preferred, for the pleasure to be derived from them never ceases and does not satiate.

II. Eccentricities. - From a similar cause, all manner of eccentricities in a garden will, if they have nothing better to boast of, never obtain lasting admiration and, as in personal character, are more generally the evidences of a feeble mind than of the possession of genius. It is far safer and more 
conducive to that impartation of pleasure to others which all seek or profess to wish for, to keep only in the beaten track and strive after excellences which are sufficiently known and acknowledged. Enough of freshness and originality to satisfy any reasonably active mind may easily be attained by new combinations of the ever-varying materials of nature, without striving to jumble together things that can have no possible correspondence or relationship.

Everything partaking of the nature of a sham, also whatever is wanting in real excellence, will be discarded by persons desiring to obtain credit for correct taste. Artificial ruins, mere fronts to buildings, figures to represent animals, bridges that have no meaning or for which there is no necessity, or any other merely artificial representations of natural or other objects, where the aim and intention are to induce the belief that they are really natural, will commonly be despised when the trick is discovered.

12. Formality. - The problem of how to treat a very small place is an exceedingly difficult one. On the one hand a large formal treatment is apt to appear pretentious, while on the other hand, the natural style is sure to seem cramped. Whatever is attempted must be carried out with extreme simplicity. In general modern taste leans toward very simple compositions in geometrical lines, avoiding both the incongruity of flowing lines and the ambitiousness of complicated formal work.

I3. Large geometrical figures, unless they embrace the whole garden, are never satisfactory, even when kept extremely simple. The more their parts are multiplied, the more destructive they are to dignity, breadth, and repose. Flower gardens, therefore, and other separate parts of a place, when geometrically laid out in close beds, and put in the front of the house, should bear but a small proportion 
to the rest of the garden or they will annihilate all semblance of extent. At least two-thirds of the length of the lawn, measuring away from the house, should be free from such innovations. And if three-fourths, or even five-sixths, of it be unencumbered in this manner there will be greater harmony of parts.

Two exceptions to the application of this doctrine may probably be admitted. Where a rich pastured country, sufficiently spotted with timber trees, lies in front of a place, and by the skillful treatment of the boundary fence appears to belong to the owner, a strictly formal plan of the garden may be effective. And the same remark will apply where a very picturesque and rugged piece of natural scenery joins on to a place. [This opinion of the author is allowed to stand on account of its general interest, though it is by no means shared by the present editor.]

I4. Monotony. - Akin to the style just condemned in its relation to moderate-sized gardens, is a certain baldness and plainness, which may likewise exist under different modes of arrangement, and which, more than almost any other characteristic, contributes to make a place appear poor and uninteresting. Where the space will at all justify it,- - and it must be restricted indeed if it will not do so, - the walks and plants can be so disposed as to afford as many different views as possible. From no single point, unless it be an elevated one, should every part be seen. A lawn need not be like a bowling-green, with a simple fringe of plantation, but should have a variety of minor glades and recesses, that are only to be discovered and examined from particular points. Bareness is nearly as faulty as meretriciousness of ornament.

Monotony of character may likewise often be deepened and confirmed by the endeavor to bring the whole of the garden too much into one level or slope. In the formal style, some 


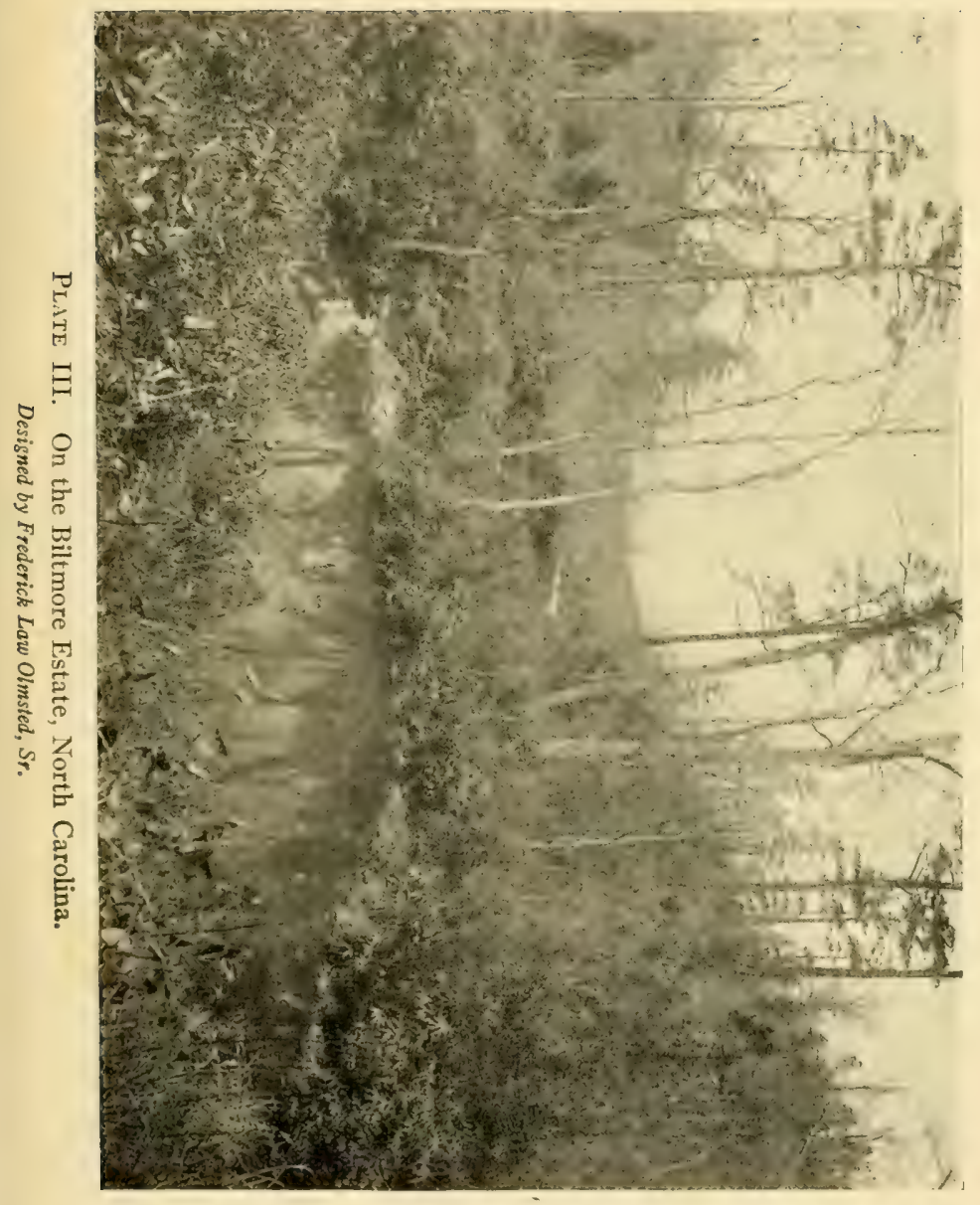



approximation to flatness is positively required. But for irregular gardens, with broken groups and serpentine walks, any natural undulations, or even some little attempt at artificial variety of surface, will be a decided improvement to a garden if softly and appropriately finished off. It is customary, however, for persons who do not study the subject to commence laying out their gardens by making all the ground as level as possible. A more unfortunate error could not be fallen into, for character might be better obtained by changes of level than by almost any other similar means.

15. Needless Drives. - In the treatment of a small place it is further expedient to reject everything that has an air of ostentation or appears only proper to more extensive domains. In many instances, therefore, a carriage drive to the house, although often very convenient, would not accord with the limits of a garden and is consequently better omitted. No positive rule as to what length of approach would justify the use of a drive can be laid down but in general it should be at least thirty or forty yards. However, the extent of the entire place will be the best guide.

It should be borne in mind that a carriage-drive not only looks assuming, but it tends greatly to reduce the size of a small garden by cutting it up and exhibiting a large portion of it in gravel. From the peculiar color of the latter, it always deceives the eye as to the extent of surface it covers; an area of gravel never appearing nearly so large as one of equal dimensions laid down in grass. Green is at once more conspicuous and more agreeable to the sight. And grass possesses these qualities at all seasons. Hence, to make the most of a place as to size, broad masses of gravel should be kept out of a cottage or villa garden.

Where a house is sufficiently contiguous to the high road and its general character warrants such an appendage, an 
entrance court, treated architecturally and with proper accompaniments may be an excellent substitute for a short drive; and in this case a large graveled area with perhaps bold margins of grass, a few evergreens and some climbing plants here and there scrambling over the walls would be wholly unobjectionable.

A carriage-drive that would pass the windows of any of the principal rooms of a house or terminate nearly in front of them would be still more exposed to the objections here urged. For callers or visitors to have to pass the windows of sitting-rooms is always an undesirable arrangement though this has sometimes to be tolerated from a variety of considerations. But the evil is much aggravated when such an approach is one for vehicles also, and servants as well as friends have thus the free use of it. Of course this will depend very much on the arrangement of the house, the correct position of the entrance door being a matter frequently overlooked by architects.

I6. Kitchen Gardens. - Some gardens are so contracted or of such a peculiar shape that the appropriation of any part of them to vegetables or fruits appears quite inconsistent with the attainment of any kind of beauty in the ornamental portions. And in such instances the kitchen department may very properly be omitted. A mere scrap or corner of kitchen garden which only serves to mar the general design can afford no real pleasure, and the food it would supply is commonly otherwise easily obtainable. The propriety of devoting a piece of ground to these purposes will depend more on the general figure of the land and the position and arrangement of the house than on the mere size of the plot. If the ground lies entirely in front of the principal windows and is but narrow, a kitchen garden would seem inadmissible in point of taste. Besides, kitchen gardens are 
usually by no means so profitable as they are thought to be, and must be regarded more as a luxury than a source of saving. Vegetables can in most cases be purchased more cheaply than they can be grown, and it is merely for securing their freshness, and the pleasure of having grown them that a kitchen garden is worth consideration. Herbs and salads are alone of any real consequence, since it is very convenient to have these at hand for any emergency, and they can ordinarily be put in some quiet corner of the grounds, where they will not obtrude on the attention. 


\section{CHAPTER III \\ General Principles}

In proceeding to the various points which the designer of a garden should endeavor to compass, as far as the nature of the locality and other unavoidable conditions will allow, it may be well to premise that any rules here furnished can only be of general application. It is obviously impossible to lay down principles which shall embrace every case, and hence some who practice landscape gardening depend mainly on their eye both in creating and judging of artificial scenery. Doubtless, too, there is much in almost every garden which requires it to be treated peculiarly, in some way or other; the outline and surface of the plot, the position, arrangement, and aspects of the house, and the requirements of the owner, having something in them different from what they are in any other place, and consequently needing a corresponding difference of treatment. And it is in the skillful use and blending of these various objects and purposes that the art of the landscape gardener consists. In reference, therefore, to such circumstances, general rules would seem at first sight to be of little use, or an actual disadvantage, embarrassing and encumbering rather than aiding the practitioner.

But the advantage of fixed principles, even in the most uncommon and complex examples, will be overlooked only on a cursory view. Closer observation will always show that, although there may be cases in which no recognized law could be carried out in its naked simplicity, yet some modification or mixture of one or more rules must be adopted in 


\section{General Principles}

order to produce any really good effect, and that, while such a result may be accomplished by accident, it is far easier, and more satisfactory, to attain it by design. In what follows, then, most of the rules given will be found more or less applicable to all gardens of the class treated of, though they will often require much consideration, and some ability, to adapt them to pa ticular localities. It will, however, be a primary aim to render them as suited as is possible to the condition of the majority of those likely to consult them.

r. Simplicity is the first thing to be aimed at in laying out a garden. In its absence there can be no indication of refined taste. A design may be essentially simple, without being bald or serere; and intricate, without becoming labyrinthine. Simplicity is the opposite of ostentation and extravagance; intricacy, of mere blankness. Simplicity is the offspring of the highest taste, and is a prime element in pure beauty. Not that it altogether characterizes the beauty which is, "when unadorned, adorned the most." For it is perfectly consistent with some degree of chaste ornament.

A garden should have more or less simplicity, according to its size and character, in its main outlines, arrangements, and furniture. The transitions in it should all be easy and flowing, the lines all graceful, the decorations elegant. Very rarely will a small garden bear being furnished with any striking evidences of wealth, luxury, or elaboration. The hand of art should touch it so lightly as to leave few traces of its operations. Its forms and figures ought all to be gently rounded off, and unite softly with each other. Lawn and gravel, shrub, tree, and flower, with all the less common and more costly apjendages, must appear to belong to one another, and to fit into the place in which they occur.

2. Intricacy. - At the same time, the intricacy which arises from a partial and pleasing involution of parts, from 
slight and insensible changes, and from that artful arrangement of single plants and groups which produces freshness of aspect and newness of vista from so many different points of view, must not be neglected. For a garden may be all that is correct, tasteful, and classical, and yet, like a wellmolded countenance, prove dull, tame, and void of expression. It is play of feature, - a something behind and beyond, which has not been explored, - novelty of expression, variation of aspect, an alluring attraction onwards after higher beauties, - that constitutes, in both instances, the life, the spirit, and the charm. Intricacy is, in fact, the very soul of landscape gardening.

3. Convenience is likewise a thing which requires to be duly studied and provided for. As, in a house, a beautiful exterior will never compensate for defective internal accommodation, so, with a garden, the most perfectly tasteful disposition of parts will never give real satisfaction if comfort and convenience have been sacrificed. It must be remembered that a garden is intended not merely to be looked at from the windows of a house or the elevation of a terrace-walk, but to be used and to be enjoyed. The walks should therefore pass as easily and as directly to their appointed objects as can well be accomplished, and they should be dry in wet weather and smooth during drought. The land must also be well drained, so as to be capable of being worked or walked upon at all times. Every feature of interest ought always to be comfortably accessible. A flower garden and a greenhouse should be near or adjoining the house for the sake of affording the family ready means of examining or gathering the flowers. A kitchen garden should not be far from the kitchen, that the produce may be conveyed to the latter with little labor, and without attracting observation. It should further be placed near the stable-yard, that manure may be easily 


\section{General Principles}

moved from the one to the other. And, when practicable, a kitchen garden may, on one side at least, abut upon a road or lane, that soil, manure, etc., may be carted to it at any time.

Places for preserving tools and depositing rubbish, and means for obtaining water when required, back paths or roads to the kitchen and offices, space for drying linen, lengthened walks round a paddock for exercise, with an arbor or summer house in it for shelter from showers or storms, and for reading and retirement at other periods, are some of the various conveniences which should be taken into account in laying out a place, especially as many of them cannot be obtained at all unless they are secured in the first instance.

4. Compactness. - In order still further to attain the full advantage of convenience to economize space and labor, and to make everything appear orderly and well-contrived, compactness of arrangement will be particularly influential. Nothing tends more to exhibit a want of design, or to produce general slovenliness, than a scattered and ill-considered disposal of the different parts of a place. Each department that is connected with another - and all should be but parts of a combined whole - ought not merely to adjoin but to fit into its neighboring department, so that no space may be lost, no untidy corners created, and no unnecessary expenditure occasioned in the erection of walls or other divisions. In fact each wall or fence in the interior of a place should, if possible, be made to serve a double purpose, and act as a boundary to two separate compartments, or form a part of two distinct sets of buildings. Thus, the wall on the north side of a kitchen garden may be made to constitute one of the fences to a house-yard, a garden-yard, a stable-court, and even a small farm-yard; while the back of such a wall might 
also be used to support various low lean-to sheds, that may happen to be needed in either of these yards.

5. Seclusion. - Few characteristics of a garden contribute more to render it agreeable than snugness and seclusion. They serve to make it appear peculiarly one's own, converting it into a kind of sanctum. A place that has neither of these qualities might almost as well be public property. Those who love their garden often want to walk, work, ruminate, read, romp, or examine the various changes and developments of nature in it, and to do so unobserved. All that attaches us to a garden, and renders it a delightful and cherished object, seems marred if it has no privacy. It is a luxury to walk, sit, or recline at ease, on a summer's day, and drink in the sights and sounds and perfumes peculiar to a garden, without fear of interruption, or of dress, attitude, or occupation being observed and criticized.

Something more, however, than mere privacy is involved in the idea of snugness. It includes shelter, warmth, shade, agreeable seats for rest, arbors for a rural meal, and velvety slopes of turf, overshadowed or variously checkered by foliage, to recline upon. A room that may fitly be called snug is small in its dimensions, and rather amply furnished, with its window not open at any point to the public gaze. A garden, likewise, to deserve the same epithet, should have its principal or subordinate parts of rather contracted limits, be furnished somewhat liberally with tall-growing plants and trees, which will produce some degree of shade and present an air of comparative isolation.

Where there is sufficient extent, it is probably better to have one or more small nooks, or partially detached gardens of a particular kind, to realize something of both snugness and seclusion, and give the leading and broader portions of the garden a more airy and open character. Still, in any case, 
unless it be purely for show, a certain amount of privacy ought assuredly to be sought after. And the more thoroughly it is gained, the more pleasurable to most persons, and the more accordant with good taste, will be the entire production.

6. Unity and congruity of parts are probably among the easiest things to attend to, yet the most seldom attained. Curved walks along the front of a house, - figures, vases, and other architectural ornaments in a different style to that of the principal building, - straight walks passing off obliquely from other straight ones, or even curved lines issuing from or crossing straight ones at an oblique angle, - a mixture of general styles of treatment, - gay roses or honeysuckles twining around funereal pillars or urns, - the most somber-looking plants placed against a building in a florid style of architecture, - the commonest greenhouses tacked on to structures of some pretension as to correctness and purity of manner, - these, and a variety of similar incongruities, are most abundant and conspicuous in gardens.

Taste, on the other hand, demands that there should be a perfect harmony between the various portions of a garden both with respect to each other and to its buildings. Every structure ought to have its appropriate garden fittings, to impart or preserve to it its proper expression. The part just around a house should be treated somewhat architecturally or formally, and the transitions from this to the more distant portions of a garden, and from these again to the field, and so on to the surrounding country, be gradual and almost imperceptible. And where any sort of rusticity or picturesqueness is wished for, or some other feature essentially distinct from those which characterize the garden generally, such pieces ought to be separated from the rest by a well-marked though inartificial division, so that the two are not seen together.

Connection and order are the universal laws of nature, and 
can seldom be safely infringed by art. Contrast, it is true, may sometimes be admitted into a garden, and will occasionally be very effective, but it is available chiefly in small matters of detail, such as the colors of leaves and flowers, the habits of plants, their heights, etc. Harmony in other things is of far more consequence. It is the only true foundation of greatness or excellence. To have several notable characteristics, or to perform many things well, falls to the lot of very few individuals; and a garden that affects to have more than one marked expression or tone, is too frequently a failure. Unity, however, and a well-balanced and wellblended adjustment of parts, impart to it a weight of character and a dignity of aspect which are sure, in the end, to win for it esteem. That which is really good and tasteful, while it is certain to obtain the approbation of those capable of judging it, will quite as surely at some period, however remote, secure the suffrages of the multitude. An inferior object, on the contrary, may please for a time, but will speedily grow distasteful. It is only for true beauty that a lasting and general relish is excited.

7. Blending. - Isolation of parts and ornaments is the converse of connection, and would be quite alien to all beauty. Garden decorations mostly require supporting. Nakedness is commonly repulsive to right feeling in art, drapery, furniture, and accompaniments being demanded. The bare outline of a plantation, or a solitary specimen or group, will appear harsh and out of joint. Openings or glades, that are perfectly simple or unfurnished, also present a certain hardness and severance of parts. They look like mere gaps. It is in the artistic distribution of plants and groups, so as to do away with continuity of lines, and blend perceptibly each individual object with all the rest, that the highest power of a garden or other scene will reside. 


\section{General Principles}

8. Symmetry. - That a palpable attention to symmetry should distinguish gardens laid out in a formal manner, no one will dispute. The ridicule conveyed in the well-known couplet, -

"Grove nods at grove, each alley has a brother, And half the platform just reflects the other;" -

is, though widely circulated, and often revived, by no means to be admitted as the test of truth. Such gardens would be nothing unless the nicest balance was preserved. Symmetry and regularity are their very essence, as well as that of architecture, on which they are founded; for in good models of the most irregular buildings, the truest adjustment of parts is strictly observed. There should also be a beautiful balance maintained, however subtile and disguised it may be, in the proportions of every garden, whatever be its style. Not that the same description of objects placed in similar positions should be found on the opposite sides of gardens, but that their general effect should be that one side is, as a whole, about equal to the other in height and breadth; or, at least, that such an impression should remain on the mind of any one glancing over the two.

9. Gradation, or the agreeable transition of one part of a garden into the other, without any decided breaks, or marked interference with harmony, should always be striven after, as it will enable the designer to use parts of different styles and a variety of ornaments, and yet preserve enough of consistency and smoothness. But the gradation to which I would most directly advert is that which treats the different parts of a place as so many ascending steps, until the highest and best points are reached. As in a house the exterior should be but little decorated, the vestibule or porch plain, the hall only a trifle more ornate, and the various rooms more and 
more enriched, till the saloon or drawing-room, which is the most showy of all, is arrived at, so, in the outdoor domain, the exterior look, while unexceptionable, should be quiet and by no means attractive, the approach private and not adorned with flowers, the pleasure garden a little more enriched, and the front of the house, with its lawn and flower-beds or flower garden, be in the very highest style of art and beauty. It may, perhaps, be impossible to develop this system of arrangement fully, in consequence of the shape, size, or peculiar accessibility of the land, or from other local considerations. But the more thoroughly it is inwoven into the plan of the place, the more perfect and pleasurable will that place be made.

Where the best parts of a garden are open to every one who approaches from the outside road to the house, there is not merely no privacy, but nothing to mark any distinction between the treatment of friends and casual callers. All the delight of showing the former round the garden, and revealing its more sacred and elaborate features, is completely sacrificed if they can see them before reaching the house. In this respect, a garden should be a sort of practical climax.

Io. Apparent Extent. - A great deal of ingenuity is often demanded to give apparent extent to a place that is, in fact, extremely small. There are several ways of contributing to the attainment of this. Attention to some of the points already discussed will partly accomplish it. If a garden be simple in its plan, there will be a good deal of open space in it, and a dash of intricacy will rather heighten than diminish such an effect. Harmony of parts will further maintain the idea of size, for, where everything is linked together to form a united whole, there will be none of that distractedness of attention and division of interest which tend to make a small place appear still smaller. Repose is indispensable to 


\section{General Principles}

the production of an appearance of extent in a narrow compass, and unless everything conspires to maintain the idea, no attempt to awaken it will be successful.

Breadth of lawn must be fully attained before any notion of extent can be conveyed. A garden will always look meager without a good open lawn. One broad glade of grass should, therefore, stretch from the best windows of the house to within a short distance of the boundary, with as little interruption from walks as possible. The plants and groups may be ranged irregularly on either side of this opening, and, where the space will permit, there may be smaller glades through and among these at varied intervals. If such a broad glade of greensward can be had on two or even three sides of the house, the effect of size will be still more fully realized.

The openness here advocated must not on any account be converted into plainness. There is no more common error than to suppose that a place which has simple borders along two or three of its sides, and the enclosed area entirely unfurnished, presents the best possible representation of size. Because a very small space, such as a room, will appear larger for being nearly or quite empty, it must not be assumed that a garden is to be judged similarly On the contrary, a simple area, which is taken in by the eye at one glance, invites attention to the sharpness of its boundaries. That which requires no mental effort to understand and embrace will never seem extensive unless of gigantic proportions. The notion of size is not to be realized, within straitened limits, by mere simplicity. It is indefiniteness alone, - the giving the eye a number of points to rest upon, and recesses to explore, and the imagination a field for its active exercise, that can produce the required result. What we measure piece by piece, through a lengthened process, will always be 
considered larger than that which strikes upon the vision at once, in all its proportions.

Where there is an opportunity of connecting a lawn with the field or park by means of a sunk fence, and keeping the park closely fed down, so as always pretty nearly to resemble the lawn, the place will be much enlarged in appearance. Even the existence of a wire fence to separate the two, instead of a sunk wall, will not very materially lessen the result sought to be produced by this union of parts. But the edge of the lawn and that of the outlying park ought to be about on the same level, for if the earth be raised on the top of the sunk wall, or on the upper edge of the slope from the bottom of the wall into the park, the eye will be prevented from traveling smoothly and continuously across the two surfaces, the division line will be more or less harsh, and some of the actual space will be concealed by the raised bank or darkened by its shadow.

To make an open glade of lawn appear still larger than it is, the expedient of turfing closely around the plants and masses along its margin may be adopted. It has previously been stated that an object of one color, and that a green one, acquires a striking apparent augmentation of size. And if the plants that flank an open lawn are principally evergreens, and their branches sweep the grass, without any soil being visible, the space is thereby very much expanded in appearance.

What has just been said as to the effect of a single and uniform color in giving breadth of effect, will apply moreover to the injunction now added that all walks should, as far as is practicable, be concealed from the house. This can be done in great measure by using plants of very various heights, whether in groups or as specimens, and, more rarely, by raising the grounds lightly towards the walk and then dropping 
it rather suddenly within a few inches of its edge. The mode of effecting this may be seen in fig. 10 , which is a section of a lawn falling away from the house, and crossed by a sunk walk, the dotted line over the latter showing what the level would be if the walk were not there or not depressed. Where plants would be out of place on account of breaking up a glade, or spoiling a vista, or intruding upon a recess, this raising of the ground for some distance to a uniform height, or giving it a very gentle undulation to cover a walk, may be successfully adopted. It should be recollected, however, that, as before hinted, any portion of a lawn that is raised takes off several inches or feet from the view of the

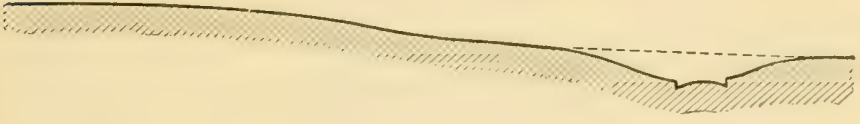

Fig. Io. Method of Grading for Walks.

part behind. And this consideration should suffice to keep such banks down to the lowest level consistent with the fulfillment of their design.

At any point in which there is a great change in the line of a walk, or other walks branch from it, there is a special necessity for having a mass of shrubs or some other opaque medium to shut out such abrupt transitions from the house and the rest of the grounds. Sudden turns or breaks should, if necessary at all, be accomplished quietly and privately, being at least screened from notice until they are actually reached. Besides, the point from which a branch walk diverges requires concealing for the additional reason that the eye might otherwise travel from the house or lawn some distance along this branch line, and a walk that can be thus 
seen lengthwise is more conspicuous and offensive than one of which only a cross view is obtained.

Another motive for keeping walks retired and out of sight which may here be mentioned, though it does not so much affect the question of extent, is that they may be more private and shaded, less liable to be overlooked, more cool and refreshing in summer, and warmer and more sheltered in winter. By passing along them, too, when they are thus secluded, the various views of the place which occur at the many openings that may be left give, by reason of their number and diversity, a more exalted impression of size. When persons walk in their gardens, and choose the paths for the purpose, they will usually desire to be to a certain extent unseen, so that their motions and occupation may not be the subject of observation or comment.

One of the best methods of adding to the apparent limits of a place is to get rid of anything like obvious or glaring boundary lines. This can be done by planting, throwing up mounds of earth, the use of very light and low fences, sunken walls, the treatment of a low wall as an architectural feature, the covering of a dwarf rough wall with ivy, and letting this straggle out from it wildly and irregularly, by broken thickets of common shrubbery, or by a mixture of several of these things. The worst and ugliest species of fence, where it is much seen, is a plain wall, especially if it be high, a close wooden paling, unless it be quite a rough one, of split oak, or a hedge that is kept regularly clipped. All these present a formality, hardness, and liny character, which are continually making themselves conspicuous, and there is no losing the consciousness of a near and disagreeable boundary when it is composed of such materials.

It should be observed that, as few places offer facilities for getting rid of the boundary line entirely at all points without 


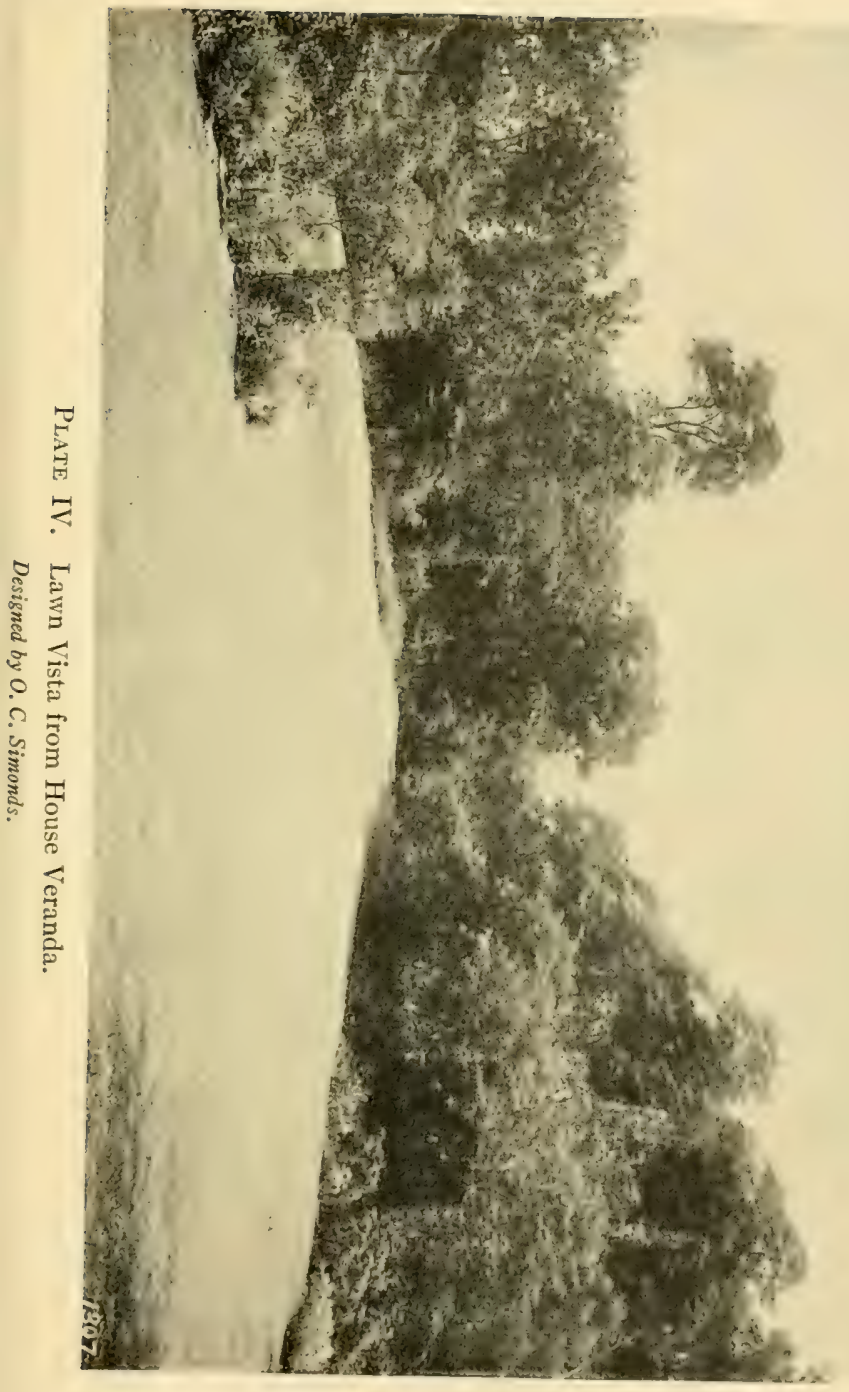





\section{General Principles}

a regular enclosure of plantation, there is little objection to its appearing occasionally, provided it does not stand forth too prominently or present any positively bad features. The chief point is to keep any length of it from exhibiting itself, and to procure, in the spaces that come between such exposed portions of it, sufficient connection with what is beyond to dismis: all semblance of a continuous boundary fence in that direction.

The subject of the concealment of the fences of a place is one of considerable moment, and will be more definitely and practically treated on a future page. At present, the enforcement of principles only is sought.

Still further to carry out and complete the idea of extending the limits of a garden, good and beautiful scenery or objects outside the place should be brought as much and as conspicuously as possible into view, and all vulgar, deformed, or disagreeable things, or such as do not appear to belong to the property or to be fitting adjuncts, be thoroughly excluded. In the latter class, common houses or cottages, outbuildings, neighbors' residences which are very near or staring, high or ugly fences on an adjoining property, public buildings that are not in good taste, agreeable, or striking, will furnish a few illustrations. They are to be shut out in various ways, according to their height, position with respect to the best front of the house, and nearness. For hiding large buildings, one or two leading points of observation may be selected, of which the drawing-room windows of the house should invariably be the principal, and the object to be gained should be attempted in relation to these. It is hopeless to seek to darken one or more great eye-sores from every part of the grounds, for in so doing the most beautiful views may be intercepted from the better and more important stations. 
One simple rule of perspective should never be forgotten in dealing with ugly masses of buildings that are both high and near. It is that the nearer we bring to our point of vision any object that we wish to interpose between ourselves and another object, the larger will be the surface of the latter, both as regards breadth and height, that we screen from view. A reference to this fact will often enable the operator to accomplish a good deal with scanty materials and to do it at once. Very large trees, for instance, are not always possessed or to be procured, and if planted they may not thrive so well as others of a lower growth. The knowledge of the above

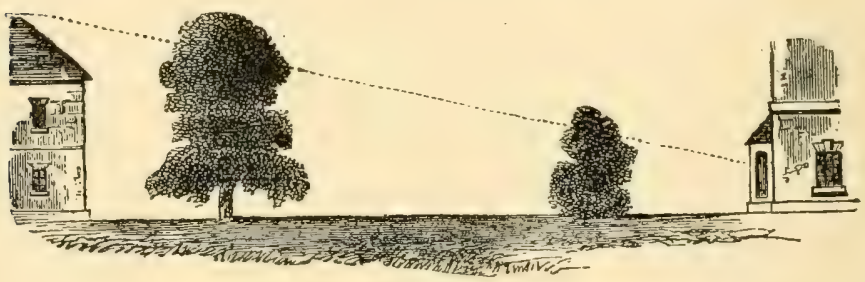

Fig. II. Practical Perspective.

truth, however, will render the use of the smaller ones as perfectly and as immediately effectual as the larger would be in a more distant position. And in this way a moderate-sized evergreen may be made to answer a purpose which a tree of great magnitude would scarcely be sufficient for in another place. It need hardly be said that evergreens are much more suitable for the office, where they can be had large enough, as they do the work well at all seasons of the year. It should be added, that any extreme application of the rule would probably bring the trees employed too close to the house, or too much on the lawn, both of which have to be shunned.

The sketch, fig. II, inserted here will suffice to convey the 
necessary idea of what is intended. The dotted line, taken from a window as the point of view, will make it evident that a bush is just as useful when sufficiently near as a large tree in a more remote position. And it may be mentioned that where the ground falls away from the point of vision towards an object that is to be shut out, the application of this principle is still more striking.

Such deformities in a landscape as are somewhat distant, and either not actually large, or which, from their remoteness, do not appear to cover much space, may at times be appropriately blotted out by a neat greenhouse or summer seat, a small temple, or any architectural feature akin to these. In connection with a flower garden, too, the same point may be compassed by a colonnaded wall, an ornamental or trellised covered way, an architecturally treated wall for climbers, or a short range of glass houses. But ornaments of this class are fitted only for peculiar positions and styles of architecture, to which they require skillful adapting.

There are certain features to be met with in some landscapes, which, though not in themselves inelegant or deficient in beauty and interest, may have their character and effect very much improved by the way in which they are made visible from a place. Such are church towers and spires, fig. I2, pillars and obelisks, distant and pretty cottages, prospect and flag towers, ruins, lighthouses, windmills, and many other more commonplace erections, which may yet, from their position, their outline, or their historical or local associations, be worth directing attention to particularly. The most characteristic and effective plan of introducing such to view is by openings in the intermediate or boundary plantations, which shall create a kind of vista at the end of which the object intended to be seen occurs. If the sides of such vistas are tastefully and naturally finished off, without 
any appearance of formality or indication of art, and the trees in the outer landscape at all favor the design, very beautiful effects may be produced in this manner out of the most ordinary materials.

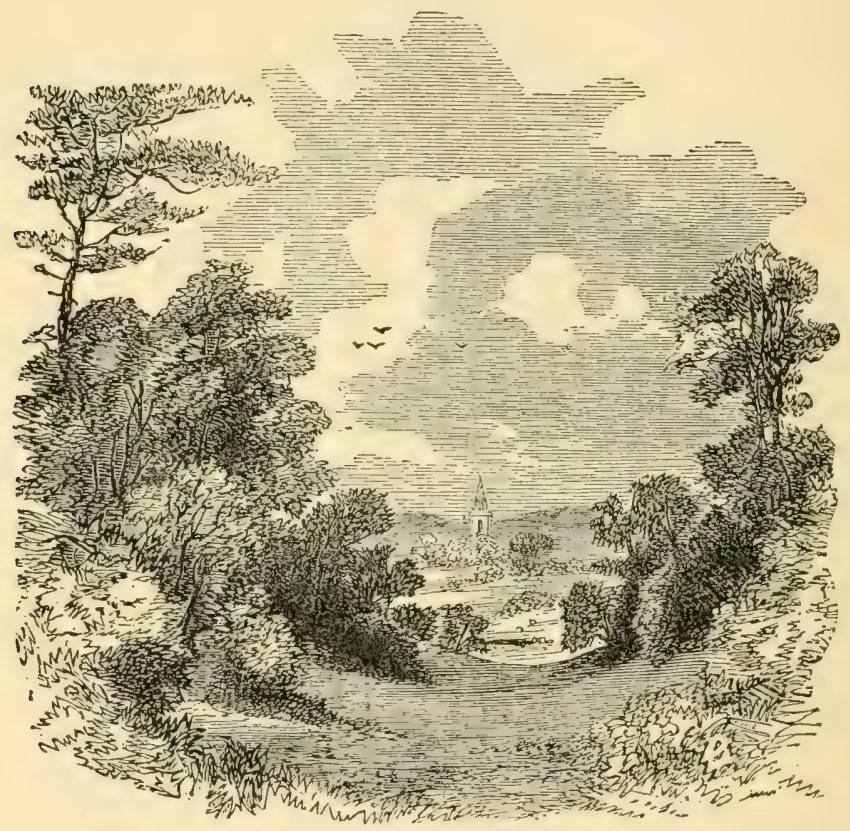

Fig. 12: Vista Showing Distant View.

Broader sweeps of landscape, when the nature of the surrounding property sanctions their introduction, will of course require to be treated differently. It will not do to cut them into shreds, or exhibit them in mere patches alone. Nevertheless, very bold ranges of uninterrupted scenery, however fine, are almost incompatible with the confinement of a small 


\section{General Principles}

garden. For the very amplitude and grandeur of such scenes serve to render the meagerness of the home view all the more marked and inconsistent. In addition to which, it may be assumed, as a sort of rule, that every landscape, distant or otherwise, should have a distinct foreground, and that this should be obtained within the home estate and tolerably near the principal points of observation. So that to create such a foreground it will be needful to separate the prospect into two, three, or more divisions. And if this be happily executed, omitting merely the tamest portions, and making the openings of various widths, with very differently shaped plants or groups to compose the framework of the picture, a result more consonant with the character of the place, and more attractively beautiful though less imposing, will be realized than if the whole had been left to its native boldness and breadth.

The treatment of foregrounds may be exemplified however imperfectly, in figs. $\mathrm{I} 3$ and $\mathrm{I} 4$, the former of which represents a foreground to a flattish and quiet landscape, and the other to a lake or the sea. In all these cases, the materials of which the foreground is composed are natural ones, and are treated in the natural manner. Of course, however, different kinds of ornamental fences might enter largely into the composition and become characteristic elements of the scene.

This principle of dividing a large landscape into several portions, in relation to a place of narrow limits, by the introduction of very irregular masses of trees and shrubs along or near its front boundary, may be yet further developed and applied to cases in which only such smaller scenes can be admitted. For the treatment of both would be the same, and the effects of each would be alike suitable and desirable. Examples will not be unfrequent where snatches of delicious scenery can be gleaned with the aid of much contrivance here 


\section{$64 \quad$ Landscape Gardening}

and there around the best sides of a house, the intervals being wholly blocked up with something beyond the owner's territory and control. Only let it be established that these glimpses or partial views of outlying beauties are those most proper to the accident of having but a small garden, that they best accord with its necessary internal arrangements, and most forcibly enhance its own apparent size, and so far

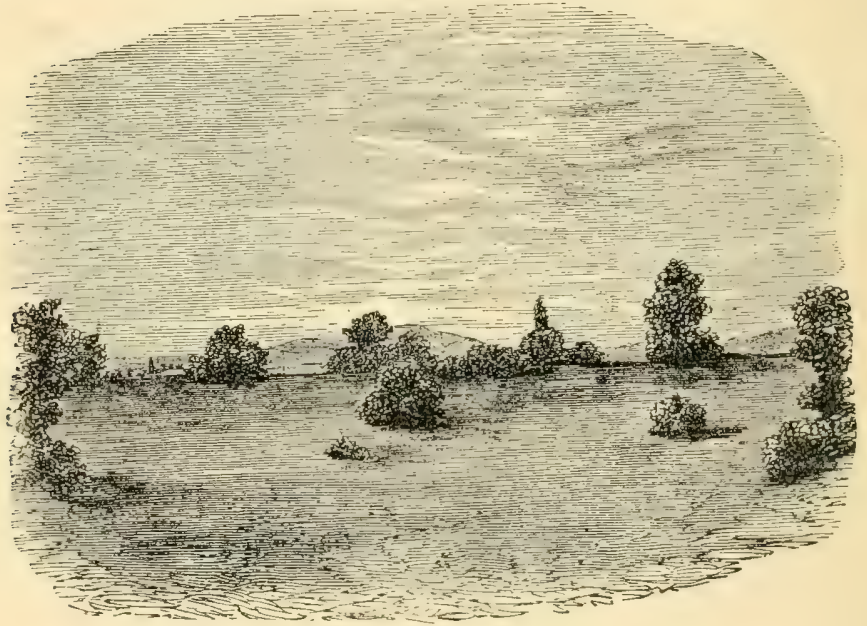

Fig. I3. Treatment of Flat Foreground.

from such conditions being the subjects of chagrin and vexation they will be hailed rather as felicitous and appropriate. What a person guided by the highest taste would endeavor to effect were there no restrictions and impediments, it can surely be no disadvantage to another to be compelled to submit to.

In its fitness for awakening and fixing the attention, the separation of a country scene into several minor portions, 


\section{General Principles}

instead of exhibiting it all at once, may be a little longer dilated upon. There are few natural pictures, except such as are very fine and commanding, which do not lose their power of attraction in the precise ratio of their breadth. That which is gazed upon through a variety of comparatively narrow openings, though only just above commonplace, will win more notice than if it lay before the observer in its naked expanse. And as we pass along behind a screen that is gracefully unfolded, as it were, at intervals, to reveal to us fragments of landscape, curiosity is excited to catch those points hidden by the opaque portions of the screen and an extreme diversity of prospect is gained.

Whether the plantations between different openings, made to exhibit a pleasing landscape, be the result of necessity, to hide what is objectionable, or of choice, to heighten and impart variety to the pictures intermediately displayed, their outlines and edges alike require to be most carefully and artistically treated. Not that this should be artificially done, but with such refined and delicate art that it shall appear as if nature herself had polished them off. Roundness, and yet irregularity, play of outline, an intermixture of evergreen and deciduous plants, forest trees, tree-like shrubs, and such as are decidedly shrubby, with variety of form and color, should be their chief characteristics.

When any broad sheet of water, such as the sea, a large river, or a lake, forms the principal object from the front of a house, or from some point in the garden, the value of a good irregular woody foreground, fig. r4, will be even more apparent. A great glare of water is seldom agreeable to the sight, and in some kinds of weather may be most disagreeable or melancholy. The passage across it of vessels of all sorts likewise becomes far more interesting and delightful when it is only to be observed at intervals and is occasionally 
lost sight of. If water be looked at through a leafy screen, it is, moreover, in some degree sobered down thereby. It does not dazzle or pain the eye so much. It has all the charm of light and shadow. Its own luster and loveliness

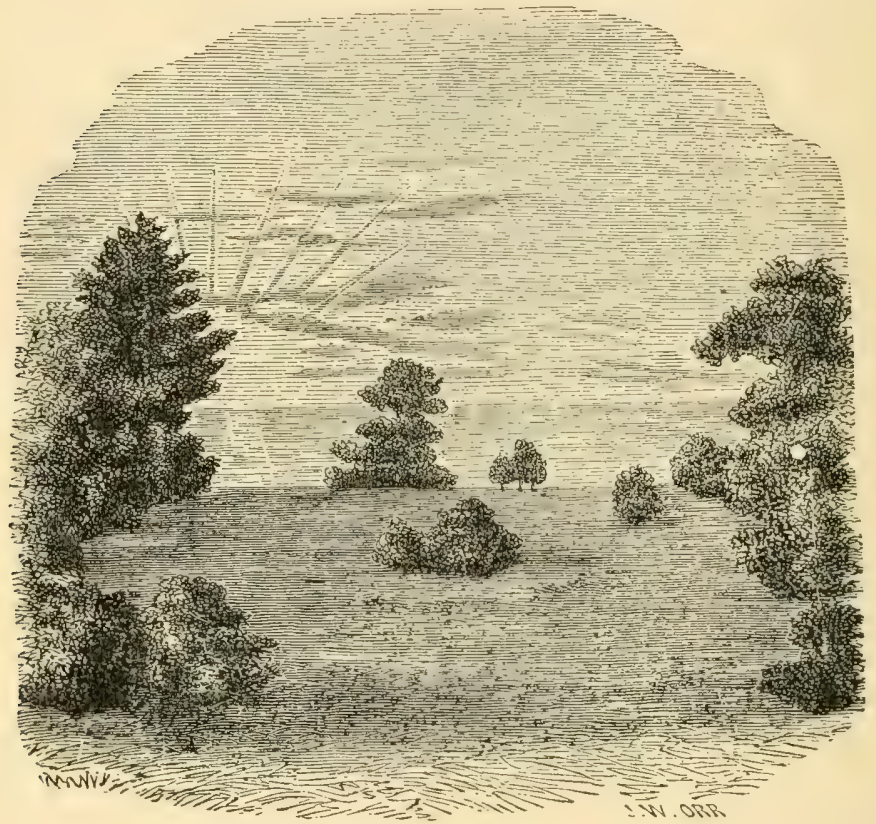

Fig. I4. Treatment of Foreground with Water View.

are brightened by the contrast. It is a gem with a dark setting.

There may be states of the atmosphere in which a large unfurnished expanse of water will be perfectly satisfactory. On a rich summer's evening, towards sunset or during twilight, especially after warm showers, water may often be in 
the highest degree beautiful without any accompaniment. But in general it will either be too glittering or too cold to be altogether satisfying without some aid from trees as a foreground. It is wise, therefore, to provide for common and usual enjoyment, and to leave extraordinary pleasures to be otherwise obtained. The scene that is most pleasing at all seasons of the year will undoubtedly furnish the largest amount of gratification, and make a habitation most cheerful.

II. Richness and Polish. - Nothing imparts a greater air of refinement and gentility to a garden than a certain amount of richness and polish. The first of these may be attained by means of a tasteful selection of plants and flowers, and by the sparing use of appropriate architectural decorations. Polish is more a matter that relates to the mechanical execution of the design. Still, it may be advanced a step higher, and applied to the expression as well as the finish. In the outlines of figures and beds, in the arrangement of plants, and in the shaping of the ground, much may be done to create this delicate grace. Everything straggling or ragged, all that produces confusion, and as a rule all angularity and harshness are completely opposed to it. Extreme smoothness, easiness of transitions, gracefulness of lines, softness of undulation, lightness and elegance of ornament, are some of its leading manifestations.

Both richness and polish will, to a certain extent, be the result of keeping, as well as attention to matters of detail in the first formation. A place can never possess either, unless the taste shown in the design be carried into the minutest details of the execution, and be maintained by subsequent care and correct feeling. Hard deep edges to the walks and borders, slopes or undulations which unite with the general level by a convex instead of a concave line, and little irregularities in the surface of a lawn, are quite incompatible with 
high polish; as extreme thinness of plants in beds, poverty and weakness of masses or specimens, large staring patches of bare soil visible in the borders or beds skirting a lawn, an inferior order of plants in the neighborhood of the house or by the sides of the grass glades, and the use of commonplace or uncongenial ornaments, are inconsistent with richness.

I2. To conceal the offices and out-buildings belonging to a residence is a matter of the most ordinary kind, yet it may be very clumsily effected. Planting is in general the most effectual means. It should not, however, becarried so close to the building as to darken the windows materially or occasion dampness. And that this may be attended to without intruding too much upon the space of the garden, the arrangement of the house must be adjusted accordingly. A good deal, in short, will depend upon the architect. Perhaps it is best, when the servants' apartments are on the ground floor, to keep them wholly on the least important side of the building as regards aspect and scenery, and have their windows looking for the most part into the house-yard, which can then be easily planted out. If treated as an inferior wing to the house, they should always recede far enough from the principal elevation to give space for the admission of light and air between them and the plantation or whatever else is used for screening them.

I3. Variety. - I come now to the consideration of that very essential element in the composition of a landscape, variety. This has been happily termed "the spice of life," since without it existence has no true relish. And its influence in landscape gardening is equally potent, for it gives a viracity, a freshness and a piquancy which nothing else will supply. It is the crowning grace that makes even uncouthness tolerable, and invests beauty with superior attractions. Sameness is but another word for feebleness, variety for 
power. It is that for which man has a kind of innate and insatiable thirst, to which nature is perpetually ministering. Whoever saw the sky dappled or tinted in exactly the same manner, or a plant or tree developing itself precisely, part for part, as another does? No two natural landscapes could ever be found alike in all particulars. In stream, and forest, and mountain, with all their shades of modification, and minuteness of detail, there is a wonderful dearth of near resemblances or more than general relations. It is the province of art to consult and to weigh these indications of nature and the corresponding tastes in man, and to derive lessons from the one and endeavor to gratify the other.

Variety may be partly obtained in gardens by curved walks. If we observe from some elevation the course of a small river with its numerous and varied meanderings, or follow the devious track of a wild forest path, we shall soon be convinced of this. It is the graceful contortion of line that at once pleases the eye and stimulates the fancy, carries the observer onward, and continually rewards him with fresh beauties. But as neither a small stream nor a forest path will be nearly so alluring when a number of their convolutions are spread out in one view, as they would be were it necessary to pursue their course in order to discover each particular turn and pry into its individual charms, so a curved walk in which several of the curves are seen at once, or where they very much resemble each other in sweep, loses the chief and most engaging part of its variety. It is of prime concern, therefore, that the curves in a walk should be varied as much as they can be (fig. I 5), and that they should not be exposed to each other at any point. The views to be caught from the numerous stages in the turns of such a walk should embrace every good aspect of the house, the garden itself, and the adjoining country. 


\section{0

To prevent the curves in a serpentine walk being visible from one another, groups composed pretty liberally of evergreens are most customary. They will of course be principally wanted at or near the hollows of the curves, though it would be unwise always to put them just at the extreme

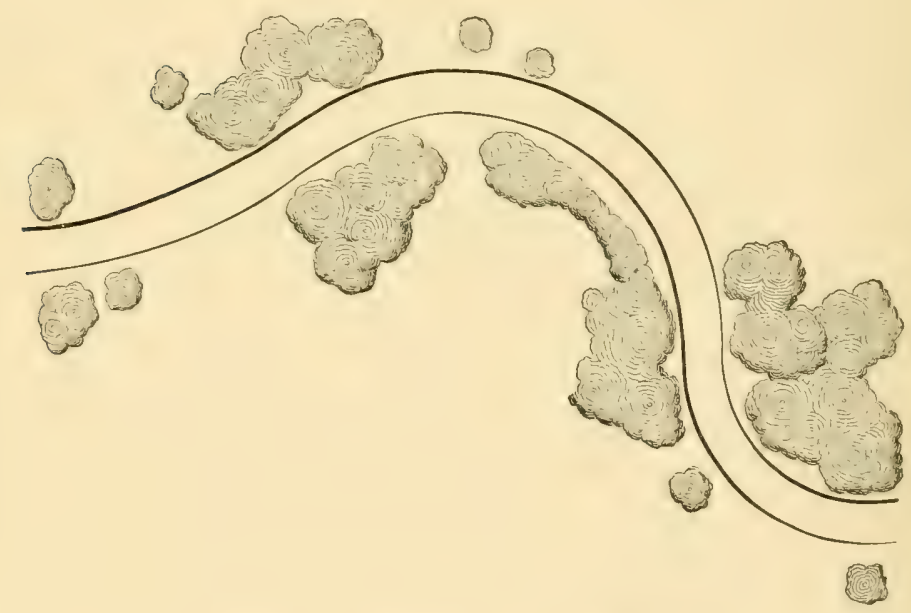

Fig. 15. Treatment of Curved Walk.

center, because, in those turns that sweep away from the lawn especially, the greatest depth of grassy bay may there be procured. Figs. I5 and 16 will assist in explaining this. And one merit in the management of such things will be in making the position, outline, and character of the groups extremely different. 


\section{General Principles}

Other modes of shutting out one curve of a walk from another are the formation of a swell in the ground; a group of rocks or roots, thrown together rudely, and partially planted

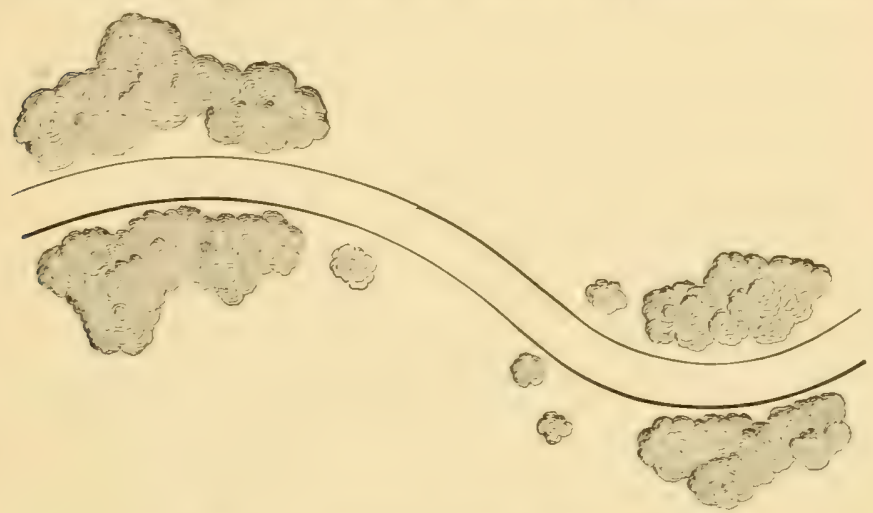

Fig. 16. Grouping Shrubs along a Walk.

with low evergreens and alpines; a covered seat or summerhouse, backed, if needs be, with masses of shrubs; or two or three specimen plants, or a tolerably large and spreading tree.

And here the remark naturally occurs, that variety may be further attained by placing single plants and groups on a lawn. See fig. I\%. In doing this, everything like straightness and formality is specially to be discarded. The size and shape of the groups, while they are in due measure adapted to the lines of the walks, can scarcely be too unlike,
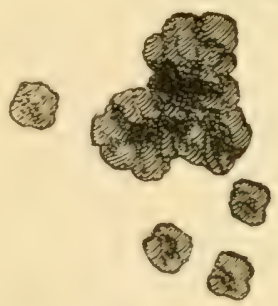

Fig. 17. Typical Group. provided the changes in their shape be not extravagantly numerous, trifling, or violent. There should be enough 
planting to furnish a lawn, and shut up the walks here and there in order to produce freshness, but not so many as to encumber and cramp the place. A few good, bold openings between them, where the space is small, will be better than a great number of petty ones. And all such openings should be carried as far as is at all practicable into the surrounding or outside border, that the eye may be required to explore them and not scan them in a moment.

In the old-fashioned systems of gardening it is usual to place all the dwarf-growing plants at the front of the bed or border, and those of greater height behind them, reserving the taller and more stately forms for the center or the back. A regular slope of branches and foliage is thus occasioned which has the most perfectly artificial appearance that can be imagined. It is of course utterly subversive of all variety and may be likened in form to the sloping roof of a house, wherein only convenience is contemplated. In nature, the very opposite of all this is observable. Bushes and trees, herbs and bushes, blend together in the freest and most indiscriminate manner, as in fig. I8. And while the edges of natural groups are commonly rounded off with exquisite finish, spiry forms sometimes also jut forth from them and beget a charming diversity.

And thus should it be with masses of plants produced by art. They should have a roundness of outline, and yet be in the strongest sense irregular, the tallest plants being brought near the fronts at some of the most prominent parts, and interspersed through the groups at various intervals, being backed up by those of the next size, and the interspaces filled with smaller and medium-sized plants. Ordinarily, the boldest swells in the groups should have the boldest plants in them, and the smaller projections be furnished with plants a size or two lower, while the retiring and narrow parts may 


\section{General Principles}

be made up with low or second-sized shrubs alone. Here and there a tree or plant of upright or fastigiate character, such as the Lombardy poplar, the arbor-vitæ, fig. I9, and the Irish yew, will make a very striking break towards the front of

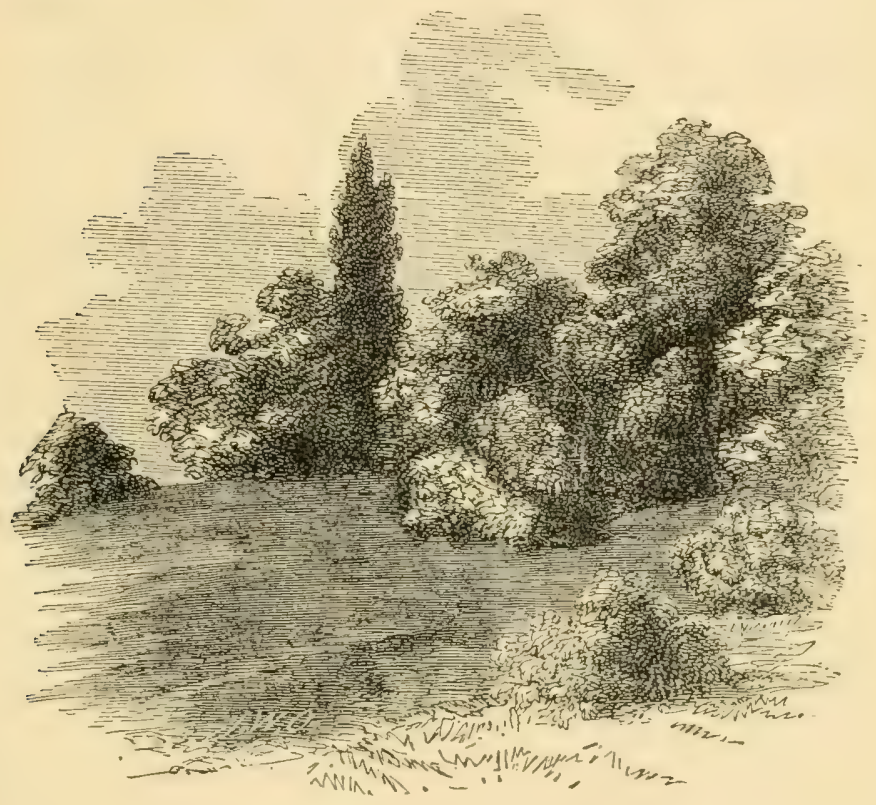

Fig. I8. Elevation of Group.

the swells, or even nearer the middle of the mass, if well supported with lower plants of another character.

Single specimens on a lawn ought to be disposed with the greatest nicety and care. For the most part they should be attached to the groups, fig. I 9 , by being put at some of their salient points, to carry out and soften off the swells in them. 


\section{$74 \quad$ Landscape Gardening}

The more prominent the projection of a mass, the better will it be fitted for receiving one or more specimens as an adjunct or extension. By thus adding, in effect, to the bolder points, a much greater play of line will be produced. In the openings between the masses, single plants should be very sparingly inserted, as they will lessen their size. Still, where an opening extends beyond a walk and is not very narrow a specimen plant or two, not exactly in the middle of the opening, in the hollow part of the curve of the walk, may often be

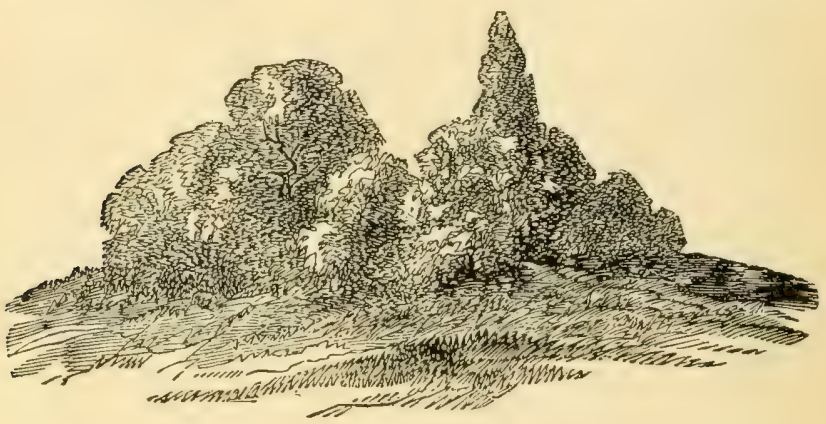

Fig. 19. Group on High Land.

useful to break the plainness of a bay, and give more occupation to the eye and the fancy.

On lawns of any considerable breadth, one or two small groups and a few scattered specimens will sometimes be necessary in other parts than at the mere sides (see fig. 20), to communicate length as well as breadth and a larger share of variety. In arranging these groups and specimens regard should be had to several points at which the lawn extends most nearly to the margin of the place in order that, by very irregular and broken files of plants, the eye may be thrown into these furthest recesses and have in the plants on either 


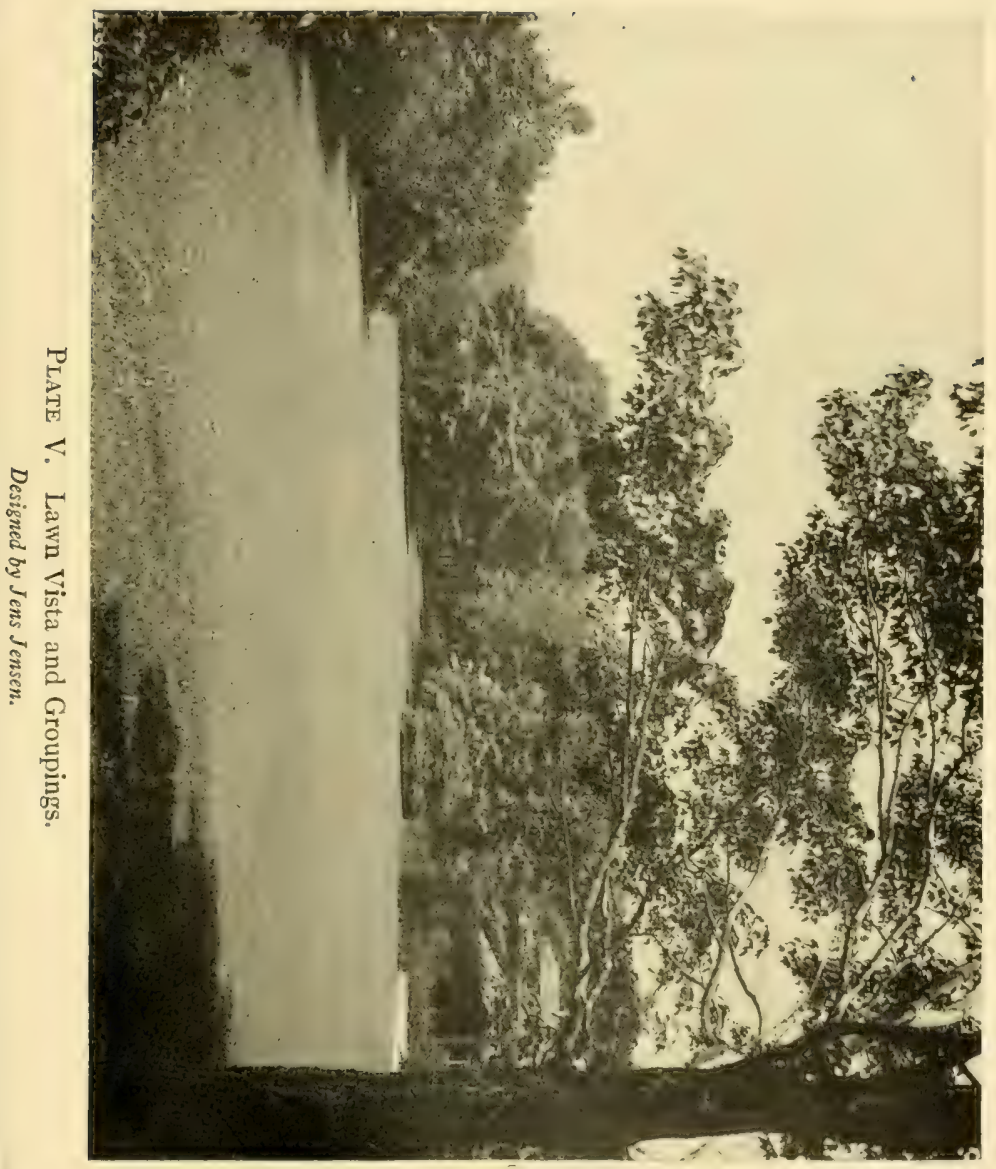



side of the view the means of measuring its full length. A lawn that has its glades flanked with something like rows of low trees or shrubs will seem considerably larger than it is, and will of course present more variety of view. By rows and files, however, is not meant literally what the words express, but an ingenious disposal of the groups and specimens so as to have some of the effect which rows would produce.

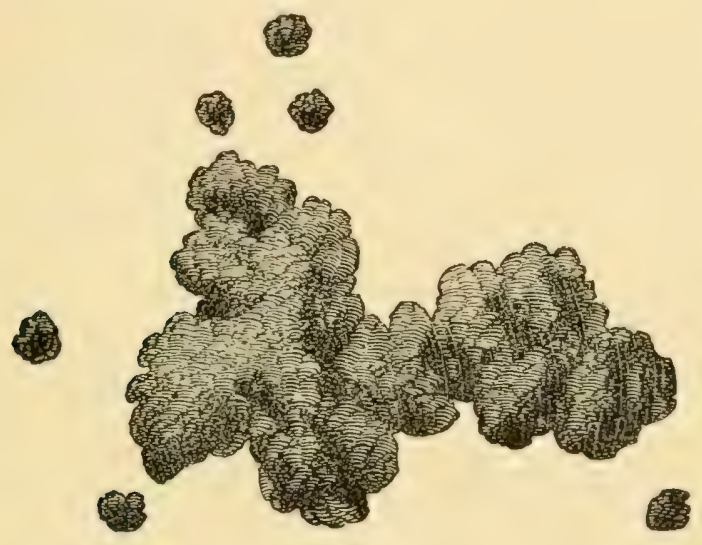

Fig. 20. Plan of Proper Grouping.

Should a house be so unfortunately placed as to look obliquely upon one of the boundaries of the property, variety may be occasioned by drawing lines from the best windows of the house, at different distances, in the direction of that boundary, fig. 2I, and jutting forward the plantation or specimens along some of these lines into the lawn or field, leaving deep irregular bays or recesses between all such projections, these bays or openings being marked, in the figure, by arrows between dotted lines. Not that the plants should be put in rows along a portion of either of these lines, but spotted about 


\section{$76 \quad$ Landscape Gardening}

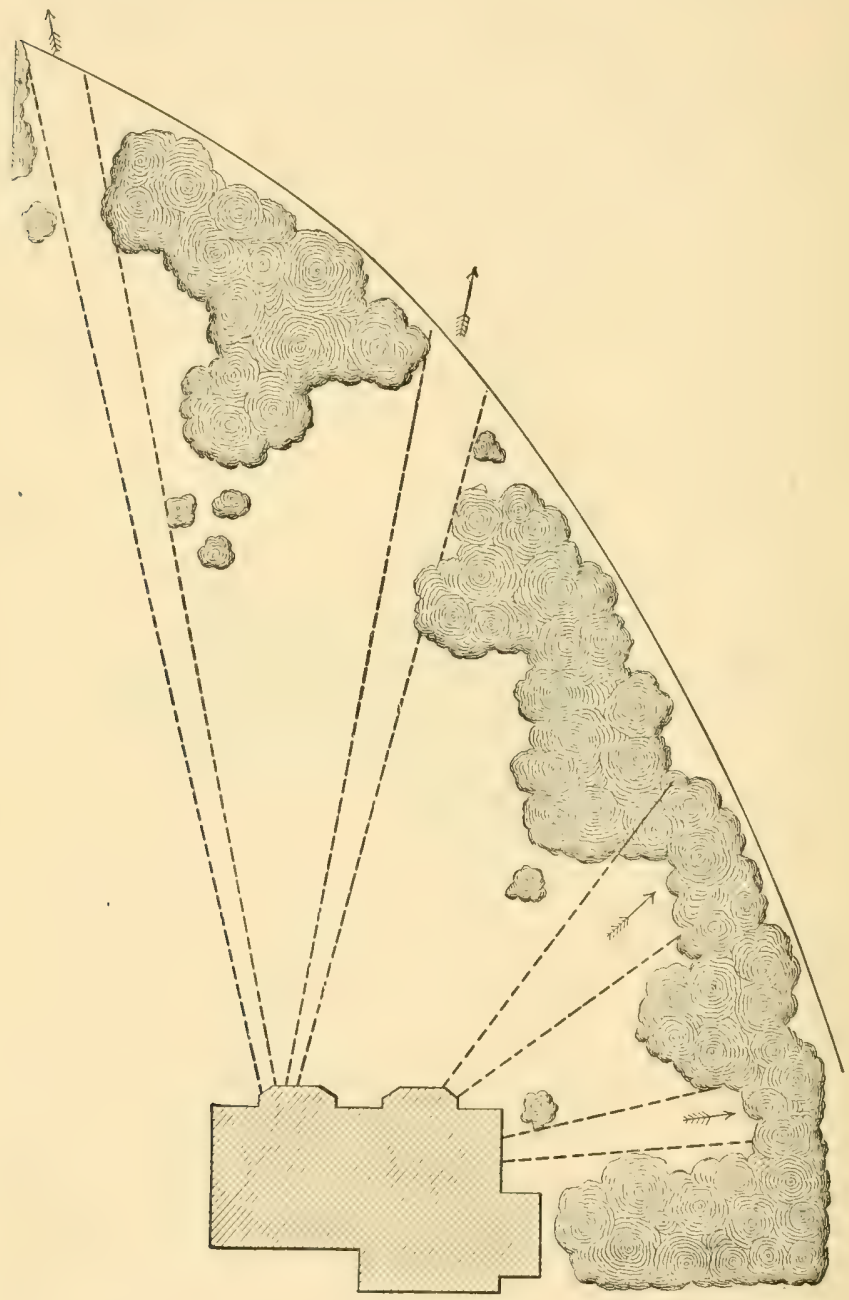

Fig. 2I. Method of Diversifying Views from Residence. 


\section{General Principles}

between any two of them in larger or smaller patches. The plants at the end of such recesses should likewise be the lowest by which the boundary can be hidden, to carry the eye as far as possible beyond them. This will tend to mitigate the meagerness of the estate on that side and give some degree of relief and change in the place of a hard and monotonous line of 'fence or plantation.

A leading point to keep in mind in the disposal of single plants and masses on lawns is, in fine, that they have to form, furnish, support, and give extent to a variety of glades, vistas, and recesses. From the drawing- or sitting-room windows of the house, therefore, this arrangement should be principally considered and fully sustained. No specimen should stand out in the middle of a glade, or destroy the continuity of a vista, or be thrust forward into the sides of a recess. Nor should a group be placed otherwise than to create and maintain these various features, or ever fill up, except very partially, those bays in which a greater length of lawn can be obtained.

The house must always be regarded as the chief point of vision in a place, and the best views of the grounds should consequently be had from it. The windows of a house are most used for looking at a garden, and the points of interest can there be inspected more leisurely. For these reasons, and because occasional visitors see a garden more from the windows of the house, it is a good plan in laying out a garden to form a series of lines radiating from one, two, or three principal windows of the house, at irregular distances apart, towards the outside boundary, and to place the requisite specimens and groups of plants solely within certain of the triangles thus made, according as they may be wanted, never suffering the specimens nearest the house to be so large as to cover a greater space at the broad end of the triangle 
than may there be required as a plantation, and disposing the whole of them so irregularly, that nothing like lines of plants shall ever appear. The practice of such a system need in no way interfere with the beauty and variety of the lawn as seen from other parts. This may just as easily be attained at the same time. Indeed, cross lines from all the openings at the sides of a place will be of equal service in the formation of subordinate views. This idea is illustrated in figure 22.

By a due admixture of different sorts of plants, variety may be additionally realized. The habit and character of trees and shrubs exhibit a wonderful amount of variation. Some of them, indeed, possess unusually striking characteristics and assume a most peculiar garb. But there is something of difference in all, and little peculiarities show themselves to advantage in a small place. The selection of plants for a garden should therefore comprise all the best sorts for which there is proper room and a suitable situation.

In attention to the heights of plants, and the color of their leaves and flowers there is much variety to be found. Diversity of height is as telling as variety of shape and arrangement. And colors are, perhaps, even more expressive. Certain kinds of trees produce foliage of a delicate pale green, or silvery gray, or with a marked variegation. Others have a dark, massive, somber look, and are evergreen. Such sorts should be particularly sought after, and placed where they will exhibit themselves most strikingly, and be backed by others that will help to throw out their colors by contrast. With flowers, too, the same measures should be resorted to. The species may be arranged so that one enhances the beauty of the other, and all together make a lively and varied whole. The modern practice in America, however, tends to a more restrained use of plants with 


\section{General Principles}

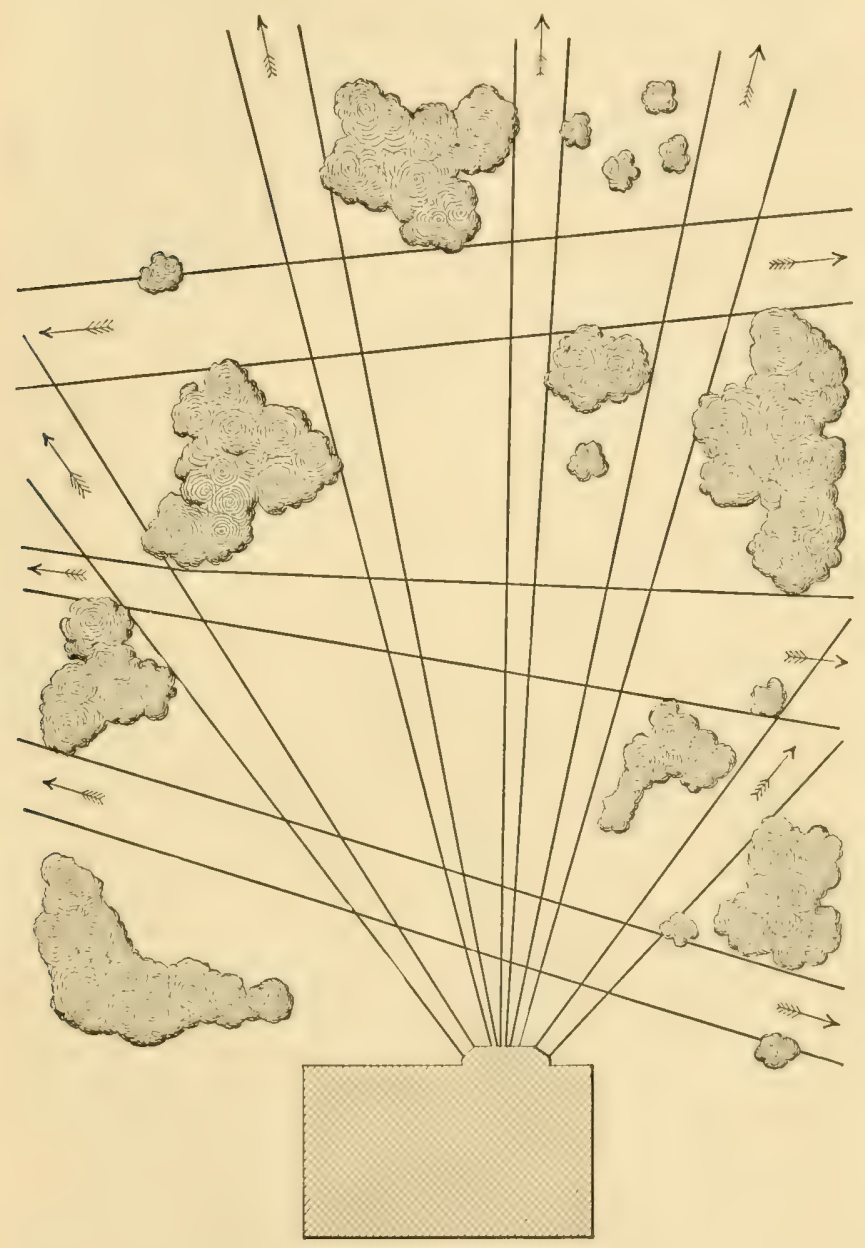

Fig. 22. Vistas with Cross-Views. 
striking foliage. The best landscape architects nowadays depend more on the subtle blending of closely related tints.

Objects of a lighter color than that of any mere vegetable forms, such as vases, statuary, foun ains, buildings of any kind, or pieces $0^{-}$water will largely contribute to variety. Anything lighter than the color of ordinary stone is, however, hardly admissible, for the whiteness of plaster figures, independently of their coarseness and commonness, is too little in harmony with a garden scene to satisfy a cult vated taste. Greenhouses that are painted white on the outside are similarly incongruous. They should be of the same color as the building to which they are attached.

Water, with its beautiful changes of aspect and complexion, deserves to be more distinctly mentioned as a source of variety. The feathery spray of a fountain or cascade; the ripple of a pool as it is agitated by winds or disturbed by fish; the reflections of lawn, plant and sky, which are so softly mirrored on its glassy surface after a warm rain; the murmur and music, and life of a stream; the transparency, the glitter, the coolness, almost inseparable from the possession of water, in any form, are all causes of a well-nigh endless variety. And if aquatic plants can be cultivated in it, or water-fowl encouraged, its variations and its liveliness will be far more conspicuous.

Like the atmosphere, which it in some measure resembles, and with which it is sympathetically affected, water is susceptible of a wondrous variety of impressions in different states of the weather. Taking only its capacity to reflect objects, an attentive observer will find that, as a landscape never looks precisely the same under different atmospheric conditions, so a smaller scene is pictured in water alike differently as to clearness or dimness, shades of coloring, play of light and shadow, distinctness or indefiniteness of lines, and all 
those nameless little graces which go to make up the interesting diversity that atmospheric phenomena occasion. At morning, midday, twilight, or moonlight, beneath sunshine or deep cloudiness, before or after rain, when the weather is soft and balmy, or harsh and chill, - at all seasons, in fact, and under all circumstances, except when a wind is stirring, water will present, like the atmosphere, a constantly changing medium through which a landscape may be examined.

A final constituent of variety is undulation of the surface of the ground. It is not all places, of course - possibly not many of them - that afford scope for the adoption of this. And it must be set about with great judgment. Undulating

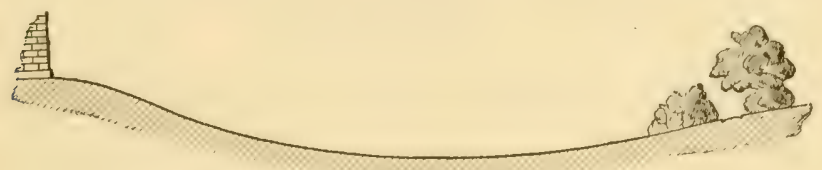

Fig. 23. Treatment of Boundary.

the ground, for the mere sake of doing so, when all the country beyond is flat and tame, will only appear peculiar and eccentric. There must be a reason for what is done, and if there be some correspondence, likewise, with the district outside the garden, it will be still more correct and appropriate.

In building a house, its ground floor is now generally placed several feet above the natural level of the land, and there has consequently to be raised around it an artificial bank. Along the boundary of a place it is often further desirable to form another low bank, fig. 23 , if the material can be had, and to raise the beds or masses towards the edges of the lawn, that the limits of the ground and the line of the walks may be more perfectly hidden. Between these banks, then, there will be a sort of hollow basin, composing the lawn, and sus- 
ceptible of some little variation, while the shape of the banks themselves, if worked nicely into the level of the lawn, will give more or less play of surface. If there be a pool of water, a fish pond, or a small lake of varied shape, the sloping of the ground down to either of these will supply the means of getting a little more undulation, and the earth taken out to form them may be employed in making increased banks.

Undulations may exist naturally in a garden or field, and these should be scrupulously preserved and rather be added to than curtailed. As a rule, the bottom of a hollow should

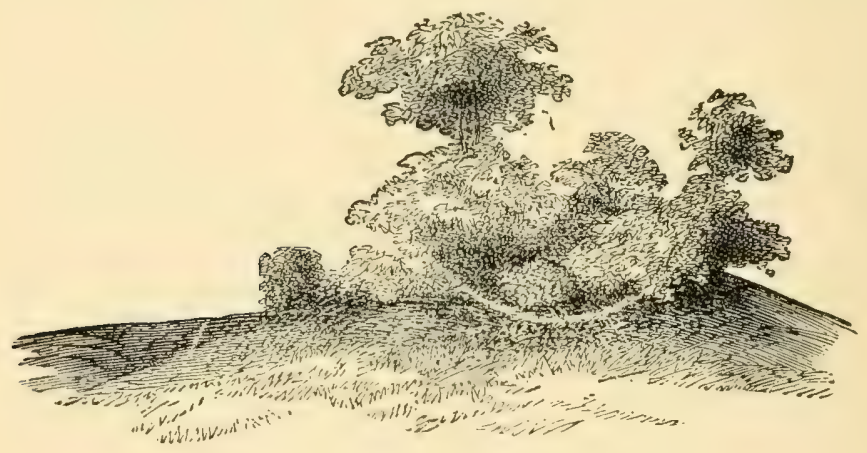

Fig. 24. Location of Group on a Knoll.

never be planted and only portions of its slopes. Plantations in hollows lessen their depth, not only in proportion to the height of the plants placed in them, but because the surface of a mass of plants is always more or less broken, and a dell so filled will appear several inches or even one or two feet shallower than if it had a smooth grassy bottom. Planting by the margins of streams in hollow's is sometimes effective, but it should be decidedly irregular, and in clusters or groups rather than in large masses. When a hollow or glen 


\section{General Principles}

is so deep or so remote from the house that its bottom is not seen, keeping it unplanted will preserve the indefiniteness which is one of its finest effects. If the eye cannot fathom any such dip in the land, there will be a mysterious character about it which will lead the imagination to paint it much deeper than it actually is. And the full knowledge of its precise limits will not dissipate the pleasure. Knolls, swells, or any trifling elevations may be advantageously selected for groups of trees, as, by giving them thus a greater height, the depth of the intermediate or surrounding depressions is

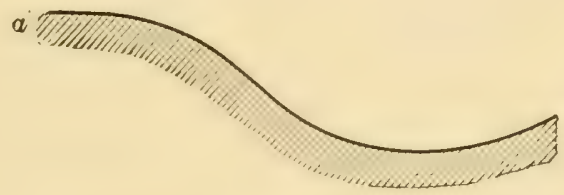

b

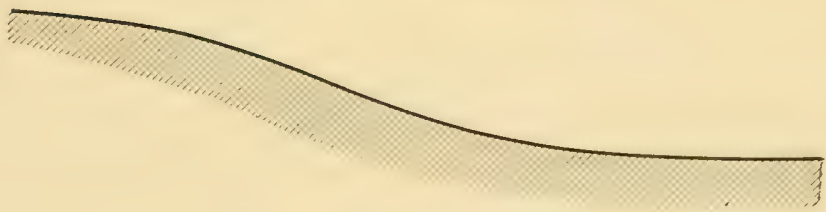

Fig. 25. Treatmerit of Grades.

increased. Even an almost imperceptible rise in the ground should not be lost for such a purpose where its position happens to be suitable.

The greatest charm about undulations of land lies in their softness and freedom. The lines should all melt into each other. Angularity, sharpness, or straightness, will be unknown in them. In the meeting of two lines (fig. 25a) they should seem as if they had been gradually attracted towards each other for some distance previously. They ought never to unite with apparent reluctance. And however good and 
desirable change of surface may be, beauty must not be sacrificed to variety.

The slape of any elevation, therefore, however small, should be so prolonged as imperceptibly to merge into the common level (fig. $25 b$ ) and by a concave line of the gentlest possible description. For the mere lengthening out of the slope will produce ugliness rather than beauty, if some degree of concavity be not expressly sought. After any ground line once begins to reach the middle of its descent, it should then almost immediately commence to curve under.

More positive, because more sudden, variations of surface, may be engendered by what is termed picturesqueness. In this kind of scenery, the forms are all rugged, the lines broken, the changes abrupt. Rough and tangled tufts of vegetation, ground that has in no way been smoothed and leveled, jutting masses or bold faces of rock, gnarled trunks and tortuous branches of trees, and ruined buildings, half mantled with the ivy, the wall-flower, the fern, and the pellitory, are illustrations in point. Little, however, can be done in this way with small gardens, which are too near the house - itself an object of the highest art - to be capable of being rendered picturesque.

In some retired parts of the garden, rockeries, collections of ferns, rocky streams, waterfalls, or other picturesque objects, can be easily added in many localities, and will be most prolific in all the resources of variety. Rustic arbors or seats - broken pillars, old vases or urns, partially covered with some rude climber - baskets for flowers, made of rough wood, with the bark on, or old trunks of trees, scooped out with the necessary hollow in the center, - are a few of the more architectural among picturesque decorations.

14. Contrast is a characteristic which, though rarely attainable to any extent in small places, must not be wholly 


\section{General Principles}

rejected. It has been shown that it may be effective in heightening color, but it merits, as a principle, a little more development. It necessarily involves a certain amount of suddenness in change, whether as to color, form, or general character. Very violent transitions are not to be included in the idea, at least not so far as its adoption is here considered recommendable.

If a rule might be ventured in reference to this rather difficult matter, it should assume that harmony ought to reign paramount, and almost alone, over the general features of a place, and that contrast should distinguish its episodes or more detached accessories. What is meant is, that a garden, as viewed from the house, or from most of its own principal points, should consist of parts and objects that have some decided agreement with each other, or that the several constituent parts should blend and interfuse insensibly; while peculiarities, whether of treatment or vegetation, can be reserved for little side scenes, shut off from the rest, or most imperfectly disclosed, until the observer finds himself all at once in the midst of them. The full effect of a contrast may thus be secured, without any interference with the much more important principles of harmony or congruity.

Still, the occasional admission into a more open landscape of things which will produce contrast, is by no means altogether to be condemned. I remember being frequently attracted, and always with the same pleasure, to a beautiful specimen of the weeping birch, growing by the side of a noble cedar of Lebanon on a lawn. And I have also noticed with admiration, in several parts of the country, a kind of companionship established between beeches and fine old specimens of the common yew. In both these instances there was a marked contrast both of form and color. But the branches of the two plants were so nicely interwoven, and their foliage 
so happily mixed together in broader or smaller patches towards the junction of the two, that while the strongest contrast was apparent, there was at the same time by the irregularity with which the outlines of each were intermingled, the masses of light and shade gradually losing themselves in each other, - a really gentle and easy transition.

The illustrations thus referred to appear to teach several things. If two trees or plants, or two masses of either, having very opposite characters, are sought to be placed side by side, for the purpose of contrast, they should be put near enough to enable their branches to intermix with one another, that the contrast may not be too sudden. In the case of two groups of very different plants, such as light-leaved deciduous and dark-leaved evergreen varieties, being wished to be brought together, a few of each sort should be irregularly thrown into the adjoining group, to produce the same effect as the interwreathing of branches would do with single specimens.

Again, where a contrasted tree or shrub, or group of the same, is not desired to be placed so near its opposite neighbor as to allow the branches to mingle, or the sorts to blend at the edges of the mass, some intermediate plant or plants of a quiet neutral tint, or some breadth of lawn, in which the grass will answer the same end, should be interposed between the two to soften away the abruptness of the change.

The examples further show that the particular expression of contrast which is most desirable to be attained, need not detract from the general harmony of a place. There is that about plants which renders it possible, by letting them grow into each other, as has been shown, to put the most strikingly different species side by side, without any violent or startling effect resulting. If the same thing were done with objects having square or regular edges, that were equally dissimilar, 


\section{General Principles}

nothing but ugliness and incongruity would follow. The pleasing union of two contrasted things is only capable of being effected when the parts to be joined have an irregular margin and can be imperceptibly and intricately inwoven.

Certain sorts of plants are much more fitted to produce contrast than others. Those with either pinnated leaves, or extremely small or pale green or silvery foliage or slender or weeping branches may be particularly noted as adapted for contrasting with dark and heavy foliaged evergreens. Acacias, several species of sumach, ailanthus, common ash, weeping willow, deciduous cypress, weeping birch, and common larch are examples of the first class. Cedars, yews, pines, and evergreen oaks are some of the opposite kinds. Early and gay-flowering shrubs, or those which have white blossoms, show to great advantage when backed by evergreens. An almond supported by two or three pines, a few red-flowering currants scattered among rhododendrons, syringas flanked by hollies, and rhododendrons in which the pale flowers and dark leaves are united, make excellent contrasts.

In colors, the deepest contrast may sometimes be had without at all trenching on the laws of harmony. White flowers, whether in borders or in beds, where only one color is used, will always match well with any shade of red or blue, and yet nothing could be a greater contrast. Green will likewise adapt itself to any other color, and perhaps all the more appropriately the more it is in contrast with it. Dark green is the best contrast and the nicest mixture with white, and pale yellow green with dark red or deep blue. Green also seems to improve a light stone color; and hence houses built of common white stone, as it is called, look best when they are reposing on grass; and the pedestals of vases or other sculptured figures follow the like rule. 
15. Originality. - Although everything approaching to eccentricity has been fully deprecated in a former page, a few lines may now be devoted to advocating originality as a principle to be aimed at in a garden. The scenes of nature are continually sought, because, while they are "ever charming," they are likewise "ever new." And a garden should be made to combine some little freshness, - something that will distinguish it from other gardens. Departure from rule is not, it will readily be believed, the kind of originality to be desired. It is rather such as results from newness of arrangement, of combinations, of expression, and character. It is rare, indeed, that two places will have the same shape, soil, aspect, surface, and accompaniments, and every peculiarity that is not really bad should be seized upon, and worked into some kind of novelty.

Originality is antagonistic to all sorts of tameness. Even a slight deviation from established laws will often be preferable to their dull and expressionless embodiment, though such a course cannot at all be allowed to be necessary. That which is commonplace, - which is the exact counterpart of what everybody else has, - never leaves any impression upon the observer's mind nor wins him back to a second inspection.

Freshness of aspect may be the result of any one particular circumstance or a combination of them. The treatment of the foreground of a place may produce it, by presenting the trees and shrubs brought up nearer to the house than usual (but not so as to darken or make it damp), narrowing the lawn very much at that point, and letting it gradually expand towards the boundary, so that the house will appear, from a distance, to be a species of nest in the midst of a plantation, though not actually so. The boundary lines, again, may be treated so as to get the greatest possible 


\section{General Principles}

freshness of view both within and beyond them, and plants of an uncommon kind may be liberally introduced. In some districts, certain sorts of trees and shrubs and flowers abound and are met with in every place. They seem to have acquired a local standing and to be distributed from one neighbor to another, and are met with in every place. It will be well, therefore, to break through these prescribed limits, and select something altogether different.

By giving a chosen tribe of plants the chief place in a garden, originality is not unfrequently hit upon. The almost total exclusion of deciduous plants will have a very marked effect, if the evergreens be well selected, and those which bear flowers predominate; otherwise they will be rather dull in summer. Azaleas, or roses, or any other very showy class of plants, which produce a great blaze of flowers, will, if not too exclusively grown, contribute to the same end.

I6. Character. - As the result of a number of principles judiciously combined and elaborated, a place should always possess some more or less decided expression and tone; and, as the character of a garden will usually attach itself in great part to the owner or occupier, so that his own dispositions and tastes will be judged of by the kind of feeling displayed in his garden, it becomes of consequence that this point should be kept continually in view while laying it out.

A garden may be distinguished by its gayety of tone. This will be principally produced during summer by a variety of showy flowers, by masses of brilliant-flowering shrubs, by standard and other roses, by a conspicuous flower garden, and by a variety of purely summer decorations. The shrubs and low trees will be chiefly flowering ones; green-house plants in flower will be freely placed about, or beds of them provided, and everything will have an exotic air. In winter 
the same tone will be preserved as far as possible with variegated evergreens, shrubs that bear red berries, and other flowering or gay-looking evergreens, with an abundance of early-blooming bulbs and herbaceous plants, to betoken the first approaches of spring. The whole character of the place should also be light, open, airy, - not at all crowded, or overgrown, or overshadowed. The gravel in the walks should have a warm, reddish-yellow tint, and the architectural enrichments should be lively, and rather florid than otherwise.

But the expression of a garden may, if required, be that of quietness, - a modest, unassuming, medium state, between plainness and ostentation. It need not be wanting in beauty or refinement. It may be correctly and even elegantly arranged and furnished, yet there will be no peculiarity of tone on which the eye can fasten. All will be good, but nothing extravagant. Flowers will be cherished, though not in extraordinary profusion. Every kind of evergreens will be unreservedly admitted, but there will be no attempt at display, no thrusting forward the evidences of wealth. Taste will be shown in concealing all its manifestations, - in the little arts, and ingenious contrivances, and kindly cares, which embellish gardens, as they do life, without ever revealing the machinery of their action, and of which the effect is seen and felt in their results rather than their processes, in the whole rather than the details. A quiet-looking garden, like a well-educated individual, presents no particular feature that can attract special notice, - all is smooth, easy, agreeable. And perhaps this quietness of expression is the surest index to refinement and taste, though the latter is not incompatible with some amount of luxury and sprightliness.

Art should be pretty obviously expressed in that part of every garden which is in the immediate vicinity of the house, and may sometimes retain its prominence throughout the 


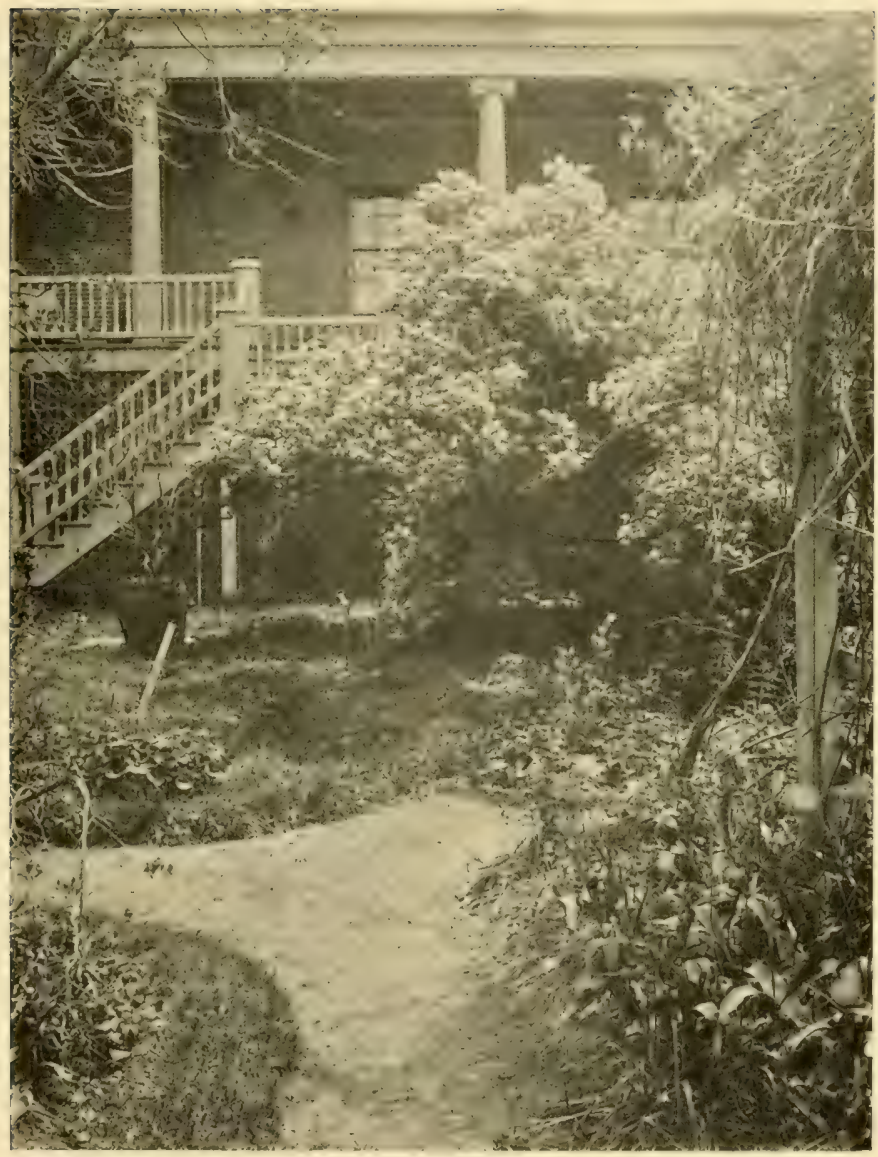

Plate VI. Old Fashioned Garden, Burlington, Vermont. 



\section{General Principles}

whole place. In the latter case, terraces, straight lines of walks, arenues of trees or shrubs, rows of flower-beds, and geometrical figures, with all kinds of architectural crnaments will prevail. Considerable dignity of character may certainly thus be acquired; and, if well sustained, the expression of art will be a very noble one. But there are not many places which will bear to be thus treated, and it is less frequently suitable for one of small dimensions. It is, moreover, a very costly style, and requires the lawns to be on the most perfect level, and the grass, beds, and masses to be always in the highest preservation. A warm part of the country, where a rich landscape surrounds the place, will best warrant its adoption. In the near neighborhood of towns, or in a bleak and ungenial climate, it will appear too bare and cold. A purely town garden, however, may be treated thus with excellent effect. Terrace walls, balustrades, flights of steps, vases filled with shrubs or flowers, and even statuary, will here be most important accessories.

Certain classes of plants seem peculiarly fitted for a garden in which much art is to be displayed. Round-headed standards and upright or fastigiate shrubs are singularly appropriate. Rhododendrons, Portugal laurels, roses, and some species of cytisus, treated as standards, will make admirable lines of plants to flank a square or oblong lawn. Irish yews, on the other hand, with several species of juniper, cypress, and arbor vitx, fit most beautifully into the corners of flower gardens, or points in other plots geometrically arranged.

There is a possibility of such things as porerty and heaviness constituting the tone of a garden, and every effort should be employed to obviate this. A large proportion of somber evergreens, a dearth of flowers, or a neglect of finish and keeping, may impart a gloomy character, which is particularly 
unhappy. A garden seems naturally intended to communicate cheerfulness and pleasure, and this design should never be frustrated by making it look like a cemetery. A great many large trees would, by their shadow, and the destruction of the grass beneath them, conduce to the same fault, and lumpish masses of trees with few breaks, little variety of outline and a scanty addition of detached specimens, would deepen the impression. Only massive and inelegant ornaments will then be wanted to complete its wretchedness.

Poverty of expression is almost worse than heaviness. It conveys the idea of meanness, inattention, indifference, hardness and narrowness of mind in the possessor, and coldness of heart. Some gardens are thus poor in design, others in their details, and many in regard to their furniture. The first may exhibit a deficiency of thought and taste in adaptation, everything being dashed off or jumbled together as convenience or ease might dictate. The second class will denote the absence of taste in execution, and of care to put the finishing strokes to everything. The third section indicates a meagerness of materials, - the commonest description of plants, and a scanty supply of them. The defect of the first will be paucity of invention; of the second, insufficient application; and of the third, dearth of means. Each may exist separately, or all be found together. They are capable of easy remedy; though the last, if it arise from pecuniary causes, must be either endured, or the materials be so selected in respect to their rapidity of growth and showiness, and so artfully disposed, as to be made the best of. Where shrubs or plants enough cannot be had to furnish a place fully, it is better to put them sufficiently thick in smaller masses than to scatter them over a larger space in which there will be much bare earth visible.

Instances in which an aspect of poorness arises from the 


\section{General Principles}

soil or the climate being uncongenial can be rectified by improving the one and using such plants only as will thrive in the other. Experience and attentive observation of what succeeds in the neighborhood will supply the requisite information as to climate. Hereafter, however, a few guiding suggestions will be given with reference to both climate and soil. Poverty in the aspect of a country may be greatly relieved and atoned for by an extra amount of furniture within a place and by restricting the views from it. A barren and unsightly waste, common, or moor can be made to subserve the purposes of art, if only glimpses of it be here and there afforded through masses of rich foliage; for, with such a foreground, its extreme poverty will be neutralized and become a foil to set off the richness and cultivation inside the place.

I7. Styles of Gardening. - No garden should be altogether destitute of manner and style, however feebly or indistinctly they may be expressed. Purity and correctness of feeling in regard to any given style are the most important things to be sought after, for it is barely possible to give rules which shall embrace every variety of detail. In little matters, indeed, the properties of different styles may be associated, under special circumstances, without any breach of rule; a right appreciation of the spirit of each alone being wanted to enable any one to adapt parts of the others thereto. A close analysis will show that some features are common to two styles, or even to all of them, the great distinctions consisting in larger characteristics.

There are three principal styles recognized in landscape gardening, - the formal, geometrical or Italian style; the natural or English style, and the picturesque. Of each of these I shall offer a brief explanation in the succeeding chapter. 
I8. Adaptation. - Notwithstanding all the rules hitherto furnished, there is a principle yet to be considered, which can alone give them their proper weight, and ensure their being of any real use, and that is - adaptation. In every place that can be met with, or conceived of, there are always peculiarities which should influence the disposal of the various parts, and give their cast and coloring to the whole design. And it is in the adaptation of particular styles, rules, or modes of treatment to the circumstances or objects actually existing, that the credit of the landscape gardener and the satisfaction of the owner can alone be attained.

Very seldom will it be found that a garden is without something or other that may be regarded as a fixture. Buildings and the position of their entrances and windows, trees, swells or variations in the surface of the ground, external gates or entrances, fences, and numberless other things may be already on the ground, and it may not be desirable to remove them. The scenery of the outlying country will ordinarily, likewise, be beyond the reach of the designer. It will be needful then to fit in every part of the plan to what is really on the ground and must be retained there, not neglecting to take advantage of everything that can be made to give greater effect, or to keep out of sight such objects as may be considered deformicies. Dealing cleverly with difficulties, so as to leave no evidence that they have had to be encountered, is not the least or the lowest merit of landscape art; and, as I have frequently heard remarked, it is out of awkward and apparently intractable irregularities that a competent designer may generally create the most characteristic and remarkable beauties.

While deliberating on this subject, the shape of the ground, its aspect, the nature of its surface, the wants and tastes of the family, the character of the neighborhood and the prob- 
abilities as to what it may become, or what might be done by adjoining owners, will all pass under review. Nor will the nature of the local climate, and the necessities that spring out of that consideration, be forgotten. Particular climates may require more shelter, and a limited selection of plants; certain neighborhoods may demand extra security from theft or other injury; in many localities, such as the nearer suburbs of large towns, plants that endure smoke will be wanted, and the whiter kinds of architectural ornament must be omitted as liable to get too much stained and blackened; one family may prefer sunshine, openness, and display, another shade, privacy, and quiet enjoyment.

Great natural features abounding in the neighborhood of a place, especially within view of its windows, ought seldom to be multiplied within it. If the sea or a large river, for instance, be visible from the house, it will seem ridiculous to have an artificial pool of water for ornament in the garden or park. In the same manner, should the district be a rocky one, and good specimens of rocky scenery be within sight of the garden, there will be equal weakness in forming an artificial rockery within the place. The mind will be continually instituting comparisons between the feebleness of art's creations, however well arranged, and the nobler forms of nature, thus brought into immediate conjunction, and the result must inevitably be to the disparagement of the former.

Thrown in a tract of country where a sylvan character is the reigning one, an exception in the treatment of a garden to the rule just given may very likely be prudent. Here it will be the aim to blend the garden as much as possible with the outer district, so as to make them appear one property, only giving to the garden the warmth of evergreens, and the cultivation which rarer plants will express, as a foreground to the larger scene. It is a very great point to adapt the garden so to the 


\section{$96 \quad$ Landscape Gardening}

surrounding scenery that there is no break to its apparent continuity.

Perhaps a small garden in the outskirts of a town should have more flowering plants and flowers cultivated in it than would be wanted in the country, as flowers are much valued and produce a more delightful contrast in such situations. It is very doubtful, however, how far training climbers to town houses, in the cottage or village style, is accordant with good taste, especially as they seldom look healthy or flower freely. Consistently with a good supply of flowering plants, moreover, a town garden cannot well have too many evergreens, for they produce liveliness and verdure at a season of the year when, in towns, the most leaden dullness often reigns in the atmosphere.

19. Fitness is a variety of adaptation that has little claim to be regarded by itself, and yet it will suggest another thought. A thing may or may not exhibit fitness for accomplishing its intention. It may be unhappily conceived, or carelessly executed. There might be a deficiency of right feeling displayed in it. The expression of a place might be unfitted to the character and habits of its owner. Its style may be too ambitious for its keeping. Certain plants in it may be out of tone. On the other hand, there may be an appropriateness in everything, even the minutest. The very turf may, by its fineness, freshness, smoothness, and freedom from coarse weeds, denote the proprietor's attachment to his garden and elegance of taste, while larger matters will always be in the right place and of suitable class.

20. Appropriation is an idea to be realized in gardening on a small scale, which, though already more than once glanced at, calls for a separate elucidation. It is that appearance of possessing property which, though it may be continually belied by one's own consciousness, is productive of almost as 


\section{General Principles}

much pleasure to the eye, at least, as though it were really owned. Everyday experience will confirm the familiarity of the remark, that some individuals glean more delight from the opportunity of inspecting another person's property than the owners themselves. Proprietors of extensive and beautiful estates rarely appreciate them. Men generally value less what they hold by no uncertain tenure. The things which we retain on sufferance, or which we may some day be deprived of, are those which, if we are not overburdened with them, we most earnestly cling to and perseveringly admire. This tendency is neither illegitimate nor pernicious, in reference to natural objects, while it may entail much innocent gratification.

To cater to an appetite so unexceptionable is surely not beneath the dignity of art. And as it can be done without any great difficulty where the frontage of a place is towards an open country, it should always be taken among the established requirements. The ways of accomplishing it have before been enumerated. But it may be observed that a boundary fence which looks most like that which would form the division between one part of an estate and another, with such groups of trees and shrubs between the openings as would be placed to give a foreground to the distant view, even were there no separating fence behind them, will most favor the illusion and enable the occupier to appropriate as if it were his own, all that is beautiful in the general landscape. Even fences, sheds, cottages, etc., on the property thus surveyed, may often be got rid of by a few specimen plants, placed so as to cover or to diminish such divisions in it as would detract from the semblance of expanse and ownership.

2I. Imitation of Nature. - Readers who have traveled with me thus far will have perceived that I have had occasion 
more than once to refer to nature as the great school of landscape gardening. It may be worth while, then, specifically to inquire how far the imitation of nature is possible and right. I profess not to be of those who would carry the principle very far, or into minor matters. It is in her broader teachings and general promptings that materials should be gathered for practical use. And these, be it remembered, will be solely available in idealizing and exalting art.

To regard a garden otherwise than as a work of art would tend to a radical perversion of its nature. It is and must remain that which its proximity to the house alone enables it to be. No ingenuity can convert it into a forest glade or a glen. Nor is such a transformation to be wished for, were it possible, any more than that a dwelling should be transmuted into a hut, a den, or a cave. A garden is for comfort, convenience, luxury, and use, as well as for making a beautiful picture. It is to express civilization, care, design, and refinement. It is for the growth of choice flowers and the preservation and culture of exotic trees and shrubs, with novel and interesting and curious habits, which could not be reared without the most assiduous guardianship and attention. In these respects it is fundamentally different from all natural scenes.

Reflections such as these will make it plain that they who would imitate nature in gardens must do so in another way than by copying her piecemeal. They ought, indeed, to be imitators, but not copyists, transcribing her spirit and not her individual expressions, - her general countenance or aspect, and not her particular features. An artist, be he a painter or a landscape gardener, or an amateur in either branch, should go to nature to study principles, gathering up snatches of scenery and storing them in his memory or his portfolio for future adaptation and use. He should note all that 


\section{General Principles}

pleases him and endeavor to understand how and why it influences his mind. By thus filling his brain with numberless beautiful little pictures or images, and his intellect with the foundations and sources of pleasure in his art, he will come from nature doubly primed to give practical utterance to his imaginings, and prepared to embody in a composition the finer touches and more artistic and spiritual elements which he has collected from such a variety of sources. It is in this way that the imitation of nature will be but the ennobling of art, - the airy elegance and flying graces of the one being engrafted on the more substantial characteristics of the other.

22. Beauty. - That beauty should be the ultimate aim of every operation in landscape gardening, may seem so selfevident a proposition as almost to excite a smile. It is one, however, which I must not fail to enforce. There may be different opinions as to what constitutes beauty, and of what ingredients it is made up, some affirming that its chief elements are those of form, and others that it consists solely in association. I shall assume that it is to be found in both.

Most persons will be agreed, in the main, as to what is really beautiful, though almost every one will have some kinds of favoritism and prejudice. Considering the multitudinous forms of vegetable life and the fact that all are endowed with more or less attractiveness, I have often been struck with the narrowness of affection for plants which is commonly possessed, many people having a few favorite trees or shrubs and proscribing nearly all others. I have been told of a celebrated landscape gardener who always kept the nurserymen's stock of two or three particular trees at the lowest ebb, and could never get enough. And it is matter of gardening history, what thousands - probably millions - of his famous "locust-trees" Cobbett spread abroad throughout the country, - although it is now well understood that, for all prac- 
tical uses, the tree, even if it would yield any available timber, is very nearly if not altogether worthless.

But I cannot and do not profess to comprehend why gentlemen should impoverish their plantations, and strip their gardens of the first element of beauty, by cultivating only a few particular species of plants, and not merely harboring, but cherishing a dislike to all others. A garden or plantation denuded of half or three-fourths of its proper ornaments, is much in the same predicament as an individual with only a portion of his ordinary garments. It is imperfectly clothed, insufficiently furnished, weak in its expression of the beautiful.

Beauty of lines and forms is possibly less powerful than that of association, but it is more prevalent, and better apprehended by the mass. A wavy, or undulating line, has been styled the line of beauty, and the assumption may be true that it is the most beautiful of all lines. But in averring that there is no other line at all beautiful, it is of course far wide of the truth. Every one will acknowledge that the lines of a dove's body, when in full plumage, are exquisitely beautiful, and that a circle is one of the most pleasing of figures. But few, I should think, will deny that a cube possesses beauty, or that a triangle is not destitute of it. An avenue is the subject of universal admiration, and so is a long straight road, that conducts up a gentle ascent, to a church, or other sufficiently dignified and conmanding object. Still, an avenue to a common workhouse, as I have witnessed, loses its influence; and a long road, ending in nothing, may simply be a dreary blank.

The truth seems to be that some kinds of lines require the accompaniments of fitness and association to render them interesting, while others have an inherent power of impressing men. A wavy line is the most truly graceful; it is the thing 


\section{General Principles}

that imparts beauty of form to human beings and animals; it is indefinite, and awakens the idea of infinity, with its exhaustless stores for the imagination; and it is of the commonest occurrence in natural scenery. Hence, it may fairly be invested with the palm.

Beauty of form, in a work of art, is of a superior order to beauty of color or embellishment. It betokens a deeper acquaintance with principles, a higher refinement, a finertoned feeling. Colors are mere adventitious aids, and are always liable to fade or change, while floridness of ornament simply pleases the fancy, but rarely satisfies the mind, and soon satiates. Beauty of form is the most enduring.

The influence of this rule on all the adjuncts of gardening cannot be over-rated. It will affect the shape of the ground, the direction or curves and levels of the walks, the position and outlines of all the clumps and keds, and every sort of ornament that can be conceived of. It will be far more significant than mere costliness or elaboration or ingenuity. And it will extend as much to the proportions of a plate as to its individual elements.

Beauty of tint or tone, though inferior to that of form, is what must never be throw $n$ entirely into the shade. Delicate colors are intrinsically the most beautiful. Shades of pink, or mixtures of pink and white, light blues, pale greens, strawcolored yellows, the softest tones of crimson and vermilion, are the most expressive of beauty. All stronger colors may be rich, showy, and valuable in contrast, but they are less positively beautiful. None of them need be kept out of a place, though the above hints will be suggestive of what is most desirable, where the highest beauty is sought, and they may denote the colors which should be selected in painting either the exterior or the interior of buildings, fences, etc.

Nor do I seek at all to decry beauty of ornament and 
detail. It will, however, be necessary to keep in mind that minuter beauties do not tell in or upon objects that have to be viewed from a distance, and that, in architectural forms, they are more fitted for internal than exterior decoration. A building that has to be entered should always be much more ornamented and enriched inside than it is without; and little delicate finishings, though highly expressive when in place, ought only to be put where they have to be closely examined, and near enough to the eye to be thoroughly scrutinized and appreciated.

Beauty of association is founded on the suggestion of pleasing ideas, such as fitness, harmony, poetry, or the awakening of images that have formerly delighted. It is especially connected with anything aged, - with that in which our ancestors or family have borne a part, or in which we have personally shared. A tree or plant, which we, our relatives, or some known and noted personage has planted, reared, or tended; a summer house that is rich in family or other ancient records, or in which we or those we love have thought, or studied, or felt much; a retired nook or secluded little garden, which the fair hands of the departed have, by their former ministrations, hallowed and rendered sacred; - these may all be abundantly fraught with the beauty of association.

By this benignant law man is linked at once to the material and the spiritual world, and the elements of a garden become pregnant with both poetry and history. The chords of the human heart are strung responsively to a variety of objects, and a sight, or a sound, or a scent, may at any moment waken their melody. Delicate perfumes, bursts of nature's vernal music, gleams of gladdening sunshine after rain may stir the shades of long-buried thoughts and emotions and quicken them into new life with a thrilling power.

Practically the beauty of association is hardly a thing to be 


\section{General Principles}

aimed at or cultivated. It is an instinct which twines itseif with our being, and makes its own existence known and felt. All that tends to excite or develop it may, however, be religiously fostered, for it is as beneficial as it is pleasurable, softening and humanizing the heart, and refining the entire nature. And even in the newest places, where not a solitary vestige of human feelings or interests is found, every plant, to the lover of a garden, may soon acquire a little history of its own, and be the source of endless amusement, by personal trimming and training, and watering, and protecting; while a sentiment can easily be attached to particular spots, by dedicating them to the various affections, virtues, or purposes which adorn or illustrate human life. However unfortunate a disposition to allow plants to become overcrowded and spoil one another may be, one always augurs well of the heart, at least, of the individual who shows a peculiar sensitiveness about the removal or destruction of anything he has once cherished, and with which are swept away sensations and pleasures never to be recalled.

23. Combination of Elements. - Having thus gone over the numerous principles which those who would lay out a garden will have to take into account, I have now to indicate the manner in which they can all be harmonized and combined so as to compose a beautiful and consistent whole. It may appear to some that many of the points discussed are incapable of being conjointly carried out, - that such a thing as variety are incompatible with unity and simplicity, and that, in observing some of these principles, others must be violated. That such is not the case I shall proceed to demonstrate.

Let it not be supposed, then, that any stress is intended to be laid on one principle to the depreciation of the rest, or that the marked elaboration of either is advocated. The perfec- 
tion of a garden will consist in no one of them being carried to an extreme. Each is to be consulted separately, but the joint teachings of all acted upon, such as will best suit the circumstances and demands of the case being kept paramount. Not that such things as different tones and styles are to be sought after in the same place, unless it be a large one and susceptible of partial division, but that some kind of expression, and one particular manner should be sought, and the place not be made devoid of manner or expressionless.

That simplicity is not altogether at variance with richness, however incongruous they may appear, there will be little difficulty in proving. A garment may be of the most superb material and yet its shape and color be very simple. Dignity and even majesty of mien may often be accompanied with an air of simplicity which may exalt rather than weaken it. And so a garden may be devoid of a single rudiment of complexity, - be simple in its plan, its purpose, and its ornaments, - but that simplicity shall be so tasteful and so noble and sustained with such excellent materials that richness will be manifestly consistent with it.

Nor will unity be a whit the more incapable of being attained in conjunction with variety. This last has only to be prevented from degenerating into extravagance, - to be duly pruned and restrained, - and not a thread of the woof of harmony need be broken. It is not any unusual number or diversity of instruments and voices that will jar the music of a chorus. Such a powerful orchestra will rather swell the concord if well regulated and rightly attuned. And variety in a garden will alike heighten its harmony, when the multiplication of parts is effected with judgment and forethought.

Again the blending of parts has been shown in an earlier page to be not utterly foreign to contrast, since things of opposite characters may be brought together, and even into 


\section{General Principles}

contact, by interweaving their parts freely with each other or separating them by something of an intermediate tone.

Utility and convenience might be adjudged alien to matters of ornament. But there is no reason why they should be so. A useful thing may likewise be an ornamental one. Taste and tact will adorn the commonest processes of life, and make them in the truest sense beautiful, - sometimes poetical. So the useful and the necessary portions of a garden can be brightened by art till they will seem intended solely for ornament, though all the while accomplishing their primary purpose with the utmost fidelity.

No breadth of lawn, some may be ready to urge, can be procured at the same time with any degree of intricacy. Yet nothing is more untrue. It is not a plain bare area, on the scale of a moderately large garden, that can give the impression of size. It is the indefiniteness which complexity produces, - the partial revelations of side glades which the imagination is left to amplify and lengthen, - that alone impart any adequate notion of extent. Plainness reduces the whole to a mere matter of fact, which is measured at once. A little innocent deception, by supplying food for the fancy, and preventing almost the possibility of estimating the actual proportions, always operates in favor of expansion.

How, it may be further asked, are privacy and seclusion to be gained, without sacrificing all open views into the surrounding country? Nothing is easier, I reply. If a house be on raised ground, as it should be, the planting of thickets of low shrubs (principally evergreens) near the boundary, where it is liable to be overlooked, at all such openings, will produce the desired seclusion, and still allow the eye to range over into the district beyond. Such thickets will also give a pleasing foreground, and they can be kept sufficiently low, 


\section{06 Landscape Gardening}

if ever inclined to intercept the view, by irregular pruning, not clipping with the shears. Should a walk run immediately within them, if they are not high enough to cover it perfectly, it can readily be kept down a foot or two lower at such parts.

Originality, perhaps, may not be deemed attainable while due regard is paid to the requirements of law. Rules are not, however, made to fetter, but merely to guide. A writer of fiction is not prohibited from representing character in a wonderfully developed and exaggerated manner. He is only forbidden from caricaturing it. Developments and extravagancies that are according to nature are in fact among the greatest merits of a work of fiction. They are at once more exciting and more elevating. A celebrated artist is represented to have replied to a brother of the easel, who was contemplating one of his mystic productions, and complaining that he had seen nothing in nature at all resembling it, "True, but don't you wish you could?"

With respect to all other principles, in which there are no apparent repulsions, the means of combining them will be too obvious to need describing. They can therefore be dealt with or embodied in a place as its peculiar nature or the inclinations of the owner may best warrant. 


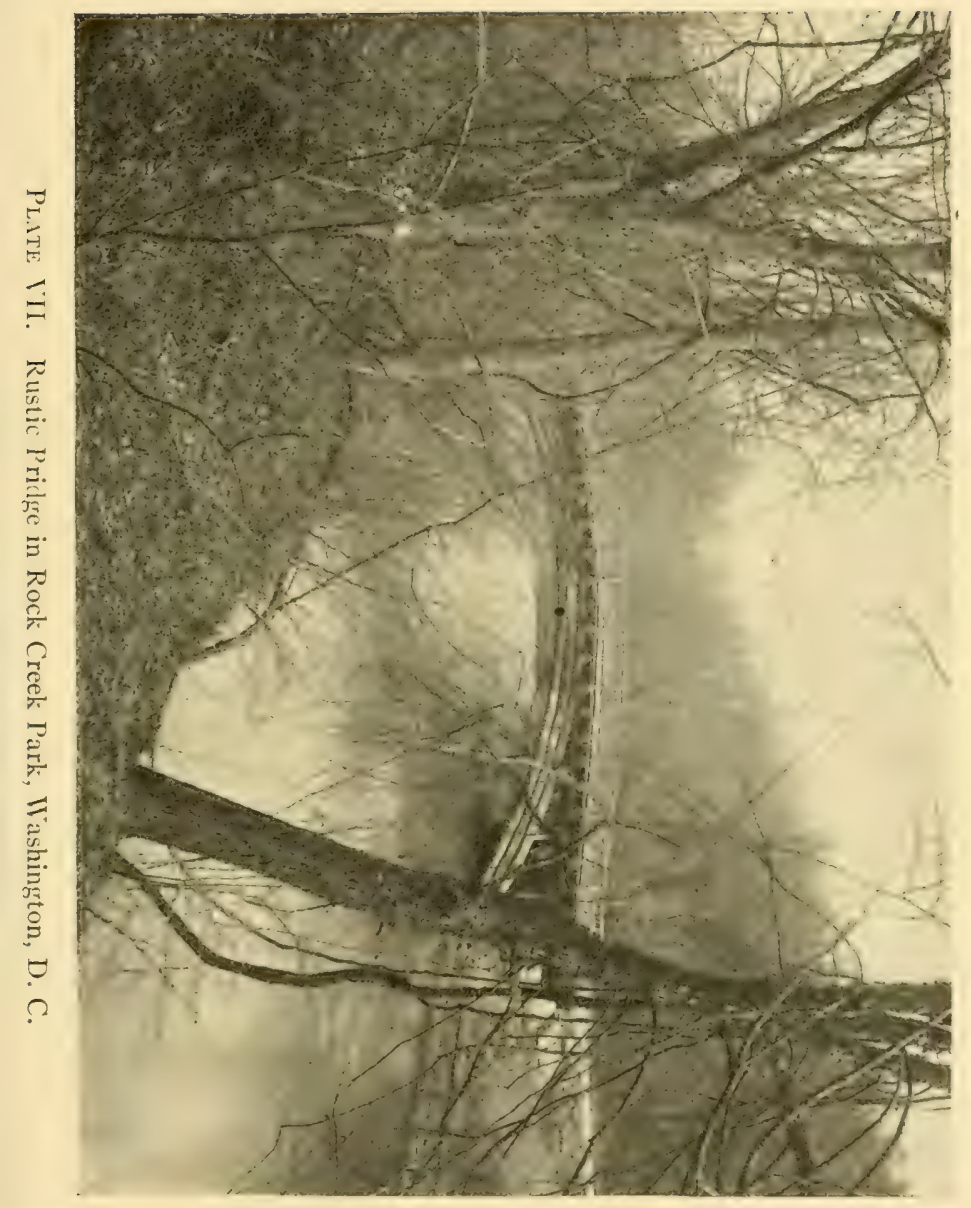





\section{CHAPTER IV}

\section{The Several Styles}

AtTACHed to the geometrical style there is a greater degree of originality, distinctness, and art, than to either of the others. It is the most easily defined, and therefore, probably, the least difficult to practice for a person at all familiar with the simplest rules of architecture. It treats a garden solely and entirely as a work of art. And the forms of nature which it impresses into its service are simply those which have the closest affinity to its own characteristics and are in fact most artificial.

Doubtless the geometrical style is that which an architect would most naturally prefer, for it subordinates everything to the house, and is a carrying out of the principles common to both itself and architecture. A series of straight lines joining one another at right angles, and of beds in which some form of a circle or a parallelogram is always apparent or which fit into any regular figure, are, as just before remarked, the leading and most expressive features of this style. Flights of steps, balustraded walls, terrace banks, symmetry and correspondence of parts, circles, ovals, oblong and angular beds, exotic forms of vegetation, raised platforms, and sunken panels, are some of the materials with which it deals.

To apply the style now under notice successiully, the character of the house and the nature of the surrounding land must justify its use, or be brought into accordance with it. Grecian, Roman, or Italian forms of architecture are those in connection with which it can be most freely adopted. 
A mere terrace, or series of terraces, may accompany a Gothic house, and can be attended with a geometrical flower garden or with other straight walks. But to produce a whole in this manner, one of the three architectural styles I have mentioned would form the best foundation work. Hence, the practice of the geometrical style has often received the title of Italian gardening, it having been most extensively adopted in Italy and in relation to the architectural forms peculiar to that country. Still, there may be cases in which from the particular form of the ground, or the character of the outlying district, or from other local circumstances, a house in the Elizabethan or any kind of Gothic style may be fitly accompanied with a purely regular garden possessing all the features of the formal school.

Commencing at the house, which should always be raised three or four feet above the common ground level, this may be supported by either a flat grass platform, with a grass slope from it to the edge of a walk below, or, what is better, the walk may be on the level of the house, and parallel with it, and either a sloping grass bank, or a low ornamental wall, break the change of level, this bank or wall affording the means of obtaining one or more flights of steps. Whichever of these plans is pursued, the grass at the edge of the walk, whether on the top of the bank or at the bottom of the slope, should be quite flat, to the width of at least a foot (more will be better), and this rule must not be departed from in any similar case. The upper edge of such grass banks ought to be square, and by no means rounded off, while the bottom of them may be very slightly softened, observing to keep it quite equally so for the entire length. Terraces should never be so broad as materially to foreshorten the view of the lawn, which is a common but decided error.

If the front of a house has many breaks or projections, 
the terrace platform must be made so much the broader that the upper edge of the bank may take a straight direction, instead of being parallel with the house in all its parts. Should the center of the house only, however, or one of the principal rooms, be thrown forward in a square or partially semicircular form, the terrace bank may very properly and effectively take the same shape. The flight of steps should be put in the center of this projection or omitted altogether.

A terrace walk at the top of a slope and close to the house has the advantage of commanding a good view of the whole garden with the symmetry of its arrangements and the beauty of its various parts and ornaments. By intruding a little on the privacy of the windows, it involves a trifling disadvantage, though it will be seen, by experiment, that a walk close to the windows occasions less opportunity for overlooking than one which is a few yards distant. If the nature of the ground will allow, a small flower garden of the most formal description may be made on the same level as the house, but in limited places it will usually be more appropriate below the terrace bank. The remaining parts can be filled in as circumstances may direct. Only if the garden be not large, a low architectural wall, either with or without the addition of rases and urns or relieved simply by piers, will be the fittest boundary fence along the front.

The walks of a formal garden should always be either straight or some arc of a circle, the former being the best. Their width must be adjusted to the length. A straight walk ought, perhaps, to be made broader than a curved one, as it will gain in dignity thereby; and, in a geometrical garden, walks have to be regarded as one of the principal features. Width, however, invariably reduces the appearance of length, so that the perfection of art will lie in balancing the two, both length and width being abstractly desirable. 
Unless with long walks, the introduction of basins, sundials, or other figures into their center where another walk crosses them, however effective such things may be in themselves, cannot be commended, since they contribute greatly to shorten the apparent length by breaking it up into two parts and preventing the eye from ranging uninterruptedly along it. Still, in very small places, a group of shrubs for the center figure may enlarge the garden in appearance by concealing the shortness of the straight walk.

No straight walk should pass off from another in an oblique line, or at any but a right angle, as in fig. 26. The oblique

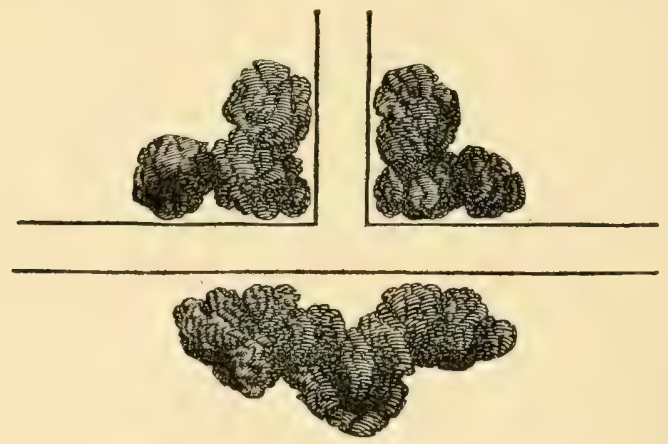

Fig. 26. Branching of Straight Walk.

walks common in the old Dutch style, once so prevalent in England, were only fit for large places, where they were supported by avenues. In small gardens they cut up the lawn seriously, and offensively intrude themselves upon the vision. Indeed, they are not adapted to the Italian style of gardening, which is that chiefly kept in view.

Every straight walk ought to have an appropriate termination, either in the way of an architectural object or an evergreen plant that takes a regular and symmetrical shape. 
This is essential to preserve the tone of art, to give the walk an object or design, and to justify any divergence from it into another walk. The ruling and blighting defect of gardens in which straight walks occur is that the ends of the walks are often left quite open and unfurnished. When they merely surround the house, or exist only on one or more of its sides, such accompaniments are not of so much consequence, and may sometimes be omitted with advantage as well as propriety. Still, a terrace walk in the front of a house ought always to have some stone or other seat, or covered arbor or similar architectural finish at its blank end, if it has one. Vases, statues, seats, alcoves, temples, urns, sundials, or mere ornamental pedestals, or any architectural form that has some little elevation above the surface, will give a suffcient termination to the end of a walk. Of the plants suited for the same purpose, rhododendrons are perhaps the best. Other plants which will answer are arbor vitas and retinisporas. Of larger kinds, the hemlock blue spruce or the Douglas spruce will be appropriate. All upright and slender forms are ill adapted to the object, being too narrow and spiry.

Masses of trees or shrubs should never come up to the end of a walk (fig. $27 a$ ), where there is room for a single specimen. They may now and then be very useful behind a single plant or an architectural figure. But the sorts immediately behind a specimen should be deciduous, if it is evergreen, and contrast with it both in color and form, to give it more prominence and relief; while those at the back of a stone-colored ornament ought to be evergreens of the darkest hue, for a similar reason.

This must be understood, however, as far from meaning that a plantation at the end of a straight walk, even behind another object, is necessarily a good thing. An open space 
where the eye can roam on into the field or country, fig. $27 b$, will often be much more pleasing, the principal walk, in both these examples, having a seat to stop it, and to form the cause of divergence. The above hints about such plantations are founded on the assumption that these will oftentimes be indispensable to cover a boundary fence. When the space opposite the end of the walk can be left open behind whatever is placed as a terminating object, care should be taken to prevent the eye from being conducted directly to a boundary wall or fence or hedge in the field, for should the line lead on to such a point, it must be stopped by a few trees or bushes, or by some mass planting. If the view into the country be a matter worth attaining, some low bushes over which the eye can travel will be enough to block out the fence, and a telescopic sort of peep into the country along a straight walk, which is possibly furnished with specimen plants on either side so as to narrow the vista, will sometimes be exceedingly fine. Whatever is placed at the end of the walk under these circumstances, should always be low and easily seen over.

A semicircular end to a straight walk, where it is to have an architectural finishing object, fig. $27 c$, will not be without effect in relieving the line and starting it more naturally in another direction. The vase or whatever is used will of course stand at the apex of the curve, fig. $27 d$, on the grass, or a semicircular seat, to fit the curved end of the walk, may be a still better termination. To justify a change of direction in straight walks, and soften the abruptness of turning them off at right angles, a vase or something similar may be put just in the center, figs. $27 e$ and $27 f$, where the middles of the two walks would cut each other, and the space which such an object would abstract from the walk be added to the latter all round, so as to produce a sort of small square or circle, of 


\section{The Several Styles}
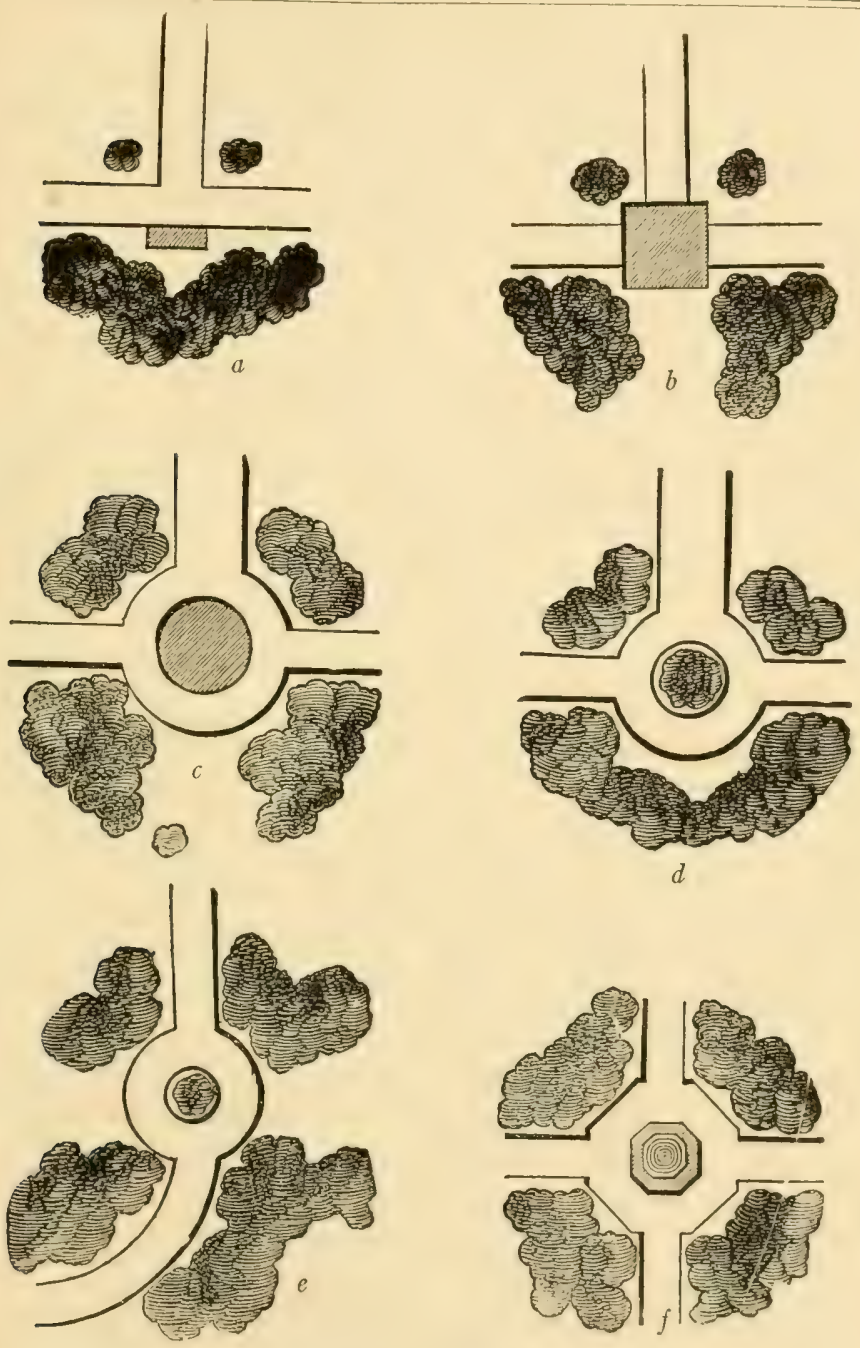

Fig. 27. Various Treatments of Formal Walks. 
which the vase is the center. The insertion of a group of statuary in a similar position with or without an architectural canopy, or the introduction of any bold architectural object, or of a basin of water, which may take an octagonal or any regular form, and have a fountain in it or not at pleasure, will present other modes of dealing with a similar case. A good shrub might even be substituted for any of these, though this would not be so satisfactory, as it would require a grass verge round it which ought to be circular, to prevent its corners from being destroyed by trampling.

Another method of ending a straight walk is by turning it off to the right and left, by the use of an open summer house, a small temple, or an aviary, at the junction of the three walks. This structure may be circular or octagonal or of any other regular figure, and may have the walk passing through or around it. In other cases the terminating object may be either a bold stone seat, a covered seat, alcove, a vase or group of statuary on a pedestal, or anything of an architectural character that does not thrust itself into the lateral walks. And though these illustrations by no means exhaust the subject, they may help to give additional clearness and force to the recommendations in the text.

Angular beds and masses appear at first sight to be absolutely demanded in a garden where straight lines and architectural figures are so general. And this view may hold good in the main with relation to the details of a flower garden in the close vicinity of the house. But the various forms and modifications of the circle are not objectionable in architecture, for they constitute its most beautiful features, as any one may perceive who will take the trouble to investigate the matter. And it is such forms that are peculiarly appropriate in architectural gardening, when only the materials of nature are dealt with. It may even be questioned 
too, where there is a possibility of choice between oblong or square figures and such as embrace any variety of the circle, whether the latter are not decidedly more characteristic for garden decoration. It is pretty certain that they are most beautiful, and that vegetable forms, with which they have to be associated, almost invariably incline more to roundness than angularity.

At any rate, there can be no doubt that figures cut in grass, and standing more or less by themselves or in rows, are more elegant, more conveniently filled, and more easily preserved, if circular, than such as have angles in them, while they are at least as much in harmony with the formal style of gardening. For single specimens, therefore, and for separate beds or groups, they are clearly to be preferred, and being susceptible of considerable variation as regards size, much may be done with them. But oval figures or oblong shapes with circular ends, or numerous combinations of curved lines uniting at an angle, will, if symmetrical, be more garden-like than purely angular ones, and will give more diversity. The chief requirement is that they should be regular, that is, that their several parts should balance and correspond.

That some more definite notion may be communicated of the way in which flower beds can be arranged along the sides of a walk, a series of examples is now given, commencing with the simplest, fig. 28 , which is a mere double row of plain circular beds, the diameter of which may be from four to six feet each and their distance from center to center ten to fifteen feet. In this and all the following instances, however, the beds will be equally adapted for putting in a single row, along only one side of a walk, if the circumstances demand such an arrangement. In the other designs the same form of bed receives a little diversity by having specimen 
I 6 Landscape Gardening
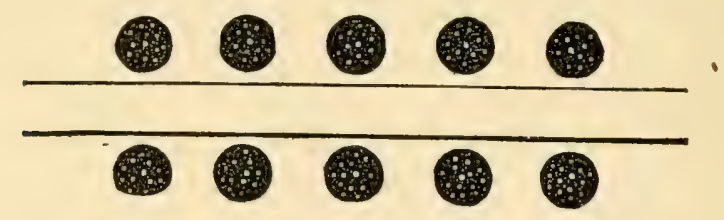

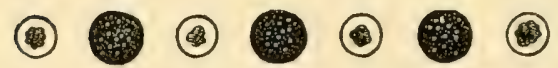

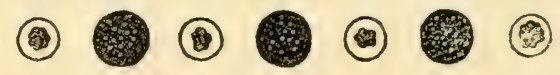

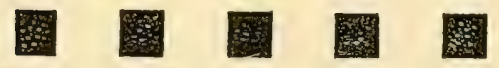

圆 圆 圆 圆

(2) (20) 170

중 (2) (2)
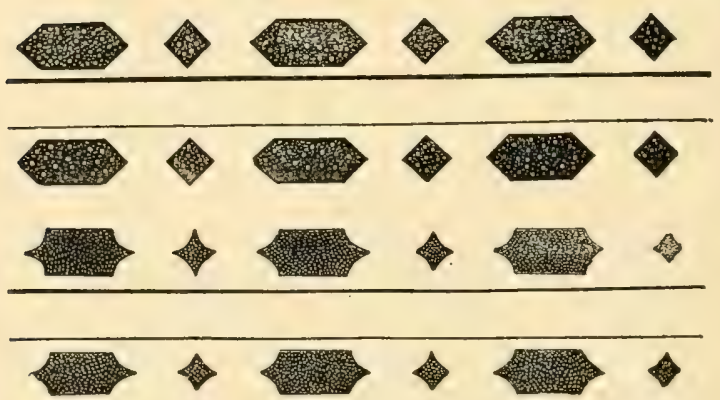

Fig. 28. Various Forms of Flower Beds. 
plants in small circles alternating with the flower beds. And a good deal of variety, again, might be given to this treatment by the choice of the plants used for such a purpose. If the line of beds form a vista to one of the principal windows of the house, and do not run across any important range of view, such plants as Irish yews, Irish junipers, standard roses and others of similar habits, either alone or alternating with those of a distinct character, will be suitable. But when the beds take an opposite direction, it is necessary to use only dwarf shrubs in them, that they may not intercept or checker the view too much. Still, even here, deciduous plants may alternate with evergreens, dark-foliaged shrubs with pale green or variegated kinds, and variety may be secured in these and many similar ways.

The square beds in fig. $28 \mathrm{c}$ introduce us to a fresh type of form which, though not so beautiful as the circles, may, in certain situations, contribute an important element of character. The lines of their sides, too, correspond with the lines of the walk. And in some instances small intermediate circles filled with shrubs might, as with the round flower beds, vary and heighten the effect without producing any incongruity. Further variety is attained in other designs by the adoption of oblong beds, about twice the length of their breadth, with semicircular ends, and having smaller circular flower beds and circles for specimen shrubs placed alternately between them. Either of the preceding forms is adapted for associating with any plain and simple style of house, which approximates to the Roman or Italian school.

An advance to a more decided tone of art is made in the next design, the pointed ends and diamond-shaped secondary beds in which take a character which can only assimilate with Gothic architecture. And the same may be said of the following design which is but a modification of its predecessor, 
I 8 Landscape Gardening

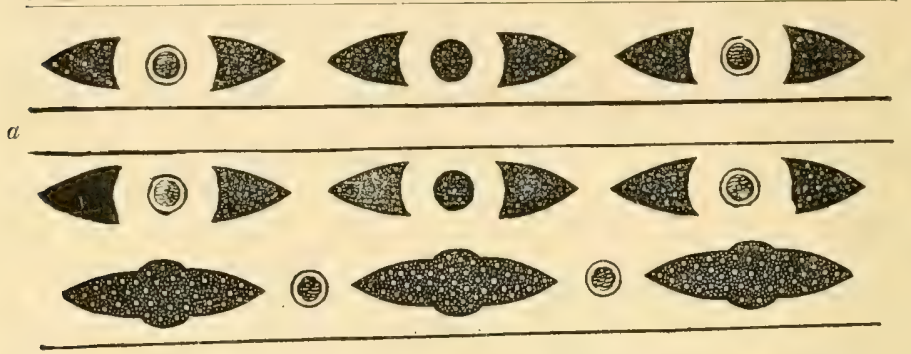

1

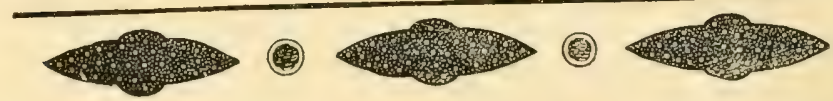
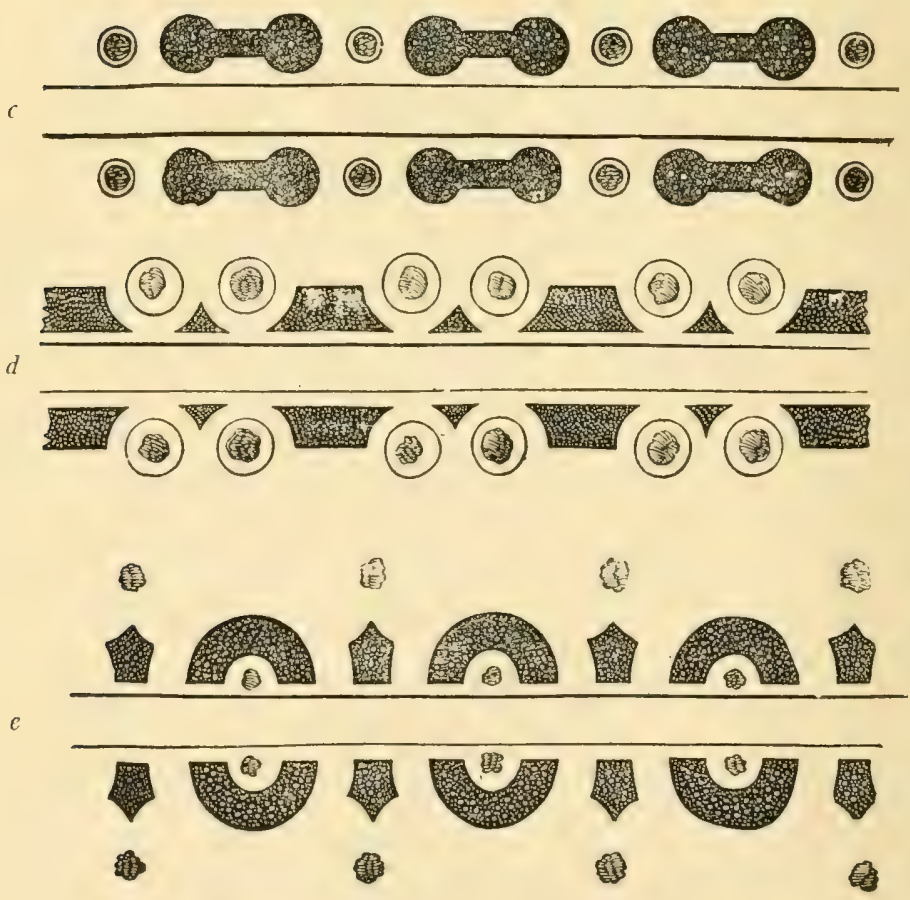

Fig. 29. Other Forms of Flower Beds. 


\section{The Several Styles}

the ends being parts of circles instead of being purely angular. It should be noted, however, that this last example is produced mainly to point out the way in which variety may be achieved, as the extremely acute corners of the beds would be difficult both to fill and to keep in their proper shape. In the next pattern we have yet another method, the beds being severed into two parts by the introduction of small circles, for alternate flowers and specimens; and this plan, while offering less of continuity than the previous one, admits of the employment of a greater number and variegation of colors.

Still further progression in the scale of design is made in fig. $29 b$ which has a prominent center to each bed, with narrower, pointed ends. These alternate with specimen trees or shrubs. In fig. $29 c$ we have still another type form, circular beds being connected by a straight portion. An additional step in the way of variety is made in fig. $29 \mathrm{c}$ where the ends of the beds are turned to the walk, and a more flowing outline occasioned. Very small shrubs are likewise inserted in the circular ends of each alternate bed. And if beds of this pattern cannot be much commended, on account of the troubled emanded to fill them nicely and to keep them correctly cut out, they may yet be useful in making a species of scroll-like fringe to a walk, where only one description of plant such as verbenas of different colors, is intended to be grown in them. In fig. $2 g d$ a strict adherence to the line of the walk is maintained in the flower beds, and a similar conformity is observed in fig. $29 e$, some little play of margin being accomplished by the interposition of dwarf shrubs at regular intervals.

It will be obvious that specimens of this character might be multiplied to an almost infinite extent, if any sufficient object could be served by their introduction. In those 
already given, however, - and which are intended rather as hints than as models, - the reader will probably find enough of suggestiveness to render a further installment unnecessary.

Towards the outside of a formal garden, or in parts sufficiently separated from the house, or from the view obtained at its principal front, there will be little objection to the use of masses of plants with a more irregular outline, or specimens scattered about in the natural style, provided a kind of connection be kept up by the help of circular or other regular beds in the center or at the corners of such compartments. When irregular lines are adopted as a fringe round the boundary, they are made as inconspicuous as possible from the house, and do not thrust themselves into notice anywhere, or weaken the effect of the more artistic parts. They will not disturb the harmony of the place unless they are obtruded.

One most important requirement in a formal garden is that the ground should be quite smooth and level. No undulations or unevenness of surface can be for a moment allowed. Regular and easy slopes or dead levels are as essential as straight lines in a house or in the walks. A perfectly flat surface is unquestionably the best for the purpose, as the lines will appear longer. When a line slopes away from the point of view it is to some extent foreshortened.

If the ground should, by any unfortunate chance, rise as it recedes from the house, it may be kept flat to as great a width as possible, and then be formed into one or more terrace banks (fig. 30), as it may require; the walks to be carried up these banks by flights of steps, and the change of level effected by grassy slopes or by low architectural walls.

When, in addition to a slope from the house downwards, or apart from it, the ground also slants naturally in a cross direction, this will demand some modification. As far at 
least as either of the main fronts of the house is concerned, the ground, to the full breadth of those fronts, and of any additional terrace bank by which they may be supported, must be brought into a perfectly level platform. There should

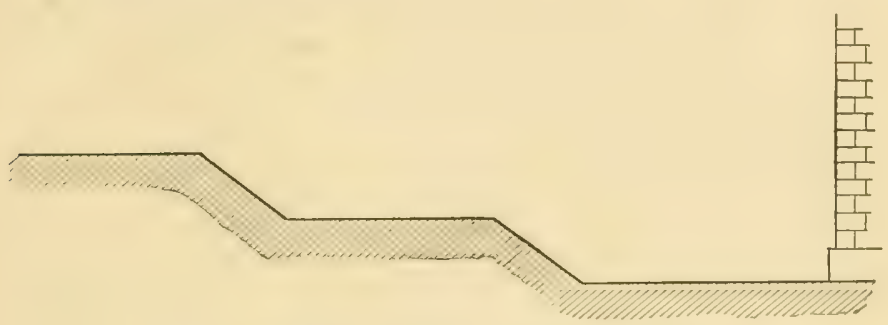

Fig. 30. Terrace Treatment of Rising Ground.

be no cross slopes, - no oblique inclination of the ground in a direction parallel with the front of the house. The level basement line of the house would in no way accord with a diagonal or sloping line in the ground, the latter being sadly out of harmony with the squareness of the style. Indeed the side of a house out of the perpendicular would be scarcely less incorrect.

From these observations it will appear that where ground slopes across a lawn and parallel with the front of the house it should, in consistency with the formal style, be reduced to a dead level as far as the front of the house or its terrace extends. In fig. $3^{\mathrm{I}}$ the dotted line indicates the supposed natural level of the ground, and the shaded line the level to which it should be reduced. The change of level from this point, in a line taken precisely at a right angle from the house across the garden, should be effected, whether ground rises or descends, by a terrace bank of grass the upper edge of which is kept quite square. Or the same thing may be accomplished by a low wall, carrying the walks either up or 
down by flights of steps. The steps resulting from any such alteration of levels, will, if rightly treated, and adorned with small vases, materially contribute to sustain the general character of the place, though they should never be without

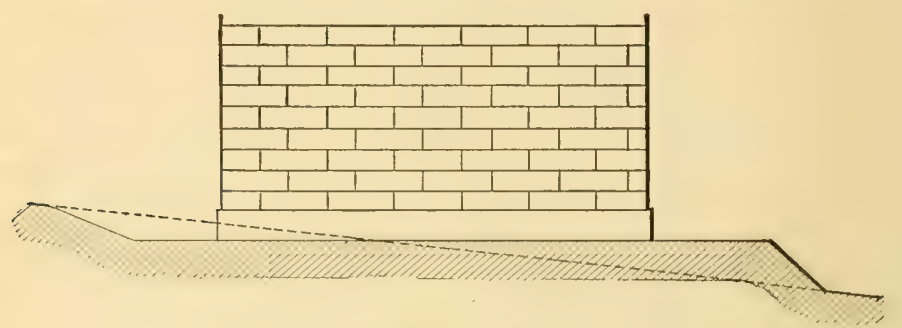

Fig. 3I. Grades about a House.

more or less massive edgings or curbs of stone, or some living substitute for these in the way of low dense evergreen hedges. Any extreme slope of the ground away from the house can be converted into terraces, as suggested for rising ground. But many terraces on a descending slope ought not to be used unless really necessary, for they serve to lessen the apparent size of the place.

Water, if admitted at all into the geometrical style, takes the shape of basins with architectural rims, or fountains, or larger pools that have sculptured figures along their margins, or very artificial cascades. Regularity of outline will, as in other things, be the leading characteristic of all such pieces of water. They may be circular or square, oblong, oval, hexagonal, octagonal, or of various shapes, as described for flower beds and masses. But they must not be irregular. Fountains which merely gurgle out the water or throw it up only a few inches, in the midst of round or octagonal basins having a stone margin, are in the highest degree appropriate and classical. And here it is worth while noting that simple 


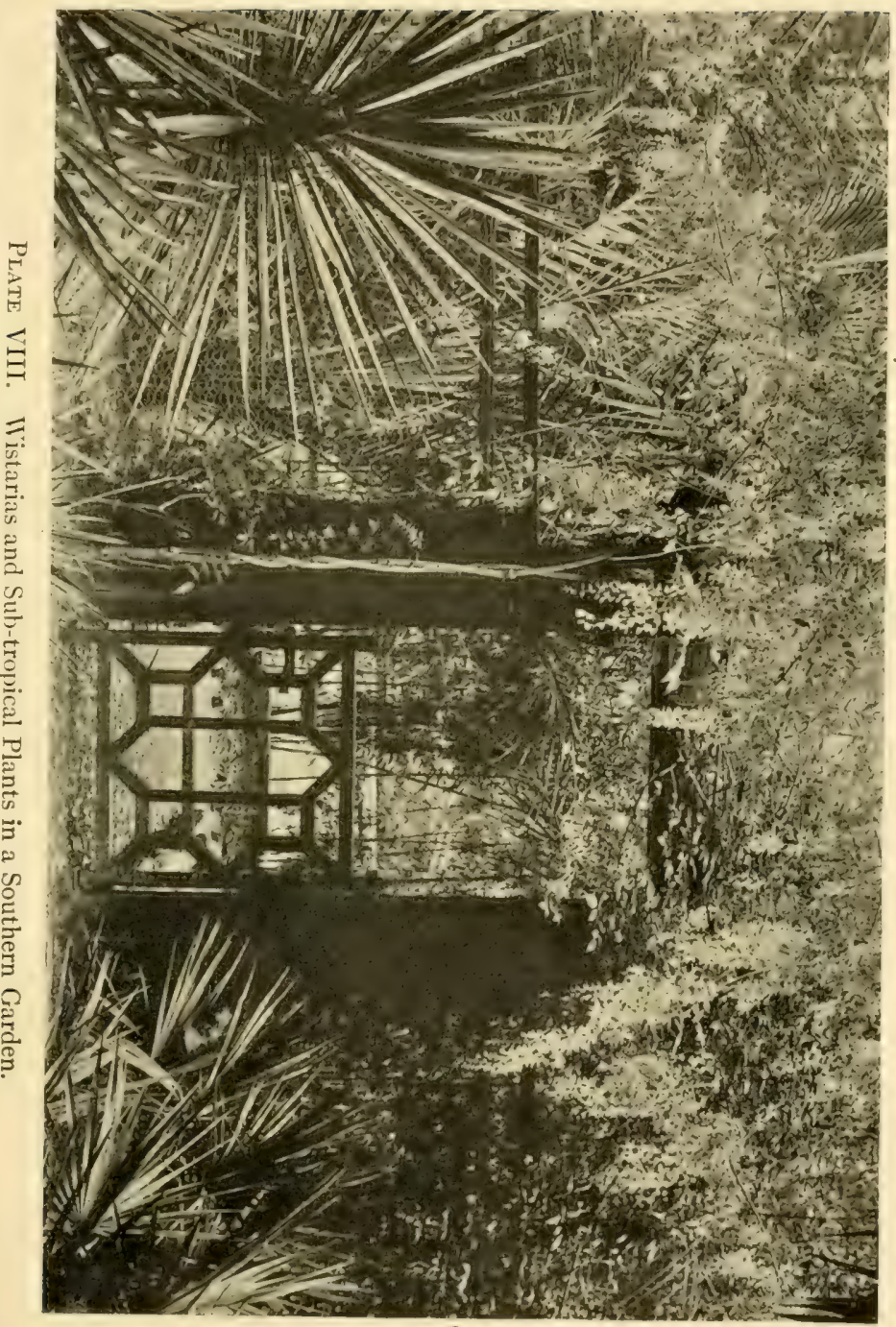



figures of this or other kinds in stone, with little or no aid of ornament beyond a good shape, will be more esteemed by those capable of judging than the most elaborate plaster decorations.

The Natural Style. - Serpentine or wary lines may be regarded as the characteristic features of the natural style. Its object is beauty of lines and general variety. Roundness, smoothness, freedom from angularity, and grace, rather than dignity or grandeur, are among its numerous indications. It does not reject straight lines entirely near the house, or in connection with a flower garden, a rosary, or a subordinate building as a greenhouse that has a separate piece of garden to it. Nor does it refuse to borrow from the picturesque in regard to the arrangement and grouping of plants. It is a blending of art with nature, - an attempt to interfuse the two, or to produce something intermediate between the pure state of either, which shall combine the vagaries of the one with the regularity of the other, and appropriate the most agreeable elements of both. It has all the grace of nature without its ruggedness, and the refinement of art apart from its stiffness and severity.

So many of the peculiarities of this style have been incidentally described, under various heads, that little remains to be added on the subject. Intricacy, every species of variety, indefiniteness, extension of apparent boundaries, polish, and the graceful blending of parts are specially its own traits. The liberal use of plants, such as trees and shrubs, in large irregular masses, more especially in outlying borders, is a distinctive feature of this style. The natural style is passed over very lightly in the original authorized editions of this work, being commonly spoken of as the "mixed" style. The twentieth-century reader in America will remember that at the time of the writing of the original 
manuscript the natural style had as yet hardly received polite recognition. To-day it stands established before the world as one of the great expressions of universal art. It has been cordially received and acclimatized in America, and is, apparently, the style most truly expressive of the taste of the American people. It is the style urged so eloquently by Andrew Jackson Downing and practiced so successfully by Frederick Law Olmsted. It is the usual form of expression adopted by leading American landscape architects of the present day, of whom Mr. O. C. Simonds and Mr. Warren H. Manning may be mentioned as typical exponents.

The natural style is rather better suited to the treatment of large scenery parks and rural estates than to small residence grounds. Yet it has been used with reasonable success even on small city lots. At its best it depends essentially on the development of broad effects in natural scenery where fields or woods, river or lake, hills or meadows, play a leading rôle in the picture composition.

In America the use of native plants has come to be regarded as an almost essential feature of the natural style. When other plants are used they are to be naturalized, as daffodils and crocuses are naturalized in the grass and Canterbury bells and foxgloves are strewn loosely into wild gardens.

The Picturesque Style. - Extreme naturalness is the distinctive mark of the picturesque. It repudiates all art, or employs it solely in order to weaken or annihilate it. There is nothing flowing in its lines, or soft in its forms. As extremes are said to meet, so, in the perfection of the formal and picturesque manners, there is something in common. Both call for angularity of figure and sharp projections. But the angles of the one are according to rule, those of the other cannot be too irregular. And while flowing lines mark 
the mixed style, zigzag, broken, rugged lines (fig. 32) stamp the picturesque. It recognizes no symmetry, and abhors everything allied to law and system.

And yet, in those examples deducible from the vegetable kingdom which may be accounted picturesque, there is much of wild grace, eccentric softness, and an indescribable but

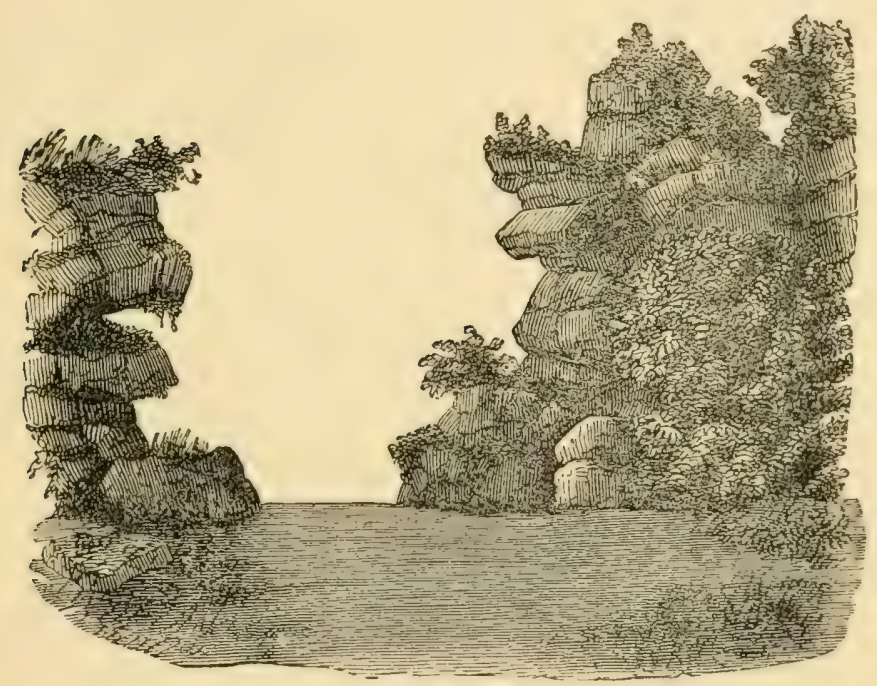

Fig. 32. A Type of the Picturesque.

charming balance of parts. Although nothing may bear the trammels of a rule, or yield to the fetters of definition in language, there is no want of the fluidity, the blending, the harmony, so ravishing to the eye, interrupted, it may be, by some accident, sudden gap or abrupt pause, but still full of spirit, and eloquent of beauty. For after all, nature's forms lie nearest to man's heart, and no devotion to habit 
will conjure away their magic power. The very instincts of our souls ally us to what is naturally beautiful.

Picturesqueness is by some restricted in its application to whatever is fitted for being effectively represented in pictures, - that, in fact, which an artist would choose to transfer to his canvas. I have here given it no such limited meaning. Possibly, however, that view of the term may help to illustrate and develop the sense more generally attached to it. For it is with wildness, ruggedness, broken ground, straggling and bold herbage, dashing water, fantastic groups of vegetation, the cracked and discolored stems and tortuous branches of trees, ruins nearly dismantled; except of the ivy and the fern, rude huts or cottages with their loose and mossy thatch or buildings copiously stained by time and lichen, that an artist would usually prefer to work. And it is these that go far towards comprising the picturesqueness of which I am here writing. 


\section{CHAPTER V}

\section{Practical Considerations}

A BASIS of sound principles being now laid, it will be necessary to advance a step further and consider those objects worthy of attainment which are most likely to come within the scope of the majority of places. I shall thus descend by gradual stages into matters more and more practical, until at last minor details and operations fill up the scale of instruction. In a field so wide, however, it will of course be incompatible with the limits of a book like the present to touch upon any but the most important heads, or to do so otherwise than very lightly.

I. Economy is, perhaps, one of the first objects to be consulted in laying out a garden, that the means of the owner may be made to effect as much as rcssible, and that his subsequent expenditure may be conformable to his circumstances. And here I must lay down as a broad principle that economy has no necessary connection with the prime cost of a place. The garden on which least has been expended may be the most costly in the end. "A thing well done is twice done" says the old adage, with remarkable truth and clearness.

A prime requisite towards securing economy is to study well beforehand what is likely to be wanted or desired and form a fixed and definite plan of procedure. Many persons begin building a house and laying out a garden on the spur of some sudden impulse, and without at all duly considering or digesting their actual requirements or the best method of accomplishing them. Hence, when they have got half 
through the work their attention becomes awakened to the subject, and all sorts of alterations, involving a great additional outlay, have to be effected; and after all, the result will rarely be a connected and satisfactory one. To deliberate and arrange and determine everything well before commencing is, therefore, the only way of ensuring economy.

The avoidance of broad and numerous walks and the adaptation of the design to the existing levels of the ground will tend powerfully to keep down the expense. The materials of which walks are made are often costly and generally have to be carted and wheeled from a distance. Much moving of earth, too, is always an expensive operation, as in addition to the actual labor of shifting it, there will be the trouble of throwing off and restoring the surface soil, both from the place that has to be lowered and that which is raised.

The cost of keeping up a place must also be thought of when the plan for laying it out is under consideration. To maintain a lawn in good order is deemed more troublesome by some than keeping beds and masses of plants clean. But if the whole of the labor has to be paid for, none of it being done by members of the family, and beds have a variety of flowers in them and are required to be kept very neat and duly raked, they will be much more exacting in point of labor than grass, especially when the constant trouble of keeping their edgings cut with the shears is computed. Lawn is consequently on the whole less expensive to keep up than flower beds and borders, and should therefore abound where economy of keeping is sought.

But, for a more general rule, whatever gives complexity and multiplication of parts to a place, decidedly increases the amount of labor demanded for its maintenance. Simplicity of plan will be by far the most economical. Little 
corners to keep clean, small beds to trim, and minute objects to tend, consume the most time and require the most constant attention. Broader and simpler spaces are most easily and quickly preserved with neatness.

In all ordinary cases one good man will be able to keep two acres of ground nicely in order, provided the arrangement of the place be not too complex and his attention be not withdrawn to other objects. On simple places where there is not much dressed ground, one man may care for considerably more than this. It must be remembered, however, that if there be a greenhouse, fruit-houses, or pits to look after, special help should always be allowed, for in attending to such things, many hours of each day are often consumed without any very obvious result appearing.

It will remain for every individual to consider these and other matters just as much as his particular case may require. These hints simply refer to a few of the means of making a fixed amount of money produce most pleasure, by being distributed over a greater number of objects. For if less is expended on one part, more will be left towards compassing other and greater ends.

2. Shelter. - There are few places so peculiarly situated as not to need some kind of shelter from one or more points of the compass, but still fewer which need it on every side. Before arranging the plan of a garden, it will therefore be necessary to ascertain what particular winds prevail in the locality, and are most injurious to vegetation or most productive of discomfort and unhealthiness. From a little south of east passing northwards to a trifle west of north, with the intermediate points, is the range in which protection is most commonly wanted, the winds from these quarters being never either pleasant to man or beneficial to plants. But certain districts near the sea, or on elevated inland tracts may be 
much afflicted with gales from the northwest or storms from the southwest, and will need protecting accordingly .

Many modes of supplying shelter exist, which are more or less adapted to local peculiarities. Hedges, fences of various sorts, walls, buildings, mounds of earth, or plantations, may all be good in certain situations, and in reference to special objects. It is important, however, to bear in mind that anything hard and dense, such as walls and close fences, only serves to divert and increase the current of the wind, directing it with greater force to some point beyond, so that these things simply afford shelter to objects immediately behind them, and do injury to such as are not within the range of their protection. It will be easily observable how severely any plants that happen to grow a little higher than a protecting wall are cut by the power of the wind, and to a far greater extent than such as have been entirely unsheltered.

It follows then that comparatively open and meshy and intricately branching materials, such as masses of trees and shrubs, are the best means of shelter for an area that is more than a few yards across, as they subdue and in a manner entangle the currents of wind. This is much on the same principle as that by which modern breakwaters act. It is now a well-settled fact that the strongest stone walls are less durable and influential against a heary sea than an irregularly webby or cellular mass of wood or iron, into which the waves can play, and by which their force is so divided and broken as to become soon exhausted. This diffusion and the multiplicity of parts in the resisting material renders it much more potent.

Currents of air, which are very similar to currents of water, may be best broken by trees in the same way, only the parts of trees and shrubs being more minute and numerous, they effect the object of shelter even better than any breakwater 
could soften the action of the waves. But plantations in order to fulfill the purpose well should be pretty dense at the bottom as well as in the higher parts, and the broader they can conveniently be made the more efficient they will be. Mounds or banks of earth, with plantations upon them, will be perhaps the best means of shelter in most positions. If walls be chosen they will be much more useful when backed by a plantation. Fortunately, whatever is usually employed for shelter need rarely produce any kind of shade, the north and points adjoining it being those which most call for protection, and those also on which the rays of the sun will never be intercepted. This is assuming, however, that the materials used for shelter are kept mainly towards the outer edge of a place, as they always should be if the ground be nearly flat, because they would there tend to promote privacy as well. In a hilly place, the flower garden or pleasure grounds may require extra shelter in their immediate neighborhood. This should be accomplished where possible by shrubs only or by trees of a lower growth, that the ground behind may not be rendered useless by shade.

As any openings in a line of objects producing shelter would only serve to draw in more violent and destructive currents of wind, it is essential that the material used should be pretty continuous. If it be a wall or a hedge or a bank of earth alone, or any other close object, this point will be of still greater consequence, and the narrower the opening, the more fiercely would the wind sweep through it. Any obstruction to wind will drive it round the ends or through the apertures of that obstruction with accumulated force; and the smaller the aperture, the more concentrated and powerful will be the volume that rushes through it, particularly if the obstructing medium be a hard and impervious one. All such openings will consequently be bad and destructive, though 
any little variations of height in the upper line of sheltering plantations must not be condemned, because these will be beautiful in themselves, and will not at all diminish the protecting power.

Sea breezes and gales occur with such frequency in some localities and are sometimes so injurious that protection from them should be obtained by the thickest and broadest plantations that can be afforded. And in such instances, even the openings through which views of the sea or of a landscape in that direction may be desirable should be planted with low shrubs that can be seen over and not left unfurnished. For if the wind strikes at once on the ground its full force will spread itself through the garden, whereas when it first meets with a kind of leafy or branchy network, however low, its momentum in the line of the ground's surface, where the most delicate plants are supposed to exist, will be considerably reduced.

3. Mode of access to a house, whether by a carriage-drive or a walk, should be kept as far as possible out of sight of the pleasure grounds and principal windows, that neither of these may be overlooked by persons coming to the house. It is much better to cramp and confine an entrance than to open the garden to it. Not that I should choose to do either, but merely regard the former as by far the lesser evil. At the same time it should be noted that no house ought ever, on any of its sides, to stand in a field or park, but should be entirely surrounded with a greater or less breadth of garden to maintain its character as a house and to harmonize with its domestic expression and objects.

What may be termed an architect's view of a house, which is one that embraces the entrance and best garden fronts, looked at obliquely, so as to get them both in perspective, is often unattainable from a drive, without sacrificing too much 
of the breadth and seclusion of the pleasure ground. Still it is very desirable that the first view obtained of the house, in passing along the drive, should be a favorable one and that the approach should appear at all points to tend towards the house and not to the stables or outbuildings or in any other direction. Hence it is always well that the architect and the landscape gardener should be consulted simultaneously before the plan of the house is determined, that the architect may adapt the character of his elevations to the

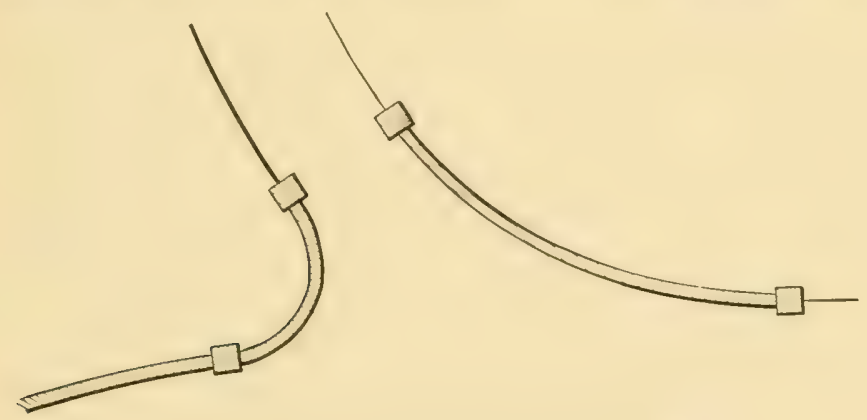

Fig. 33. Oblique Turn-in from Public Road.

points at which alone they can be seen from the carriage drive.

An approach ought never to pass the house to which it leads and then return to it, for the mere sake of gaining length, or of showing off the house or grounds. Such an arrangement is most unnatural and will do away with all the privacy of the place. Nor should the drive enter at the farthest point from the house and skirt the boundary all the way to it unless that is the most convenient or the only point at which an entrance can be made. There is great affectation in desiring mere length in a drive when it simply follows the line of the outside road. All drives or other approaches should rather 


\section{I34 Landscape Gardening}

take the most direct and nearest course from the usual point of entrance to the house. But if a little deviation from such a course, even to the extent of going beyond the house and returning to it, be ever justifiable it is when the ascent to the front door is so steep as only to be comfortably reached by a circuitous route.

No entrance should start at an oblique line from the outside road, unless it be at the corner of a place, or from decided bend in the road, as in fig. 33; and then the line of the

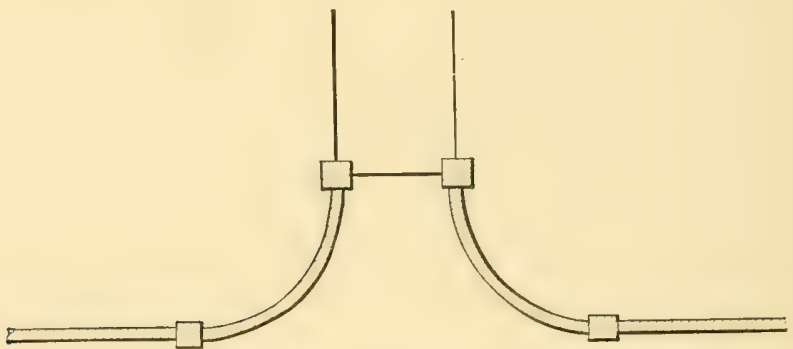

Fig. 34. Turn-in at Right Angles.

drive should decidedly turn away from the line of road. Generally a drive requires to commence at right angles from another road (fig. 34), even though it should have to take a sharp curve in another direction almost immediately afterwards. In the great majority of cases, the wing walls or other fences on either side of an entrance should present a convex form to the high road, as this is the natural form of approach, and affords less opportunity for the accumulation of weeds or nuisances. But if a dignified architectural character be sought, and the entrance is intended to be bold and imposing, walls of a reversed or concave figure will perhaps be preferable, and a light post and chain fence, in a convex 
curve, can be placed outside, enclosing a piece of grass on which a few shrubs or trees may be grouped.

As a house ought invariably to be on higher ground than the bulk of the garden, in order that it may not appear damp or buried and shut away from all views into the surrounding country, so the approach to it, especially where the place is small, should be contrived so as to be on a gradual rise all the way. A slight dip in the drive with a subsequent and more decided ascent where it exists naturally, may sometimes be the means of heightening the ground about the house in appearance. But a constant rise in the approach will be the most uniformly suitable.

Any curves in a drive or walk to a house will be better if they have a very easy sweep, that there may be no temptation for vehicles or foot passengers to injure the grass verges by taking a shorter turn.

In tracts of country that are excessively flat, and when the form of the house is tolerably regular, having a center and two wings, should the exterior boundary of the place be about parallel with the entrance front of the house, and the distance between the two sufficiently great, a straight drive through an avenue composed of two, four, or more rows of trees will of ten have a grand and noble appearance, particularly if the grounds are otherwise arranged accordantly. Wherever the drive is deficient in length, there should be only one row of trees on each side of the road, and the width of the drive and the distance from it to the trees should be also proportioned to the length of the avenue.

As bearing directly on the subject of avenues, I shall make no apology for inserting the following extract, being part of a description of the park at Windsor, from a small work of mine on the "Parks and Gardens of London and its Suburbs." 


\section{36 Landscape Gardening}

"The drive known as the Long Walk is three miles in length, in a straight line, and is supported on either side by two rows of elms, which have attained their full size, and, with a very few unimportant exceptions, are yet in the greatest vigor and luxuriance. This avenue will be sure to strike the visitor as exceedingly grand. It is somewhat marred, however, by being carried over a considerable swell in the ground about half way up it, which helps to shorten its apparent length, and to make the drive seem as if it were not straight, while a more decidedly objectionable feature is that it ascends a hill away from the castle at the further end. If there are any two circumstances which, more than others, require to be kept in view in the formation of avenues, they are that the ground over which they run should be nearly level, or have one continuous ascent towards the mansion or principal object to which they lead, and that consequently this object should be on the highest ground, at least as respects the avenue. Any avenue that commences on a hill and passes down that hill towards its terminating object, even though it afterwards rise again near the end, must appear to some extent inverted, and every undulation or swell of the ground in it will necessarily be a deformity. The idea which is conveyed to the mind by the elevation of the Long Walk at Windsor, as it reaches its termination in the Great Park, is that the Castle ought to be somewhere about the site of the statue of George III, by which this walk is so appropriately finished.

"Those familiar with the Champs Elysees at Paris will remember that the grand avenue there, like this at Windsor, is partly on a steep ascent, away from the palace of the Tuileries to the Triumphal Arch at the summit. And although this circumstance enhances the effect as viewed from the front of the palace, yet, regarded as an approach 
to the Tuileries, it causes the latter to appear more or less buried in a low marshy tract."

Avenues that are not in a straight line but are curved or otherwise irregular may be convenient or answer some useful purpose, as in the road on the northwest side of St. James's Park, London, but they can never rise to the dignity of art. And when, as is the case with one at Woburn Abbey, they are both curved and pass along the ridge of a hill, where, if seen from the side and from a lower point, they exhibit a flat and monotonous sky line, and also appear thin and meager, they are doubly objectionable.

Anything in the shape of a single row of trees along the side of a drive, or a double row that is broken at intervals, unless this last be done in the most formal manner, and for the sake of opening out a decided vista, would be quite inadmissible in an artistic point of view. And the rule will hold good with reference to bold and important walks in pleasure grounds, except where a square or oblong plot, that is complete in itself, is merely flanked on either side with a row of appropriate plants, the two rows in such case, however distant from each other, actually constituting the arenue.

There is commonly a great propensity to make the sweeps of gravel at an entrance door for carriages to turn in a good deal too large, for the accommodation of careless coachmen. This disfigures and reduces the apparent size of a place considerably, and must be protested against. The smaller the space that can possibly be turned in the better it will look. From thirty to forty feet in breadth will be ample, and the former will suffice where the approach to the front door is by a nearly parallel line, or on a long and gentle curve. The error of having the immediate front of the house occupied with stretches of gravel drive instead of with green lawn is very common in America. Every arrangement of this sort 


\section{38 Landscape Gardening}

should be avoided. All sorts of houses, except the largest and most formal, where a straight approach to the front is required, will be better planned with the carriage entrance or porte cochere on the side. The breadth and extent of the carriage turns may then be reduced to a minimum.

Wherever it may be possible, the entrance door or porch of a house should be approached laterally, and so as to have the door on the left. It is very difficult to drive up to a door when the line of approach is at a right angle with the house,

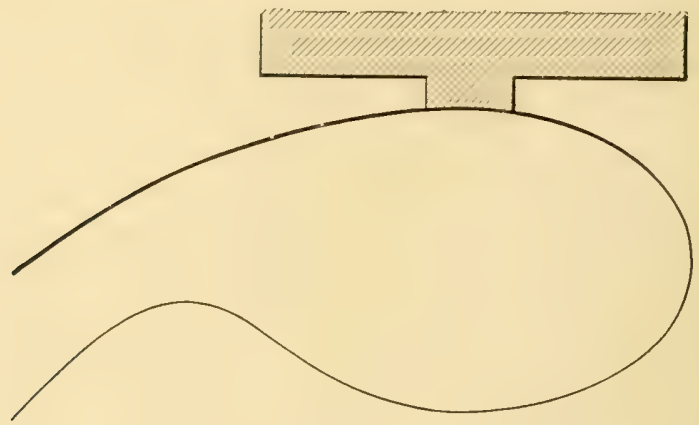

Fig. 35. Carriage Turn for Small Grounds.

and demands much more space to turn in. By keeping the door on the left, too, any one who may be riding with the coachman, or any lady who may be driven in a pony carriage or phaeton, will alight at once from the side of the carriage on which they are seated. Figs. 35 and 36 will exemplify this, the former being a simple sweep of the usual shape while the latter is broken up by the insertion of a large shrub or group of shrubs in the center.

Cases may occur in which, from the extreme shortness of the drive, the character of the house, the desire to make the garden private, or the existence of a natural bank of 


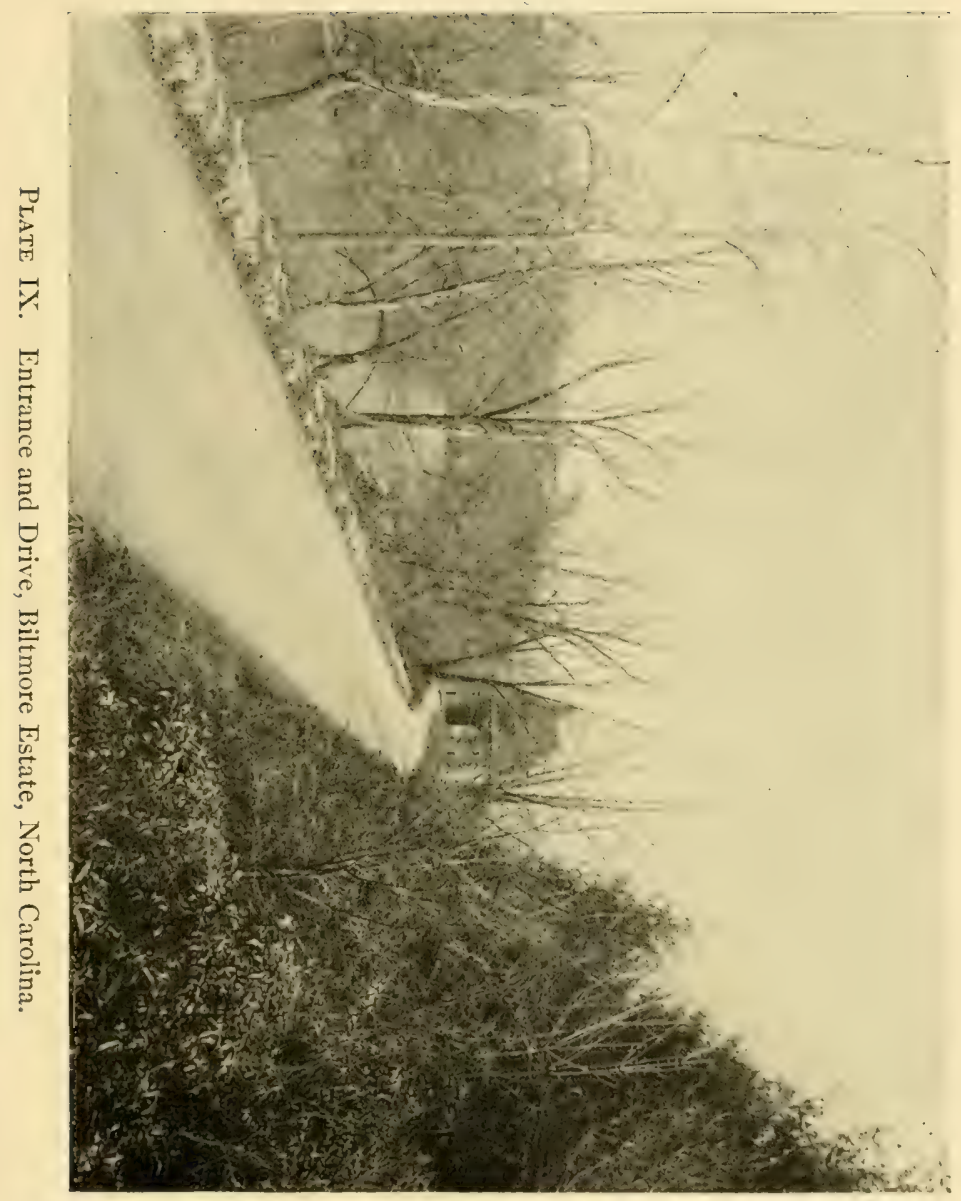



earth against the carriage sweep, the formation of a walled entrance court will be both prudent and ornamental. If the walls be but low (three or four feet high) the area of such a court need not be much larger than an ordinary carriage sweep. But if the court be surrounded with walls ten or twelve feet high, it will require to be much larger, and be decorated with shrubs and climbers. In either case the wall should be architecturally treated and made a main element in the design.

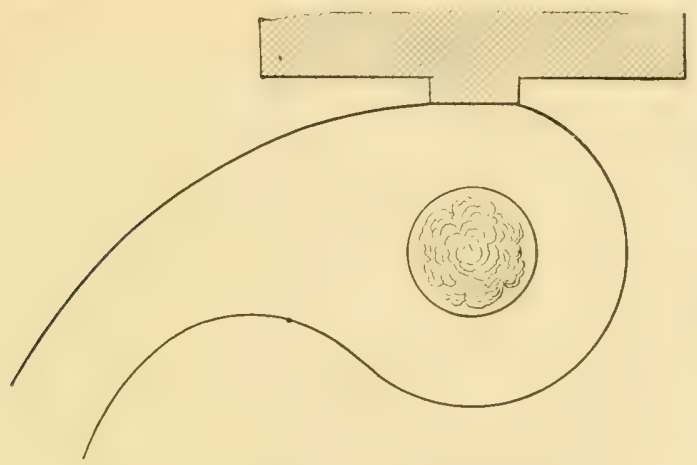

Fig. 36. Carriage Turn with Embellishment.

In obtaining access to the servants' apartments of a house, a few leading rules will have to be observed. If at all practicable it should be made quite a separate thing, from the outside, and will be more useful if it will admit carts to convey supplies to the house and rubbish from it. But where this cannot be done, the access may be compassed by a branch road or walk from the main approach, keeping this as far as possible from the entrance front of the house, and rendering it smaller or more confined and less direct than the main approach, that the two may never be mistaken for each other. 
4. Treatment of walks. - Independently of the approach to the house, there will be a greater or lesser number of other walks in a garden, the treatment of which will demand much attention. They should not strictly follow the boundary of a place, unless it be purely in the formal style and its fences be architectural. But wherever they diverge from the neighborhood of the boundary, and indeed at every point throughout their length, the outside fences should be kept in the background by masses of shrubs and trees, especially the former.

Walks should be made to embrace particular views, to take a variety of levels, to be concealed from each other, and to have a definite object. All the more interesting aspects of the house, the garden, and the country, ought to be seen from them at particular and favorable points. These points should thus be situated where the ground is highest, in a generral way, that the view may be more commanding. But the house itself ought not to be seen from a greater elevation than it actually occupies, unless there be a hollow between it and the point of view. Undulation in the surface of walks, where it can be suitably attained, will be very effective in the production of variety. It must be very gentle and gradual, and like the curves in the ground line, the changes should pass softly into each other. Sudden swells or hasty dips should be alike unknown, unless they are to accomplish some special end or are rendered necessary by the natural conformation. The highest or lowest parts will best occur towards the center of the curves, where the lines are easiest.

If two walks be seen from each other, when they are taking parallel directions, one of them will appear to some extent needless, and in the same degree objectionable. Masses of shrubs, or banks of earth partially clothed with these, are the most natural and gentle divisions for placing between them. 


\section{Practical Considerations}

A walk that leads nowhere or ends in nothing gives an impression of an unfinished place, and is as unsatisfactory as all other abortions. If it be not desirable to continue it beyond a certain point, and yet be of consequence that it should proceed as far as that point, a summer house, or arbor, or seat to obtain a good view, will be a sufficient terminating object. Otherwise the walk can be carried round a small loop filled with shrubs till it returns again into the same part. A mere

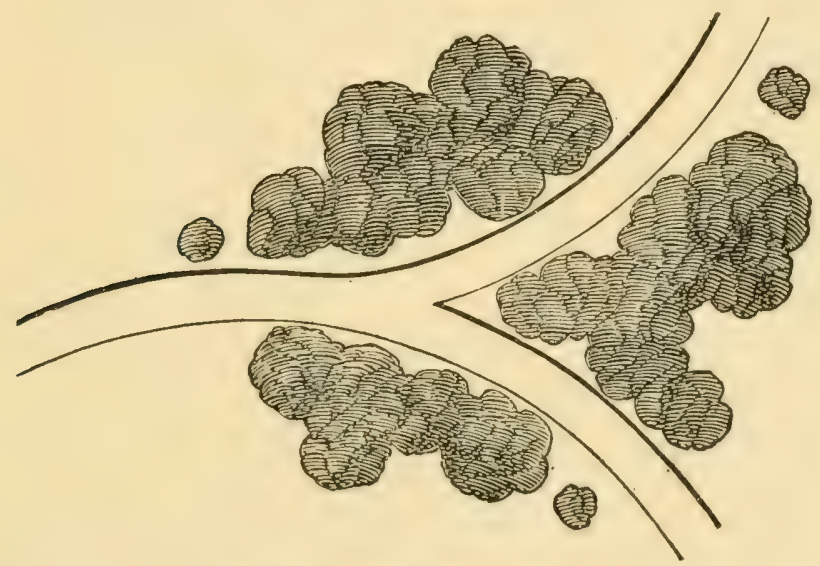

Fig. 37. Branching of a walk.

cul-de-sac in which a walk or drive expands into a truncated form without any outlet is extremely undesirable.

-No walk must ever turn aside from its course except for some sufficient object. A great change of level, a tree, plant, or group of plants, and a variety of such things, will justify a curve in a walk; and when it is straight, something must be distinctly placed to stop it where it turns off in a lateral direction. It should appear as if it could not go any further 
in the same line. Repton suggests as an excellent rule that where two walks branch off from one another at any point, they should take a decided outward turn (fig. 37) so as not to seem as if they would soon unite again. Cf course this will not apply to the case of their merely passing round circles or ovals, where it is simply assumed that the obstacle in the center causes a temporary diversion.

While the shrubs and plantations that skirt the sides of walks at intervals are nerer flaced so as to nake a formal line or hedge, nor pruned or clipped into regular shapes, in relation to curved walks, they cught not so to intrude upon the walks as to prevent their being confortably used in wet weather. Regard should be had at the time of planting to their usual character and habits, with an ultimate view to this convenience.

In the formation of serpentine walks it is not well to set their curves out to any regular radius but simply to please the eye. The length or extent of divergence of the curves from a central line cannot be too varied and irregular if the turns be not sudden and abrupt. Great variety of curves will best conduce to newness of scene and maintenance of interest. The most delicate point in working them out will be to blend two curves nicely together without producing a straight or a tame line at their junction.

Whatever may be at the sides of walks, whether raised banks, borders, depressions, or comparatively level ground,

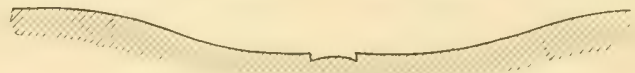

Fig. 38. Grading to a Walk.

if a grass edging be used it should always be perfectly flat for a greater or less width, according to the space, and then gradually rise (fig. 38 ) with a concave curve, till it 
joins a bank or elevated bed. Or else it should gradually fall with first a convex (fig. 39) and then a concave curve till it unites with the line of a depression or hollow. With very precipitous banks that are compelled to be brought close to a walk, this rule must be set aside, though rocks, stones, roots, etc., clothed with trailing plants, or masses of

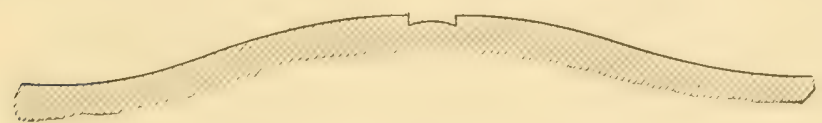

Fig. 39. Grading to a Walk.

ivy or cotoneaster alone, will be preferable to grass for such places. Nothing can be more ugly than a convex grass bank reposing angularly on the margin of a walk, and the edge of it can never be cut neatly, while it is apt to be pared back by orderly gardeners, to keep it to some degree of smoothness and straightness, until a deep harsh line of bare earth is presented at its base.

5. Fences. - All the fences of a place, unless they be purely architectural ones or occupy some peculiar position, should be as light as they can be made consistently with strength and be otherwise quiet and inconspicuous. A fence is a thing of necessity and not of ornament, and though the latter feature may possibly be added to it, it is not usually to be wished for. The material, therefore, the color, and the form, should be such as will least excite attention and can be most readily concealed or disguised.

Sunk fences are the best of all barriers, when the nature of the boundary admits of their application, especially if the land beyond them be in grass, for they are not at all seen from a distance and are as good as a common wall in keep- 
ing out cattle or other intruders. But they are very rarely fitted for any place except between the lawn and the park, where they are invaluable. If the lawn and park be not on the same level where the sunk fence separates them, they should be made pretty nearly so, or the line of division will show itself too much from the house and from some part of the park, and the apparent size of the land will be lessened. The sunk fence has not been used in America as much as its merits and American needs would warrant.

A sunk fence may be of several different kinds; but, in any form, it is important that the ground lines of the excavation should be carefully regulated. The simplest and most

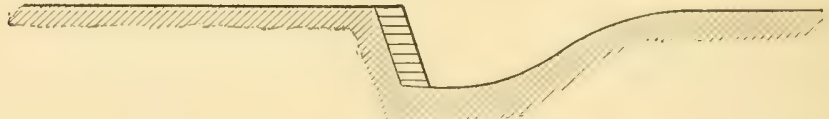

Fig. 40. Sunken Wall or Fence.

common mode is (fig. 40) that in which a wall is introduced to sustain the earth on the side next the pleasure grounds. This wall should always batter slightly and stand about five feet above the ground at its base, the sloping line from it extending twelve or fifteen feet, as shown in the figure. In

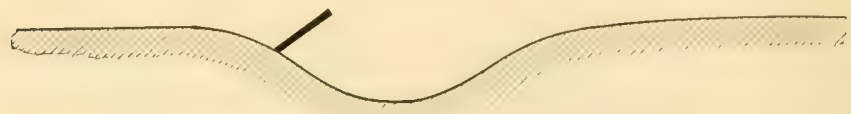

Fig. 4r. Sloping Invisible Iron Fence.

fig. $4 \mathrm{I}$, no wall is used, but a slight iron or wooden fence is placed on the inner slope, and is so slanted that it makes an effectual barrier from without, while it is hardly at all perceptible from the inside. It may be remarked in passing 


\section{Practical Considerations}

that it is, of course, more difficult for man or animals to get over a fence that slopes towards them. An ordinary wire or hurdle fence is, in fig. 42, put in the bottom of the excavation, this latter being just deep enough to make the fence

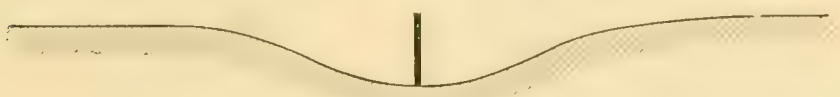

Fig. 42. Common Wire Fence Sunken.

invisible from the lawn of the pleasure grounds. The inner slopes in the two last plans might be used for a collection of the dwarfer kinds of shrubs in irregular patches, or for spring flowers, when the aspect is sufficiently sunny.

For outside boundary fences something that is rather secure will be principally wanted. Iron railings on the top of low walls are most ornamental, and give a friendly, hospitable, and open character to a place. Walls or close wooden palings may be useful near towns or in bad neighborhoods, but they should not ordinarily be more than five feet or five feet six inches high. Wooden fences are decidedly the most troublesome and expensive in the end. Stone walls will have a much less ugly appearance if furnished with a neat stone coping. Both these and close wooden fences may be mounded against on the inside, to the depth of two or more feet, which, if the bank be made the full breadth of the border, and softly worked into the common level of the garden, or to the edge of a walk, will greatly take off the height of the fence from the inside, and make it much more easy to hide it with low shrubs or masses of wild-looking ivy. Fig. 43 represents a fence of this description in which there is a low wall about two feet six inches high towards the road and a hedge planted immediately within the wall on a sloping bank. The hedge, when fully grown, would overhang the wall and be cut flush 


\section{46 Landscape Gardening}

with the face of it, as shown in the sketch. Such a fence would be peculiarly neat and trim, and yet quite countrylike, in any suburban or purely rural district, and it has the

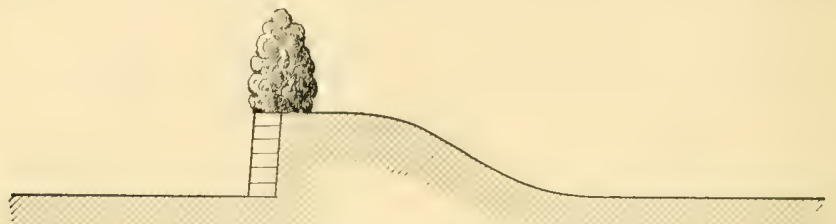

Fig. 43. Boundary Wall with Planting.

merit of presenting no bank which could crumble or be trodden away on the side next the road, while on the inside the entire fence is as inconspicuous as possible.

Inside fences for separating one part of a place from another or for protecting plantations in a park need not be nearly so strong as those for the exterior boundary. Hedges in such places are mostly deformities in a scene. Between the field and the lawn they cut off all connection and the field might as well not exist, as far as effect is concerned. Around plantations, too, they are scarcely a whit more in place, for they give them a hard and stiff outline and prevent the branches of the trees from sweeping the ground, which is a prominent beauty. Trees never show to advantage unless one can see distinctly where they rise out of the ground, and how their branches rest upon it, or incline towards it. Hedges around them coop them up in a kind of nest. If the hedges be trimmed, as they must be to become at all useful, their effect will be decidedly worse. When left to grow wildly and irregularly, they may be somewhat less objectionable.

Different descriptions of light iron fence, especially wrought iron, will be superior to anything else for divisions in a place, 
or for surrounding plantations in a part grazed by sheep or cattle. A wire fence is the lightest, strongest, neatest, and best for a decided fixture, and may be adapted nicely to any sort of curves. Galvanized wire, of which it is sometimes made, is liable to become corroded, especially by the action of sea air. The supports of a wire fence should always be bedded in stone or cement. If this kind of fence be used for a straight line - across the foot of a lawn, for instance where no extra stays will be needed, it is extremely light and quiet looking. The greater the number of curves, and the more sudden these are, the more expensive will be the fence on account of the increased number of stays; but under any circumstances it will be the cheapest lind of fence, taking everything into account, and considering its durability.

A common wire fence can be three feet six inches or four feet high, and have six horizontal wires, which will exclude lambs. These last easily get through the ordinary fences, and may do great mischief in a garden or plantation. The fence should be placed at least six feet from any plants in a garden or a group, that cattle may not easily browse them, or sheep crop off all the ends of their lower shoots.

In certain parts of a place disagrecable objects, as rubbish or yards, require to be excluded and walls would perhaps be objectionable or too expensive, while hedges would either be too long in growing, or the situation is so shaded that no hedge could ever thrive in it. For such positions, the rustic close fence, fig. 44, composed of larch poles with the bark on and intended to be partially covered with iry and other climbers, is quiet and harmonizes well with any shrubs or trees that may be in the neighborhood, and creates at once a complete screen. It may be six or eight feet high, or even higher if necessary.

To protect single trees planted in a field, a low circular, 


\section{48 Landscape Gardening}

square, or octagonal frame, to stand about three or four feet from the stem of the tree, composed entirely of larch or pine

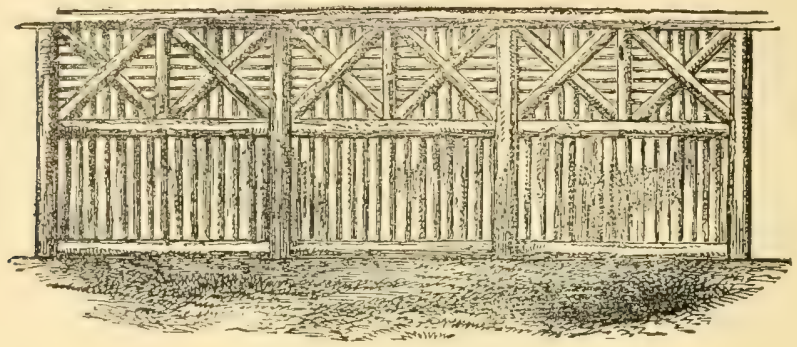

Fig. 44. Rustic Fence.

wood, two or three inches in diameter, split into two and the bark left on, will be a convenient and sightly mode.

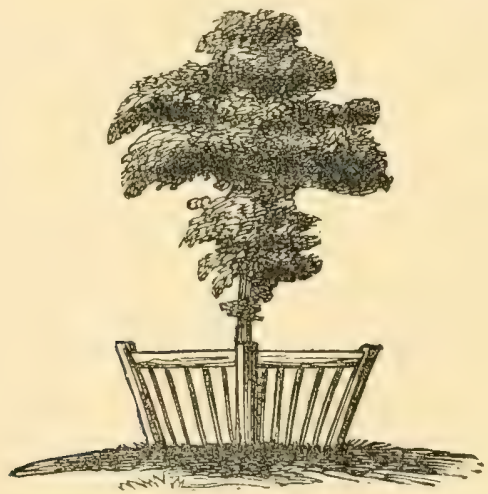

Fig. 45. Simple Protector for Tree.

This frame can be formed either wholly of upright pieces of wood, about two or three inches apart (fig. 45) and fastened to connecting cross bars inside, the four corner pieces 


\section{Practical Considerations}

being longer than the rest, and fixed into the ground; or, if square, the sides may be made of similar wood, fastened crosswise at about the same distance apart to inside uprights, the four posts at the corners being retained as in the other case. The guards might, if desired, be placed much nearer the tree, and made twice the height, or about six feet from the ground, in which case the sides should be filled in with

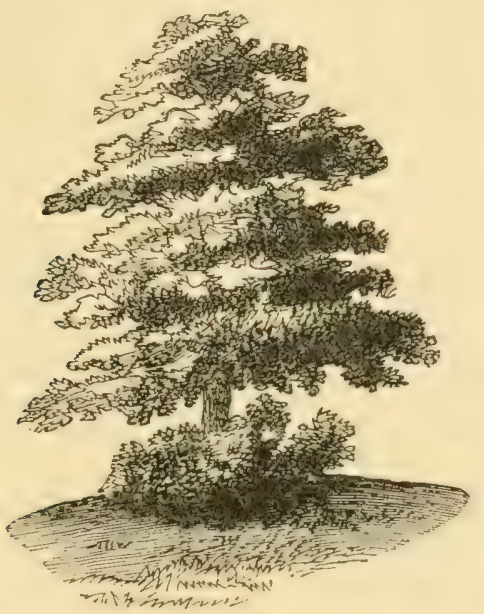

Fig. 46. Tree Protected by Undergrowth.

horizontal instead of vertical bars. The bark-covered side of the whole should be presented outwards. Strong iron wire guards, six or eight feet across and dividing into tro parts, may likewise be used, especially where the branches of the trees grow low upon the stem.

Where a permanent fence around single trees in a field would be considered an eyesore, this may he dispensed with by planting around the base of the tree irregularly, and as if by accident, two or three common thorns, (fig. 46$)$, with an 
occasional holly or kalmia to vary their appearance, and give them more liveliness in winter. If left unpruned and suffered to take entirely their own course these plants will, after a few years' protection, become quite sufficient guards to the trees, and will have rather a picturesque effect. Unquestionably, however, they will detract from the symmetry and dignity of the tree.

That the color of fences is by no means unimportant, will readily be deduced from what has been urged as to giving them a quiet appearance. All light paints, such as white or stone-color, will be exceedingly out of place, unless the fence is very handsome and intended to be made conspicuous. Green, as harmonizing best with the color of grass and vegetation generally, will be the most appropriate.

6. Outlines of Beds. - In dealing with the outlines of beds and masses, besides the variation, freshness, easiness and grace of sweep, which it is desirable to procure in respect to such as are to contain shrubs, or shrubs and trees, much may likewise be done by the manner of planting them. Although it is necessary, to secure any degree of order and beauty for a few years, that the shape of irregular masses should be set out in a series of bold, well-connected and flowing curves, the actual outline of the plants, when they have reached some eight or ten years' growth, must never be supposed or arranged to take any such figure. On the contrary, each plant, in the front at least, like the heads of old trees in a forest, should jut forward or retire with a curve of its own, forming an infinitely more numerous and more varied series of little curves, these again uniting, in their general outlines, to fill up and vary the series of larger sweeps at first marked out on the ground. Fig. 47 will best explain this, the dotted line along the front exhibiting the curved outline of the plantation as it would be set out on the 


\section{Practical Considerations}

ground, and the broken, inner, shaded line immediately behind it indicating the kind of shape which the trees and shrubs would take, in their front lines, when fully grown.

Instead, therefore, of the outside plants in a mass following implicitly the lines by which it is defined on the ground, they should stand forward or recede in the most irregular fashion, approaching nearest to the front of the bed at the prominent parts, and towards the middle or one of the sides of the recesses, but retiring a good deal in other places, and especially in those portions of the recesses on either side of the

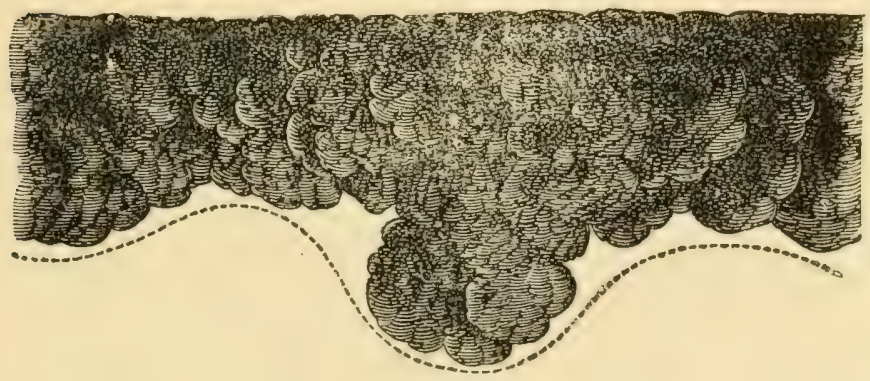

Fig. 47. Proper Form for Border Planting.

advanced specimens just named. In addition to this, and to heighten the variety of outline still more, the larger growing things, and such as will spread forward most on the grass, may be put here and there along the very front rank of plants, the smallest growing kinds being kept among such as are planted farthest back. Thus, when the border comes to be turfed over, if ever it should be so covered, the edges of the mass will be as broken, yet as softly rounded and blended, as those of a nutural thicket; and should the front of the border be retained for flowers, the shrubs will still produce 
the same effect as to outline, though it will not be exhibited so well.

Mere rows of plants that have length without breadth, and are easily seen through at all seasons, will ever appear poverty-stricken and meager. Every group should have some kind of proportion preserved in its parts, especially between its two principal dimensions. All narrowness and thinness will be fatal to this. It is clusters or masses, not mere strips, of plants that are wanted in a garden, a field or a park. Long and slender beds of them look too much like hedges.

Each plantation or mass of plants upon a lawn will demand to be treated separately, and yet in relation to others. Its own individual outlines should be such as I have described, but these must make part of a series of lines of which the sides of a lawn are composed. It will not be enough to have one group well and tastefully defined; each group must play its part in the whole scene and be shaped so as best to exhibit both itself and others. In laying out a number of groups, then, it will be proper first to arrange them in the plan as if they were one continued mass, and then regard them as severed up by walks or other divisions, in the way that may be afterwards found expedient. Two or more beds, where a walk divides them, should have their outlines arranged (fig. 4 S) so as to look like one when viewed from a distance. The edges of these beds towards the walk may be either broken into bays, as in fig. 48 , or be made continuously regular, with a verge of a uniform width. Either of these modes may be adopted at pleasure, or the latter may be selected where the masses of shrubs are but narrow and small and the former used when they are more ample.

7. Sky Lines. - But the best arrangement of plants as to the shape and relative position of the masses will be unfinished 
and defective unless their upper outlines, when fully grown, are properly calculated upon. From some point of view, whether nearer or more distant, the tops of almost every mass of plants will cut the horizon, and stand out against a background of mere sky. If nicely disposed this sky outline will yield the most charming effects. But it may also be hard or tame, and thus become disagreeable or utterly ineffective.

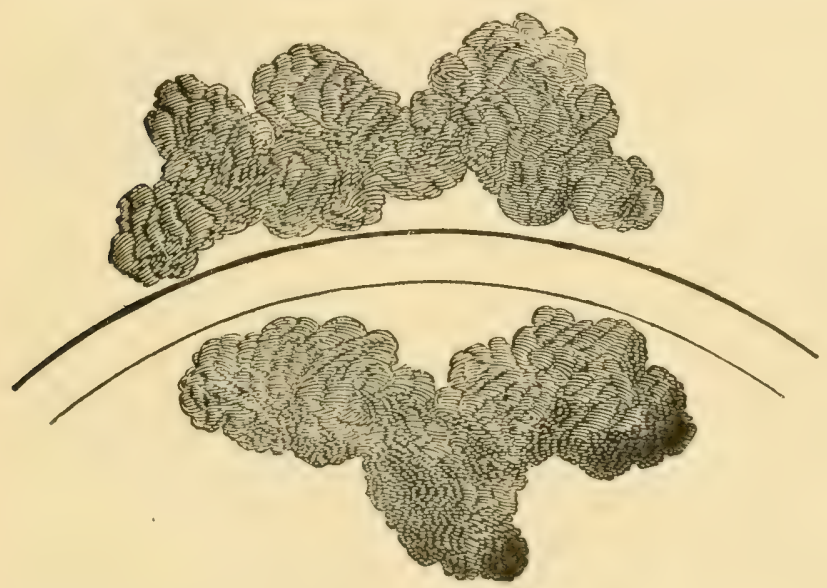

Fig. 48. Two Groups which look like One.

By a reference to nature, especially in her older vegetable forms, a few large and comprehensive hints may soon be gathered on this point. In the horizontal outlines of forest groups, the greatest diversity, and yet the most pleasing roundness and interfusion of parts, is observable. Like the ground lines of shrubberies which I have just attempted to sketch, there will be a great number of bolder or lesser curves united to make up broader sweeps and more expansive variations. Occasionally a tree or shrub of some spiry or unusually 


\section{54 Landscape Gardening}

upright character will spring out of the masses of roundheaded vegetation and give increased variety to the outline without weakening the general smoothness of the effect, while

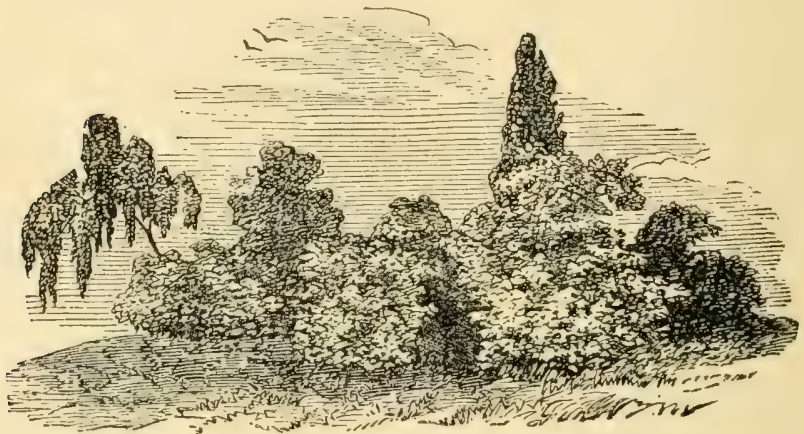

Fig. 49. A Mixed Group.

the edges of the masses will be delightfully softened off and feathered down, so as to unite by an easy and graceful line with the sweep of the ground in the glades between them.

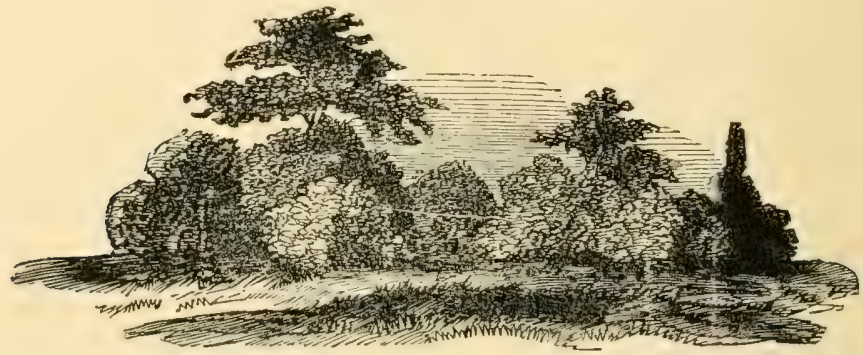

Fig. 50. A Good Picturesque Grouping.

It is something of this sort, in a humbler way, that is wanted in garden or home plantations. The sky line requires to be broken, but not in a hard or abrupt manner. Trees 


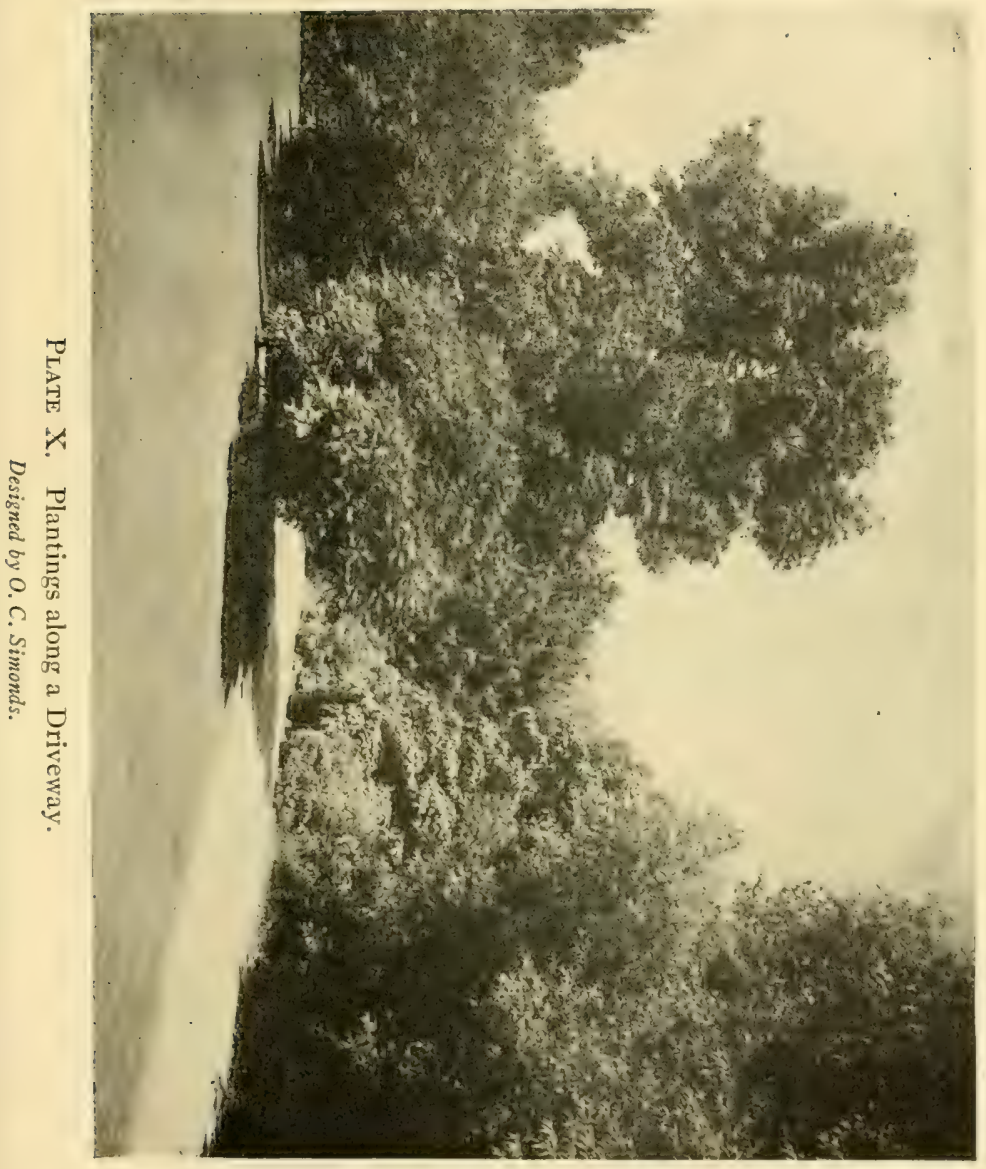



or shrubs should tower out, here and there above the rest, but they must not be unsupported. (See figs. 49 and $5^{\circ}$.) Their edges should blend with other forms by the softest transition. Boldness, as well as easiness of change, will be highly effective. But it should be like the bold swell of a general curve, composed, it may be, of several parts, but the outer of these gradually carrying down the line to the lower and humbler forms. Or, if the more spiry plants now and then find a place, as they may do most usefully, to give greater change and strength of character, they should not rise very

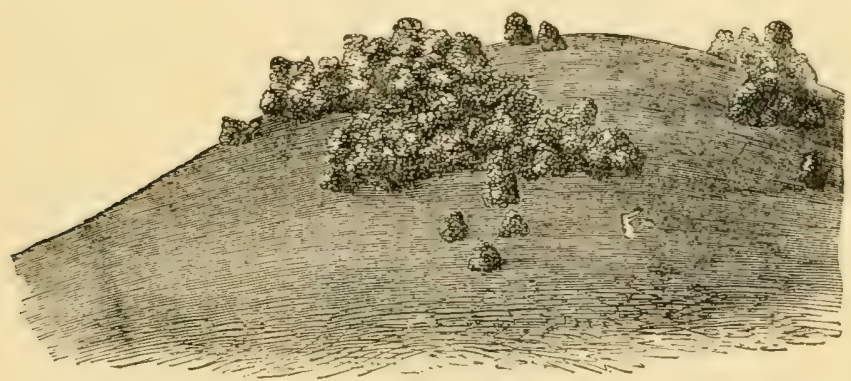

Fig. 51. How to Plant a Hill.

much above the rest and should appear to belong to a group of the more spreading and clustering kinds, like the spire of a church peering out from amid a grove of ancient elms.

On estates where there are sufficient variations of surface and extent of property to admit of the introduction of such a feature, a most happy effect may sometimes be produced by partially planting the summit and slope of an adjacent hill (fig. 5I), so as to convey the idea of large woods, of which the parts seen are but the straggling arms or off shoots lying behind and on the other face of the hill. And if treated with proper boldness and regard to diversity, such masses of 
wood, with their outlying specimen trees or bushes, will greatly enrich the hill and relieve it from any tendency to undue roundness or tameness of outline. An excellent mode for this treatment may often be seen in the delightfully picturesque and ragged patches of common trees with which nature sometimes clothes the faces of hills of a similar character, such masses nearly always presenting a remarkable freshness, freedom, and beauty of outline.

8. Herbacepous Plants. - In respect to the disposal of flowers in gardens, if we include in that term all the simply herbaceous kinds that are not shrubby, or at any rate merely such additional low shrubs as are grown out of doors only in the summer, a considerable reformation in the prevailing practice seems demanded. The beds or masses of shrubs on a lawn are often entirely surrounded with a strip of ground appropriated exclusively to the herbaceous tribes. The edges of groups are thus most defectively and tamely finished off; they have an exceedingly blank appearance in winter; the size of the lawn is materially diminished; and such borders can never, without a great deal of trouble, be very neatly kept. To compensate for all this, they impart a little additional gayety during summer, which might, however, be readily attained in other ways.

The desirable plan would be to dismiss all common herbaceous plants from the fronts of groups on the lawn, and to grow such flowers in a separate flower garden. The greater merit of this plan is nowadays widely accepted.

Not to banish the large class of herbaceous plants and bulbs which could not be thus brought together in beds, and many of which, more especially the spring-flowering species, are extremely interesting, I would grow them in the places usually assigned to them round all the masses of shrubs for the first three or four years after these were planted, and until they 


\section{Practical Considerations}

became fit to be surrounded wholly with turf, when the lower tribes might be consigned altogether to those back borders, which faced the side walks and were not seen from the lawn, or to such other parts of the pleasure grounds as did not come into view from the house, and of which the shrubbery walk will be an illustration.

It must be remembered, then, that shrubs which are but just planted and insufficiently established, will not bear turfing around for several years without injury. They require air to their roots to start them freely. And any neglect of this treatment, by turfing around them prematurely, will be productive of the very worst consequences. It has been known to retard their growth for many years, or even to go very far towards destroying them altogether. But they need not have a broad border for this purpose, and anything beyond four or five feet will be both superfluous and ugly.

By keeping the commoner herbaceous plants in such private parts as have been named, they may be cultivated just as fitly as if they were in the more exposed places where they are now usually grown. And they can thus be allowed a breadth of border which will give them a much finer opportunity of developing themselves, only taking care that specimen shrubs are brought forward singly or in groups here and there, along the border, to do away with all monotony and produce a little more freshness and life.

9. Flowers in Grass. - Certain kinds of flowers, especially spring bulbs, succeed admirably if planted freely in the lawn. Crocuses and daffodils are especially well adapted to this treatment, and give most excellent results. The poet's narcissus is a favorite for planting in the grass, but the trumpet varieties of narcissus are equally good, while even tulips and hyacinths may be naturalized in this manner with reasonably good results. In attempting anything of this sort the bulbs 
must be strewn with a liberal hand. They should be planted by thousands, - not by dozens.

Io. Specimen Plants. - Where a place is so small that there cannot be many single plants grown upon the lawn, to exhibit their full beauty and proportions, it will be a judicious plan to treat a number of the plants in the beds or groups mainly as specimens, that they may show themselves better and that the natural desire for individualizing objects of attention and watching and tending them during their progress may be duly gratified. Besides which, by thus making each plant a more or less perfect one, a way will be prepared for subsequently covering more of the soil in the bed with turf, and so increasing the size of the lawn, or ultimately turfing over the whole and leaving the best plants to stand on the grass.

The method of rendering individual plants shapely and fit to stand by themselves is very simple. It is not by planting so thinly in the first instance; for, however that plan might succeed in some soils and climates, it will more generally be found serviceable to plant rather thickly, in order to afford encouragement and shelter. It is by early and annual attention to thinning, and by preventing any one plant from intruding on another, whether as to light, air, or nourishment from the soil, that the best specimens can be reared. And though it may be prudent to put in at first such kinds of plants at such distances as will finally be required for fixtures and fill in between them with commoner sorts for a temporary purpose, it will be wise in thinning to choose rather those which have made a good healthy growth, and are not really inappropriate, than mere sickly objects which may have been intended to remain, and have not individually made progress enough, or do not exhibit sufficient promise to justify their retention. 
Sometimes, when persons have thoroughly imbued themselves with the notion that specimens are the chief thing to be desired in a small place, they gradually acquire the impression that nothing else is proper to be encouraged and that everything should be made into a specimen. This opinion, however, if fully acted upon, would lead to as much sameness and dullness as if nothing but dense and rariegated masses of plants were cultivated. The most beautiful combinations and the most exquisite variety will result from letting a few plants of different heights and characters grow together in some parts as they do in a state of nature, where bushes and trees often mingle their forms and are linked into closer union by the tangling clematis, lusty briar, or luxuriant bramble.

II. Thickets. - Towards the boundaries of a place the plants in a border, especially if it be narrow, will have to be treated still more generally, and with a less regard to their individual appearance. Here the aim must be to obtain a good undergrowth if there be trees, or to permit the formation of thickets where there are only shrubs. They may likewise be parts of an inner plantation or group, where peculiar denseness is wanted to cover some defect, or to make the walk more perfectly private; and in these the same characteristics should be cherished.

Thickets, besides being useful as screens to various objects, will be interesting both for the variety and beauty. They will form a great change from the more open method of culture, and exhibit much beauty of connection and contrast. There will be a luxuriance and a freeness and an indefiniteness about them which will not fail to please. It is not to be assumed, however, that such masses are intended to be as thick as the plants will stand on the ground, or to be left to a pure state of nature. In that case the stronger would soon overpower the weaker and the better sorts would die 
out, leaving serious gaps where they had grown, and a wildness and want of cultivation foreign to the character of a garden would speedily ensue. The term thicket is used here to define a plantation in which shrubs prevail, and where they are kept but sparingly thinned out, and are allowed to grow into each other pretty freely so long as they are not likely to destroy one another. It is a mass wherein the plants are so arranged, and stand so thickly, that it cannot be seen through, not one which has been produced by neglect.

Undergrowth will be chiefly, almost solely, requisite beneath trees which are growing so closely together that their branches cannot reach the ground, and the bare stems become prominent and unsightly in consequence, while the object of the plantation, as respects the concealment of a boundary, is defeated. Scarcely any plant is equal to the holly for undergrowth, since it will flourish under trees, and is not limited as to height, and is a thorough evergreen. Privet is superior as a rapid grower and of a denser habit, if not too much drawn up, but it is deficient in the size of the leaves, and in not being entirely evergreen. Rhododendrons thrive exceedingly well under shade, but require careful watering for a year or two. Common laurel will endure some amount of it, but are injured by an excessive quantity. All these are evergreen and of course so much the more adapted for filling up permanently the space under trees. Elders, dogwoods, the Norway maple, snowberries, and even lilacs, as deciduous plants, will thrive beneath shade, though they cannot be expected to bloom much in that position. The true secret of causing any of the plants mentioned to succeed permanently when largely overshadowed by trees lies in renewing the soil around and above the roots occasionally to compensate for the exhaustion produced by the more extensive absorption of its nutritive properties by the trees. 
I2. Evergreens. - As a garden will only contain a comparatively limited number of plants, it is a matter of policy to have a number of these evergreens, that in the winter season, when all else is so dreary, it may wear a moderately green and cheerful expression.

Although evergreens may fitly thus prevail in a place, it will be unwise to cultivate them to the exclusion of deciduous shrubs. The latter by their lighter foliage and sprightlier manner of growth and showier flowers seem to be the natural bodying forth of summer's richness and gayety. And this glorious season would scarcely appear rightly attended and adorned without them. They are indeed as thoroughly the life of summer as evergreens are of winter; and perhaps, of the two, the absence of winter's decorations would be least regretted by the mass.

Nor must the higher forms of deciduous plants, which take the shape of low trees, be at all omitted from our consideration. These and a few of the more striking and peculiar kinds of larger trees - such as the purple beech, the variegated sycamore, the scarlet oak, the lombardy poplar, and numerous others - will be invaluable in the way of contributing variety and improving the outlines. It will be sufficient to mention laburnums, almonds, the extensive and deeply interesting tribe of thorns, the double cherries, double peach, and douls?e almonds, the sumachs, the Pyrus spectabilis, the bird cherry, the mountain ash, and the service berries.

I3. Garden Architecture. - The subject of architectural gardening has been incidentally discussed in relation to the geometrical style of treatment and in other parts of this book. But the feeling for it is one that is so rapidly growing, and so little sound knowledge of its details is commonly possessed; that a few additional particulars and illustrations 
become essential. In adverting to it, however, I am tempted to make a short incursion into the territory of a neighboring profession - architecture - with which indeed it is so closely connected, that it would be impossible to treat of the one without trespassing on the other.

Gardening and architecture, like all the fine arts, have much in common. And that department of architecture which belongs more exclusively to the garden has especially a great affinity with gardening in its broader principles. In fact there is much more relation between the two than is usually admitted or the ordinary products of practitioners in either art would at all justify us in believing.

Architectural decoration is not, as many would assert, unfitted for English or American gardens, because stone gets speedily weather-stained and sobered down in color, and the fine evergreens and beautiful grass of these countries will, in association with architectural objects, impart sufficient warmth of tone.

Modern tendencies in gardening have been too much away from its character as an art, and the more it is restored to its legitimate position the more nearly will it be brought into kindred with architecture. On the other hand the too commonly cumbrous, regular, and unyielding nature of architectural objects, when used for garden decoration, has tended still further to detach two pursuits which are essentially and obviously allied. For as a house and a garden are naturally and intimately associated, and it is a law of the universe that the boundaries of each domain in the natural kingdom should insensibly mingle and be lost in each other, so it is plain that an unvitiated taste would be most gratified when the province of architecture is extended so as to embrace lightly and harmoniously such parts of the garden as may be most contiguous to the house; while the garden also in these parts 


\section{Practical Considerations}

rises in character to meet the requirements of the architecture, until either art is so refined and attenuated that it would be most difficult to say what belongs exclusively to each.

Still, there is that about gardening, which in the nature of things, and apart from the difference of the materials with which it has to deal, constitutes it a distinctive art. And garden architecture has lineaments of its own so decidedly removed from those of house architecture, and so seldom studied, that the ordinary architectural practitioner is at sea the moment he enters the region of the garden. It is less a matter of rule and measurement. Its effects are more to be judged of by the eye. It comprehends a far greater variety of combinations. It requires a man to be as much an artist (at least in feeling) as an architect, and to be familiar with natural groupings and tones, - to take in an entire landscape in the range of his design, and not merely isolated or detached objects. In fact the garden architect has to make a general picture and not simply to set a work of art, as it were, on a solitary pedestal.

The province of garden architecture is primarily to supply fitting appendages and accompaniments to a house so that the latter may not appear naked, alone, and unsupported. If judiciously applied it will be effective in helping to produce a good outline or group; to carry down the lines of the house; to connect it with other buildings, such as a conservatory, arbor, etc.; to provide a proper basement for the house; to afford shelter and privacy to a flower garden; to extend the façade or frontage of a house; to shut out back yards, offices, etc.; to enrich, vary, and enliven the garden; to supply conveniences, such as shelter, receptacles for birds, plants, sculpture, etc., with museums for works of art or specimens of natural history, and supports for climbing plants; to indicate refinement, wealth, and a love of art; and otherwise to blend 


\section{I64 Landscape Gardening}

the various constituents of a garden with the house and harmonize the two by communicating a more artistic tone to the garden.

Wing walls to a house, broken by a conservatory, and terminated by a summer house, aviary, museum, or sculpture room; corridors, similarly broken and terminated, and glazed or open so as merely to form covered ways; viaducts, aqueducts, arbors, arches, arcades, tunnels, boathouses, temples, prospect and flag towers; with an almost infinite number of smaller objects, such as sculptured figures, sundials, statuary, pillars, obelisks, terrace walls, etc., constitute the elements with which garden architecture has to work.

In its leading traits it necessarily comes within the same category as house architecture, and is governed by the same principles. Like the house it should exhibit design, some degree of symmetry, harmony of parts, unity of expression, consistency of style, fitness for the locality, adaptation for the intended purpose, and stability and permanence of appearance.

But it should also display a greater amount of lightness and elegance; a comparative absence of regularity; a decorative rather than an exclusively useful purpose; a superior variety of outline; extreme attention to general grouping; a blending of its forms with those of nature; an especial regard for placing its creations where they will have a distinct meaning and object; a leaning to the use of good materials, but somewhat rougher than those employed in the house; a preference rather for a picturesque outline than for mere ornamental details; and, as a most important characteristic, a marked boldness and prominence of parts. Indeed, picturesqueness, such as would be occasioned by changes of level in the ground, by diversity in the heights of walls, by prominent piers, buttresses, or cornices, by broad projecting 


\section{Practical Considerations}

eaves to the roofs of buildings, and by any arrangement that will yield depth of shadow, should be the ruling constituent of garden architecture.

Every architectural object admitted into a garden should form part of the general plan of that garden and fit into its proper place. It will create a serious incongruity if merely put down at random, or not duly established as a part of the main design. Smaller architectural ornaments, too, must be adequately connected with and kept in the neighlorhood of the house or other sufficiently important building, otherwise they will be too different from the forms of nature to appear harmonious.

A strictly garden building or object, unless very large, should never be obtrusive. It ought always to be quiet looking, and not violently different in color from the surrounding vegetation. Hence, white, whether in marble, stone, or painted objects, is decidedly to be avoided, and a warm drab or darker tint preferred.

When a terrace or other ornamental wall - whether balustraded or otherwise pierced, or simply deroid of any relief in the way of openings - becomes the principal foreground to a garden or other scene, as viewed from the windows of the house, it will appear too hard, cold, monotonous, however much it may be broken up by piers, vases, etc., without some aid from grass and shrubs. In all such cases, therefore, there should be a broad band of grass between the terrace walk and the wall, and a few clusters of evergreens, rising in broken matses above the line of the wall, or of climbers mantling its summit in occasional patches, will require to be skillfully introduced; otherwise the wall would seem to divorce rather than mingle with the landscape beyond.

To pass from the consideration of garden architecture, which, however seductive a topic, scarcely falls within the 


\section{I66 Landscape Gardening}

range of this work, I now return to the subject of architectural gardening. Its distinctive principles are as follows: a strict observance of rule; a prominent indication or exhibition of art; the maintenance of a decided harmony and connection with the house and other architectural objects; the adoption of regular figures; the employment of rigid, formal, and exotic plants; the necessity for flat and even surfaces, with the use of terrace banks or extremely regular slopes; and the production of a conspicuous character of dignity and repose.

The proper field for architectural gardening is the immediate neighborhood of the house; as an accompaniment to particular styles of architecture, especially the Italian; in connection with detached architectural structures, as temples, plant-houses, etc.; within the circuit of the flower garden, parterre, rose garden, etc.; in the gardens attached to a palace, mansion, or first-class villa, rather than to a small villa or cottage residence; the kitchen garden; and, where the circumstances are favorable, the town garden.

There are certain incongruities and defects which frequently attend the practice of architectural gardening and which should be sedulously avoided. Some of these are the mixture of inharmonious styles; the use of rustic or unarchitectural ornaments, except in remote parts, and where they will not be observed as constituents of the general scene; the placing of terrace walls or other construction on a sloping bank, or where they have shelving ground immediately below them; the extension of a formal mode of treatment into the park; generally the obtrusion of a flower garden into the view from the principal windows, unless it be on a lower level than the base of the house; an avenue or row of trees that crosses any main line of view, or one on the summit of a hill that forms the line of horizon; a curved avenue, unless it be obviously laid in the arc of a circle; a ground line 


\section{Practical Considerations}

that is oblique to the basement of the house, on either of its chief fronts; diagonal lines of walk on lawns, or walks crossing or starting from other straight walks at any but a right angle; plants trimmed into formal or grotesque figures, unless it be the heads of standards, plants with naturally appropriate habits, or confined in tubs, being preferable; gravel walks, in flower gardens, that are inaccessible; monograms, or very intricate patterns, in which the beds are too small to admit flowers, for parterres; and the employment of pavements, gravels, or sands, of different colors, in the place of flowers, or merely for producing variety or contrast.

Among the most characteristic details of architectural gardening prominence should be given to terraces; broad, flat, and conspicuous walks; extreme smoothness and polish; changes of level effected by formal banks or walls; raised beds and sunken panels; avenues, vistas, rows of flower beds; walks and vistas terminating with some proper object, as a temple, obelisk, pillar, etc.; rectangular forms, or those in which various segments of a circle are combined; with a sunk fence and parapet wall as boundaries to a garden.

There are likewise many desirable accessories, of which a few may be noted. These are as follows: a sufficient breadth of open lawn between the house and the park; a detached flower garden, with accompanying plant houses, or walls for ornamental climbers, and the opportunity of looking down upon this garden from a raised terrace; a rose garden, in a retired spot, with attendant rose house or houses for delicate sorts; a winter garden, to be filled exclusively with evergreens, the beds arranged in pattern, with a due admixture of specimens, and all the plants selected with reference to their habits and the color of their foliage in winter; a garden for bulbs, florists' flowers, etc., in some spot which need not be made accessible during the winter; standard or fastigiate 
plants; plants that blend best with architectural objects; groups or beds of plants, in which one kind or class prevails; and hedges, whether to frame and enclose scenes that it is wished to detach, or, in a diminutive state, to make borders and edgings to flower beds and clumps.

In applying practically the principles of architectural gardening it should be remembered that, as extreme irregularity is a merit and a beauty in most kinds of Gothic architecture, the garden accompanying it will also bear to be treated in an equally irregular manner. But in relation to any variety of Grecian or Italian house, the garden, like the architecture, should be more distinguished by symmetry and regularity. Architectural gardening would be out of place in connection with a house inferior in design, or destitute of character and style. It is peculiarly suitable for a tame and smooth general landscape; but is quite admissible, for contrast, in a picturesque, bold, and wild region. It especially demands that everything should be good, and nicely finished; that the plants shall be of the best and most carefully selected kinds; the grass evenly laid; the figures, and beds, and edgings of walks neatly and accurately cut; the gravel fine and well laid and its smoothness not obviously broken by gratings. The edgings, too, should all be particularly shallow, the edges of terrace banks quite square and even at the top, and the soil in the beds and clumps very slightly raised above the level of the lawn. The spaces for specimens, flower beds, and masses of shrubs should, moreover, be cut out of the flat lawn and not have the grass curved up to them as in the more natural style of treatment. And all the lines, whether of walks or other edgings, ought to be extremely straight and regular, thoroughly well beaten and level, and the grass be very fine and smooth.

In making terrace walls where they do not run along the 
principal front of a house, or are far enough from it not to come into absolute connection with it there will sometimes occur a slope, of greater or less steepness, at the base of the wall, such as scarcely any ingenuity or any labor would suffice to get rid of, and where it is most difficult to reconcile the discrepancy between the raking ground line and the level courses of the wall or of the house. Fig. 52 will afford a hint of the way in which I have dealt with a case of that sort by keeping all the ground lines, where they are in grass, exactly parallel with the courses of the wall, and effecting the changes

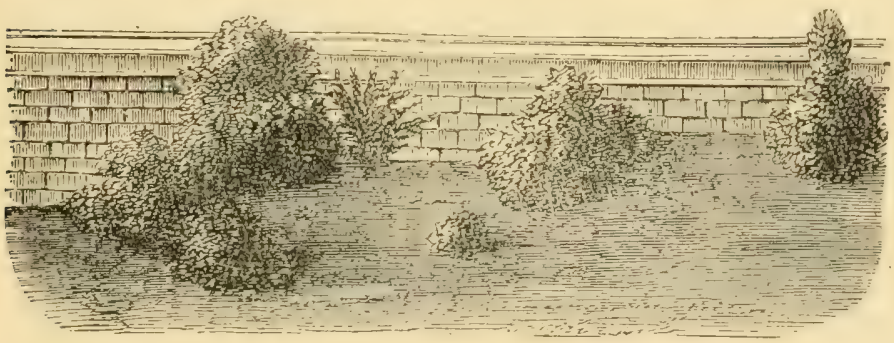

Fig. 52. Terrace Disguised by Plantings.

of level in the ground at the points where patches of shrubs are introduced. These shrubs, being mostly evergreen and in varied groups, not only mask the breaks in the ground line but blend beautifully with the wall, and, aided by a few intermerliate climbers, clothe it most picturesquely.

The practice of employing masses of evergreens to cover changes of level in grounds, to break the transition between a terrace bank and a natural slope, to fill up the corners of terraces and relieve the hardness and bareness of their walls, and in many ways to reconcile discrepant lines in the form of ground, is one which I have largely and for several years adopted. And I have invariably found it of the greatest 
possible service, while the result obtained from it is always satisfactory. Indeed, this seems to be the only feasible and really thorough solution of a problem which every practitioner who has to direct the shaping of ground about houses must be constantly encountering.

As an elaborate example of architectural gardening, on a tolerably extensive scale, I may now introduce fig. 53 , which depicts a portion of the pleasure grounds which I arranged a few years ago for John Naylor, Esq., of Leighton Hall, near Welshpool. The smallness of the engraving unfortunately renders the minor parts of the plan very indistinct and prevents me from giving the full details of the treatment. Enough of the entrance front is shown to indicate that there are two roads of approach and a large graveled space on the west side of the house; and from this front the terrace (I) and the flower garden (5) are screened by a handsome stone wall, which, like the house and all the other walls, is composed of a nearly black species of trap, with white freestone copings and dressings. The terrace (I), which stands about three feet above the lawn and is supported by a neat parapet wall, extends along the northern and eastern sides of the house, and in front of an ornamental wall connecting the latter with a camellia house (9) whence it passes eastward and terminates against a steep bank, the walk ranging round a raised bed of evergreen shrubs (II) with a stone edging to it. There are steps and communications from this terrace at various points with other parts of the pleasure grounds. The kitchen court is at 2 , and 3 points out the back approach to it.

A leading walk from the terrace, opposite the principal tower of the hall, conducts us over a viaduct (4) of several arches to other important walks not included in the plan; and from the viaduct there is a view of the winter garden to 


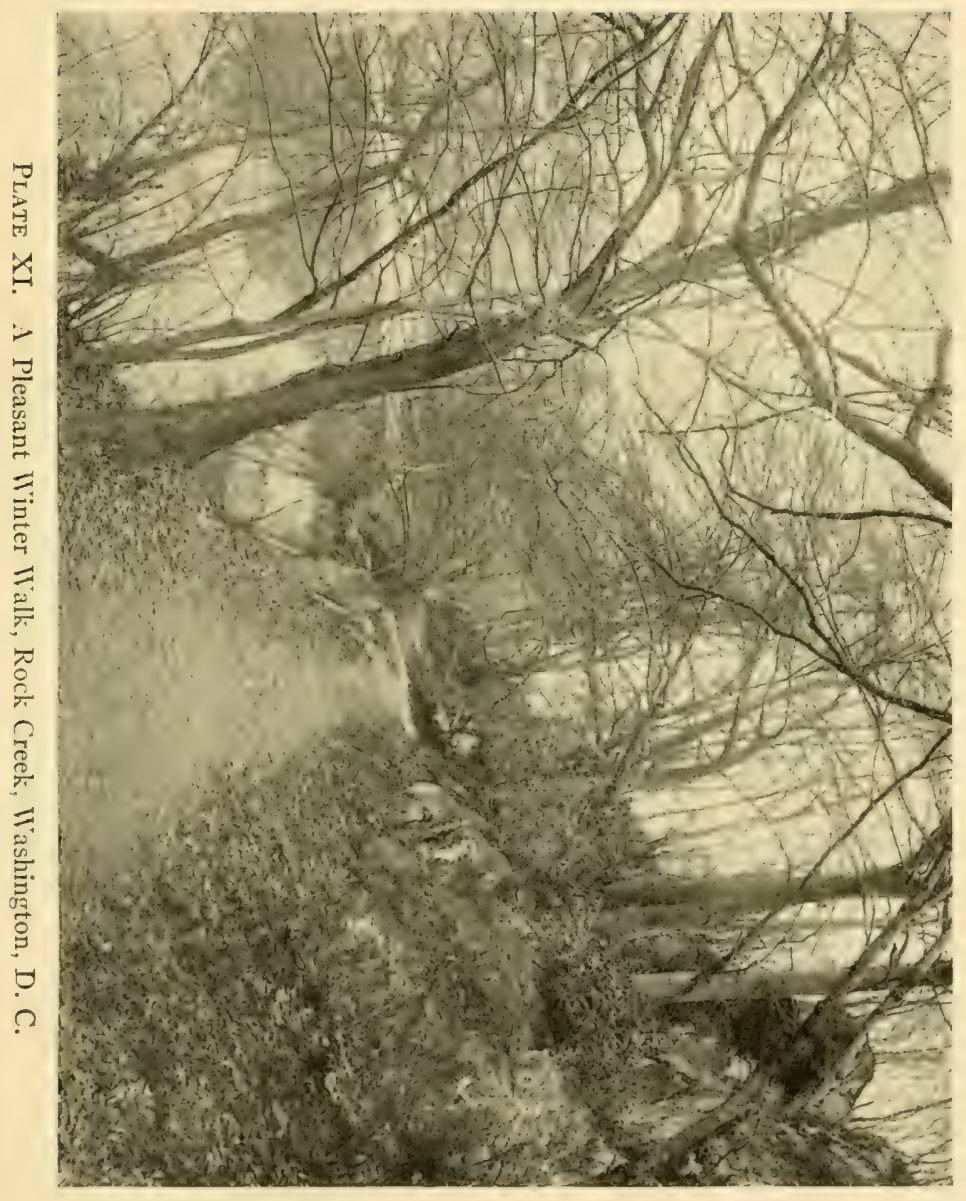





\section{Practical Considerations I7I}

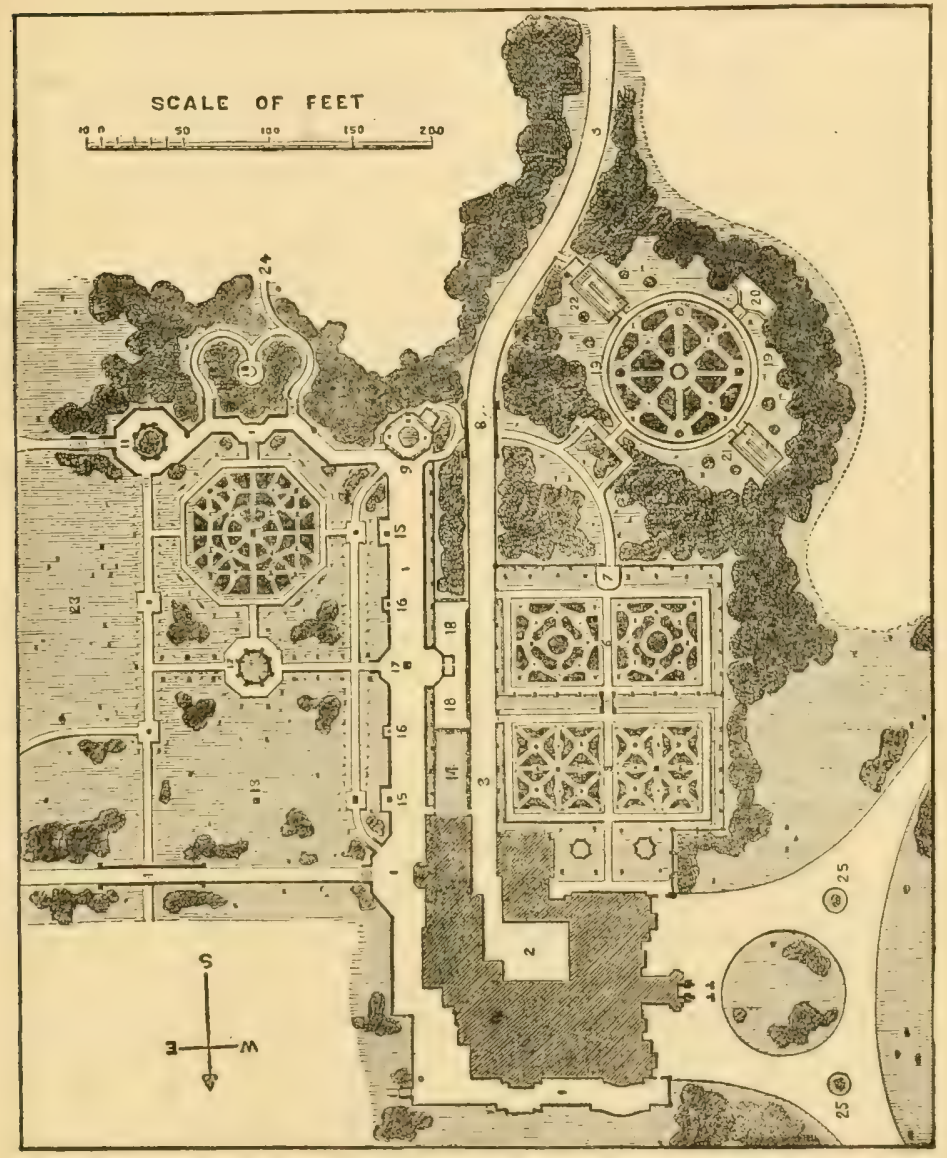

Fig. 53. Plan of an Architectural Garden. 
the south, and of a small irregular lake on lower ground to the north. The flower garden is at 5 on the south side of the house, and is enclosed by an ornamental wall about eight feet high with buttresses. It is divided into two parts, separated by a terrace bank and a low wall with vases upon it; the part 5 being intended for purely summer flowers, in beds of one color, while the upper half (6), which is four feet higher, is designed for mixed herbaceous plants. The whole is diversified with specimen plants and vases, and the center walk is terminated by a summer house through which the walk passes between high banks clothed with rhododendrons and beneath the back road by a small tunnel (8) till it emerges through a door in the wall on to the terrace at (9).

From the southern arm of the terrace an ascent is made by steps and an inclined walk, to a raised mound (Iо), on the summit of which, twelve or fourteen feet above the general level, is a canopied seat, from which there is a view of the winter garden and the principal part of the pleasure grounds. A branch walk from this elevated point descends rapidly into a narrow natural valley, commencing at 24 , through which the walk winds, the banks being covered with rocks and roots as receptacles for ferns and similar plants. At I2 is a basin of water, in which is erected a very costly fountain, composed chiefly of bronze figures. The walk to the east and west of this basin has on either side of it a row of small groups of statuary on pedestals alternating with specimen evergreens; and the octagonal figure between I $_{2}$ and 10 is furnished and surrounded by beds and specimens of the greatest possible variety of dwarf evergreens arranged as a winter garden, the wall at the back of the eastern terrace being also covered with evergreen climbers. At $\mathrm{I} 3$ and in a corresponding position at the center of the winter garden it is proposed to put large groups of bronze figures, on pedes- 
tals, and the squares which will be noticed in the walks to the east and west of the winter garden contain vases on pedestals in their centers. The ground falls rapidly from I 3 towards the viaduct (4) and continues to descend on the northern side of this latter. At I4 is a drying ground, and I8 a yard for receiving rubbish and for the gardener's use, there being also a small tool-shed between it and the terrace. The kitchen garden, garden yard, and sheds lying at a considerable distance, and being on very much higher ground, it is convenient to have the means of depositing rubbish and storing tools at this point.

Several projecting parts or bastions, for the purpose of obtaining more variety, are made in the principal terrace, and the effect is further heightened by the introduction of vases into these. At I $5_{5}$ are two urn-shaped vases of Aberdeen granite or other dark material, while there are two sundials on white stone pedestals at 16 and a large white Warwick vase at $\mathrm{I} 7$.

The walk between 7 and $\delta$ is, as has been mentioned, cut through between high banks, the natural level there being twelve or fourteen feet above that of the flower garden. Flights of steps ascend from this walk to a detached space (I9), which was arranged for a rosary. In the center of this plot is a basin of water, intended to be canopied by a wire temple for supporting climbing roses which would thus be reflected in the water. At 20 is a rustic summer house with an open porch from the principal walk to it, and this was to be the medium of exhibiting the freer growing and more rambling kinds of climbing roses which would scramble over both the sides and roof of the summer house. Two spanroofed glass houses (2I and 22) were to be placed at the sides of the garden, for receiving the more tender sorts of roses, the one house (22), which is nearest the back road 
being heated, and the other not. It was proposed to plant out the roses in these houses, and train climbers also to the rafters, and use the low external wall for supporting the dwarfer and more delicate varieties. The beds in the rosary are arranged to receive one family each, and space is allotted for standards and pole roses, the whole being screened from the back road and the park by a plantation, chiefly filled with evergreen shrubs.

The ground at 23 rises rather abruptly towards the east and becomes an appropriate position for accommodating some of the finer members of the coniferous tribe, which, being scattered in groups on this grassy bank, show themselves to advantage, and associate well with the winter garden. They are backed, as is the whole of the pleasure ground to the east and south, by an old wood of oaks, larches, and spruces. The small circles at 25 enclose two specimens of the Cedrus dcodora, and there are masses of evergreens and a very picturesque old oak in the larger circle. 


\section{CHAPTER VI}

\section{Particular Objects}

ANother step towards what is practical has now to be made. Several peculiar and more definite objects which could not with propriety be called general because they apply to special cases and less common circumstances have here to be discussed. And in thus traveling towards minuter matters, I cannot do better than begin with noticing the influence of little things on all questions of taste.

I. Small Matters. - As most of the comforts and all the elegancies and refinements of life consist in attention to numerous small matters which are in themselves insignificant but which together compose a beautiful and agreeable whole, so the expression and character of a garden will be cultivated and tasteful or otherwise according as its minor features are well arranged and well executed. It is surprising how much a few trifling objects or circumstances may do in the way of imparting tone to a place. There is comparatively little difference between the mode in which a first-rate artist and an inferior one would work up a picture consisting of the same elements, but in that little what a world of meaning and expression might be conveyed! In laying out a garden, too, where much the same general features have to be dealt with, how much alike, yet how very distinct, would be the products of an untutored and unskillful operator and the creations of the studied, practiced, and delicately perceptive lover of art.

A lame or imperfect curve; an artificial or abrupt connection of lines in reference to raised ground; deep and clumsy edg- 


\section{i76 Landscape Gardening}

ings to walks; the arrangement of plants in rows in irregular gardening, or the occurrence of three conspicuous specimens nearly in a row upon a lawn, where a decided line is not sought; plants that should be in a row, at all cut of the line; specimens not placed exactly in the middle of a circle, or planted with an inclination to one side where they ought to be upright; wavy lines in near and parallel association with such as are straight; unmeaning and sudden inequalities of surface in a lawn; - these are things which are of very slight moment, regarded individually, but of great and weighty influence upon the general character of a garden.

Where a pleasing and refined expression is aimed at, then, there must be no fancied superiority to little things, no neglect of the elegancies of finish, no inattention to the most delicate propriety. And the less perfect and effective a garden is, the more will it be necessary to consider and polish the most minute of its parts; for, while striking and extraordinary things may pass off a few deficiencies without exciting observation, such as are of an inferior and more commonplace stamp will need all the aid they can derive from minor details to preserve them from the lowest mediocrity.

2. Mounds and banks are features with which a great deal may be accomplished in a garden, if they be properly treated. As frequently met with, they are the greatest possible eyesores, altogether destitute of beauty and having no visible relation to the general surface. They are commonly either long straight ridges or banks, such as a hedger would throw up, only with the sides softened away; or are mere lumps of earth, pretty nearly resembling compost or manure heaps.

The commonest use of mounds to-day in America, and doubtless the best use - if indeed not the only legitimate employment - is to form a closed boundary about a garden or park. Such a raised border mound will nearly always be 
completely planted with heavy masses of trees and shrubbery, so that the minute conformations of its design will not greatly affect the visible result.

The great point to be attempted in mounds is some degree of naturalness and connection with the other parts of the ground. They should not at once show that they have been put in their place by art, and solely for some purpose of convenience. But this they always will do when they rise suddenly from the ordinary level and do not at all appear to belong to the rest of the ground. In nature, where swells and undulations of mere earth occur, without any rocky constituents, the greatest possible softness and extenuation are perceptible in the lower lines, which blend with the surrounding land in the most gradual manner. And even with rocky hills the contour lines are mostly gentle, except in a few rugged parts, and the base, by its natural formation or by the constant accumulation of soil and fragments washed from above, is usually carried out with a gracefully prolonged sweep till it blends with the hollows or plains.

To realize much of natural freedom and still more of beauty a raised bank or mound (always excepting a terrace bank of which I do not treat in this place) should be varied in its ground outline and have more or less undulation on its surface. A bank that is backed by a wall need be no exception unless it is to be covered with grass, when it should be managed as a terrace. Hard and straight lines never look well in contact with flowing ones, but if the bank is to be planted the wall will be hidden.

For the outlines of a mound or bank intended as the groundwork of a plantation, the directions given a few pages back, for shaping masses of plantings, generally will apply just as forcibly here. They should be bold in some parts, always free, adapt themselves to the form of walks, or the 
intended shape of a lawn, and to the objects for which they are made, becoming broader where large and ugly things have to be concealed, and narrower where they are less urgently wanted.

In shaping the outlines of any raised masses of earth, a correct and practiced eye will be the safest guide. Nevertheless, it may be remarked that all the more prominent and higher points should also be the fullest, the roundest, and the steepest, while the retiring parts can be scooped out and sloped back into a kind of hollow basin. This is the shape almost universally found on the face of natural hills, where fullness and precipitancy are the common attendants of the more forward projections, but are seldom or never seen in the recesses. The reverse of all this in gardening is among the worst features that can be introduced. Concavity should be rigidly adhered to in all the receding portions of mounds.

Perhaps the most influential characteristic of an artificial bank is its being well tailed out into the ground, and by a decided under curve. There can be no resemblance to nature without this. It gives the very crowning stroke of finish and grace. But as this point has been more than once previously insisted on it does not demand further pressing.

Much of the success of any efforts to vary and undulate banks of earth will turn upon the way in which they are planted and the turf is brought up their faces. The boldest swells require to be as boldly planted, that is with the tallest description of plants admissible. The smaller elevations and the hollows can be planted with smaller varieties, thus making the entire range a series of undulations on the surface of the plants, as well as that of the ground, the first corresponding in a great degree to the last. Along the fronts, also, the plants should come much lower down on the fuller 
parts, so as to increase the effect of their fullness; and any weeping specimens, or such as naturally send forward their branches in a more horizontal direction, should be placed here with the same object. In the hollows or bays, on the contrary, the planting should retire nearly to the upper surface of the mound, the turf, of course, following the line of planting within a foot or two in both cases. Grass may even be carried over the edge of the mound in some of the hollows, and so far across it as just to leave room for a few shrubs to cover the wall or fence that may happen to be behind. Or, if there be nothing to conceal, some of the lowest hollows may have a glade of grass carried entirely across them, which will greatly relieve and lighten a lengthy range.

According to the several purposes for which mounds are used should be their ordinary treatment. If for covering boundary fences they ought to be almost entirely planted and should also be continuous. Where they are placed between parallel walks, to separate them from each other, if they are of any length, several of their hollows can be turfed through, leaving a low specimen plant or two on the grass irregularly in one or two of them. They may also have more of undulation than those of the former class. If a mound be made to furnish a good view of the garden or a prospect of the neighbouring country from its summit, great height should never be attempted in a small place, and it should, if possible, form part of a range that it may not appear too conspicuous and unconnected. The breadth must constantly bear some proportion to the height or it will seem glaringly artificial and a mere conceit. Besides it will be difficult to convey a walk to its summit unless there is some breadth to wind around.

Such a mound as the last-named may be partially planted 
with close tufts or clusters of shrubs, to cover the walk, and shut in some parts of the view. A few low trees more sparingly dotted about will contribute to give it stability and character. The walk should of course be quite narrow, and may ascend by a zigzag route on one side only, or by curving round the entire face of the mound. It might appropriately be composed in its steeper parts of easy flights of rustic steps.

3. Shapes of Trees.-Among the trees adapted to associate with different styles of buildings there are three distinct classes easily recognizable by the particular shape their heads and branches assume. The first and largest group produces roundish and clustering heads, when their full growth is attained. The oak, the ash, and the English elm are familiar examples. Another set much more thinly scattered send out their branches horizontally throughout their whole height. The cedar of Lebanon, the varieties of fir or spruce (not pine), the yew less perfectly, the larch, and the deciduous cypress in its usual state, will illustrate this section. The third tribe which has very few members consists of upright or fastigiate trees. The Lombardy poplar is the commonest instance, though the upright elm is another very good example. If such as have pointed or spiry heads be included, many of the second class will come within this also, - the firs especially. Larch, and several round-headed trees, in their younger state, before the upper branches get dense and spreading, will give a pretty clear idea of spiry-topped trees.

Repton, in his Sketches and Hints on landscape gardening, lays it down as a general principle that round-headed trees harmonize best with Gothic forms of architecture, and trees of spiry shape with Grecian buildings, on the ground that the horizontal lines which prevail in the latter style, and the perpendicular in the former, are best exhibited 
and relieved by contrast with vegetable forms of an opposite character. Without questioning the soundness of the rule, which appears quite unexceptionable, it may be doubted whether, in the case of Grecian and Italian structures, at least, the appropriateness of the fir and cypress tribe is not the result of association. The cedar of Lebanon, the branches of which are purely horizontal, is the most magnificent of all accompaniments for any variety of Grecian architecture, but is not at all suited for either of the forms of Gothic. And so perhaps the old ancestral elms and oaks in which many an English Gothic house is often embosomed may, by the commonness and antiquity of the usage, have given a propriety to the employment of that kind of tree in relation to all similar edifices.

Still if it be admitted that certain descriptions of trees accord with the forms of certain architectural styles, it may be fairly assumed that the use of those trees in such situations had its origin in their fitness, or supposed fitness, for the purpose; and that, though they may be peculiar to any given country in which the style of building to which they are now allied preponderates, or has at some former period prevailed, that very style may have been founded on its adaptation to the natural characteristics of the country, trees not being among the least significant of these.

Possibly I may not be far wrong in accounting for the connection which has somehow sprung up between particular classes of trees and particular styles of buildings, by a reference to the character of the leaves rather than the distinctive lines of the branches or heads. Light, thin, and feathery leaves characterize all the plants that look best when in contact with the varied class of Grecian structures, - the heaviness (or rather massiveness) and regularity of Grecian forms demanding some such contrast and mitigation. Gothic build- 
ings, on the other hand, already light and playful, full of variety, and abounding in small decorations, require more of the depth and breadth of foliage for which round-headed trees are conspicuous, to bring out their elegance, and impart at the same time a more substantial character.

Trees can, without impropriety as to appearance, be placed nearer to a Gothic than a Grecian house. Gothic architecture is rather improved by a framework of trees; Grecian only just tolerates them. With either style, however, the sudden dip of the building to connect with it a low wing, or the equally abrupt rise to form a tower, may often be softened with advantage by the introduction of a good and appropriate tree in the angle, if this does not cover any window or other detail of consequence. In the same way a suitable lower plant or shrub or group of shrubbery in a deep angle of the building, or at a very bare corner of it, will sometimes divest it of a cold and naked appearance, and adorn rather than deface it. If one corner of a building stands higher above the level of the garden than the other, as will sometimes be the case on sloping land, it will particularly require help from a good large shrub or group at the corner that rises most out of the earth, to give it the requisite balance.

The high ends of buildings frequently demand some kind of plants to support them, and take off the hardness of their edges. No building should appear altogether naked and alone, but should form a constituent part of a landscape. If the lines therefore be not duly carried down in the building itself and blended with those of the ground - a thing which can very rarely be accomplished - the effect of connection should be attained by accompanying trees. Where a house is placed on a knoll, mound, or other kind of elevation, some such assistance becomes all the more essential. But the trees need not in all cases approach closely to the end of the build- 
ing, as enough of union of lines and balance of parts may be produced by placing them at a little distance from it.

No subject perhaps is less studied by landscape gardeners, or occasions more alarm in the mind of an architect, than the necessity that exists for assisting the effect of houses by the felicitous introduction around them of a few trees or shrubs at the right points. Without some such help, a house might almost as well be in a town as in the country, and the most artistic combination of parts will fail to satisfy a tasteful observer, unless there blend with the building, at certain intervals, larger or smaller patches of green foliage. Even a mansion of the highest and most classical kind will not be exempted from this rule.

4. Grouping. - To produce strong and striking effects in a garden there must be not merely a tolerably varied collection of plants disposed so as to give variety and contrast, but groups of particular kinds should be planted in prominent places that occasional broader masses of a peculiar form or color may be obtained. From three to six or even eight specimens of some showy kinds may thus be planted in an irregular group at any jutting point in a bed or on some swell of a mound, and will create a very striking impression by their foliage or flowers. They should be placed near enough to each other to grow into a thicket without injury to any of the plants, that only one dense mass of heads and none of the individual stems may be seen, and that the effect may be more like what one immense specimen would yield.

The effect is even better if plants of more modest and less conspicuous character be used in much larger masses. Spireas, dogwoods, viburnums, and the like (native plants especially) can be used in decided profusion. This is one of the great discoveries of twentieth-century landscape architecture in America. 
For smaller plants and even for annuals the plan is fully as suitable. Every one is now aware what splendid displays are created by the various kinds of half-hardy plants with which gardens may be decorated in masses during summer. Some things in fact which would when solitary be almost contemptible acquire a marked showiness if collected into a group. And many annuals that are straggling and poor as individual objects become in broad patches (which is the best way of growing them) highly ornamental and handsome.

5. The Study of Shadows. - When planted on the sunny side of a garden or of any part thereof, trees and shrubs project a variety of shadows, which an artist would rightly esteem some of the most decided beauties of a landscape. Light and shade is what an architect of sound feeling always aims to procure in the exterior of his building, and the plan that secures a due admixture of these will be most praised and admired, other things being equal. In a garden scene, too, although this is a matter very little considered, an immense deal of the beauty will depend upon the nice arrangement of parts to secure these.

Open bursts of sunshine are not more essential, and are generally less effective, than shadows in a landscape. It is during showery weather, when gloom and sunlight are continually succeeding each other, and nature is shrouded in dullness one moment, but brilliantly illuminated the next when the outlines and motion of the clouds are faithfully pictured on the earth as they hurriedly sweep over hill and valley - that beautiful scenery becomes far more lovely and pleasing. And there must be a compounding of the same elements of light and shade in a garden to give it its last finish.

It will, however, be chiefly on the west and southwest sides of a place that the shadows will be most interesting. 
The sun is too high in the heavens at midday to occasion any but the smallest shadows, and those only to the very tallest trees. It is towards evening, when the stillness and softness of the air, or the glory of the descending sun, invite to a closer communion with nature, that shadows will be most conspicuous and most rapidly changing. The lines or grouping of western' and southwestern plantations should be particularly arranged with reference to their shadows, that these may be varied, but pleasingly rounded, and softly mingled. And as the shade from everything becomes exaggerated in its dimensions the lower the sun descends, there will be the more necessity that the upper lines of the plantations under notice shall be gentle, elegant, and finished, while the plants should rarely be very large, or their shade will cover the whole garden towards evening. If the full light of the sinking sun can be let in uninterruptedly through two or three openings on to the lawn, the result will be a more checkered and therefore a more beautiful one. There may be a large amount of pleasure drawn from this source by a devoted student.

Other sides of a place, though of less consequence in regard to shadows, will not be unproductive of them. On the south margin it must be a pretty high tree that will produce any very manifest effect, and large trees can be very little tolerated in that quarter. More than two or three, at distant intervals, would be decidedly undesirable. Further east a little may be done, but it must be set about cautiously for fear of creating injurious shade. All the specimens and groups on a lawn will, at some period of the day, give forth partial shadows, and this will be one of the advantages of varying their outlines and arrangement. As a series of only little patches of light and shade would be wearisome and distressing to the eye, this shows the necessity of having a 
good open glade of lawn, entirely free from plants, in another and vivid light.

6. Climbing Plants. - To furnish the means of growing to perfection the very charming tribe of climbing plants, beyond the always objectionable mode of training them to poles, there will occasionally be places in a garden where a small covered way, formed of wooden or wire trellis, can be erected and rendered both ornamental in itself and fitted for supporting a few choice roses, etc. Such an object may either be attached to the front of a wall, and be open only at one side, having a close roof, when it will be a good means of disguising a blank wall and, if attached to the house at one end, will make a dry and agreeable winter promenade. Or it may be in the shape of an arch, trellised all over and capable of sustaining plants on its entire surface. It may serve as a connecting link between the pleasure grounds and the kitchen garden, or from the general garden into any retired rosary, or flower garden, or other separate part, or even over one of the common walks, where the shrubs close in upon it on either side, and it will not be seen from the house. An arch or pergola of this kind will be very useful and pleasing. Wire is the most durable and wood the most effective material for composing it, and may be worked into any shape. It will possess more style if, in addition to the simple arch, it assume without heaviness or intricacy some rather architectural form, in accordance with the character of the house.

Anything in the form of a veranda, or an external corridor put in the recess of a house, would furnish another means of growing the better sorts of climbers; and would likewise, especially in very hilly or picturesque localities, or with reference to any house that partakes of a cottage character, or that would admit of such an accessory, assist materially in improving the outline and in creating effective masses of shadow. 


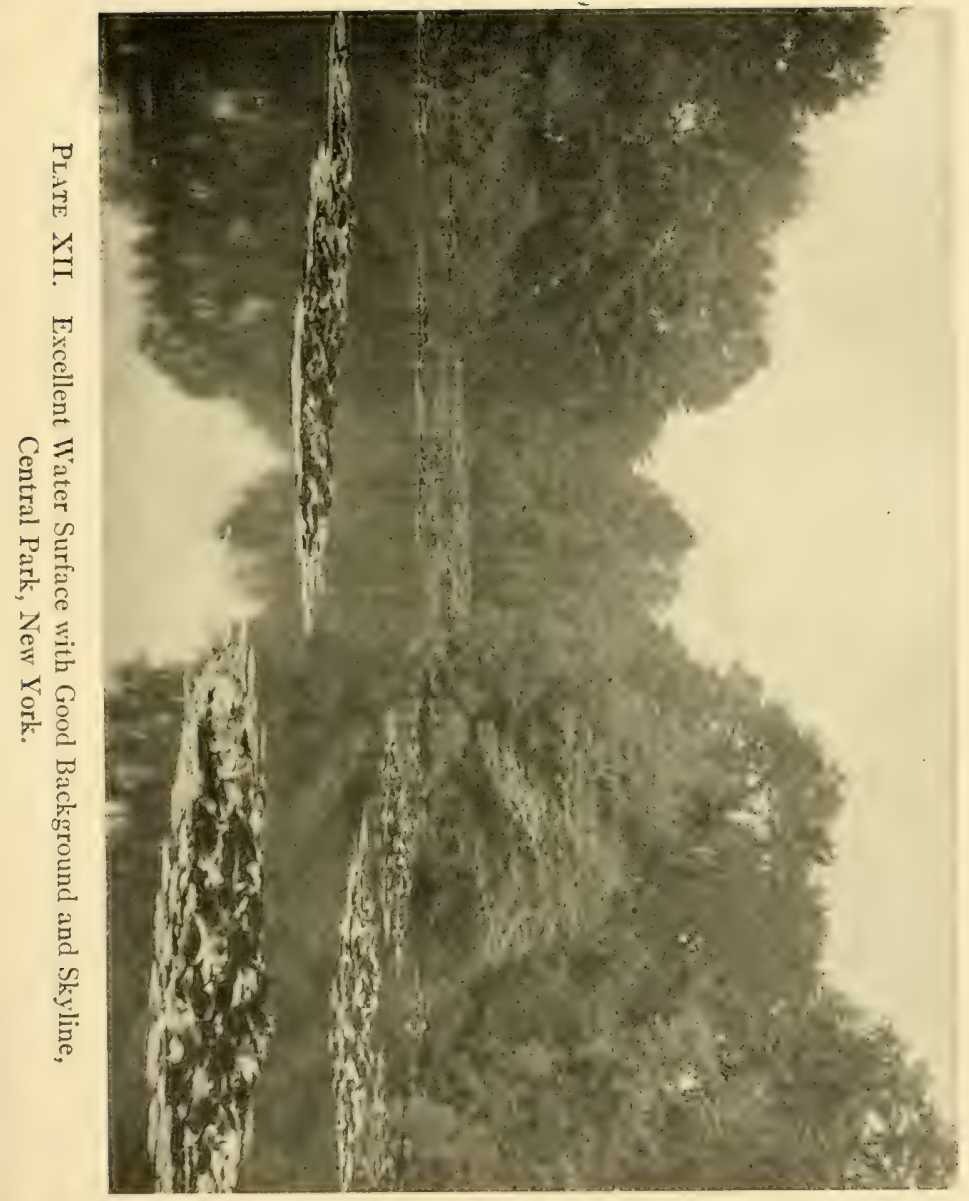





\section{Particular Objects}

If made sufficiently lofty, too, such verandas need not at all interfere with the admission of light to the windows of the house, and in summer, when the climbers would be in fuller foliage and more diffuse in their growth, the little extra shade they would occasion would be grateful rather than annoying.

For the center of a rosary or secluded flower garden, or in the middle or one corner of any formed flower garden that does not immediately adjoin the house, or at the end of a straight walk in some situations, a small ornamental temple or summer house, for training climbers upon, and supplying a summer arbor, will sometimes be a very pretty and pleasant feature in a garden. It should however be chaste in design and not at all elaborately decorated, being rather of a good general shape than ornate in the details of the pattern.

7. Flower Beds in Winter. - Lest the occurrence of a number of empty beds on a lawn or in a flower garden, where the system of massing summer plants is adopted, should impart to a place a bare and desolate aspect during winter, a store of the lower kinds of evergreens should be kept in pots and plunged in some part of the kitchen garden or in any reserved corner through the summer, to be transferred to the flower beds directly their gayer furniture has been cleared away in autumn. Such a plan is less troublesome than it appears to be, for if the plants be kept constantly in pots, summer and winter, and merely plunged in the ground, a simple repotting once a year, with an occasional watering in only the very driest summer weather, will be all the attention they want for three or four years, when they will require renewing by propagation.

The fittest kinds for the office will be several dwarf heaths, particularly the Erica carnea, Cotoneaster microphylla, Berberis aquifolium, Mensiesia polifolia, Andromeda floribunda, the common dwarf juniper, small spruces, arbor vitas and retinis- 
poras. By a judicious choice and variation of these, putting one sort only to a bed, some amount of verdure and liveliness will be produced during winter, at a cost of labor and materials which are entirely insignificant in comparison with the effect realized. The plants should be potted in rather a poor soil, lest they grow too luxuriant and send their roots too far beyond the pots.

8. Shady Spots. - Beneath trees and shrubs which are so dense or create such a thick shade that grass will not live, and has to be renewed every year, a simple and convenient plan of carpeting the ground is to plant it with patches of periwinkles or English ivy where the latter will thrive. Bare earth, which does not even produce weeds, and on which, in consequence of the number and strength of the roots from trees, a sufficient undergrowth of shrubs cannot be obtained; has an exceedingly cold and poor appearance, and tends to make a place look smaller. English ivy or the larger periwinkles form a rich and luxuriant carpet in such places. But these dwarfer sorts of undergrowth are principally adapted for such plantations as are nearer the outside of a place and those which may run along the sides of a shrubbery walk in a field, and they must be well watered for a year or two after planting.

9. Treatment of Hedges. - Where hedgerows are employed as a boundary fence, or are used inside a wall or paling to conceal it from view, their ordinary unsightliness and hardness of line may be very greatly relieved by a little attention to pruning and by fronting them here and there with a few scattered bushes of the same or other kinds. In assuming that a hedge is unsightly, however, I would not be misunderstood. When perfectly developed, furnished, and nicely trimmed, a good hedge is rather a beautiful than an ugly thing in itself; but, as I have before alleged, no 


\section{Particular Objects}

description of fence conveys an agreeable idea, and a fence that is formal becomes all the more distinct, setting a conspicuous limitation to a place, and interfering with or cutting off the landscape beyond. The more effectually a boundary line is disguised therefore, the greater latitude of dimensions will be attained.

One way of dressing a hedge so as to destroy its regularity of line is, after it has become sufficiently strong and sturdy, to prune out individual branches only, and not cut it to a uniform height. Several of the plants may, in places, have their heads individually cut down without destroying the smaller spray, while in other parts, at unequal intervals, only one, two, or three heads need be cut off. By carrying out

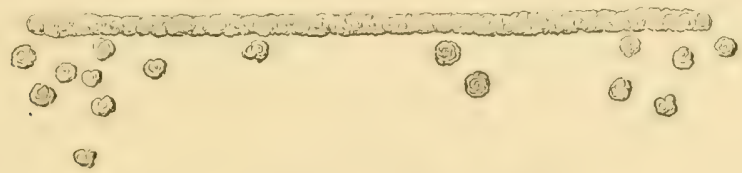

Fig. 54. How to Manage a Hedge.

this plan with the utmost irregularity, and letting some of the bushes grow up more wildly, a ragged, broken, and more natural looking line may be produced; and this is particularly important where in the case of a high hedge it rises above the line of the horizon or stands across a view that is obtained into the open country.

But however tastefully a hedge may be cut, its ground line will still remain a straight one, and to vary this a few tufts of bushes may be scattered at different distances and in different numbers along its front, as in fig. 54, and never be pruned at all. Of course such plants should be put only where the hedge behind them has been left comparatively unpruned, and not opposite the pruned parts. In this manner, by the exercise of a little judgment in disposing and 
diversifying the groups, the harsh line of a hedge may be nearly hidden. A wall or close paling, where there is no hedge, might be similarly darkened and concealed by the same means, taking care to prune down the plants partially and irregularly at points where, after they acquire their full size, they would intercept the view. The propriety of using common thorns and common hollies jointly for this purpose will be seen when it is remembered that they are both indigenous plants, that both grow naturally into irregular and picturesque shapes, and that both, when quite established, are sturdy and prickly enough to deter cattle from attacking them.

One of the chief advantages of the plan is, that though the plants thus used will require protection from cattle till they have thoroughly grown, they nay subsequently be left entirely unprotected.

Io. Shelter Plantings. - New plantations will often call for a greater or less amount of temporary shelter, as they may happen to be in any degree exposed, or as the plants in them may want what is usually styled "nursing." In some exposed districts a few coarse and rapid-growing kinds, towering above the mass of the plantation, will catch and break the power of the breeze, and if in foliage, preserve the lower and better sorts wholly unharmed. Several species of poplar and willow are found to be the most valuable of such nurses, and their mean appearance may be well endured for a time, in consideration of their services. They should be gradually cut out as they become less needed, and entirely destroyed as soon as they have thoroughly done their work.

Poplars, maples, and Norway spruces will, with a few others, be useful in more inland places, when scattered among the better kinds temporarily, to give them a good start. An ornamental tree or plant, so far from being injured by having 


\section{Particular Objects}

rather near and common neighbors for three or four years, is thereby aided in making an energetic and more speedy growth; and if the nurses are not placed too close to the permanent plants and are kept within due bounds they will assuredly be beneficial in helping forward the plantation, and can be taken up or cut out at any time.

Exactly the same principle will apply to shrubs, among the best of which privet, common laurel, common holly, etc., may be found of the greatest use in encouraging them onward for a few years, though greater care will be requisite here to hinder the inferior sorts from trespassing on their more aristocratic companions, otherwise they may do them irreparable mischief.

In those parts of the country where the prevalence of particular winds at certain seasons renders special shelter for newly planted shruls indispensable, this should be afforded on the like basis to that previously recommended for general protection. Light and air must not be excluded. And the materials of shelter should be placed on one or two sides only, shifting them about as the wind may blow injuriously from any quarter. Such materials, also, as are partially open and not perfectly impervious will be preferable, as staying, and not merely turning, the violence of the wind. Large spruce or pine branches stuck in the ground at a short distance from the plants to be protected, or hurdles interlaced with the same or with reeds or laths and placed about a yard from the plants, will afford enough of shelter to them without diminishing their hardihood. If necessary the same kind of screen can be renewed in succeeding years.

I I. Edgings for Walks may be exceedingly various, but there are very few indeed that will give lasting satisfaction. Grass is almost the only one that can be altogether commended for pleasure gardens; and it is one which, if carefully 
laid and diligently kept, will be sure to please, for it has a good color, smoothness, regularity, durableness when not under trees, and harmony with both the architectural and the vegetable constituents of a garden. It furnishes, likewise, the best ground tint for setting off the colors of flowers, as in a flower garden. As an edging, it should invariably be flat, and at an equal height (not more than half an inch) above the surface of the walk at its margin, with about an inch or even two in depth along the inner line, next the bed or border, to allow for the washing down of the soil towards it. It must not be too narrow or it will be difficult to keep cut and the sides will be likely to crumble away.

Box edgings are troublesome, liable to great irregularities, apt to harbor insects, not hardy in most parts of the United States, and suitable merely for quaint figures and old-fashioned geometrical designs. They are the proper accompaniments of parterres and small flower gardens that are laid out with numerous narrow gravel walks. Rough stone, bricks, thick slates, and tiles may make strong and durable edgings for kitchen gardens. The smaller periwinkle, kept in due limits, is useful as an edging under trees; as is the English ivy. The Cotoneaster microphylla is likewise suitable, whether on level ground or among rocks, and will bear a great deal of trimming.

The most valuable requisites in an edging are evenness, diminutiveness or capability of being regularly trimmed, quietness of appearance or harmony with whaterer is behind it, and permanence. In each of these respects grass will, in nearly all circumstances except in the kitchen garden, have the advantage. Where it is least in character is immediately alongside of any rocky surface. There the common heath, undressed, would be most expressive and characteristic.

Of late years, it has become the fashion in many cases to 


\section{Particular Objects}

put edgings to beds, whether these be filled with dwarf shrubs or with flowers. In respect to beds arranged formally, and occupied with dwarf shrubs, as in regular winter gardens or in peculiar positions on lawns, edgings of some dwarfer shrub than the one employed in the center of each may help to define the beds more clearly, to impart an additional air of neatness, and to secure greater contrast and variety.

For flower beds, again, the same practice, where a plant of a dwarfer and compacter habit is used as the edging, may be equally suitable; and if a decided change of color be thus introduced the effect may become even brilliant. But the system requires to be pursued with judgment and caution, and in reference more to individual beds or small groups than to a regular flower garden.

A degree of quaintness and an appearance of antiquity are sometimes attained by surrounding large flower beds on lawns with an edging of some shrub or tree, and keeping this duly clipped. I have seen even the common oak and the Turkey oak thus applied and kept at the height of about nine inches, presenting a dense mass of leaves in the summer season.

As a rule, all sorts of freak edgings are to be eschewed, as, for example, the wire edgings in vogue fifty years ago, or edgings of whitewashed stones, or of bricks standing uncertainly on their corners. One occasionally sees flower beds edged with telephone insulators, inverted beer bottles, or other convenient débris, which no matter how curious and striking can hardly be said to be ornamental or in good taste. 


\section{CHAPTER VII}

\section{Special Features}

If a place be separated into its constituent elements, it will be seen to consist not only of a number of objects, but to comprise at least a few individual departments that have features of their own and demand peculiar treatment. Should any of these not be very important in point of extent, much of what is lacking in dimensions may be made up by extreme attention to the disposal and regulation of every part, that if there be no palpable merit there may be perfect freedom from fault.

I. Fields. - To make anything of a park or field, it must be managed simply as if it were a park, on however diminutive a scale. Its size will not materially affect the question of design, for the largest field or park would only contain similar features much more boldly carried out.

In the arrangement and furnishing of a park the same principles are to be observed as in the treatment of a garden, only in a much rougher and bolder way. There should be breadth of glades, with planting chiefly at the margins, disposed in masses or groups, with openings between, and fronted by occasional single specimens. Bareness and baldness will be as faulty as on a lawn. The attempt to save a few yards of ground for pasture, at the expense of all richness of clothing or variety of aspect, will be but a shortsighted policy.

Around the sides of parks or paddocks, any smaller plantations may be composed of a coarser and commoner description of plants than those used in the garden, and evergreens 
need not be so abundant. The common oaks, elms, and chestnuts will be the most appropriate of these, with any other indigenous species common to the locality. Such plantations should always be pretty dense, with a lower growth of the commoner shrubs to give richness, massiveness, and depth.

Very showy or very rare and exotic plants will be entirely out of character as specimens in such a park. Ornamental trees that are not conspicuously peculiar may be admitted, though not liberally, and scarcely at all if they flower much. White-blooming thorns or dogwoods will be very suitable, but not scarlet ones, unless in the close neighborhood of the garden, and double-blossomed ones on no account. Shrubs will be wholly improper on the grass, except groups where they will almost adjoin a plantation.

Where bushes exist in a park, they should on no account be trimmed at the base, which would make them look too much like trees; but their branches should be allowed to spread freely down to the ground, that the eye, in glancing over a series of glades, may have to travel round the bushes, and that thus a more varied and inviting range of views may be offered from different points. Bushes are sometimes very useful also when sparingly scattered about groups of trees, in carrying their outlines better to the ground and softening away everything like abruptness or want of pliancy.

The kinds of ornamental trees that are mostadmissible into private parks in America are the elm, maples, chestnut, and all kinds of oaks. In the middle states poplars are sometimes quite in place. Where evergreens are native they may also be freely used, especially pines and spruces.

To form and plant a park effectively requires almost greater care and attention than designing a garden, inasmuch as the trees used are of a grander character than the plants employed 


\section{96 Landscape Gardening}

in a garden, and if placed improperly become more offensive and obstructive. An error into which the unpracticed commonly fall is in making the whole spotty by the too liberal insertion of single trees, or by needless interruptions to the breadth and continuity of glades. The glades are of the very last importance, and should from the house, the drive, and the chief walks in the pleasure grounds, be quite unmistakable and decided, although their edges must, like those of the glades in the garden, be irregularly furnished. Of course the glades in the pleasure grounds and those in the park should unite, and continue expanding in the latter till they reach the boundary, where by means of a low fence or of only small bushes they must be carried forward into the more remote distance.

Single trees in a park, however beautiful they may be as individual specimens, ought not to be very freely multiplied, and should rather as a rule attach themselves as offshoots to clumps and groups than stand entirely alone. It is masses of trees, varying in number from two to twelve or fifteen, and exhibiting the most irregular arrangements and combinations, that are chiefly suitable for parks. Occasionally seven or eight trees of the same kind as the weeping birch, planted near to each other, will, when the heads are thrust out by the expansion of the interior trees, cause the stems to become crooked and to assume the most picturesque outlines. Such a group would have the happiest effect on the edge of a rough slope or on comparatively broken ground.

In shaping the land, too, while a certain amount of smoothness and ease is desirable in the ground lines where they approximate to a garden, a greater degree of roughness and irregularity should be preferred towards the outer boundaries of the park, thus assisting to render the transition from the garden to the land beyond as gradual and as gentle as possible. 
It is principally of consequence to regard a park as a link between the dressed parts of a garden and the wilder and freer characteristics of nature. In its furniture, therefore, it should resemble the garden about the parts where they unite, and the more general features of the country towards its outer edges. It must by no means be a detached and isolated thing. Nothing in nature is so. The plantations at the bottom of the garden may decidedly run into those of the park or field, and be extended into it as far as comports with obtaining proper views from the house.

Indeed the garden and the mere field can be yet further united by the employment of a shrubbery walk round the whole or a portion of the latter. Notwithstanding the charge of affectation so freely imputed to walks of this kind, because they skirt the actual boundary of a small place, it must be averred that they are very useful in affording exercise within the private domain, and in presenting the garden, house, and exterior country in more varied aspects. In relation to even a large park, a walk may often appropriately be carried for some distance along one or more of its sides, or be directed through some of its woods, especially where any picturesque natural elements, such as rocks, broken ground, or steep banks exist, or where the woods adjoin and furnish a sheet of ornamental water.

2. Shrubbery Walks. - A shrubbery walk should be in all respects more simple than the garden in point of art. The curves should be less studied, the margins slightly rougher, and the material of an inferior and less polished kind. The keeping also should be decidedly less perfect, the dress and finish of the garden being quite undesirable here. As much shade and shelter as possible should be attained in such a walk, but it must not be without open parts for sunshine and views. Here and there a seat may 
be placed for rest or for enjoying a prospect, and clusters of common roses, or particularly sweet-scented flowers, or even patches of strawberry plants, may occasionally be put in to attract persons to use it. Fruit trees may often be used in its plantations for the same purpose. Of course, like the garden walks, it should break away from the boundary fence as freely and irregularly as the space will permit; and it is by no means necessary that the plantation be continuous, as the walk may pass out into the open field or park in a few parts for variety.

Advantage should be taken of any peculiarities in shrubbery walks that may be favorable to the cultivation of particular tribes of plants, that the walk may by such means be rendered more interesting. Indeed a walk of this description, where the locality allows, may be made into a small arboretum, in so far as one or more families of plants is concerned, except that the specimens should not all stand apart and alone, but be dis ersed through the fronts of the ordinary plantations and now and then brought together into groups.

It might frequently happen in such a walk, too, that a wellcontrived little episode, such as would be yielded by converting a small dell or hollow into a rockery or a fern garden, could be easily accomplished. Or a pond for the use of aquatic birds or for the growth of rare water plants might be brought into notice. Or a spot by the side of a shrubbery walk might be selected where a patch might be devoted to wild natural vegetation in which briers, brambles, thorns, honeysuckles, clematis, and other picturesque indigenous plants could be allowed to assume their native luxuriance and tangle together in unrestrained profusion.

In any case, the sides of the shrubbery walk and the ground beneath its plantations can always be appropriated to the growth of such hardy herbaceous plants as violets, 


\section{Special Features}

snowdrops, squills, primroses, lychnis, anemones, narcissus, crocus, harebells, and other showy or early flowering species, which can readily be induced to carpet the ground in sufficient masses to render their effect conspicuous and even striking. Ferns in all their elegant variety may also sometimes find a congenial home by the sides of streams or on shelving banks that are brought within the range of the shrubbery walk.

To enliven a park or a field, and give life and motion to a home scene, sheep and cows may be freely admitted. Sheep of the larger and better breeds are always the most quiet, and crop the grass most evenly, and are less disposed to injure shrubs and trees, such as have been reared in hilly or poor districts being exceedingly wild and objectionable. Horses and colts are particularly mischievous where they can reach the branches of trees, and should therefore generally be kept out. Deer are similarly inclined to damage trees, and when they are admitted will always require extra fencing to keep them from young trees and to prevent them from straying.

3. Concrete Examples. - From the limited size of these pages it is obviously impossible to illustrate the treatment of parks of any magnitude. But two or three designs, embodying some of the more essential constituents, may now be given. The first I shall present - necessarily on a very small scale - is a plan of the grounds and what may be called the home park of a place which I arranged for Charles Longman, Esq. It is named Shendish, and is between Hemel Hempstead and King's Langley, in Hertfordshire. The house and homestead have been erected on the summit of a hill, where there was an excellent platform for the purpose, and whence the ground descends in a convex form, gently at first but afterwards more abruptly, till it falls into 
a valley on all sides. Unhappily the estate had been sadly denuded of trees by former owners and a good deal of planting has therefore become requisite. The position, however, commands an extensive variety of wooded undulations, both in the middle ground and the distance, and the great desideratum was therefore to create within and in the neighborhood of the pleasure gardens a suitable and sufficient foreground.

The engraving (fig. 55) will show pretty clearly the way in which this has been accomplished. The house is approached from the northeast by a constantly ascending drive of about half a mile in length, which, after crossing the railway by a characteristic bridge, winds up a natural hollow with the undulating slopes of the park on either side, till it passes over a sunk public footpath by another appropriate bridge (30) and enters what I have termed the home pasture (29), traversing which, it soon after reaches the enclosed pleasure grounds and thus arrives at the house. A branch to the west first separates from it and skirts the home pasture on its way to the farm buildings. There is a subordinate drive from the opposite direction (24) which conducts to the house by way of the farm road and which is chiefly used for farming purposes.

The home pasture consists of an area of about twenty acres and is detached or fenced off from the rest of the place, partly for grazing purposes but mainly because it is bounded to the north and east by a public footpath and has arable land beyond it to the southeast and the southwest. The footpath which comes from a northwesterly direction formerly crossed the middle of what is now the home pasture in a line which would be nearly due south. There being two branches to the path, however, it was easy to divert it into the line 32 ; and by sinking it five feet and putting a wall (3I) on the side next the home pasture a capital sunk fence has been 


\section{Special Features}

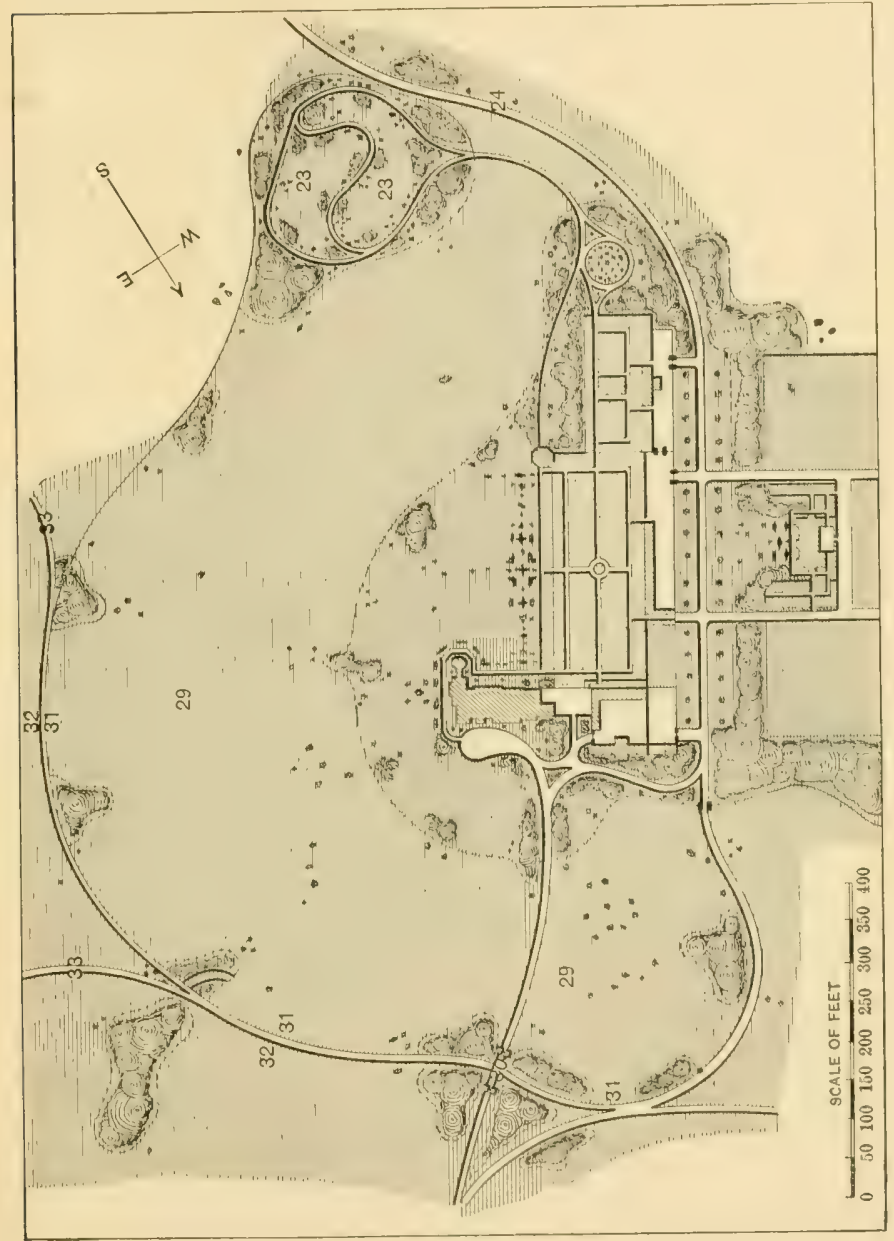

Fig. 55. Plan of a Home Park. 
obtained for the latter, and the persons using the footpath are not observed from the house. The ground being well sloped away from the path on the outer side, it is open and cheerful, and being well drained and formed, is really a boon to the public as compared with an ordinary field path.

On the west side of the carriage drive, between it and the farm road, there is a cluster of old elm trees, and there are some old sycamores and elms to the east of the drive, near the figures 29. All the plantations and groups had to be newly made. In one of the plantations near the sunk wall, northeastward from the house, we may enter a bridle road between the home pasture and the footpath.

At 23 the existence of an old chalkpit is made to conduce to the variety in the place by carrying a walk to it from the pleasure grounds and extending this walk around and across the excavation. In the latter case the lines of walk will be more broken and irregular than it was possible to show on the plan, and the whole is made the medium of displaying rugged masses of natural vegetation, of which the wild clematis (common here) will be a conspicuous feature.

A great deal of earthwork has been executed, both in the pleasure grounds and the home pasture, by reducing in some parts and raising in others to assimilate the general form of the land to that which is beyond and produce an easy but positive convexity of shape without any undulations or dips. From the conformation of the surrounding country this arrangement became a matter of artistic necessity, without which the whole would have appeared trifling and artificial.

4. The Flower Garden. - The flower garden should be situated on the warmest and most private side of the house, and fronting the drawing-room windows. Or the flowers may be placed in a sheltered and sunny corner of the pleasure grounds, where a wall at the back will keep them warm 


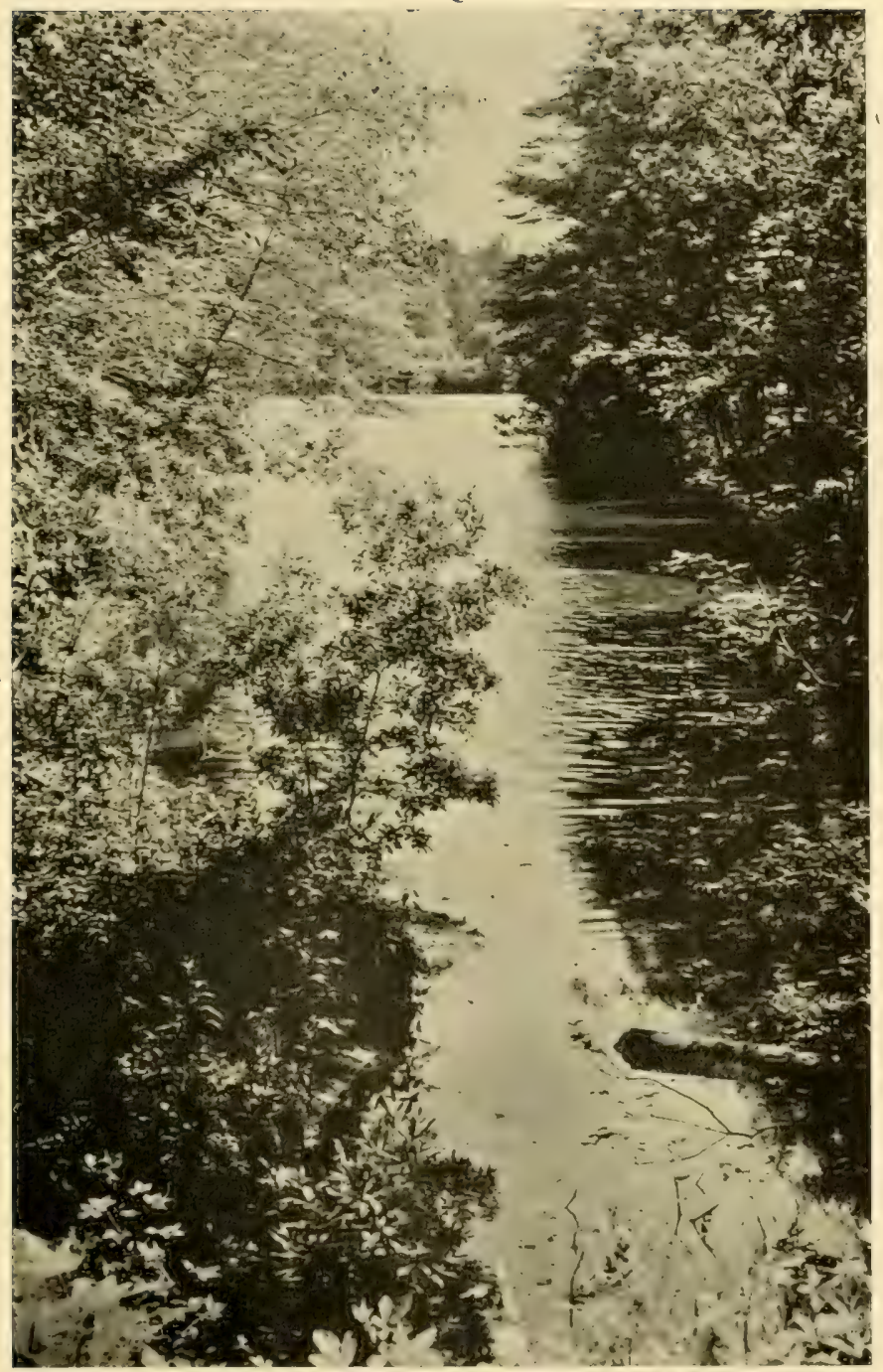

Plate XIII. Vista across a Pond - Private Estate in Georgia. Designed by Warren H. Manning. 

by protecting them and reflecting the sun's heat as well as make them more secluded. The same situation will furnish the opportunity of growing tender climbers.

The beds of a flower garden should be symmetrical and fit nicely into each other. All elaborate figures and scrolls are generally undesirable, as they tend to multiply work and cannot be so effectively planted. Beds of simple shape, in which no very acute angles occur, will be the easiest to keep in order, and will exhibit a good arrangement of plants best. Flower beds ought never to be large, or it will be inconvenient to attend to them; nor should the openings between them be very narrow, lest they become inaccessible, or the plants in each bed be insufficiently separated from those in the others. Grass evenly laid in tolerably broad strips constitutes the most effective division between flower beds, as it sets off the colors of flowers best and gives greater unity and breadth to the whole. Gravel, with box or stone edgings to the beds, will not be unsuitable for some styles of flower garden, especially where the beds are large, or complex, or intended to be filled with mixed plants.

The modern style in America has reached pronounced conclusions with respect to the use of flowers and flower beds in landscape gardening. It is very generally held that in the free and natural style of gardening flowers are to be used in only two ways: first, where they can be naturalized in considerable masses, as may be done with narcissus and crocus; or, second, where they can be massed in irregular flower borders. These borders may contain either hardy perennials or hardy annuals, or both in judicious combinations. The addition of tender greenhouse species to these informal borders is likely to give unhappy results, as palms, camellias, cinerarias, or even geraniums, will always show their artificial origin and thus contradict the naturalness of the landscape 
effect. In other words, they offer continual opposition to the primary artistic motive of the garden.

In many private parks where space and soil conditions permit there may be arranged suitable "wild gardens," which consist simply of collections of hardy flowering plants naturalized in place. Unless such a wild garden be designed with much skill, however, and unless it be kept with equal taste, it will hardly prove a success.

On most private places, where the grounds are designed in the natural style, and where flowers are wanted in considerable quantities, especially for cutting, it is best to grow them in a separate enclosed garden. This garden will be set off and managed precisely as the fruit or vegetable garden. By this means the flower garden is saved from encroaching on the artistic unity of the place, while at the same time the flowers themselves receive a more suitable culture and give a much more satisfactory harvest.

On the other hand, when we have to deal with a formal or Italian garden, the design will often be filled out to best advantage by the introduction of flower beds. These will be designed in such sizes and forms as will best fit into the general structure of the main design.

Figure $5^{6}$ includes the flower garden and part of the pleasure grounds which I had executed for Samuel Job, Esq., Holmefield, Aigburth, near Liverpool. A portion of the house is shown. At $\mathrm{I}$ is a bay window to a corridor, the dining-room, drawing-room, and library being on the southwest front. A terrace walk (2) extends along the southwest and southeast sides of the house, and is joined to the lawn by a grass bank ( 3 ) four feet deep. There is a straight walk direct from the terrace to the flower garden, the latter being quite flat, of a circular figure, open to the sun and the field on the east, south, and southwest sides, and sheltered from 


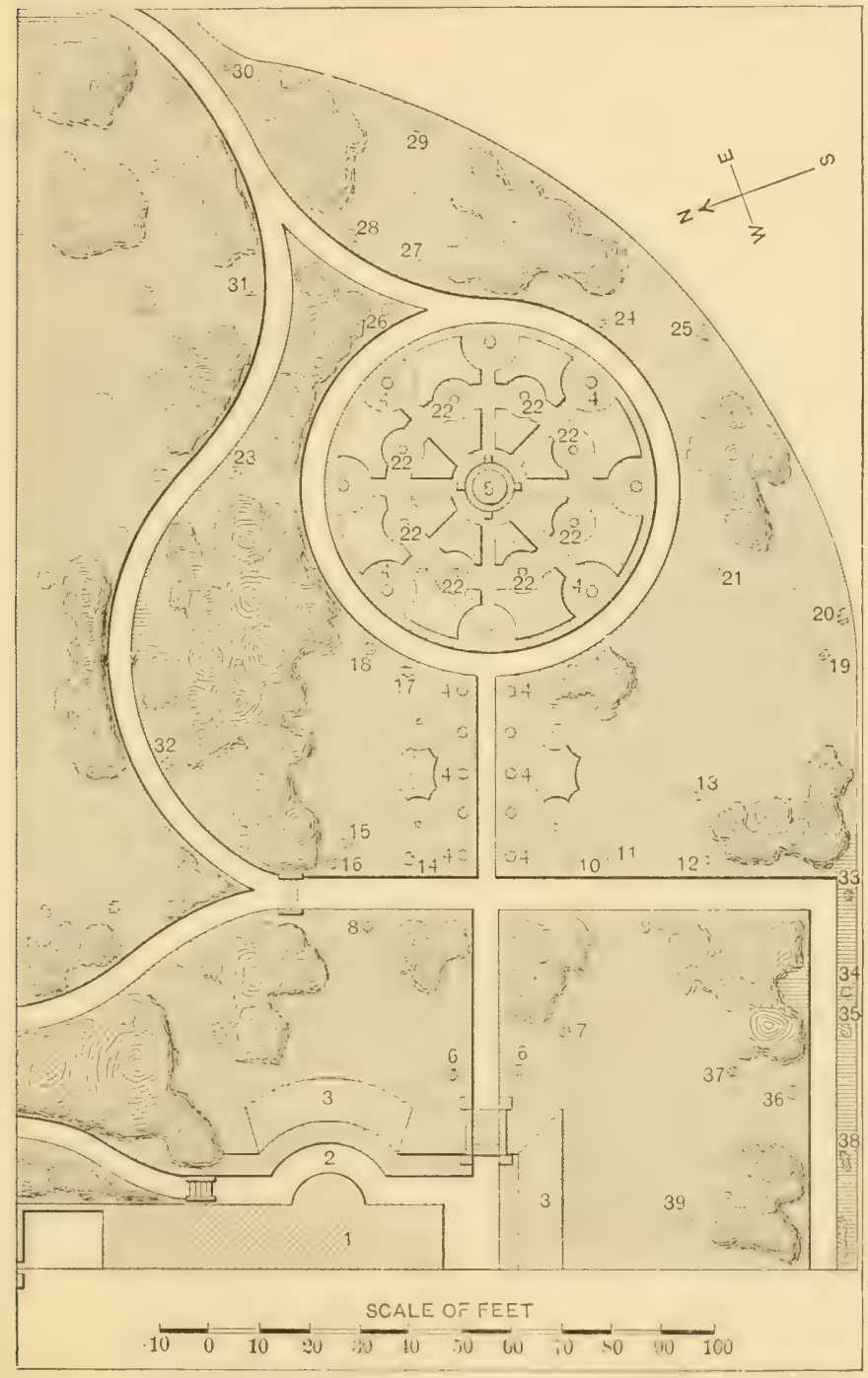

Fig. 56. Design of Residence Grounds. 
the northwest by the house, and from the north and northeast by masses of trees and evergreens, though a glade to the extreme north admits a view of a very pleasing little hollow in the pleasure grounds.

Small vases on pedestals (4) alternate with circular flower beds on either side of the walk to the flower garden and with similar beds round the margin of the large circle, 5 being reserved for a basin of water, which might also receive a small fountain. The names of the specimen plants, pointed out by figures, may possibly interest some reader and are therefore inserted.

6. Andromeda floribunda.

7. Spirca Lindleyana.

8. Daphne pontica.

9. Hybrid Rhododendron.

Io. Cotoneaster microphylla.

II. Weigela rosea.

12. Tree Ivy.

I3. Weeping Elm.

14. Yucca gloriosa.

I5. Yellow-berried Holly.

16. Ribes sanguineum.

I7. Ilex balearica.

18. Erica multiflora.

I9. Scarlet Thorn.

20. Golden Holly.

21. Cedrus deodora.

22. Irish Yews.
23. Aucula japonica.

24. Narrow-leaved Alaternus.

25. Double Pink Thorn.

26. Hodgins's Holly.

27. Standard Weeping Cherry.

28. Cryptomeria japonica.

29. Silver-blotched Holly.

30. Ilex marginata.

3I. Pernettya mucronata.

32. Gaultheria shallon.

33. Rhododendron.

34. Variegated Prickly Holly.

35. Berberis aquifolium.

36. Ilex Madeirensis.

37. Araucaria imbricata.

38. Double Furze.

39. Cupressus macrocarpa.

Holmefield contains about twenty-four acres and is agreeably situated in the Aigburth valley, on a comparatively private road, and with views of the bolder parts of the Welsh hills to the southwest.

For a secluded flower garden, apart from the ordinary lawn and either enclosed by shrubs or taken out of the north side of a kitchen garden that is not walled in, the design, fig. 57, 


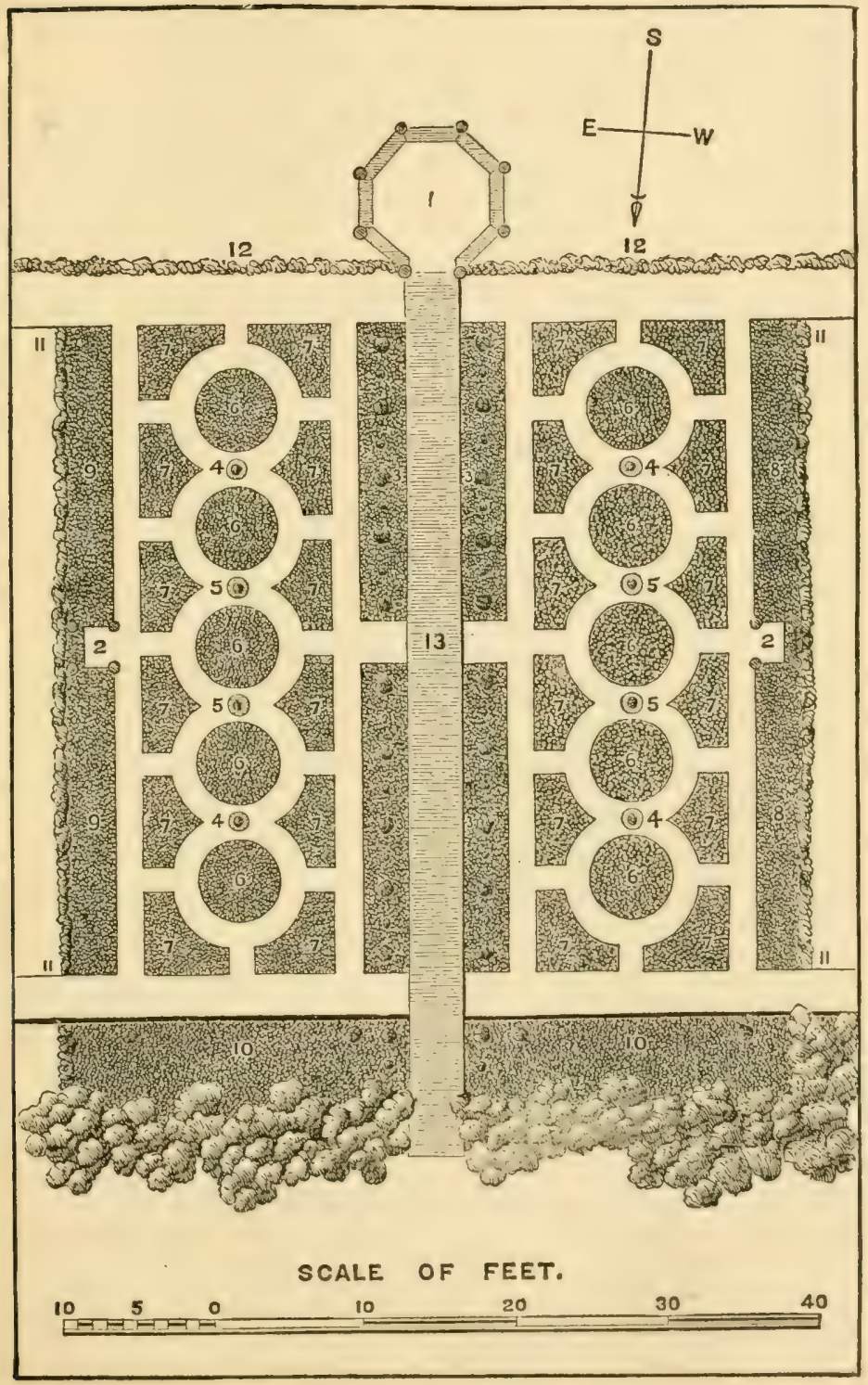

Fig. 57. A Secluded Flower Garden. 
may possess recommendations. It was made for James Barratt, Esq., of Lymm Hall, near Warrington, England.

Lymm Hall is an ancient Elizabethan edifice partially surrounded by an old moat with rising ground in the pleasure garden and field on the south side. A little to the eastward of the south front a dense mass of hollies and other evergreens screens off the kitchen garden, and it is on the south side of this plantation, attached to the kitchen garden, that the flower garden now under notice has been made. It is connected with the lawn by a grass path through the screen of evergreens; and this grass path (I3) passes up the niddle of the flower garden, being terminated by a summerhouse (I) which is covered with clin bing roses. 'T he rest of the walks are of gravel and have box edgings, differing in this respect from any that I have yet described.

At 2 there are garden seats canopied and enclosed with ivy, which is grown on a wooden trellis. In the borders (3), which are devoted to roses, there are at regular intervals alternate specimens of standard and climbing roses, the latter being represented by the larger dots, and being trained to poles, and to chains hanging between these, in the form of festoons. In the circles (4) are specimens of a tery dwarf and compact variety of the common juniper, while fuchsias occupy the other circles, marked 5. To the beds (6) were assigned different varieties of verbena, with one sort in each; but they could of course be filled with other kinds of plants that are sufficiently dwarf. The whole of the beds ( 7$)$, or twothirds of them, were also intended for mixed flowers, though they could all, if desired, be retained for summer flowers, with one sort to a bed. The border $(\delta)$ is for violets and other spring-flowering plants, and the opposite border (13) for lilies of the valley and such things as prefer more shade. There is a border strewn with rocks at Io, for alpine plants, 
small trailing shrubs, etc. A yew hedge about five feet high (II) encloses the garden at the east and west sides, and on the south (I2) is a sweetbrier hedge, with standard roses in it at regular intervals.

5. Rockeries and Fern Gardens. - Persons who have a fancy for a rock or fern garden will do well to keep it somewhere in the background and not in sight from the windows of the house or the principal parts of the lawn. It may be made very interesting if thus secluded, and may be approached from the main walk of the garden through a rustic arch mantled with climbers or in some similar and convenient manner. Masses of rockery may even be placed fronting the chief line of walk, at some distance from the house, where a good dense screen of planting can be interposed between them and the lawn, or where they can be made to look as if they were naturally cropping out of a bank. Or they may be employed as a sort of rustic basement to some outbuilding. To grow ferns upon them, the shade of trees or some other objects will be indispensable; but many rock plants prefer an open sunny situation, so that rockeries should not be entirely shaded. If accompanied with a small pool of water having a broken rocky margin, a few of the rarer aquatics and sedgy plants may be grown, and goldfish can be kept. The moisture exhaled from such a piece of water would be very beneficial to many rock plants, and the jutting pieces of stone or overhanging shrubs would afford shelter, privacy, and shade to the fish. Where a clear running stream can be turned through a rockery and be expanded into a pool, trout may also be preserved in the latter; and if there be water enough to dash down a minature rocky ravine in the shape of a cascade, another characteristic accessory will be added. Of course it will be readily understood that considerable room will be required to develop any such ambitious plan. If such 
things are undertaken on too small a scale they only succeed in appearing ridiculous.

Rockeries should be formed as much as possible of natural materials. All the products of art, such as fused bricks, scorix, and the far more vulgar constituents of which such ornaments are often constructed about towns, are quite incompatible with any amount of rusticity. And this last should be the distinguishing element of all rockeries.

As in the material employed so also in the mode of construction followed, rockeries should be conspicuous for a natural character. No appearance of art and no approach to the regularity or smoothness proper to works of art will be at all in place here. On the contrary, the surface of the whole cannot be too irregular or too variedly indented or prominent. An additional projection must be given to some of the parts by moderate-sized bushes, or short-stemmed weeping trees. Evergreen shrubs or low trees will be particularly useful. Provision will therefore have to be made in the placing of the stones for planting a few shrubs and a greater number of herbaceous rock plants in their interstices, which should be left broader or smaller according to the size of the plant that may be required in them. No rockery will ever be interesting unless well supplied with all such fittings.

For ordinary practice, the materials of which a rockery, however small, is formed should lie on their broadest or flat sides, and not be set on edge, much less be placed with their points upwards. Little deviations may occasionally be allowed for variety, but the mass will have more appearance of solidity and strength and be more accordant with nature's teachings if each piece be laid flat, with the outer edge shading a little downwards rather than upwards.

A rock garden may, if its size demands it, be traversed or made more generally accessible by narrow walks just capable 
of admitting one person. These need not be of any uniform width and should have no regular margin. They may be made of some quiet-colored material, and not covered with dressed gravel, the mere stones of which the rockery is composed forming the best possible paths, if they are tolerably flat.

Any great elevation should never be sought in small rockeries. This would both be inconsistent with their breadth and would render them too prominent and artificial. They should not be carried higher than the point at which they can be well supported and backed with a broad mass of earth and vegetation. Additional height may sometimes be given, if desired, by excavating into a hollow the base from which they spring. An old quarry will supply the foundation of an excellent rockery, in which considerable height, relatively to the bottom, may be attained, and much of boldness. It should be seen, however, that in working it, masses of rock be merely wrenched or blasted off, in the most irregular manner, and no sawing or cutting to an even face be anywhere permitted. Extreme ruggedness of surface is what would be most characteristic in such a situation.

No collection of rocks should ever begin or end abruptly, but should gradually die away into the adjoining ground by means of a few carelessly scattered groups or single masses of stone. Attention to this point will mark the difference between the practiced and the unobservant artist and will exercise a great influence over the whole composition.

Shrubs with trailing habits, evergreens, and a few of the less delicately branched weeping kinds, and those which assume a wild, ragged, and picturesque character, are most congenial to rockeries. The first class, especially, including the ivy, the Cotoneaster microphylla, Berberis empetrifolia, periwinkles, heaths, etc., always seem in place and 
at home. And the more decided climbers, such as clematis, the hop plant, Wistaria sinensis, some of the better sorts of bramble, the wild roses, Virginian creeper, and several others, would, if suffered to scramble over the bolder parts of rockeries and duly pruned and regulated so as not to smother things of more value, be most important and engaging accessories.

Grass never harmonizes well with rocks if brought into immediate contact with them. They demand the adjunct of a rougher and less polished vegetation, such as attends them in a state of nature. Common heath, whortleberry, etc., cut into sods, and laid with a broken line along the margin of rocks and interspersed in parts with the dwarfest trailing evergreens, will give a good rustic finish, and may be particularly valuable in connecting the rocks with any mowed grass beyond. Everything like a perceptible or continued line (much more a curved line) must be distinctly avoided in the appropriation of such materials. Rocks should join the grass in the most jagged and inartificial manner.

Rockeries can be made to answer one or two simple purposes, which will impart meaning and spirit to them and prevent them from becoming the expressionless and pointless things which they usually are. Where there are raised banks between one part of a garden and another, rocks can be employed to face the more private side of them, and will contribute to their solidity at the same time that they increase their propriety and interest. If, again, a walk be cut through a bank, rocks may be used to hold up the sides of the opening when steep. Or where a walk travels along a narrow hollow between two banks, the slopes of the banks can be partially covered with masses of rock. In both these last cases an imperfect imitation of a small defile will be produced and may be made very consistent and natural. 
The plan will be particularly serviceable where the hollow has to be made as narrow as possible and the banks have consequently to be kept pretty upright. At any rate, such an arrangement will be infinitely preferable to having mere heaps of stones thrown together without any apparent object beyond the simple creation of the mass.

6. The Rose Garden. - Roses, which are favorites with everybody, may be fitly collected into a small separate garden, which will then be denominated a rosary. Like the rock garden or the private flower garden, the rosary should be detached, away from the general lawn and in some side nook severed from the rest of the garden by a partial screen of shrubs. It can only, of course, find a place in gardens of medium and larger size. From very limited plots it must necessarily be excluded.

As with the flower garden, the rosary requires to be sheltered (not shaded) and sunny. And there is the more reason for it to be in a retired part because it is very uninteresting during the winter season. It should be of some regular shape, with the beds tolerably bold and simple in their outlines. Very narrow parts in beds, or acute corners, would be nearly useless and look extremely meager because few plants could be inserted in them, and these would cover the ground but imperfectly. At the same time, the beds ought not to be much broader than will allow the center of them to be reached pretty easily from either side. And they should have divisions of grass or gravel from three to four feet in breadth, as the admirers of roses always want to go among them comfortably. Grass will always look better than gravel, and when it is used, there will not be more than one or two cross walks of gravel and an encircling one necessary.

Perhaps the best shape for a rosary is a circle, or a square 


\section{I 4 Landscape Gardening}

on which a circular pattern is laid, or an oblong figure rounded at the ends, or an octagon. A good form for the beds will be oblong, with the ends rounded, arranged in various sizes around a central circle and diversified by a mixture of smaller circles.

Since roses are very similar in height and character, a rosary filled with only the dwarf-growing kinds will be comparatively tame and monotonous. But with the aid of standards of various heights and habits, and climbers trained to poles, much interest and variety of outline may be produced. These auxiliaries should not, however, be commonly put in the beds (save a single climber or a cluster of them in the central mass), but stand by themselves in spaces prepared purposely for them, and arranged symmetrically as parts of the plan. Sometimes a very strong and brilliant effect may be occasioned by having a few small beds filled with roses of only one color. And a rosary may even be altogether furnished by assigning each tribe to particular beds, in corresponding parts of the garden. White and blush roses make a good mass, as do those which have the color of the common rose and particularly the dark-flowering Chinas, which bloom so long and group together so admirably.

Covered archways made of wire, or small open temples formed of either wire or rough wood with the bark on, will sometimes be interesting features in a rosary, for the support of climbing kinds. To be able to sit in the shade during summer, embowered with only elegant roses, is certainly a luxury of no mean or ordinary description.

The plan shown in figure 58 is of a rosary which I made in the neighborhood of Dulwich, near London. It lies in a sheltered and partially detached corner of the grounds, and is connected with the kitchen garden on the north side by the walk at the top of the engraving; the walk to the right 
leading eastwards into the general pleasure grounds through some wire arches covered with climbing roses, that to the left being finished by a handsome summerhouse, and the

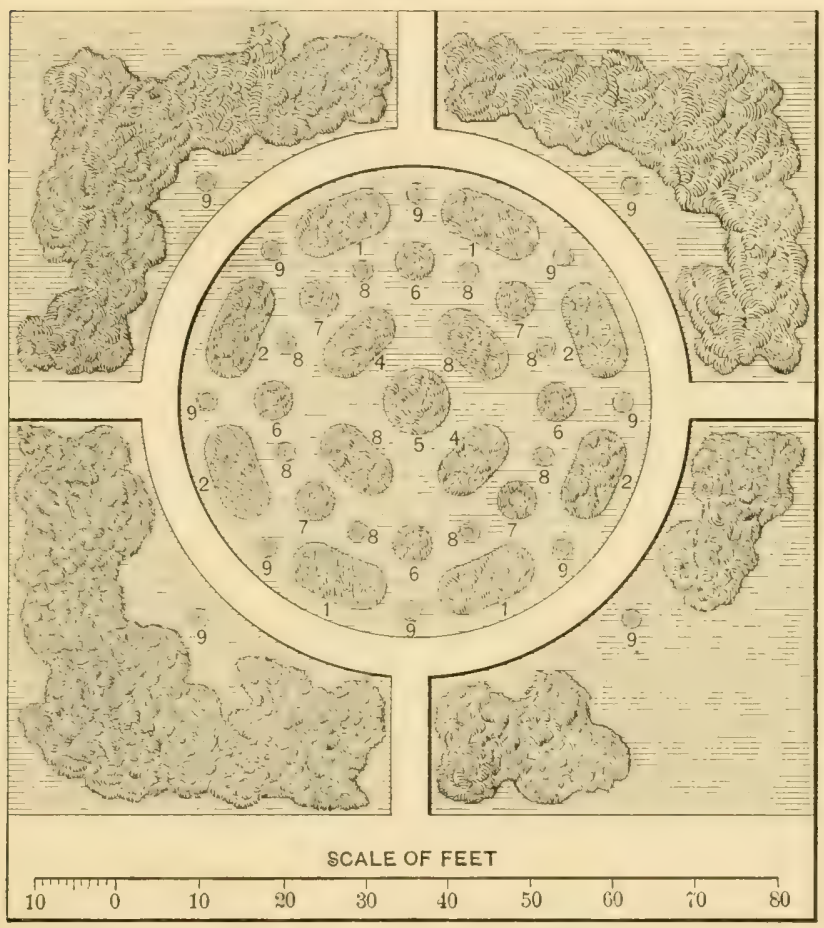

Fig. 58. Design of a Rose Garden

southern walk, which quickly turns westwards, being conducted through a small wood to another part of the estate. The whole is nicely open to the south, southeast, and southwest, on which sides only shrubs exist. On the other margins larger trees mingle with the plantations. Great sim- 
plicity and roundness of form will be observed in the beds, and the grass openings with the grass verge round the edge of the walk are varied and ample. The references will make the details quite intelligible:-

I. Beds of Province Roses.

2. " Hybrid Perpetual Roses.

3. "Damask Roses.

4. " Moss Roses.

5. Bed of Noisette Roses, with Climbing Rose, trained to a pole, in the center.

6. Beds of Hybrid China Roses.

7. ", Bourbon Roses.

8. Climbing Roses, trained to poles eight feet high.

9. Standard Roses.

It will be seen that each important tribe is brought together in beds by itself, and if the sorts be nicely selected and mixed, such an arrangement will be found usually more productive of harmony, character, and tone than any merely promiscuous mixture of all the groups.

7. Special Collections. - There are few places of sufficient magnitude to admit of the formation of what has been termed an arboretum, or complete collection of trees and shrubs classified according to their natural affinities. And where there is actually room for it, such a gathering, according to the received notion of it, would be by no means ornamental, while it would necessarily comprise many species and varieties that are quite unworthy of cultivation. In spite of all this there is the greatest propriety in selecting the most distinct or interesting members of certain tribes and allotting a separate space to them within the general compass of the pleasure grounds. And one of the most pleasing of such departments would be the pinetum.

By the term pinetum, however, I do not mean a spot that necessarily accommodates all the known or hardy species and varieties of coniferous plants; much less do I seek to advocate the common method of dotting these about, as single specimens, at nearly regular intervals, by the sides of a walk 
made on purpose to exhibit them; I merely wish to recommend the introduction, where practicable, in some remoter and wilder part of the pleasure grounds or woods, and particularly where there are natural sloping banks of varied aspect with an ordinarily sandy or rocky substratum, of a careful selection of the most peculiar or most ornamental kinds. It would be my way to distribute these about very irregularly, in broken groups or as single specimens, according to the conformation of the ground, the character or value of theplants, and their fitness for entering into combination with others or for standing alone. In short, the object of a pinetum should be to produce a new and unique but always picturesque scene or succession of scenes in a place, with the occasional exhibition of a very perfect specimen, and not, as is usually the case, a merely monotonous succession of specimens.

A remarkably eligible site for such a pinetum would be a small winding valley in an old wood towards the outside of a pleasure garden. By cutting away the wood in the bottom of this valley, and making bold indentations into it along the slopes at its sides, a walk might be conducted through the hollow, and the banks could receive the choice conifers, while the groups of these latter would be broken here and there by jutting portions of the wood, and the whole would be backed and thrown into good relief by the deciduous trees composing the main mass.

The drawing, fig. 59, will afford some slight idea of the grouping of such evergreen trees by the sides of such a walk as I have mentioned, the wood itself being nearly altogether omitted from the sketch. The lines of the walk are probably smoother and more regular than they would be likely to be in such a situation. But they might, for variety, ascend the banks in certain parts, and would thus show the conifers more advantageously. The scale is 66 feet to an inch. 


\section{I 8 Landscape Gardening}

8. The Winter Garden.-By no means widely removed from the pinetum in character and purpose would be the winter garden. In reality, as conifers are almost invariably evergreen an assemblage of them such as I have just described would in itself compose a winter garden of a particular kind. And in a similar situation a quantity of ornamental shrubby

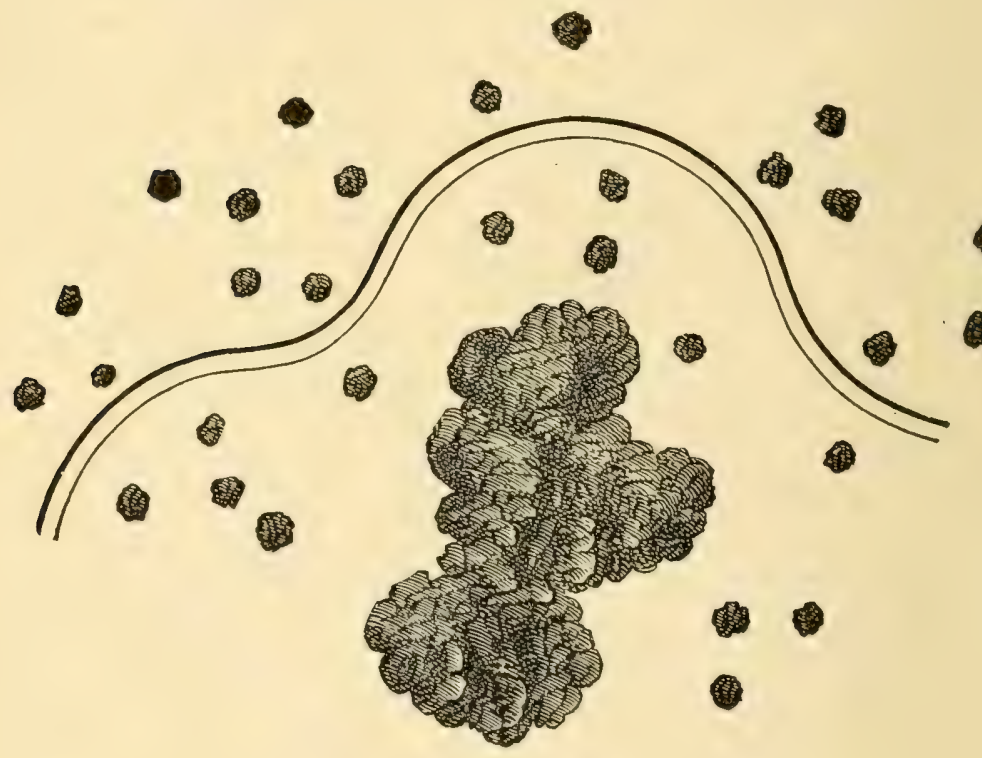

Fig. 59. The Arrangement of a Collection.

evergreens might be gathered together so as to constitute a very effective specimen of the irregular winter garden.

But the more usual or acknowledged application of the name "winter garden" would be to a plot that is arranged in a purely regular manner with the beds cut into quaint or at least formal figures, and the shrubs for these beds selected 


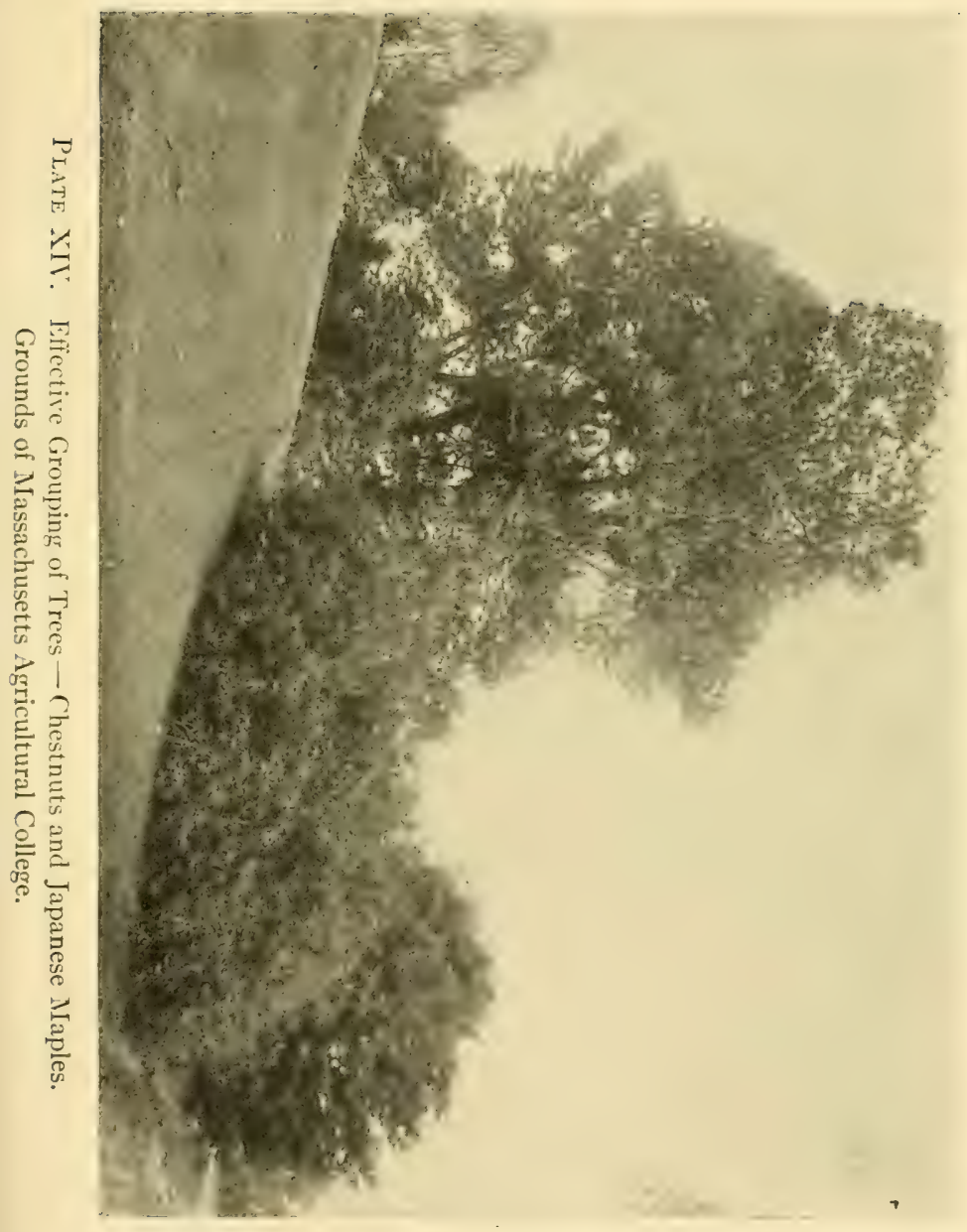



for the colors of their foliage and placed each by itself in a separate bed. With a due regard, in the choice of plants, to diversities of height and habit, to the periods of producing flowers or berries, to the variegation or other conspicuous peculiarity of the leaves, to dwarf edgings of another kind of plant, and to all similar ornamental details, the winter garden may be made very attractive both winter and summer.

It is possible also to produce highly agreeable winter effects in a less formal manner. Evergreens and shrubs with good winter colors may be arranged in perfectly informal borders or masses, just as other materials are planted for the ordinary, purely naturalistic landscape effects. In such groupings there may be used all shrubs with bright colored twigs, as the dogwoods (Cormus stolonifera, C. siberica, etc.), the yellow willow (Salix alba vitellina), Kerria japonica, etc., also plants having attractive fruits in winter; for example, the common bittersweet, many roses, viburnums, etc. All the best nursery catalogues give good working lists of plants for these purposes.

9. Playgrounds. - In the present artificial state of society, with every species of business conducted in an anxious and hurried manner, and so many persons devoting themselves to mental or sedentary pursuits, all sorts of out door exercise and amusement become additionally needful and salutary. And it is gratifying to find that there is a wise tendency towards harmless indulgence of the kind. A demand, therefore, more frequently arises for a bowling green, tennis court, croquet ground, or other play spot, as an appendage to a garden.

I believe the orthodox form of a bowling green is a square of about forty yards each way, and that the best players prefer to have the ground very slightly raised towards the center. An oblong and narrower plot, however, will suffice for all ordinary practice; and as it is in no way requisite that the 
margins should be straight or regular, a bowling green may often be concocted out of the principal lawn, where the ground is flat enough for the purpose.

Still, if there be sufficient space in the garden, and the natural levels of the land admit of it, a bowling green may be better treated as a separate thing. Fig. 60 represents one that I designed for James Ball, Esq., of Newton. It is of a circular form, the ground constituting the bowling green being sunk two feet, and there being a terrace bank defining it all round. The circular shape was adopted as being more beautiful than a square, and as allowing, between the green and the square walk around it, an opportunity of planting the margin effectively. The main object of sinking the ground, too, was one of convenience, to save unnecessary earth-work; but it also contributes to the effect, and enables those walking in the garden and keeping on the paths to see the players better.

The top of the engraving is the north side on which the house and pleasure grounds are placed. A small supplementary kitchen garden lies on the east, with a walk into it from the center of the bowling green on this side. The plantation to the south is on the boundary of the place and there is an open field to the west. A summer house (IO) appropriately finishes two of the walks, and is a convenient resting place for the players. The figures represent the following shrubs:-
I. Irish Yews.
2. Golden Hollies.
3. Hybrid Rhododendron.
4. Erica multiflora.
5. " carnea.
6. Spirca Lindleyana.

7. Mass of Rhododendron hirsulum.

8. " " ferrugineum.

9. Beds chiefly filled with Rhododendrons, with Roses on the side next the bowling green.

Should much alteration of level have to be effected in making a bowling green, the parts raised must be well trodden 


\section{Special Features}
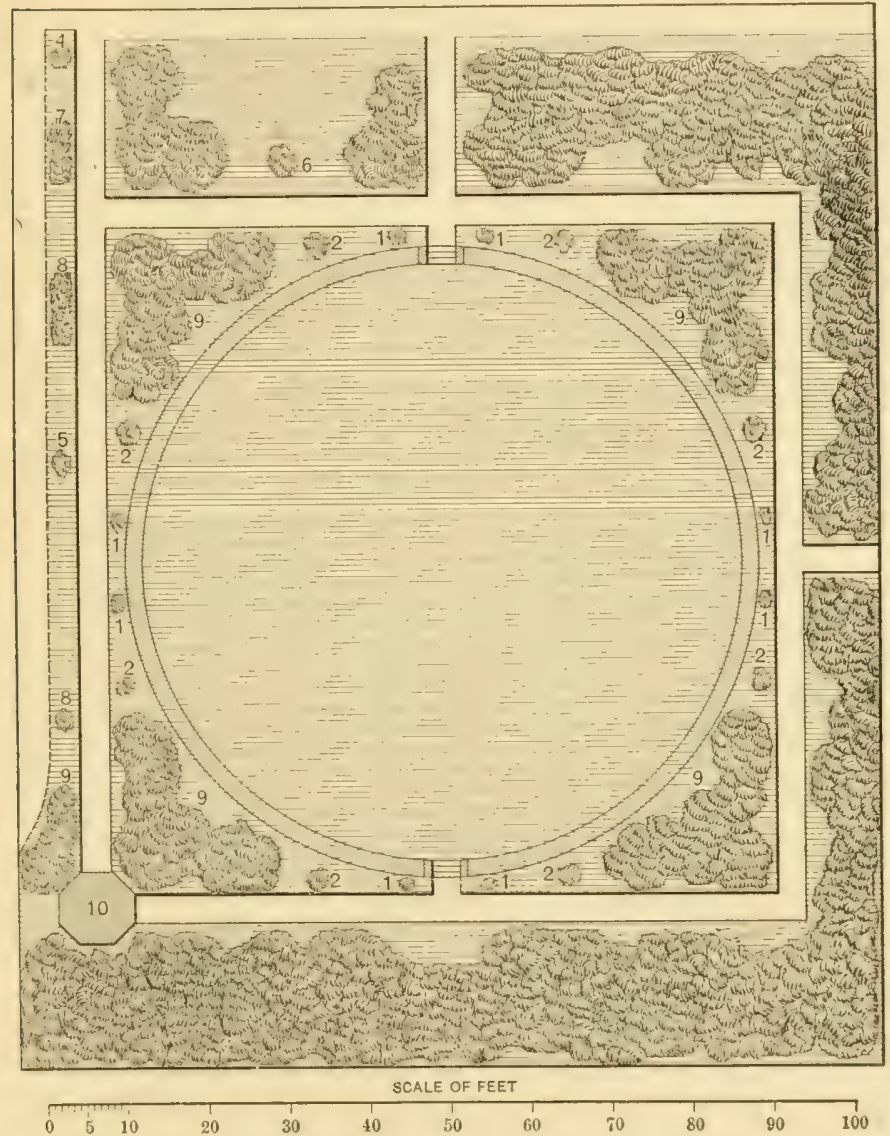

Fig. 60. Design for a Bowling Green.

and rammed at the time of filling them, that they may not settle irregularly. It is likewise a matter of importance that the ground should be laid with good old sods, in order that 
the turf may be fine, and that it afterwards may be easy to take it up and re-lay it should the levels from any cause get disturbed. For these reasons it is injudicious to sow it down with new grass seeds; for if it falls into holes or depressions, it will be impossible to alter these under four or five years, unless by the introduction of old turf in such parts.

Croquet grounds are commonly laid out anywhere on an established lawn wherever the company may wish to play. Such pastimes, however, are of sufficient value to justify more extension and thoughtful preparation. On private grounds of any importance a special croquet ground may appropriately be constructed; and this may become, not only a source of amusement to the younger members of the family, but in the hands of a skillful designer it may prove to be one of the most ornamental features of the grounds. Croquet grounds may be kept in grass, which is the preferable way considered from the standpoint of ornament, or they may be cleared and paved with gravel, brown earth, or even with cement. Such paving of course makes it possible to develop a higher degree of skill in playing, while if properly managed such a croquet court may still combine effectively with the general design of the garden.

Tennis courts are to be treated in substantially the same manner. They should be carefully placed with reference to the other parts of the grounds so as to assist instead of breaking in upon the garden design. Back stops may be clothed with pretty climbers, or may be backed up with masses of fine shrubbery or evergreens. In some cases the tennis court may be laid out on an ordinary level, mowed lawn; but as a grass court has little value for playing the game it is usually necessary to have the court paved with cinders or burnt earth. Cement has been used in some cases but it is not agreeable to the players. 
Io. Water in summer weather is always grateful by imparting at least a semblance of coolness in addition to all those beautiful and varied effects which the influence of atmospheric phenomena begets. But an essential condition to its enjoyment is that it should be pure and clear. And this it can never be unless it is either continually changing by having an uninterrupted stream of fresh water flowing through it, or by being fully exposed to the action of light and air. Ponds that are encircled by trees are nearly always foul. Having a clay bottom and slopes, however, will contribute greatly towards keeping the water pure. Aquatic plants are also of much use, when not too abundant, in preserving stagnant water from putridity.

In whatever way pieces of water may be introduced into a small place, simple forms appear by far the most congenial. Basins, either with or without fountains attached, and having a stone rim, will be in the best taste for formal gardens and can be either circular, octagonal, or of any other regular shape. Roundish or somewhat oblong pools or ponds will be another suitable class of figures for a small piece of water where more agreement with nature is sought. But if still greater freedom be desired and space be not so much an object, the shape may be more varied and irregular.

The principal advantage of a varied outline for water is that it will not be all seen at the same time and that by a tasteful treatment of its terminations considerable indefiniteness may be obtained in it. It is most essential, however, that numerous and unnecessary curves and bays which would destroy all appearance of breadth should be omitted. Islands, too, though they increase the variety and beauty of an extensive sheet of water rather fritter away and imporerish smaller lakes unless they are adapted niccly to the dimensions of the whole. 
No irregular piece of water can be made at all tasteful or pleasing unless the margins of it are appropriately planted. As with a curved walk on a flat surface, unfurnished with planting, the curves in a lake would seem needless and improper. It is therefore requisite to plant or throw up a bank on all the promontories round the margin, diversifying the shape and extent of the planting according to the amount of curve that has to be hidden. And as bare mounds would rarely look sufficient in such a position, or effect all that was required of them unless they were disproportionately high, it will be better to make them only low, and plant dwarf bushes upon them. Larger trees overhanging and dipping their branches into the water at other points will be highly effective, and the weeping kinds of tree are especially suitable for such purposes. Alders, weeping willows, weeping birch, the deciduous cypress, the liquidambar, and the tamarisk will be excellent plants for the margins of water in particular parts. For small islands, the common dogwood planted quite alone, and covering the entire island, will be very beautiful.

That a piece of water may not be too much enshrouded by trees, which I have already said would tend to make it impure, to destroy its clearness, and to deprive it of the sparkle, glitter, and capacity for reflecting objects, which constitute some of its chief attractions, a large portion of its margin, especially round the bays and recesses, should be left unplanted. All plantings, whether of masses or specimens, can be arranged mainly with reference to their actual effect when viewed from a variety of points, but not without regard to their appearance when mirrored in the water or to the shadows which they will throw upon it at certain times of the day. And in this view of the case, not merely elegant forms should be chosen, but masses of flowering shrubs which 
will produce broad effects in the way of color should likewise be employed. Such would be the rhododendrons, azaleas, hardy roses, laburnums, lilacs, etc., and, if within the pleasure grounds, hydrangeas, dahlias, or even patches of showy geraniums might be added.

Smoothness and softness in the finish of the banks around water should be a leading feature, and the grass should slope down more or less gently to the very edge of the water so that there be no hard line of earth between them. Even where the plantations come down to the brink of the water there can still be a strip of turf below them, that the water may not wash against bare earth anywhere.

In more secluded parts, water can be treated rather less artificially, and have its banks formed of partially broken ground, with rougher grass and masses of jutting rock or old roots on some of the more conspicuous points. This will heighten the variety and beauty of the reflections in it. But it requires consummate taste and art to effect anything of the sort. Gardeners in general have no notion whatever of dealing with ground otherwise than in the commonplace manner.

Aquatic plants may be grown in any piece of water, but they will be less appropriate the more artificial the water is made, and will adapt themselves better to rougher and more rustic accompaniments. If kept near the edge and placed almost wholly opposite the more prominent points of land, they will be nearly tantamount to specimen trees or shrubs planted in the front of swells in lawn plantations, and may be equally good.

Stagnant water being very apt to become corrupt and to evaporate largely in summer, some expedient should always be contrived for retaining water in lakes and maintaining a tolerably fresh supply. Thorough puddling for the bottom 
and sides will be a good safeguard against loss though it will not be needed where the subsoil is naturally a stiff clay. And as few places would yield any other resource, it will be well to keep the water in the lowest part of the land (as it should be in point of taste also) and drain the whole of the ground, excepting the kitchen garden, into it. A moderate supply, in all but the very driest weather, will thus be provided.

Where anything in the way of a small stream passes through a place, and is not at all sluggish in its course, it may be rendered additionally interesting by having its fall broken here and there with masses of rock and, where such a plan would not interfere with the general landscape, it can be covered in and darkened by plantations at various points, so as to allow small shady walks, banks of ferns, etc., by its side. When it takes a tortuous direction, walks of this description may cross it, by means of a few stones or a rough little arch, in different parts, and pass away from it for a few yards, to return again to its side in the next bend of its course.

If the position for a sheet of water be skillfully chosen, advantage will be taken of any natural stream that flows through the property, and by throwing a dam across the hollow along which it winds, a lake may be formed in a very inartificial manner and at a light expense. This is precisely the case with regard to the piece of water depicted in fig. $6 \mathrm{I}$, which has been designed for the park of Sir Robert Gerard, Bart., at Garswood, Lancashire. There is a natural concavity in the ground within view of the mansion and adjoining a small rivulet which flows from a northwesterly in a southeasterly direction, and by damming up this stream at the southern end a very little excavation would produce a sheet of water of the outline shown in the engraving and 


\section{Special Features}

leave a bank in the center for an island. The road shown in the sketch, along the eastern side, is intended for a private

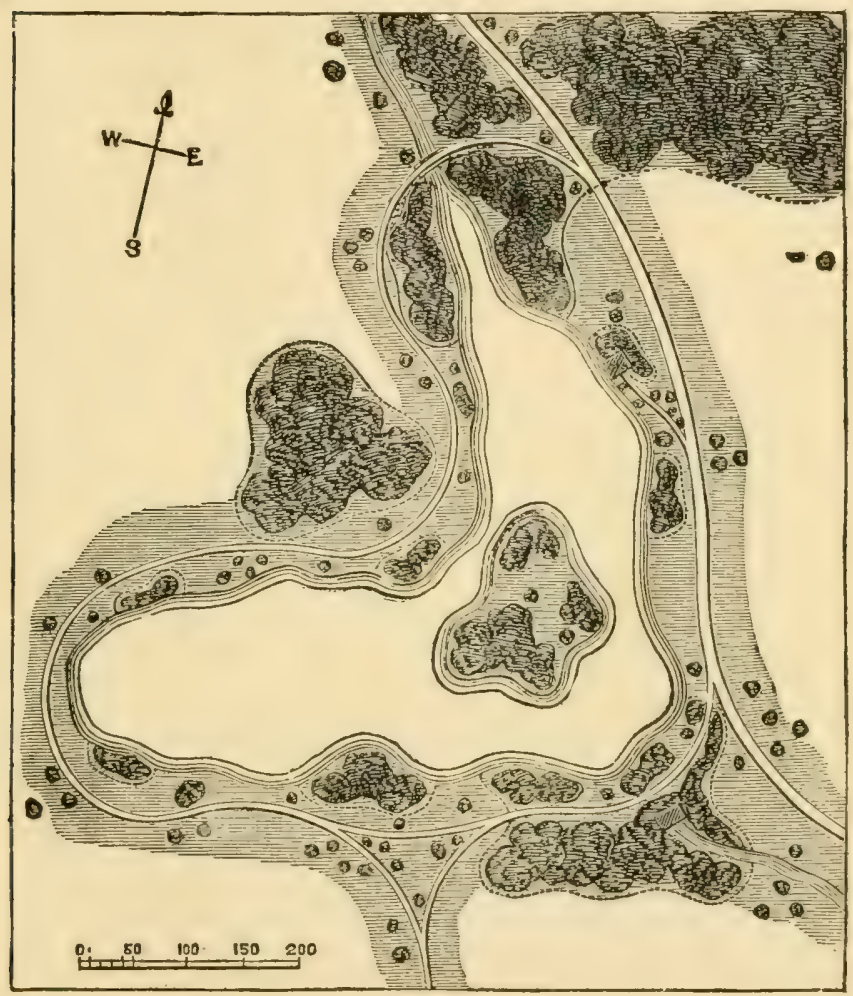

Fig. 6r. Plan of an Artificial Pond.

ride or drive, and winds from one of the main drives up the side of a picturesque hollow and through some woods to another part of the park. The short branch walk from it leads to a boathouse. And there is a separate walk from 
the house which would pass all round the lake, being kept chiefly in the open park but also running through two enclosures. The dotted lines represent the fences to all the plantations or enclosures and the mode of planting will be fully apparent from the sketch. The area of the lake would be a little less than three acres.

As will be perceived by the plan, the part about the dam is enclosed from the park, and this gives the opportunity of shaping the ground nicely there and of planting it densely. Too frequently, in such cases, the treatment of an embankment of this sort presents a singular example of poverty and feebleness of invention. It is commonly made too narrow, too abrupt, or is planted chiefly with forest trees, which, when they grow up, appear thin and meager and sometimes shut out a most charming view over the valley below.

The first requisite in making a dam is to place it at a point where the valley narrows and the adjoining banks are tolerably steep and high. A trench of at least four or five feet wide should then be taken out across the hollow and be cut down till solid ground is reached. If this be clay, it will be so much the more satisfactory. The trench should then be filled up with puddled clay and this latter be added as much as possible in a sloping bank on the side towards the intended lake, a good broad embankment being carried up simultaneously on the outside as the work proceeds, taking care also to build up a chamber and drain in cement for an overflow at the same time with a strong sluice if it is wished to have the power of drying the lake.

In planting an embankment, the predominant kinds used should certainly be bushes with only a tree or two here and there or a group of them to assist the outline. Dogwoods and willows are especially to be recommended. Any walk that crosses the dam of a lake, unless it be a branch stretching 


\section{Special Features}

down the bank for the sake of exhibiting a waterfall that may be constructed from the overflow, must be carefully kept on ground above the level of the water that it may not even appear dangerous. It may indeed be held as an established rule that water should not be allowed to be seen from a point where it seems to be higher than the ground on which the observer stands.

In making purely artificial pieces of water, the depth should not be allowed to exceed from four to five feet and

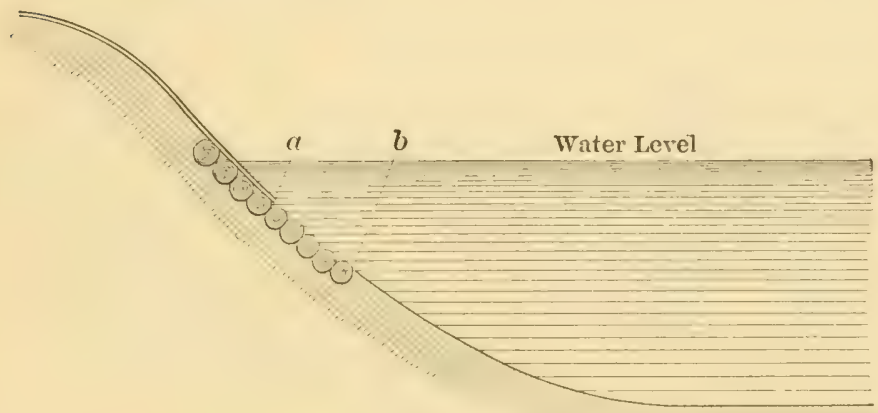

Fig. 62. Forming the Bank of a Lake.

the slope of their banks must not be too steep while it should blend nicely with the ground around. Fig. 62 will exemplify, in section, a good form for such banks. And it will also show from $b$ upwards how the banks can be pitched with stone so as to preserve them from being washed away by the action of winds on the water. The stones can either be rough boulders, more irregular small blocks set on edge, or in large flattish masses. They should be well bedded into the bank, extend two feet (in vertical depth) below the surface of the water, and present a somewhat rugged face. 
In turfing the banks above, the sod (indicated by thin double lines in the section) should stretch down into the water as at $a$, at least nine inches below the water level, for there is a manifest beauty in the perfect union of the grass and the water where the latter comes within the range of the pleasure garden. Fig. 63 may possibly suggest a hint or two in regard to the profile of groups of planting by the sides of such pieces of water.

Water birds on lakes of any magnitude in parks or on ponds in woods beyond the limits of the pleasure ground

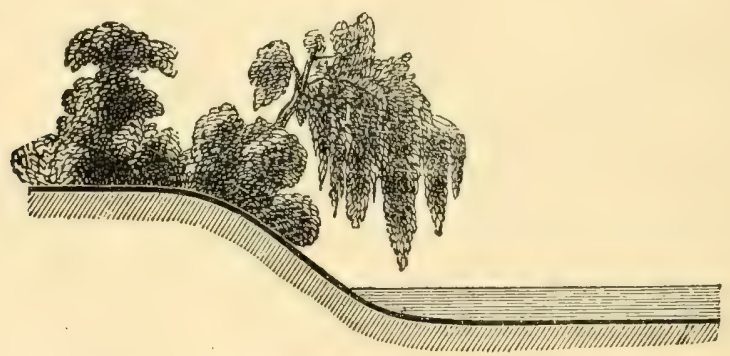

Fig. 63. Lake Shore Planting.

are generally pretty and vivacious, and give life and motion to any scene. Islands covered with dense masses of shrubs are particularly useful as breeding places for water birds, as they protect them at night from foxes and other animals of prey. Small, rude shelter houses for aquatic birds may likewise become characteristic ornaments to the margins of such islands. But water birds should on no account be admitted upon ornamental water in pleasure grounds as they destroy the beauty of the banks, foul the water, and are otherwise a nuisance. A pair of swans might possibly form an exception. 
II. Bridges, if at all wanted, ought to be of an exceedingly quiet and simple character in a small place. They should certainly never be of dressed wood or stone unless they have to carry the approach to the house over a moat, river, or similar piece of water. For merely crossing the arm of a small lake or giving access to an island, a simple rough plank, sufficiently broad and stout, with the bark left on at the edges, and a handrail made of undressed fir or larch wood with the bark on, will sometimes be suitable. Or a rather

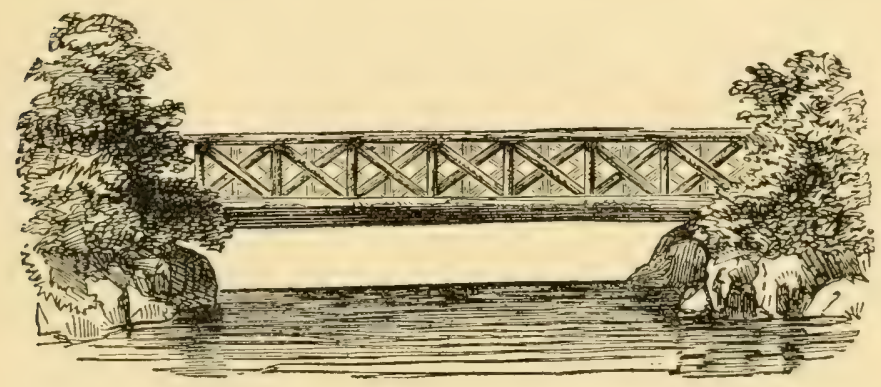

Fig. 64. Rustic Bridge on Simple Lines.

more perfect and ornamental rustic bridge, that is altogether wanting in pretension and does not stand so high as to become very conspicuous, may be chosen in other places. Lightness and yet safety, rusticity and the absence of anything marked or staring, will be the leading characteristics demanded.

One of the most obvious forms for such a bridge is exhibited in fig. 64, where two strong larch poles are thrown across a piece of water, and a path of cross pieces formed upon these, with a simple handrail, and light upright and diagonal bars of the same material on either side. This bridge is very low, 
and would not admit a boat beneath it, being designed for a stream about twelve or fifteen feet wide. But it might easily be made higher if necessary by obtaining, either naturally or artificially, additional elevation in the side banks.

Wherever bridges are used, and whatever may be their material or character, they should never appear to spring out of the bare ground or be left without proper support and furniture in the way of trees and shrubs. And the same observation will be applicable to viaducts. This provision, moreover, is not merely necessary as a matter of safety, for no extension of handrails or parapet walls would accomplish the same end. It is demanded artistically to relieve and soften the rigidity of line and to associate the object better with the natural accompaniments beyond. And where embankments have to be made at the ends of bridges to carry a walk or road easily over them, the addition of masses of shrubs to mask those embankments is all the more urgently required. The idea thus sought to be conveyed will be further illustrated by reference to the last three engravings.

12. Boathouses. - Boats are seldom desirable on a small piece of water, as they occupy it too much, seem out of proportion, and reduce its apparent limits. When the water assumes the dimensions of a lake, however, and there are islands upon it, boats become indispensable, and to preserve them some kind of boathouse will have to be supplied. In the grounds or park attached to a Grecian mansion, a boathouse in the shape of a classic temple may be appropriate. Ordinarily some very rustic kind of structure will be decidedly better.

A boathouse may take the form of a miniature Swiss cottage, and have a reading or shelter room over the part in which the boats are kept, with a good balcony towards the water to afford facilities for fishing. It may thus combine 


\section{Special Features}

three objects. Or it may, if suited to the style of the house, have a small open Italian pavilion over the boat department. Or in more picturesque scenes it may be made in the very rudest form of a low hut and simply be thatched with reeds, heather, or straw. In each of these cases however it should have a very bold, flattish, and broadly projecting roof. 


\section{CHAPTER VIII}

\section{VARIOUS ACCESSORIES}

BEsides the matters already discussed there are various other accessories sometimes convenient or even necessary in the development of the home grounds. It is hardly ever the case that all of these will be required on any one property, unless indeed it be a private park on a very large scale, yet on the whole they are often needed, and some directions for their right development may reasonably be expected in these pages. Some of these undertakings involve questions of architecture, some questions of engineering, and others bring up other technical points. It is to be expected that the householder, looking after the improvement of his own property, will consult the proper experts in all these questions. At the same time it must not be forgotten that all these matters have also their bearing on the beauty of the premises as a whole, and so come under the special view of the landscape gardener.

I. Arbors, summer houses, and covered seats of all kinds may be very convenient and productive of much comfort in a garden if a few plain rules be observed in their construction. They should be decidedly dry, and therefore must never be placed in a low or damp situation or be too much shaded or have the floor on a level with the ground. A raised floor will in fact be indispensable, and it will be drier and warmer if boarded or if open wooden stands for the feet to rest upon be fixed all round it along the fronts of the seats. 


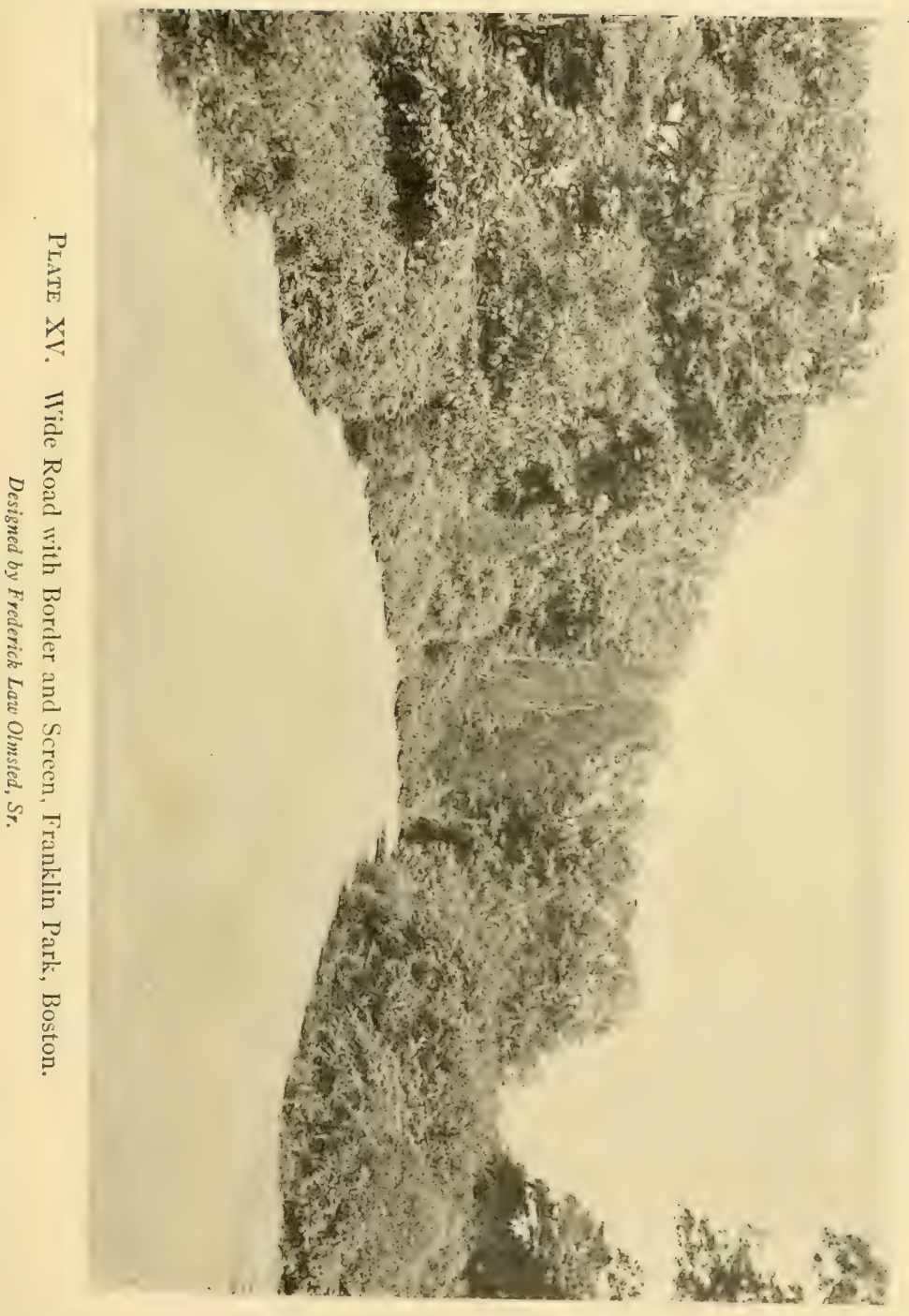



Summer houses should never be made of materials that will harbor dust, dirt, or insects. Moss or heather linings will never be quite clean, and all sorts of insects will be encouraged to lodge in them. Rough cushioned seats and backs of green baize in arbors that are open to the weather will be alike bad in the same way. And wood with the rough bark on is only a trifle better. The best lining for them is small hazel or oak boughs about an inch in diameter, unstripped of their bark which will be quite smooth, and sawn to various lengths, so as to be fixed up to some fancy figures of no very elaborate pattern. This will be clean, dry, and ill adapted for the encouragement of insects, also very durable, which none of the other things named are at all likely to be.

In point of taste summer houses should be concealed from the windows of a dwelling or correspond with it in style. A rustic arbor will not, however, be an unfit accompaniment to a building in the Swiss character or even to some kinds of Gothic if its details be accommodated thereto. But it would be entirely inharmonious with a building in the Grecian or Italian manner which demands more artistic and classical attendants. Everything rustic should, if employed at all, be planted out from the view of such houses. And perhaps the fittest form in general for a garden decoration of this sort will be some truly rustic object, made of rough wood, unbarked, thatched with reeds or heather, and partly covered with climbers, but partly supported by trees and shrubs, out of the front of which it should appear to spring. In other cases summer houses of purely classical design may be used with the very best effect on ground developed in a formal manner and in accompaniment with a house of Italian style.

Fig. 65 represents the elevation and ground plan of a rustic summer house which I erected for David Bromilow, Esq., 


\section{6 \\ Landscape Gardening}

and is made simply of unbarked larch and thatched with heather, the interior seat and lower part being lined with dressed and stained deal. It is placed on a mound in the pleasure grounds.

It is to be observed that the present style for arbors in

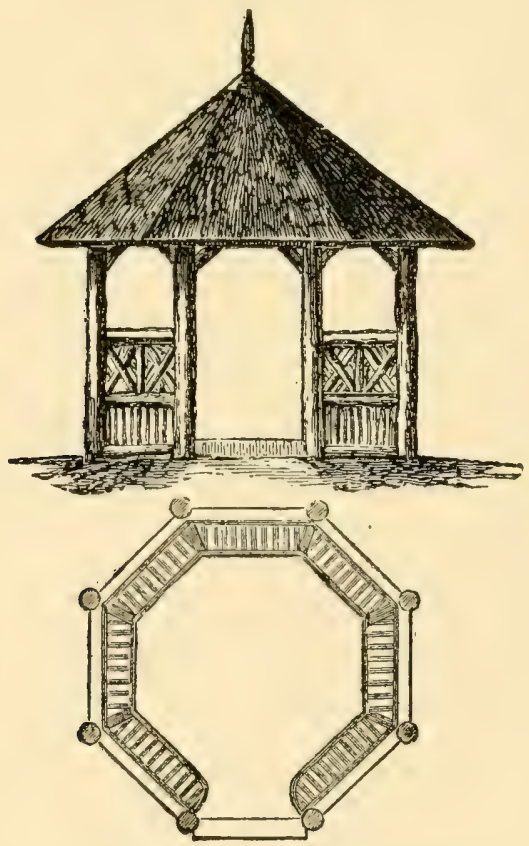

Fig. 65. Design of a Summer House.

America has taken a somewhat radical turn. Whereas fifty years ago rustic arbors were recommended by all landscape gardeners and built on almost every ground, they are now very rarely seen. Grounds designed in a formal style nearly 
always have pergolas, which in a great measure serve the same purpose under another name; but grounds designed in the natural style nowadays commonly have nothing of the sort. The only substitute is the porch or wide house veranda, where the family and friends may sit out of doors to read, sew, gossip or, at times, to enjoy a social luncheon. As outdoor life is to be encouraged in every way, and as the use of a garden or private park is equally to be recommended, the introduction of attractive summer houses or arbors really ought to come back into vogue.

2. Statuary, vases, and similar architectural ornaments, are the fitting associates of Grecian and Italian houses, and are decidedly less suitable in relation to every other style. Not that such things as low terrace walls with or without tracery, pillars for sundials, ornamented with the details of pointed architecture, and even vases or urns of a particular form and with proper decorations, will be faulty in connection with Gothic buildings, and formal gardens of the same character. Only, the varieties of the Grecian style, with their architectural arrangement of walks, beds, etc., would appear to correspond most with and demand such ornaments as vases, tazzas, urns, pillars, sculptured figures, basins of water, with fountains, and the like things, to carry out and finish their expression and design.

It may be worthy of consideration in adapting statuary or sculptured figures to the purposes of garden ornament whether there is not an unmeaning anachronism in our persevering adherence to the old classical subjects and nude representations, and how far it may not be desirable to break from such trammels and present rural objects, local peculiarities of costume, or some artistic embodiment of such ideas as the country and a garden suggest. For, apart from the mere beauty of form, it surely cannot be fitting that the 
subjects proper to a sculpture gallery should be transferred at pleasure to the region of the garden as though the latter could claim no style of embellishment peculiar to itself.

Besides the choice of subject however the style of treatment in garden sculpture requires revision. Excessive smoothness, such as will be found in naked figures, is a great charm in works that are to be examined closely and in the house. But out of doors the greater ruggedness of drapery and the introduction of rougher, bolder, and more prominent parts, such as will yield shadows and impart picturesqueness, will be more satisfying to the eye, and more in harmony with natural objects.

Figures that are composed of plaster and colored nearly white have a very paltry look in a garden, especially if they are so small as almost to degenerate into images. Plaster vases, however, or rather such as are composed of what is termed artificial stone or terra cotta, will, if properly colored and sanded, scarcely be known from stone at a little distance.

All sculptured ornaments that are employed in the neighborhood of Grecian buildings should be classical in their design, and of whatever material be well executed. Any inferior thing in either of these respects had better never be introduced. Comparatively few manufacturers seem to hit upon pure and simple forms for vases, though there is happily a better taste beginning to prevail in regard to all such subjects.

Some latitude of choice is allowable with respect to the positions of any architectural figures in a garden. They ought not, however, to be placed out on the middle of a lawn, except in very rare instances (such as sundials occasionally), nor can they usually be allowed to stand on bare earth or in the midst of a bed of flowers or shrubs. The fittest spot for 
them seems to be in the immediate vicinity of buildings, on or near low terrace walls, at the ends of walks, on gravel, at the corners of a square or oblong plot that is surrounded by walks, in the center of a circular plot, or in the middle of two walks where they cross each other.

3. A greenhouse or conservatory is a luxury which few who can afford it and are fond of plants will be disposed to forego. When attached to the dwelling house, which is at once a convenience and a disadvantage, it is too often erected as an afterthought and thus appears as a patch to the building or is merely tacked on to it by the architect as a part of the first design on account of the difficulty of making it enter into the composition of a structure. The difference between a greenhouse and a conservatory is that the former is for the entire cultivation of plants, and the latter only for their display when in a flowering or otherwise interesting state. The mere fact of being attached to the house does not of itself form a distinction, unless the bulk of the objects in it are planted out in beds or borders, when it becomes a conservatory, however small may be its dimensions or however it may be otherwise employed.

If united to the house it should be made a decidedly architectural object and not look like a superfluous appendage of a different character. Light iron conservatories with curvilinear roofs can seldom, if ever, be properly blended with the rest of the building. Sufficient lightness and elegance may always be readily attained without such incongruity. The front of a conservatory in the position under notice should generally be as high as the ceiling of the ground floor of a house, and its cornice range with the string course of the building, if there be any. The roof may be kejt as low as possible, so as to be very little seen. All heavy pillars, mullions, etc., must be expressly avoided, for one of the most vital fea- 
tures will be the free admission of light, if plants are to be grown in the house. But if intended only for flowering plants, light is not so much an object. Liberal provision should also be made for ventilation at the sicies and in the roof and a proper command of heat will be absolutely requisite. The best aspect would be southeast or southwest.

Although having a conservatory thus within, as it were, the walls of a dwelling makes it delightfully accessible at all seasons and gives a pleasant object through one of the drawing-room or library windows when it is thus entered, yet the only kind of structure that can consistently be built in such a situation will not be fit for growing plants in; and unless an additional plant house be possessed or an adequate number of pits and frames to maintain a perpetual supply of blooming plants, a house of a different character in another position will be highly desirable.

A conservatory that communicates directly with one of the chief entertaining rooms is sometimes found objectionable on account of admitting dampness, an earthy smell, or the odors from fumigation by tobacco. It is therefore generally better to connect them by a glass corridor or interpose a small ante-room, museum, or sculptor-room between them and the drawing-room, or remove them still further from the house and approach them by a covered way. It is no doubt very agreeable, where there is a suite of rooms terminating in a conservatory, to be able to open them to the latter at night, for the purposes of an entertainment. But it must be remembered where gas is used that this is highly injurious to plants, and often causes them to throw off all their flower buds.

When a corridor separates the conservatory from the house it affords an opportunity for making a difference of level between the two points. And a conservatory that is two or 
three feet below the floor line of the house will have its flowers much more favorably displayed from the window or glass door that may lie in that direction.

No conservatory should ever be put on the entrance front of the house. It is an inversion of all rule, which presents the best feature of the garden first and destroys all privacy. Where a house is very near a public road, however, and there is not room for a carriage drive within the gates, or it is desired to have the bulk of the place seen only from the principal windows of the house, a glazed corridor of sufficient breadth to receive plants on both sides of the passage will form a charming entrance porch, flowers in a vestibule or lobby always appearing to give a visitor a smiling and cordial greeting.

Sculpture of a high order in marble, or marble vases, urns, tazzas, etc., can be most fittingly accommodated in architectural conservatories, whether on pedestals or in niches and recesses. Nothing throws out and relieves marble statuary so well as dark-foliaged plants.

Color, too, may be sometimes employed in picking out the moldings of the rafters, but it should not be too glaring. It is altogether a mistake to ignore entirely the use of color for conservatories and to adhere to the cold and monotonous white which is most frequently selected. A warm stonecolor, with the mere sashbars painted white - or if the framework be of wood, stained deal or oak graining - will be greatly superior to white, and stages (of wood) should invariably be painted green.

Detached greenhouses for the growing of plants should be provided whenever practicable. Their design and erection should nearly always be left to some concern which make that work their business, though the location and external design should always have the approval of the landscape gardener. 
4. The Kitchen Garden. - It has before been intimated in passing that a kitchen garden should be placed in the rear of the house and be as near as possible to both it and the stables, communicating with each pretty easily and directly and without the necessity of going through the pleasure grounds. The reason of these things is plain and simple. As a kitchen is itself generally kept at the back of the house and a kitchen garden has to be in communication with it, the two should be in close proximity. The manure, from the stables, having to be used in the kitchen garden, ought to be capable of being readily applied, and hence the desirableness of connecting the two parts as nearly as can be done.

A kitchen garden, being intended for convenience and use, should be of some regular figure and have the walks, beds, and borders, as much as practicable, in straight lines and at right angles with each other. Any different arrangement would waste the ground and render it less easily worked.

Where practicable and when the space is pretty ample, a kitchen garden will be warmer if entirely walled in, and the walls will supply the means of growing a number of the better sorts of fruit trees, a fashion which is now coming into use again in America after many years of neglect. The wall on the side nearest the north should be at least twelve or fourteen feet high and like all the rest should have a coping to project two or three inches. There may also be a good plantation of trees behind this wall, if convenient, or at no great distance from it, to increase the shelter. The side walls may be of the same or of a lesser height - ten feet will probably be sufficient. And the front wall should not be higher than six feet or five feet six inches; or its place may be supplied by a hedge, if absolute enclosure is not needed. Where a plantation is necessary on the south side of a kitchen garden to 
screen it from the pleasure grounds, it should be composed only of shrubs.

All round the inside of a kitchen garden, whether it have walls or not, there should be a border of greater or less width, that according to its aspect the various kinds of suitable plants that take up little space or require a peculiar position may find their proper place. Such borders are still more requisite when there are walls, to give space for the roots of fruit trees to spread in them and to bring the trees more thoroughly within reach. They may vary in width from six to twelve or fifteen feet, with reference to the size of the garden and the kind of tree that has to be cultivated in them and the height of the walls. Borders with a warm sunny aspect may bewider than such as are colder and more shaded.

On the inner side of the walks and either at the front or back of another small border, a good place for fruit trees treated as espaliers will be found. When walls are not used or there are not enough of them for growing such things as some of the better kinds of pears, espalier fences will be a good substitute and may sometimes be employed with advantage for apples likewise. Strong wire fences about six feet high for espaliers are now mostly preferred to wooden ones for appearance and durability, and they are also more convenient because of the smallness and roundness of the bars. In the absence of espaliers, however, these inside borders may be appropriated to dwarf pear, apple, cherry, or plum trees, and if the space permit to gooseberries and currants as well. The borders which run north and south should generally be devoted to espalier and other trees, and gooseberry, currant, raspberry, or other bushes be put on the borders that take a contrary direction. This rule is clerived from the amount of shade cast by trees, however dwarf they may be. 


\section{Landscape Gardening}

When the form of a kitchen garden is a parallelogram the longest sides should be those from east to west that a greater length of south wall may be obtained. And if there be a secondary slope in the ground as well as one to the south it should be to the west in preference to the east; for crops that are growing on an easterly bank suffer most from spring frosts, in consequence of their catching the sun so much earlier in the morning.

Either within the kitchen garden or not far from it, there should be a moderately large cistern, basin, or pool of water, or a pump with an open cistern attached. A good deal of watering is sometimes required, and water is always so much better for plants when it has been well exposed to the action of the air in an open cistern or vessel.

Somewhere at the back of the kitchen garden, one or more sheds will be wanted for a variety of uses, together with a yard for rubbish, manure, compost, etc., and which last should be accessible at some point with a horse and cart.

Perfect drainage is particularly essential for a kitchen garden, also a rather deep alluvial soil. Beyond the depth of two feet, however, any ground or border will be unfit for fruit trees, and for the better kinds it will be prudent to put a layer of stones and rubbish below the border at that depth to prevent the roots from passing away too far from light and air. If a kitchen garden be on a slope towards any point near the south it will be drier and warmer, both of which would be advantageous.

A kitchen garden may sometimes be made to embrace an ornamental strip of ground down the center, for the display of flowers, and this may take the form of a border on either side of a grass path, or of a series of flower beds cut out of grass, on the sides of a gravel walk. In both instances the dressed portion should be well defined and separated from 
the vegetable department by hedges or by what would be much more appropriate and useful - espalier fruit trees.

Orchards should be introduced as a part of every rural estate which has more than the most limited area. An orchard will give opportunity for the growing of fruits in much greater quantity than will be supplied by the dwarf fruit trees already suggested for the kitchen garden. Nothing can be more ornamental in itself than a thrifty orchard, particularly of apple trees. The climate varies so much in different portions of America, and with it the requirements with regards to orchards, that general directions can hardly be given. At any rate such instructions can better be sought in books devoted to fruit growing than in one devoted to ornamental gardening.

5. An aviary may occasionally be a very pretty feature in a garden and give a character to a spot that would be otherwise dull or defective. It will be proper in almost any of the sites which have been declared suitable for summer houses, and may be made rustic, trellised, or architectural as the locality may demand. It ought, however, by all means, to be sheltered, sunny, and dry, or the birds will never be healthy, and to be kept close and heated artificially for tender birds or more open and airy for such as are hardier. It should be well paved or floored with asphalt to exclude vermin. A recess at the back or end of a conservatory is sometimes selected for canaries and birds from warmer climates and is particularly appropriate for any song birds, their notes seeming to sound more natural and tuneful among plants and flowers.

For bees, the kitchen garden is a more congenial place, though a neat set of hives would not be an unfit decoration to the pleasure grounds, in a private part. They ought to have plenty of sun, and some shelter, and be kept at a dis- 
tance of several feet from a walk, that persons may pass by without interrupting them, or incurring the danger of being stung.

6. The Gate Lodge.--Although the old-fashioned notion of a porter's lodge at the entrance gate of a private place has fallen into disfavor in America, and although lodges will seldom be needed in a small place, it may be well to offer a few suggestions respecting them with an eye to cases in which they may be legitimately introduced. Unless a drive is long enough to carry the entrance so far from the house that the lodge would not be seen from it, the erection of a lodge at all will be in very questionable taste, for one of the first requisites is that it should not come into view from the windows.

The smaller the place and the shorter the drive, the more quiet, modest, and low should be the entrance lodge. Sometimes however in peculiar situations the offices of the house or other buildings may be so lengthened out that the lodge will form a portion of the entire group, when it may properly have an upper as well as lower floor. In general however it should be all on one floor and ought always to correspond with the style of the house, being rather plainer in its character than more ornamental. It must likewise blend with the entrance gates and gate piers in its character and fittings.

A lodge should be so placed as to command the best view of the gates to which it must be near enough to appear to belong to them; and it should also overlook as much of the outside road and of the drive as possible. For this last reason it is better to put it on the inner side of the curve which the drive may take where this is at all practicable. A few flowers and flowering shrubs around a lodge will be proper accompaniments to it as a dwelling and will make it 
appear lively and pleasant. There should not be any regular garden attached to it however. A small porch with climbers where the style will allow it is always pretty, cottagelike, useful, and attractive. Even a plain covered way round two or three of its sides supported by rude pillars for climb-

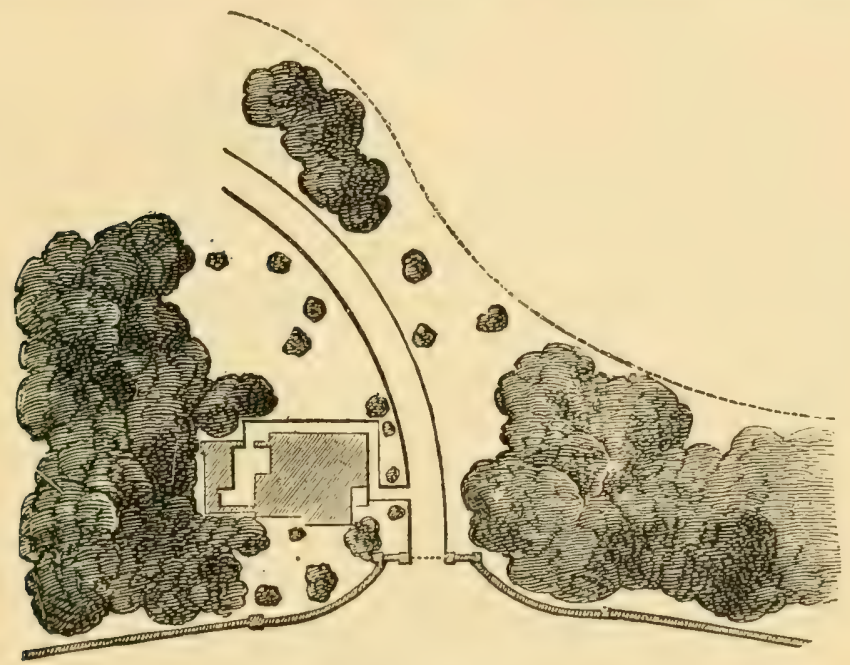

Fig. 66. Gate Lodge and Entrance.

ing plants will be a congenial and delightful feature in summer.

The position of a lodge and the form which wing walls to an entrance may assume will receive additional illustration from the examples now to be adduced. Fig. 66 shows the entrance to an exceedingly delightful place in the valley of the Lune, about three miles above Lancaster, which I arranged for Adam Hodgson, Esq., of Liverpool. The house is planted on the spot which has been aptly described by the poet Gray as presenting "one of the best afternoon views 


\section{$248 \quad$ Landscape Gardening}

in England." The site is an elevated platform, with a sudden bend in the river immediately below it, and a long, winding stretch of river extending up the valley to the east, the valley being closed in at its head by the highest of the Yorkshire hills - Ingleborough. To the southeast and south there is a most picturesque and varied hill partially clothed with woods and always presenting the most striking diversity of color. On the north side, within the estate, is a wooded eminence scarred with rock and broken by an old quarry. And the place has had the advantage, in the disposal of its woods, of artists no less distinguished than Mr. Gilpin and Sir John Nasmyth.

The entrance is in the bay of a curve in the high road and the lodge is an attractive design in the Gothic style. It is proposed to erect low walls between the piers shown in the wing fences, and put a low iron fence composed of two or three strong horizontal bars with only the necessary uprights at intervals, on the top of these walls. The drive which is only between 300 and 400 yards long will be kept entirely within the enclosure of the dressed grounds.

Fig. 67 shows the entrance to Halton Grange, near Runcorn, the residence of Thomas Johnson, Esq. The lodge here being in the Italian character and the walls about the gates being treated in a more elaborate architectural manner, there is a propriety in making them concave to the high road, a device which always gives emphasis to the entrance to a place, and also adds dignity unless the space be badly treated. The drive, too, being much longer, and there being another gate at the point where the pleasure grounds are entered, the plantations have to be fenced in separately as shown by the dotted lines, and the wire fence on the left includes the small grass plot around the lodge. This entrance is close to the boundary of the property, that being the side on which Run- 
corn lies, and it being nearly always approached from that quarter.

The plan, fig. 68, exhibits an entrance of a more imposing class and belongs to a much more extensive property. It is the principal approach to Leighton Hall, near Welshpool, the

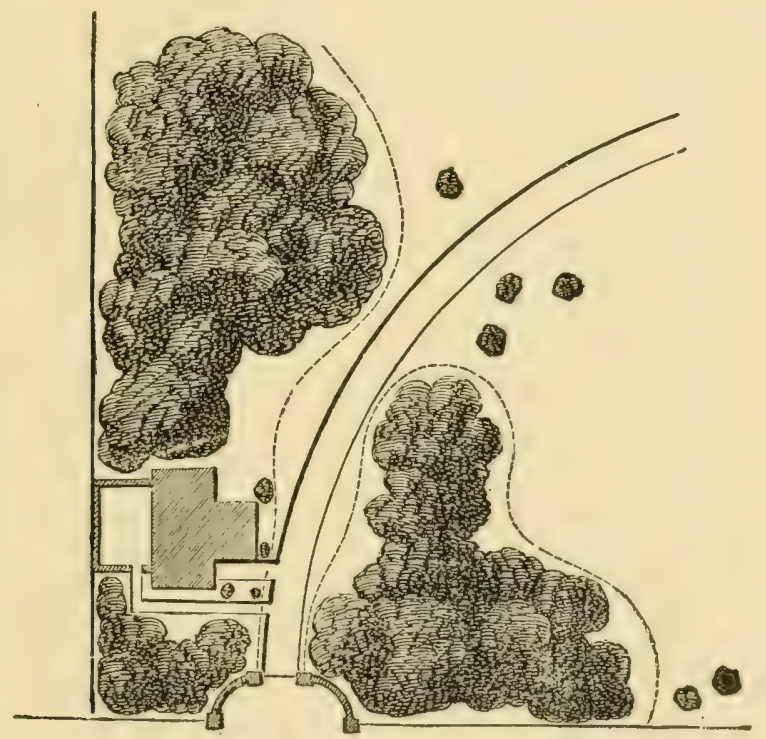

Fig. 67. Simple Lodge and Entrance.

seat of John Naylor, Esq. The wing walls and lodge are of stone, a species of black trap, with white stone copings and trimmings, and there is an elaborate and massive archway for carriages, with side arches for foot passengers. The ogee form of the wing walls is in itself elegant and is adapted to the Gothic style of the lodge and mansion.

My last illustration of this class, fig. 69 , is drawn from a 


\section{0

new entrance, sketched by me, to the property of Sir Robert Gerard, Bart., at Garswood. The point of entrance here is particularly happy, being at the junction of four roads, - a circumstance that is often of itself sufficient to determine the position of some kind of inlet to a place. Being intended

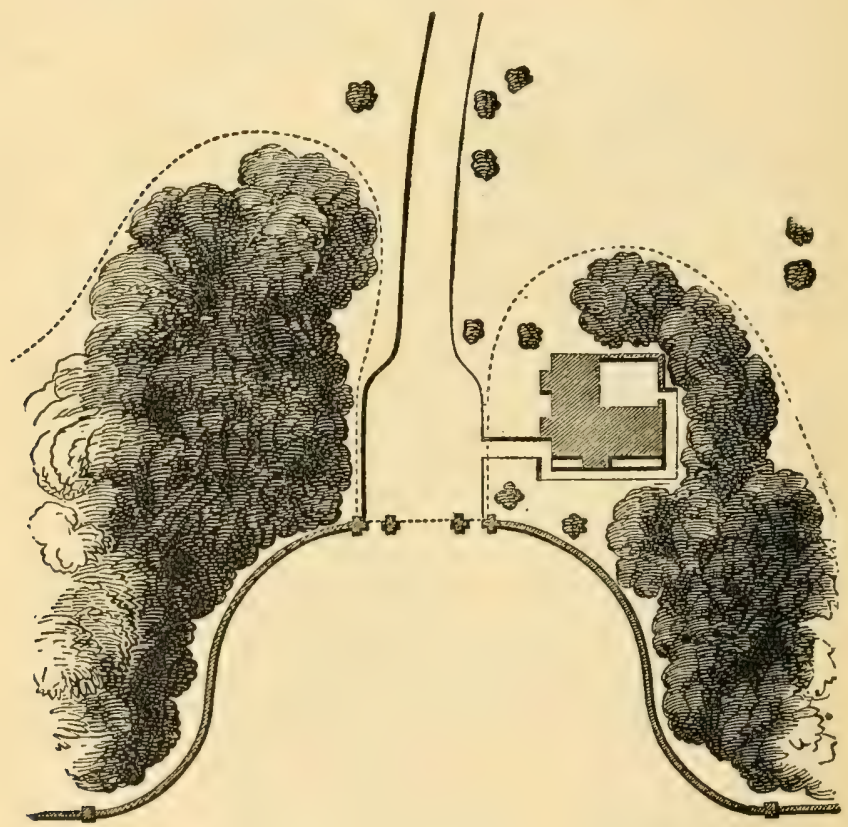

Fig. 68. Imposing Recessed Entrance.

chiefly for the St. Helens road, however, it is called the St. Helens entrance to distinguish it from two other approaches to the hall. And as the property around it belongs to Sir Robert Gerard the corners between the contiguous roads are intended to be cut off from the fields behind them, and planted in the manner shown, being kept in grass, and separ- 


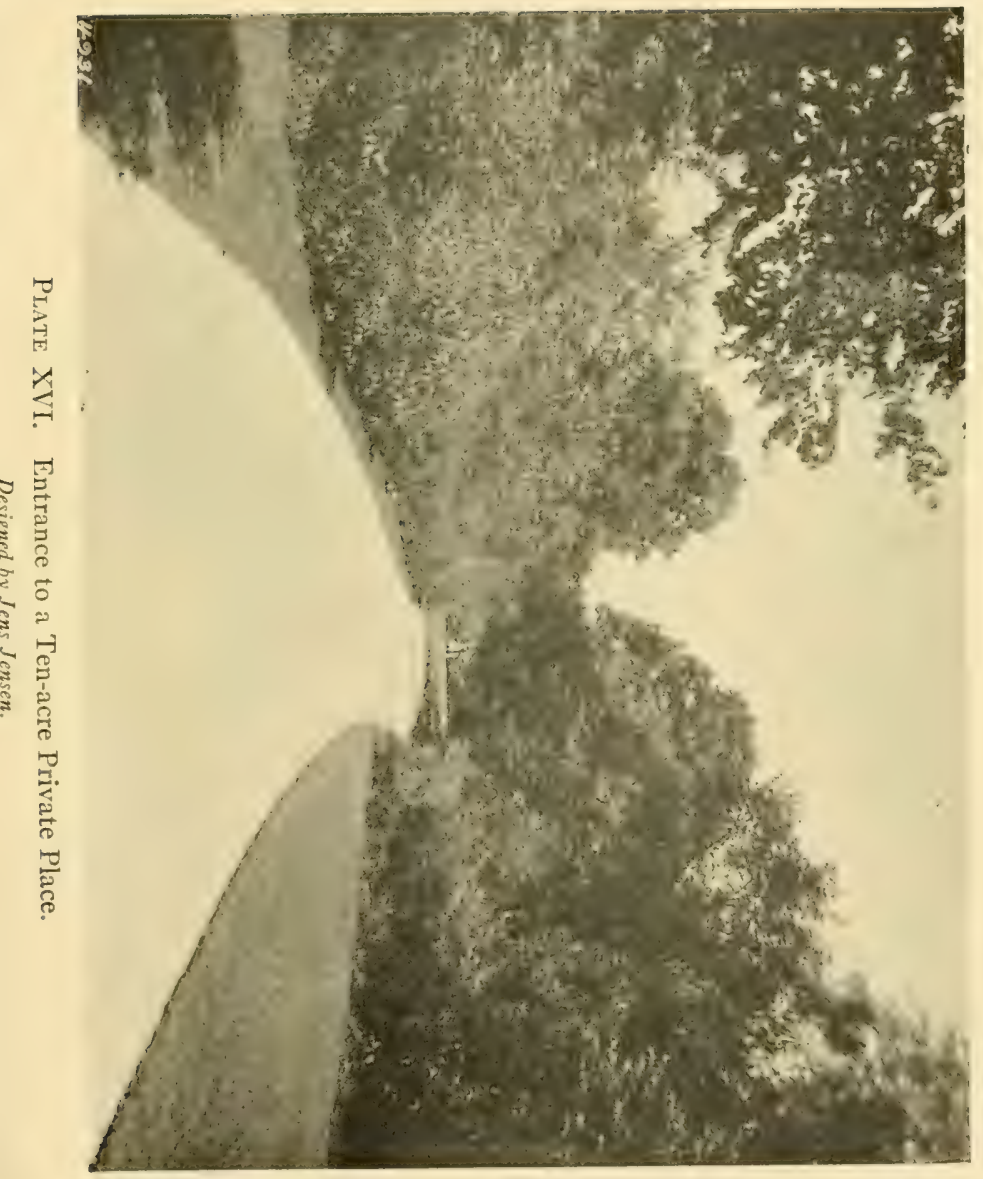



ated from the roads only by an open fence of posts and chains. In this way there will be a certain amount of suitable furniture all around the entrance. The wing fences will

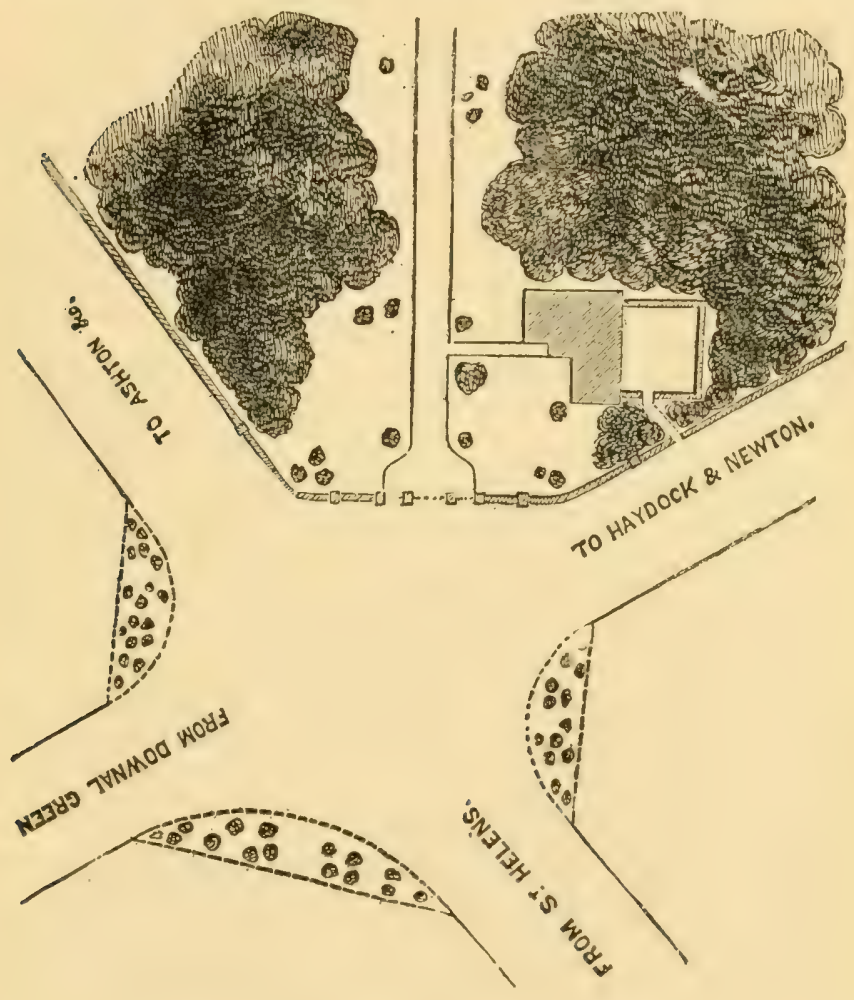

Fig. 69. An Unusual Type of Entrance.

be of ornamental iron, on a proper plinth, and will extend on either side as far as the last piers shown in the sketch where they will be joined by the park wall. The gates, of which 
there will be one for carriages, and two for foot passengers, will be of similar material. The drive is straight only in so far as it passes through an old plantation which is kept as an enclosure. After leaving this it will curve gently to the right across the park to the hall.

In each of the plans thus given the lodge is supplied in its rear with a small enclosed yard containing the usual conveniences. All the lodges are on one floor only and all are more or less embosomed in trees.

Double lodges, one on either side of entrance gates, have a great air of pretension about them and can seldom be justified by necessity. The only way, indeed, in which they can be rendered tolerable is by connecting them with a central archway or otherwise working them up with the aid of walls into one group; the lodges themselves being partly thrust out beyond the walls. Even then, however, their use is very questionable unless the entrance to a place should happen to terminate the street of a town or village, when two lodges corresponding in position and character may possibly be made effective.

7. Seaside Gardens. - Certain localities in the neighborhood of the seacoast are so liable to a visitation of violent gales, bringing with them such quantities of saline matter, that scarcely anything in the way of trees and shrubs can be induced to live in them, much less to become ornamental. And where, as is frequently likewise the fact, the surface of the land is covered solely with sterile sands, which, unless clothed with vegetation, are constantly shifting their position, it is the more important that some definite rule of treatment should be established which shall at least help to mitigate or remedy the evil, and give a special sort of interest to a place. This renders it proper, therefore, to devote a few words separately to seaside gardens. 
The mode of arrangement which I have found most satisfactory under such circumstances is to give great prominence to grass in a garden and by banks of varied form and height to secure some degree of diversity, obtaining shelter also by depressing certain parts of the lawn and throwing these into the shape of a sunk panel. Fig. 70 will more fully explain my meaning, this being the plan of a portion of the garden to be attached to a villa at Birkdale, near Southport. The land is close to the seashore, and is composed entirely of sand. The place is open to the full violence of the northwesterly gales.

In the plan, I is the house, 2 the house yard, 3 the stables and similar outbuildings, 4 a part of the stable yard. There is a descending terrace bank two feet deep at 5 , vases on pedestals at 6 , another descending grass bank four feet deep at 8 , a sunk level lawn which might have a few flower beds upon it or be used as a bowling green at 9, a strong close wooden fence along the seashore at Io, and a path to the seashore which would be common to this house and to a contiguous villa at II, the path being kept low where it passes the pleasure garden. The dotted line 7 merely shows the edge of the bank whence the ground drops rapidly to the shore.

Such peculiarities as the altered surface of the ground will present may be better understood from the section, fig. 7I, which is to the same scale (vertical and horizontal) as the plan and is made from the line A to B on the latter. By this it will be seen that the ground on the south or entrance front of the house is to be five feet below the ground immediately north of the house. This is purposely designed to act in connection with the house, outbuildings, and walls from them as a shelter to the south garden. And as the sand is so easily and inexpensively removed almost anything may be 


\section{$254 \quad$ Landscape Gardening}

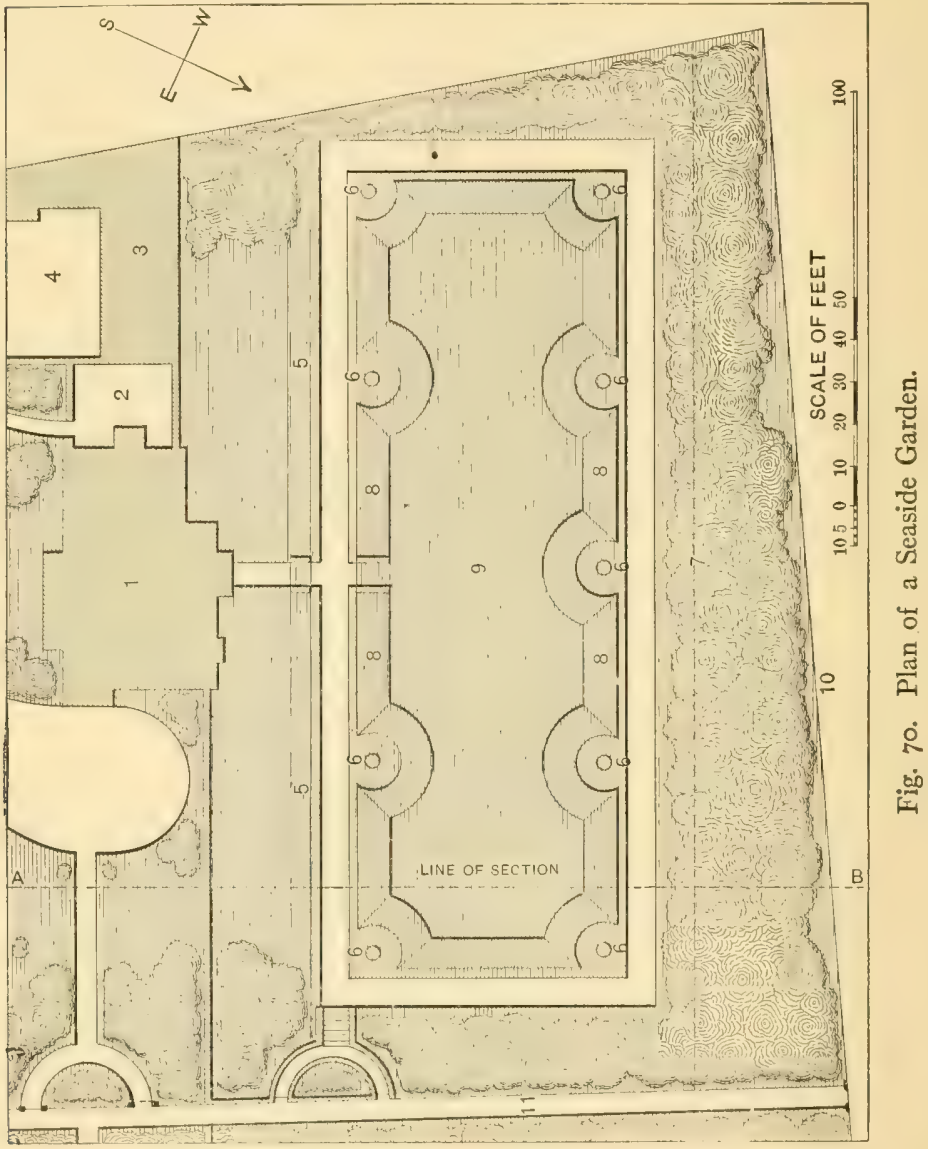

done with it. The section will further show the drops and depressions in the north garden and the slope to the northern boundary. This slope is to be densely covered with poplars, willows, Wych elms, and sycamores, which when growing 
in masses will rise five or six feet above the top of the bank and thus produce a fringe of summer foliage as well as impart additional shelter to the sunk lawn. The planting at the sides will be of a similar description with double and single furze to give a little evergreen clothing at the edges.

By the variation of line in the terrace banks, and by having the entire lawn very evenly laid and nicely kept the want of shrubs and flowers will in some degree be counterbalanced, and there will be scarcely any bare ground for the wind to act upon. In preparing the ground for either grass or planting here it is customary to fix the sand by spreading over it a coating of mud, which is obtained on the seashore and is of a somewhat tenacious or clayey nature. And it is

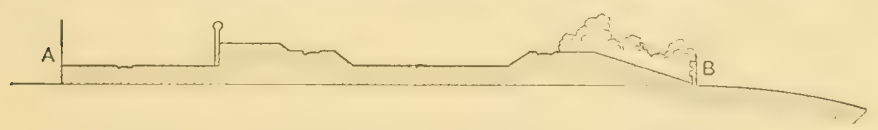

Fig. 7I. Section through Garden shown in Fig. 70.

remarkable how such trees as sycamores will contrive to draw support from the mere sand by striking their roots deep and transforming them into a fleshy instead of a woody substance. In remoring some old sycamores from a similarly sandy locality several years ago, I found that their roots had entered into the sand to the depth of ten and twelve feet, and that these roots were of a succulent nature and fully half an inch in diameter throughout.

8. The Town or City Garden. - Another description of place that calls for a brief special notice is the town or city garden which is commonly a natrow strip) of land but little if any wider than the house which stands upon it, and rarying in depth according to the value of land in the neighborhood or the position of the adjoining roads. For gardens of such a class and shape there can be little question that the most 
regular plan of arrangement will be in all respects the best. The walks should be straight and at right angles and the beds and masses be symmetrical and well balanced. A walk on either side of such a garden or one down the center will be preferable to having a walk on only one side. And effect may be aimed at in the way of lines or rows of beds and plants with a summer house, a small greenhouse, a vase, a cluster of shrubs, or other pleasing object to terminate the little avenue thus created.

As much of open lawn as is practicable and a predominance of evergreens will be desirable for such gardens, since these will be agreeable at all seasons of the year. And extreme smoothness and neatness of finish and of keeping are essential. The beds introduced should be scrupulously simple in form and arrangement. 


\section{CHAPTER IX}

\section{Practical Directions}

Questrons of taste having now been discussed to as great an extent as is compatible with the limits of a book like the present, I have only further to notice a few things respecting the actual execution of work; and these refer rather to matters of expense or comfort and the elements of success in cultivation. Of them, likewise, it may be truly said, as of points in taste, that little considerations will often be far from light or trifling in their influences but may determine altogether the propriety or undesirableness of any particular course. Indeed the nearer we approach to subjects entirely practical the more weighty and important will every topic of inquiry become, in proportion as necessary things are of greater moment than such as are merely desirable.

As books, however, can only deal with general points of practice there will not be much in this part of the work to detain us long. The more minute details belong rather to the business of ordinary gardening than to that of laying out and forming a place.

r. Drainage. - The first operation on land that has to be newly arranged will be to drain it thoroughly. No description of ornamental or useful plants will thrive well upon undrained ground that is not naturally dry and open nor can such land ever yield any permanent enjoyment and comfort. A cold damp soil is decidedly uncongenial to both animal and vegetable life.

Drainage is not merely valuable in the removal of the stag- 
nant water which is so injurious to plants and so productive of discomfort; it also has the direct effect of making the soil warmer and admitting air and gases freely. The temperature of ground that is saturated with water can never be greatly increased, by whatever power of sun it may be acted upon, nor can air circulate properly through a liquid medium. Warmth and air to the roots being essential to the healthy growth and fertility of plants, drainage becomes of the highest consequence in soils that are naturally wet.

Underdraining is now generally admitted to be the only effectual mode for any description of land, but this is especially the case with garden ground. The roots of many vegetables, and most trees and shrubs, strike down so far into the earth that shallow drains would be continually in the way of their progress, and would be very liable to be choked or injured by them. The more close, hard, and retentive the subsoil may be, moreover, the stronger will be the necessity for deep drains. Still, any extravagant depth need never be attempted. Three feet six inches to four feet below the ordinary surface will in general be the utmost depth required for common drains, while main drains should be two or three inches deeper. Where the substratum is only sandy, three feet for the ordinary drains will usually be enough. They can be about three inches wide at the bottom and fourteen or sixteen inches, or just enough to admit the draining tool conveniently, at the top, keeping the main drains one or two inches wider at the bottom in accordance with the size of the tiles to be employed. Common drains in gardens may be in parallel lines of not more than five yards apart and nearer if the soil be very heavy.

Tiles or pipes are the materials most frequently chosen for draining land, though they are certainly not the best for gardens or where trees have to be planted. They are very 


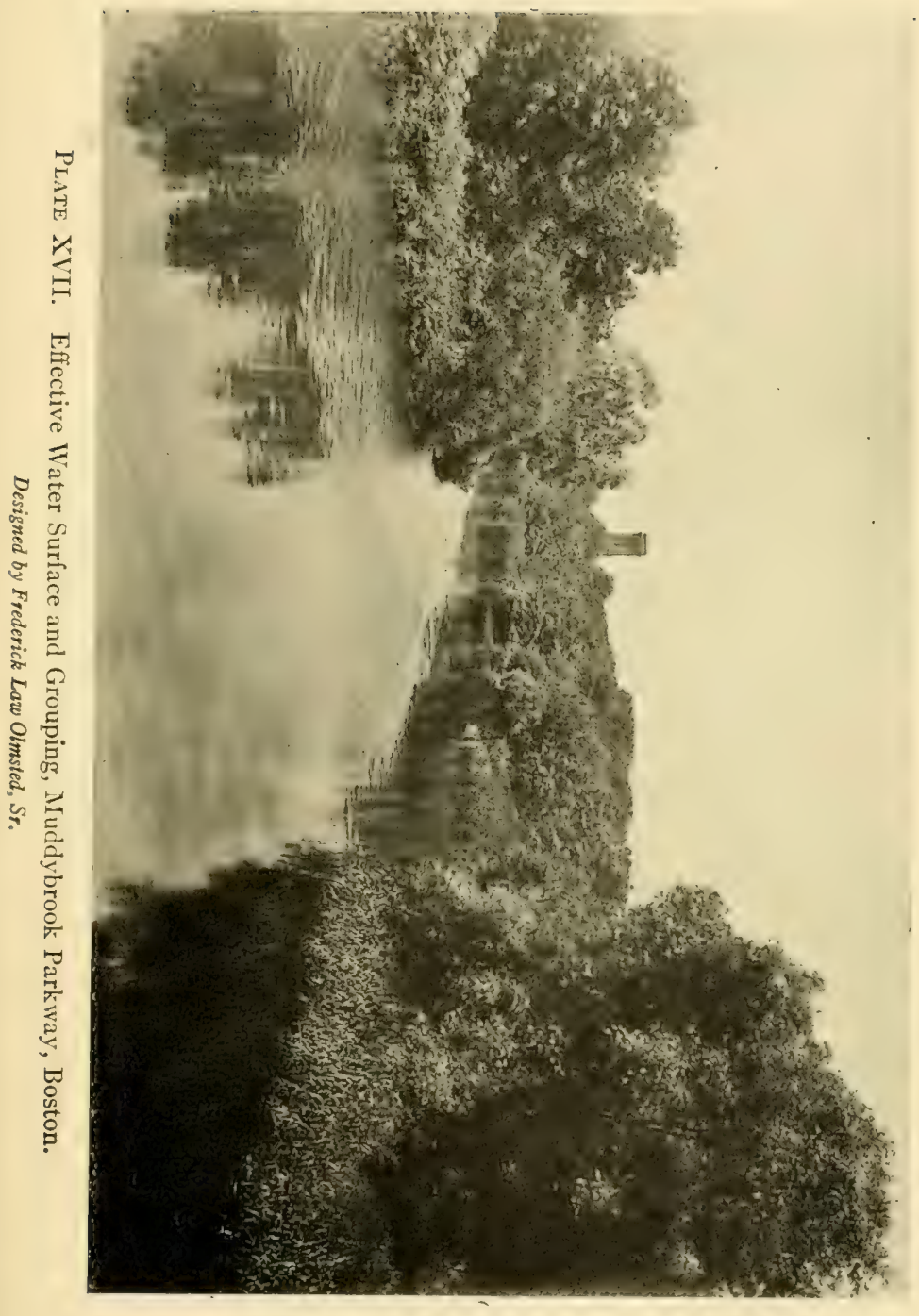





\section{Practical Directions}

apt to become filled up or obstructed by the roots of plants entering them, or by the action of moles, rats, rabbits, etc. Drains formed with rubblestone or any similar material are therefore superior to tile drains in gardens. Where rock is plentiful it can be broken into pieces of two to three inches diameter and placed loosely in the common drains, to the depth of twelve or fifteen inches; or similar pieces of broken brick, flint, coarse gravel, large cinders or clinkers, or whatever else of a like nature abounds in the district can be used instead of rock. A rubble drain should not be less than five or six inches wide at the bottom.

For main drains, however, tiles of $4^{-6}$ inches in diameter will be better as the principal conduits of water, but these should also be covered with at least twelve inches of the material of which the other drains are composed. Glazed, or "Akron" tiles, where they can be procured, wiil always be preferable to porous tiles; especially those which are made with collars to cover the joints have a decided advantage over those ordinarily used.

Over the rubble with which both classes of drains are thus filled up, a sod of from one to two inches in thickness and the full width of the drain should be inverted, to prevent the soil from crumbling and washing down among the stones and clogging up the interstices. As this sod will last many years, until the soil has become quite consolidated, it will be a most useful auxiliary to the drains, and tend to keep their action more perfect. Fig. 72 represents a minor rubble drain, with the broken stone in it $(b)$ and a sod $(a)$ inverted over the latter. Fig. 73 shows a main drain which is deeper and wider, having a tile $(c)$ at the bottom and being half filled with rubble $(b)$ with a sod $(a)$ orer the broken stone. The scale is four feet to an inch.

All drains should be cut out smoothly with even sides and 
a very flat bottom in a firm soil, that the sides may never be falling in to impede the flow of water, and that there may not be anything like little stagnant pools in them. They should each have a sufficient fall by running down the natural slope of the land, and the main drains, being the general receptacles, ought to have a somewhat quicker fall than the rest. If the ground be very flat, a fall must be obtained by cutting the drains deeper at one end than the other.

It is particularly requisite that a good and sufficient outfall for discharging from a place all the water that accumu-
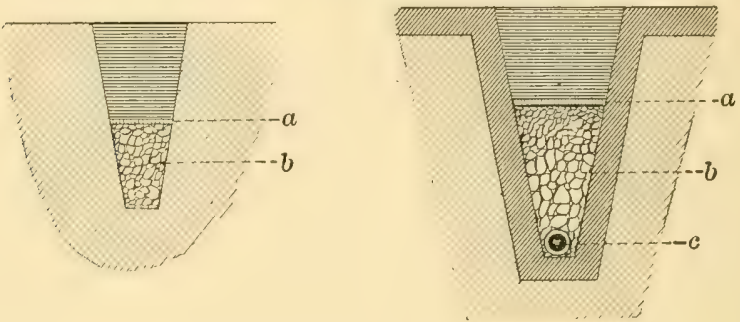

Figs. 72 and 73. Cross Sections of Drains.

lates by drainage be secured and be under due control. Where it is dependent en a neighbor, or the owner of another property, it will always be exposed to interruption and hazard. Efforts should consequently be made to preserve its independence. In these days of attention to sewerage, the common sewer which receives the refuse water from the house will be an excellent medium for taking away the soakage from the land, if this can be at all readily contrived.

2. Clearings. - In forming a new place there are often clearings to be made, and sometimes the removal of trees becomes as important a matter as their planting in other places. Where woodlands reach the magnitude of forests it will 
always be best to have such clearings undertaken only on the advice of an experienced forester. Where trees exist on the grounds in inopportune places they may often be removed to other situations where they will become of great value. The transplanting of large trees is nowadays a well-established procedure, and no good tree should be sacrificed simply because it happens to stand where it is not wanted.

Wherever old hedgerows exist and require to be removed and leveled in a part that is to be converted into a grassfield or park, the greatest care should be exercised in preserving the better part of the trees and bushes that may be in them and in retaining these rather as broken groups than merely as single specimens. Nore may be done to break the line of a hedgerow by a due regard to the retention of bushes around or in connection with trees or in tufts by themselves than by any amount of thinning that disregards this mixture. And it will sometimes happen that the transplantation of a few old thorns, so as to break the lines of others or soften off a cluster of trees will be of the greatest service.

Special pains should be taken not to cut away too much earth from such trees or bushes as may be selected to remain, but rather to add soil to the bank on which they stand than to leave the roots at all bare. By the common practice of spreading down hedgerow banks, so as to reduce them to the level of the ground around trees, the trees that are left often get blown over by wind or are gradually by the exposure of the roots rendered feebler and feebler until at length they perish from sheer exhaustion.

3. Building Walks. - Very much of the pleasure of a garden will depend on the manner in which its walks are formed. A walk that becomes muddy or slimy in wet weather or after frosts, or allows the water to lodge upon it during and after rains, or has a surface of coarse and harsh or loose materials, 


\section{Landscape Gardening}

will do much towards deterring persons from using their gardens so constantly, or at least will rob them of a good deal of enjoyment.

To be perfect, walks and drives should be dry, smooth and even, hard and firm, in all weathers and at every season. And the more nearly they approach to the realization of these things the more they will contribute to comfort and ease.

Dryness can be attained in a walk by shaping the ground properly in forming it, by rounding it up slightly in the middle, by giving it a decided fall in some direction by placing gratings and catch basins for water at the lowest points and

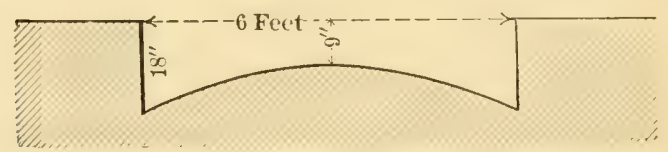

Fig. 74. Excavation for Walk.

by using suitable materials both for the foundation and the surface.

In the ground formation of a walk or drive (for the latter may be regarded as a larger description of walk in a small garden) a firm bottom should be obtained and it should be pared as smooth as possible, keeping it from three to six inches higher in the center according to its width. At either edge the ground should be sloped gradually down for about a foot or eighteen inches in width to the extreme margins where it may be six or nine inches deeper than at any other part. (See the cross-section in fig. 74, which represents the bed of the walk.) These extra cuts at the sides are to be filled with rougher material and to follow the general inclination of the walk for the purpose of drainage. They can com- 


\section{Practical Directions}

municate occasionally with the ordinary ground drains, to let off the water that may accumulate in them. By laying the groundwork of a walk thus high in the center and smoothly sloping to a kind of drain at each side the utmost possible dryness will be gained.

Here and there, however, in the lowest parts of the walk where water would collect on the surface, square holes or catch basins cut deeper than the ordinary drains of the land, to receive the water from grates placed on the surface, may be formed, and partly filled with rubble or, what is better, lined at the sides and bottom with flat tiles, bricks, or slates. These lodges can communicate, by means of short branch pipe or rubble drains, with the nearest common drain, the small drains from the lodges being on such a level as to receive the overflow merely, while the sand and sediment will remain to be occasionally removed.

A walk should have from nine to twelve inches of material upon it, and a drive rather more. Only about three inches of this on the surface need be of fine gravel. The rest may be rubblestone, flints, coarse gravel, cinders, or any angular and irregularly shaped substance that will remain porous and dry. In applying this coating, the crown of the walk may be reduced by putting a less quantity in the center than at the sides. Walks of one yard wide can be raised about an inch in the center when filled, and those of two yards wide about two inches. For wider walks that are straight, in formal gardening, a greater proportionate flatness is desirable, or they will lose some of their dignity and effect. The three inches of gravel can be evenly spread over the whole surface.

Gravel is exceedingly variable in quality in different parts of the country, and often requires some little artificial mixture or preparation before it can be brought into a right state. Gravel that contains much lime or clity, though excellent for 


\section{Landscape Gardening}

binding, will become very dirty in wet weather, and break up considerably after frost. It wants the addition of some stronger, drier, and more sandy sort. Sea gravel, again, (unless it be the muddy sediment deposited on the shores of some great tidal rivers and containing a large proportion of half-decomposed shells which help to bind it firmly but also to make it cloggy after being frozen) will never bind at all without the help of lime or pulverized clay, or a strong loam reduced to a powdery state while dry and added in the proportion of about one-fifth or one-sixth. Such a mixture will, when it becomes fully set, form one of the best possible surfaces for a walk, and will never be too wet.

As the perfection of a walk consists in smoothness and freedom from rough stones, which would also kick up in dry weather and disturb the surface, either a thin upper coating of gravel should be finely screened, or the whole surface may be very thoroughly raked, so as to get off all but the very smallest gravel. Road scrapings, where they are tolerably free from dirt, will also, if sparingly applied, make a very even and excellent surface to a walk when gravel is scarce or not of a good binding nature.

The color of gravel must of course vary according to what can be obtained in any district. Perhaps the best color, where there is any choice, is the full, deep, reddish yellow so common around London. Whitish gravels are usually too conspicuous and cold looking. There is a greater richness and warmth in the appearance of the yellower kinds.

What very much affects the character of walks is the way in which their edgings are laid. These should be quite smooth, thoroughly flat along the margins, and, for some part of their width at least, precisely on the same level at both sides and very well defined though not more than half an inch above the level of the side of the walk. The edges ought 


\section{Practical Directions}

to be kept at one uniform distance throughout, unless there be some special reason for change. Walks that are not carefully formed in accordance with all these conditions will appear more or less slovenly, deficient in the expression of art, and indicative of an unrefined taste.

To render the edgings of a walk firm, capable of being made flat, and cut evenly, they should be formed of what gardeners call rampering sods. These are thick turf-covered masses of earth cut from an old rough pasture and about six inches wide, and four to six inches or more in thickness. They are to be inverted along the edges of walks, leaving about two inches to be cut from the inner edge, next the walk, and paring down the surface until they are brought to the requisite smoothness of level. Edgings thus laid will never crumble away or become uneven unless with extremely rough usage.

To determine the width most proper for a walk, the size and arrangement of the garden will have to be taken into account. Straight walks should always be wider than curved ones, but there must be a nice proportion maintained between their width and their length, as any excess of the former would diminish the latter. From six to eight feet will generally be sufficient for the width of a straight walk, which should certainly not be narrower than six feet. A terrace walk may even be ten feet wide, or wider, if the house be large enough to justify it. For serpentine walks from four to six feet will be about the right width in gardens of the size under discussion, four feet being a little too small, unless the space be very contracted, and six feet somewhat too large. The intermediate width will be best in most cases. A drive can be eight, ten, twelve, or fourteen feet wide according to its length, and object. A back drive that is a branch from the main approach will rarely need to be wider 
than eight feet. Ten or twelve feet will generally be most appropriate for other drives.

It will be of some moment to adjust the height of walks relative to the general level of the ground with judgment and discrimination. As straight walks are intended to make prominent features in a place they should range as perfectly as possible with the level of the lawn. Any particular elevation, depression, or roundness would not harmonize with the flatness and smoothness so desirable in the grass. If therefore they are just half an inch lower than the grass at the edges and an inch and a half higher than it in the center (fig. $75^{a}$ ) they will have two inches of camber which will be quite sufficient.

For curved walks, as it will be a matter of taste to keep them more or less thoroughly out of sight, a few inches below the surface of the lawn or beds will be the fittest level for them, save where it is intended that they should command particular views, when they can be more or less raised. In the first case (fig. $75^{b}$ ) the grass can slope gently down to a narrow flat edging at their margins, while in the other the turf may rise as gradually to join, with a round edge (fig. $75 \mathrm{c}$ ), a broader flat edging at the top. Where the ground and the walks themselves are well drained, and the surface of the former has been perfectly stirred, there will be no danger of depressed walks becoming damp. And besides their being more effectually concealed from the windows or lawn, persons moving along them will see the plants in the beds or borders or on the lawn to greater advantage; they will be a trifle more private and the house will appear higher and bolder as viewed from them.

But curved walks will always require to have a greater degree of convexity (fig. $75^{d}$ ) and if they are six feet wide they should, while keeping half an inch below the verges at 



\section{Practical Directions}

the sides, be raised in the center two and a half inches above the level of those verges, thus making a difference of three inches between the center and the sides. And where the ground is very damp and low around walks that have to be made across parks and their being rendered conspicuous is
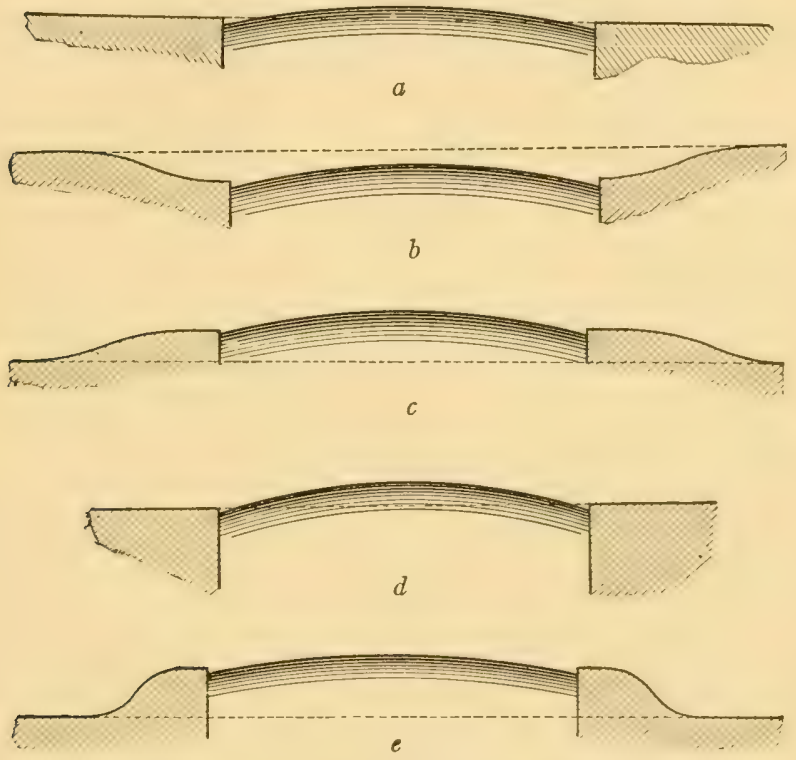

Fig. 75. Different Forms of Walks.

not a matter of consequence, it is a good plan to let the edges rise abruptly out of the ground to the height of about nine inches (fig. $75^{\mathrm{e}}$ ), as dryness will thus be effectually secured.

Grass paths that are not much used and are intended chiefly for appearance or for summer enjoyment may, in some situations, or as connected with houses in the style 
which prevailed during the reign of Queen Anne, have a very neat and lively effect. They should ordinarily be straight and will seldom look well unless they are so. They will of course require to have borders of flowers or shrubs on each side, and these might be filled with rows of one kind of plant, to form a sort of avenue, or they may be planted promiscuously. When required as a common thoroughfare at all times, grass walks will be inappropriate, because they would soon wear bare and would be wet and probably dirty during a large portion of the year.

On good firm soil and in a climate where grass thrives, turf may be grown strong enough even to bear the weight of light wagon traffic, and thus grass drives are possible in such situations. Grass drives, regularly mowed with the lawn mower, are clean and beautiful, cheap and practical, and it is a wonder that they are not more frequently used.

4. Grading. - The period at which grading is performed in laying out a garden is not the least among the practical matters that have to be considered. There is an unhappy propensity to defer this till the very moment in which planting and turfing have to be done, and thus due preparation cannot be made for the one, while the other settles most irregularly and requires subsequent altering and leveling.

Summer and autumn are essentially the best seasons for all kinds of new ground work. The earth is then driest, and can be most easily moved about, and will not be injured by trampling or wheeling. Ground put into shape during the summer gets time to settle and mellow before it is wanted for either planting or sodding, and anything that is afterwards done in the way of finishing will stand better and demand less alteration. What is not altogether unimportant, likewise, labor can then be carried on more easily and can be had more abundantly. I should therefore earnestly press 


\section{Practical Directions}

those about to form gardens not to put off the operation till spring, but to take advantage of the late summer and early autumn weather to get the principal part of the work done and the leading outlines of everything prepared. Perhaps the early autumn is better than summer for the purpose, as the ground will then be kept partially softened by rain and turf may be moved if required without being killed.

5. Preparations for Planting. - In the preparation of ground for planting and for grass the difference in their requirements will have to be kept distinctly in mind. Plantations can hardly have too much good soil. A thorough provision of suitable and mellow earth will almost neutralize the disadvantages of climate or situation and keep plants always flourishing and healthy. For lawns, on the other hand, a light, shallower, and poorer soil, if it be properly drained and worked previously to sodding or sowing, will be preferable as tending to keep down undue luxuriance, and promote the growth of the finer grasses and check the development of rank weeds.

Ground that is in any degree heavy or that has been newly drained ought to be deeply worked all over, whether for grass or plants. If the subsoil be clay, it can be turned up loosely in the bottom; but if of a lighter material it should be brought to the surface for plantations, and simply turned over in the bottom of the trenches for grass. It will always be undesirable to bring clay to the surface in pleasure gardens; though, in kitchen gardens, where it can be freely worked and mellowed for several years, the common mode of inverting the positions of the surface soil and the subsoil may be adopted. The reason for working a lighter subsoil to the top in plantations and not for grass is that additions of better earth can be made to the former, when the subsoil will be blended with this in planting, while it is rather in- 
tended to take away several inches of the topsoil from the grass land and transfer it to the plantations. Two, three, or four inches of the best earth, according to its natural depth, may thus be abstracted from the parts intended for lawn, and will go to raise and enrich the plantations without injuriously affecting the grass. From nine to twelve inches in depth of the commonest soil will be amply sufficient for growing lawn grasses to perfection.

In shaping and forming a piece of garden ground where much variation from the original surface is desired, the readiest method is to commence at the lower part of the land, take out a trench across it of about four feet in breadth, and either lower or fill up the ground as the trenching proceeds. This will be a far more simple and economical plan than stripping off all the soil and putting it aside, and then working the ground into shape, and restoring the soil to the surface.

All the soil from the foundations of roads or walks should further be applied to the ground intended for plantations. Even where the walks have to be raised rather than lowered, it will be better still to remove the soil and replace it with rubbish. The earth obtained from the foundations of the house or other buildings should also be carefully kept apart from the subsoil and used for the plantations. And it will be a prudent and safe rule to assume that no amount of good earth that is at all obtainable from any of the sources pointed out will be otherwise than beneficial for shrubs and trees, or for fruit trees and general crops in the kitchen garden.

If the soil of a garden be moderately light and a good mass of it, by the means here suggested, be procured for the shrubs and trees and for the flower beds, manures, beyond such things as lime, soot, wood ashes, decayed leaves or wood, chemical fertilizers or any similar matters will be quite 
unnecessary for the ornamental part. Roses, however, demand a richer soil and are much improved by the aid of some well-rotted manure, which should not be grudgingly administered

But where the earth is stiff and clayey and not enough of lighter soil is within reach to correct its retentiveness and incapacity for growing plants, manures wiil then not only be beneficial but necessary. Common stable manure may be largely applied with advantage in such cases, while lime, bone dust, coal ashes, or the manure from the ashpits of towns, or the sweeping of streets will be invaluable. And these may be used, though with a more niggardly hand, for the parts to be formed into lawn, as well as for the plantations. .

When the opportunities and patience of the proprietor allow it, a garden will be greatly improved both for plants and grass if it can be deeply dug up in the autumn, a year before it is wanted for finishing, and left unoccupied for the season, simply keeping down the weeds. Or it may be planted with potatoes or sown with turnips or mangels, or otherwise cropped and kept clean. All kinds of crudities in it would thus be destroyed and the texture be greatly ameliorated. Considering that there will be such a slender chance of its being broken up again and worked otherwise than very partially after the lawn is made and the trees and shrubs planted, a year's preparation of this sort is only a matter of the most ordinary policy and should not, on any but the most imperative accounts, be lost.

There is one tribe, of which the rhododendron is the representative, that wants a little peculiar attention as to soil. They will, it is true, live in any ordinary garden soil, especially if it be light. But they attain their richest state when the earth in which they are grown is in great part made up of fibrous peat. To have them in their highest perfection, 
then, they should be grown principally in masses, so that proper soil can be supplied to them, and should be furnished with about one-third or one-half of good peat or leaf mold, in a rather shady situation.

Where proper peat cannot be procured for rhododendrons, leaf mold will be the best substitute for it. And even if this should not be attainable, turfy loam, taken from an old pasture, may suffice, or well-rotted stable manure may be freely used in conjunction with common soil. Any earth that is naturally of a chalky kind or that contains much lime will be particularly unfavorable to rhododendrons.

6. Circumventing the Gardener.-- One of the greatest practical difficulties with which the artist in landscape has to contend is dealing with the picturesque. Smoothness and regularity of treatment are so thoroughly what an ordinary gardener is accustomed to, that it requires no small effort to enlighten him as to the mode of achieving anything really beautiful in the way of curved lines and undulations. But when ruggedness and an appearance of rude naturalness are sought it is indeed hard to obtain a practical operator. In this case, soil has often to be thrown down in rough heaps without smoothing, leveling, or exhibiting the marks of any tool; masses of soil or rock have to be wrenched away from the face of a bank; stones or roots have to be thrown down as irregularly and wildly as possible; tufts of rugged vegetation or scrambling shrubs must be left where these exist; all roundness or curvatures have to be avoided; and everything that is angular and broken striven after. Rocks when they are inserted require to be blended with the ground in the neighborhood by means of a few scattered groups or single stones, only partially filling up the interstices among them with soil so as to preserve a rugged surface and not providing for covering the stones too much. 
7. Present vs. Future Effects. - Planting may be undertaken with reference solely to the ultimate effects it will produce, or it can be made to embrace a more immediate and present result. The former plan is of course somewhat the easiest as far as labor is concerned, and is the least expensive when the plants have to be bought. But a garden that is planted only with the smallest nursery things will be exceedingly tame and uninteresting for several years, and it will require the planter to have a very good knowledge of each individual variety with respect to its natural or usual height and habit to make the final picture at all a successful one.

In many neighborhoods where large areas have been planted for public or prospective ends, the yearly thinnings from such plantations will be obtainable on comparatively moderate terms, and these will be very useful in giving an appearance of age and variety to a garden. As the private gardens are generally in need of thinning, a planter may sometimes pick up a number of effective specimens among his friends or in the way of exchange for other things. And when these resources fail or money is not so much considered most good nurserymen now grow plants in borders, and transplant them occasionally for the express purpose of supplying larger specimens that are well rooted and can be safely removed with balls of earth to diversify and give an air of greater finish to newly formed gardens. Such trees and shrubs can be bought very reasonably in large quantities, and their free use is always to be recommended.

Notwithstanding the extreme desirableness of attending to the present appearance of plantations, and putting in a few plants at intervals to make an immediate show and to banish the monotonous dulness una voidable where only the youngest class is employed, the great aim of the planter should be for future effect, and where the bulk of the plants are healthy 
and likely to do what is ultimately expected of them, their temporary mean or meager aspect may be entirely disregarded. And although the peculiar developments which result from accident may sometimes yield combinations superior to any that the most cultivated art could produce - such is the adaptive and plastic power of nature - yet as such fortuitous groups can never be calculated upon and may never arise, it is right to act as if all depended on the provisions of art and place each plant where from its known constitution it is most likely to yield the wished-for effect whether of outline, harmony, or contrast.

8. Planting Out. - Having got the ground into a proper condition for planting, and remembering that the place should assume as good an appearance as possible both immediately and prospectively, the next consideration will be as to the time and manner of effecting this operation. The first of these will relate to the season and the weather alone. The other is much more comprehensive.

Whatever may be said of plants bearing to be removed at almost any season of the year, if a due regard be paid to their nature and wants, it is pretty certain that the fall of the year, when the leaves of deciduous plants are just shed, is the most appropriate period for transplanting them, where choice is allowed; while evergreens will probably be less injured by being planted about a month earlier. Into the reasons for this view it would be needless here to enter, as both theory and experience confirm it. But planting may be conducted throughout the whole of the winter in open weather, and until the buds develop pretty vigorously, or the beginning of April. For deciduous plants, however, the earlier they can be got in the less they will suffer in the following summer; and evergreens, if unplanted at the time of the occurrence of the first sharp winter frosts, should be 


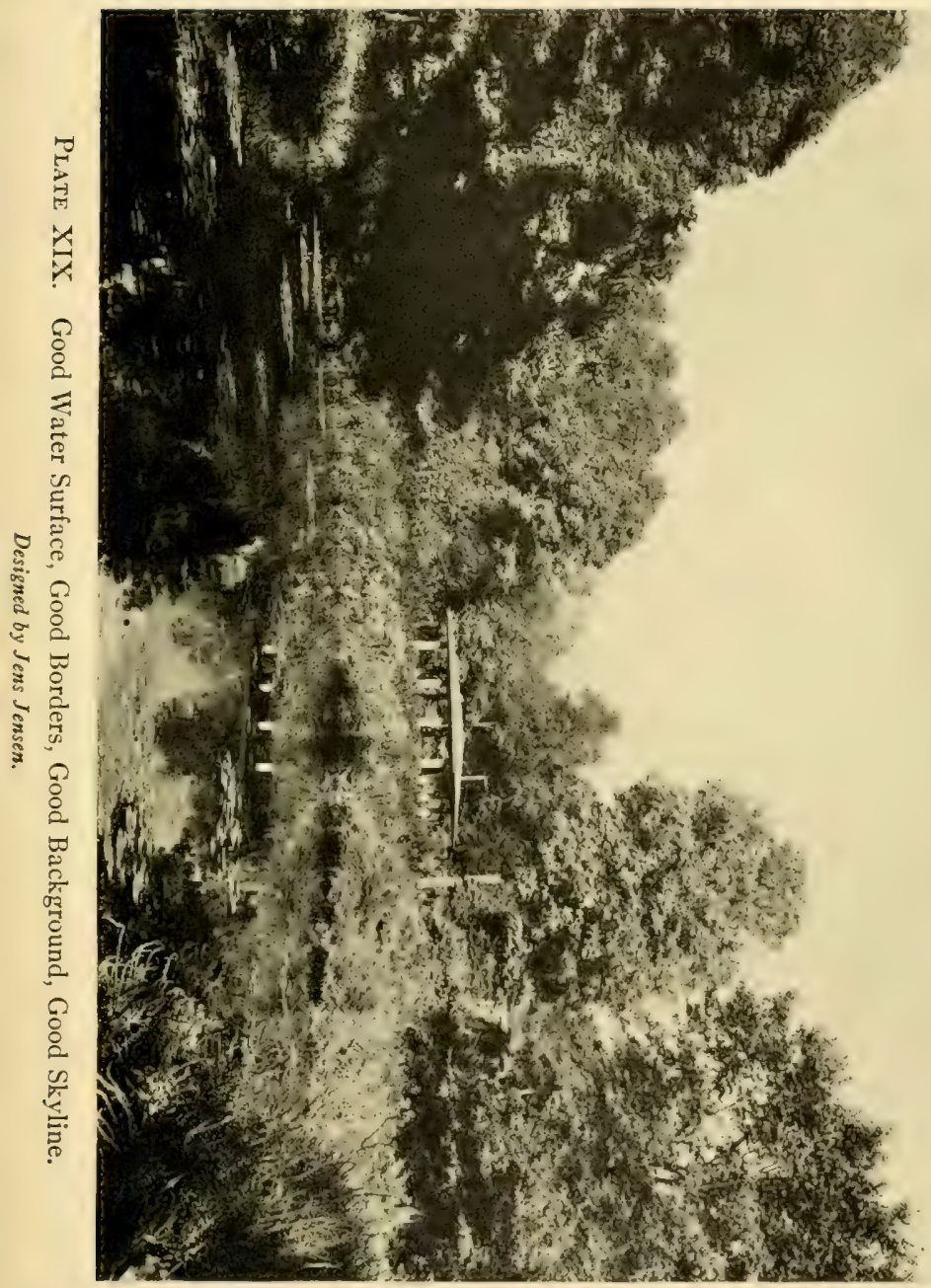





\section{Practical Directions}

kept back until about the earliest showers in April, otherwise the harsh and drying winds of March will severely endanger them.

Calm, dull, moist weather is almost of more consequence in planting than the time of year. If the sun be shining brightly, or there is any wind stirring, or the ground or the atmosphere be very dry, no kind of planting should be proceeded with. A plant out of the ground, with its roots exposed to drying influences, is in as unnatural and perilous a position as a fish out of water. Both may survive; but they have a great struggle to get over it and their future health is for some time enfeebled. No weather is better for planting than the damp and foggy period so peculiar to November in England.

Not only should planting be done on a cloudy and moist day, but it must be done rapidly, so as to keep the plants out of the ground as short a time as possible, and the roots should be preserved and spread out with the utmost care. A plant is mainly dependent on its roots for existence and support, and if these are much mutilated in taking it from the ground, or crushed, crippled, and huddled up together at the time of its replanting, its chances of life and vigor will be proportionately weakened. All the roots have their share of branches and foliage to supply; and when the former are much reduced in taking them up, or rendered inoperative by careless planting, the balance between the two is lost and great weakness or death results. The root fibers, therefore, should be strictly preserved as far as possible and laid out in their natural position when replanted, covering the whole with light and fine soil.

In transplanting shrubs or trees of any unusual size, particularly evergreens, or even in moving smaller plants of the latter from one part of a place to another or from a position 


\section{$276 \quad$ Landscape Gardening}

which admits of their being accompanied with balls of earth about the roots, these should always be kept. The ends of the roots must not be cut off close to the ball, but should be carefully taken out with a fork and the outside of the ball be left loose and guarded against every kind of compression. Where the roots become bruised or injured, they must be pruned and the jagged ends made smooth. The soil should be shaken very lightly among them and pressed under the ball by means of a blunt stick that no cavities may be left there. If the weather be ordinarily moist and the period be late autumn no watering of any kind will be necessary. But a thorough soaking with water will sometimes be useful in spring planting, and a subsequent mulching with grass mowings, manure, or litter will generally be found of service in dry summers.

It is always safest to plant pretty thickly, for where the climate or the prevailing winds are not so severe as to demand this precaution, the better kinds of plants invariably grow stronger and faster for having a little shelter, provided this does not rob them of light and air or produce deformity, and is not continued too long. All the best plants and the larger specimens should, however, first be put in a plantation, the intermediate parts being made up of commoner things and such as can easily be taken or cut out the moment they begin to do harm. The rule among modern park planters is, "plant thick, thin quick," - and it is a good rule.

If large plants be used to break the outline of a young plantation, they should not be left to stand alone and unsupported, but be at least partially and irregularly surrounded with middle-sized plants of different heights, to relieve their solitariness and the abruptness of outline, and also to shelter them a little from the action of winds and shade their roots somewhat from the drying influences of sun and air. 


\section{Practical Directions}

Single specimens of tall trees standing amidst a tribe of very much smaller ones look extremely naked and do not blend at all beautifully or softly with the rest. Nor would the hardness of their appearance be mitigated for several years.

No plant will ever answer the expectations of the cultivator if its roots be buried too deeply at the time of planting or afterwards. Such a practice would shut them out from air and speedily tell upon the health, most probably killing the plant ultimately. The crown of the root ought not to be placed more than two or three inches below the surface of the ground. As the soil settles the plant will then at length have the collar or crown of its roots just level with the ground, and this is the most natural and healthy condition.

That plants in masses should not be placed in any kind of rows, but be dotted about as irregularly as possible and at various distances from each other and from the front or back of the plantation, would seem quite a trite remark, were it not a rule that is seldom observed in small gardens. Nothing is more common than to see the plants put in either straight lines or rows following the outline of the mass, at one measured distance apart, and with two plants of the same kind occupying precisely the same position in the bed on opposite sides of the garden, thus making the arrangement of a group a system of pairs, rather than the most inartificial and broken thing imaginable. Even in some great public and national works the trees are planted in rows although the outlines of the plantations in which they occur are decidedly irregular.

All this, however, unless where studied lines or avenues are contemplated, is far too artificial for the natural style of gardening, which is essentially free, varied, and approximating to nature. And since no such things as lines of plants, symmetrical correspondence of sorts in particular parts, or anything approaching to regularity of distance 
between the plants is to be found in natural groups, neither should any of these things exist in irregular garden masses. It is observable in nature, indeed, that several stems sometimes spring out from nearly the same spot, and by the growth of the branches get forced away from each other in various oblique directions, thus making a very picturesque and pleasing group. Something of the same kind might often be attempted with advantage in gardens or large plantations with both shrubs and trees, and would get rid of the monotony of a succession of upright and shapely specimens standing free from every species of encumbrance. For ordinary plants, a distance of from three to six feet, according to the size of the plants, will be most proper. Very small shrubs may even be placed as near as two feet, but three or four feet will more generally be right.

9. Securing Stock.-In the establishment of large estates, particularly when the grounds are to be under the constant care of an experienced arboriculturist, it is usually wise to have a nursery on the place. While it will not supply all the materials needed, and while it will not usually prove to be any great economy, it will nevertheless be a great convenience. Trees and shrubs may be had of the varieties desired, and, what is more important, they will be on hand when wanted and will not have to undergo the risk and exposure of long shipments. For most private places, however, it will be best to secure plants through the regular commercial nurseries. Where trees, shrubs and herbaceous plants are to be used in considerable quantities they can always be had at reasonable prices.

The main point to be considered in securing nursery stock from dealers is to get young, thrifty, clean, well-grown stock free from disease. Old trees which have been kept for years in the nursery rows are almost certain to be the culls left 


\section{Practical Directions}

after many selections. The only important exception to this general rule is to be made for those fine large trees especially grown by certain nurserymen who supply them, at correspondingly high pricies, for planters desiring immediate effects. Freedom from insects and disease should be insured by the state inspector's certificate; but unfortunately it is not always a final test. Personal inspection by the buyer should be added to official inspection in all cases.

It is not important, as has often been claimed, that nursery trees should be grown in the immediate locality where they are to be used. There are certain practical advantages in patronizing a nearby nursery, the most important being the decreased risk of delay and damage in shipment. Aside from these questions of convenience the buyer may fairly choose that nursery which offers the best plants at the lowest prices, - always having first care for the quality of the stock and second for price.

When considerable quantities of nursery stock are required to plant a place it will be found an excellent plan to send duplicate lists of the requirements to several nurseries, asking for itemized bids. Such bids will enable the buyer to place his order to best advantage; and often he will find it expedient to order a part of the bill from one nursery and a part from another. When considerable amounts of stock of a single size and variety are wanted nurserymen will often be glad to send samples with the bids, in order that the buyer may know exactly what he is to get.

Large plants taken from nursery rows never become properly furnished, but always retain their spindly, bare, and pinched-up appearance. Where larger things are wanted, only such as have been grown separately in borders or as specimens should be used. None but the smaller plants, if obtained from rows in a nursery, will be at all satisfactory. 


\section{0}

\section{Landscape Gardening}

And it is small plants which, if well attended to, constantly produce the most healthy and perfect specimens. While, therefore, a few larger things may be admitted into a garden for variety, the staple of its furniture should be made up of lower stuff. Three to four feet in height is a good size for forest and ornamental trees and about two feet for the majority of shrubs. Evergreens answer better when planted only about nine inches or a foot high, if they be afterwards kept free from weeds and are not allowed to be smothered by other plants.

In selecting plants for furnishing a garden, character and ornament should invariably be the prime considerations. Mere novelty ought to have little or no weight. Besides the objects to be aimed at in planting which have been mentioned in previous pages, however, it may be well to take into account the appearance of deciduous trees and shrubs in winter, with respect to their general form, or the color of their shoots and buds, and also with reference to their beauty when covered with snow and frost. Such as have slender or drooping branches are particularly eligible on the latter account and none are more so than the weeping birch. For the color of their shoots and buds, birches, willows, alders, the golden ash, dogwood, etc., are most noticeable.

To relieve the excessive bareness of young plantations in pleasure grounds, dahlias, hollyhocks, and many other herbaceous species, if copiously introduced, have been found singularly useful. The leaves of newly planted shrubs seldom develop fully for the first year or two, and much may therefore be done to make the clumps look fuller by means of the plants just named without doing any injury to the more permanent occupants of the ground.

I0. Staking Trees. - Newly planted trees and large shrubs will sometimes require staking or supporting, as, if they play 
about in the ground by the action of winds, the roots will be broken and strained, and a hole for the collection of water be formed, which will in the course of time rot the roots. Evergreens are particularly liable to suffer and even die from this cause. They present a greater surface to the action of the winter gales. And all plants that are disproportionately heavy in the head are most likely to need staking.

But any kind of staking is sure to be more or less unsightly, and whatever means can be devised for dispensing with it will be a decided boon. Something may certainly be done by
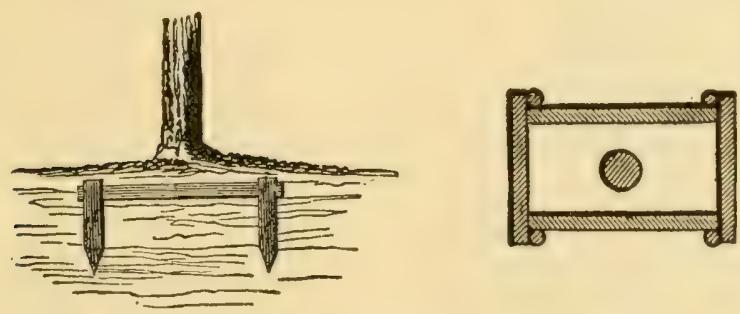

Figs. 76 and 77. Setting a Tree to Stay.

planting things of a rather lower growth around one that is apt to be moved about by winds. These will soften the force of the attacks and make the plant more proof against them. For large trees, too, that are planted with balls of earth, and have tolerably strong roots, a triangular or square frame made of bars of wood laid across the ball of the plant, and nailed to stout posts driven firmly into the ground at the corners, will be safer than any upright stakes. (See figs. 76 and 77 , the latter being the ground plan.) Strong ropes fastened to the upper part of the stem of a newly planted tree, and tied in several directions to other trees or fixed objects (fig. 78), putting some hay or matting around the 
tree to prevent it from being cut by the ropes, may occasionally be successful. Planting with good balls of soil or a little more deeply than usual will help further to stay large specimens and to make them able to dispense with extra support.

Where neither of these plans is applicable, or would not be effectual, stakes themselves must be employed. If the wind blows most roughly from any particular quarter, the principal

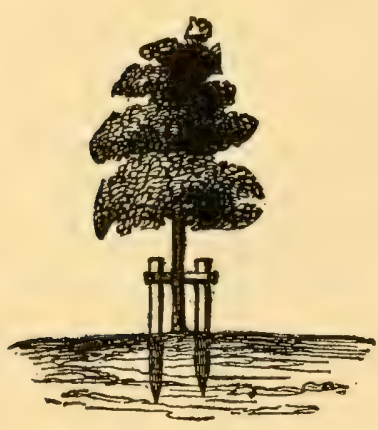

Fig. 78. Staking a Tree.

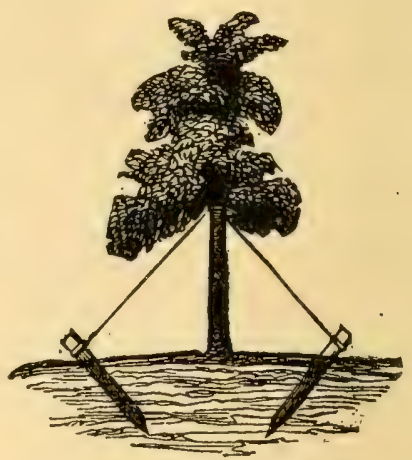

Fig. 79. Staking a Large Tree.

stake should be placed on that side that the plant may blow away from the stake and not upon it. Some hay, matting, or other soft substance should be put between the plant and the stake, and also around the plant where the cord embraces it. More than one or even two stakes (fig. 79) will sometimes be requisite for very strong or very heavy plants. But if the stakes are driven down very deeply, they need not stand more than one, two, or three feet above the ground, which will render them less objectionable. If only one stake be employed, it may by chance be able to do its work if 


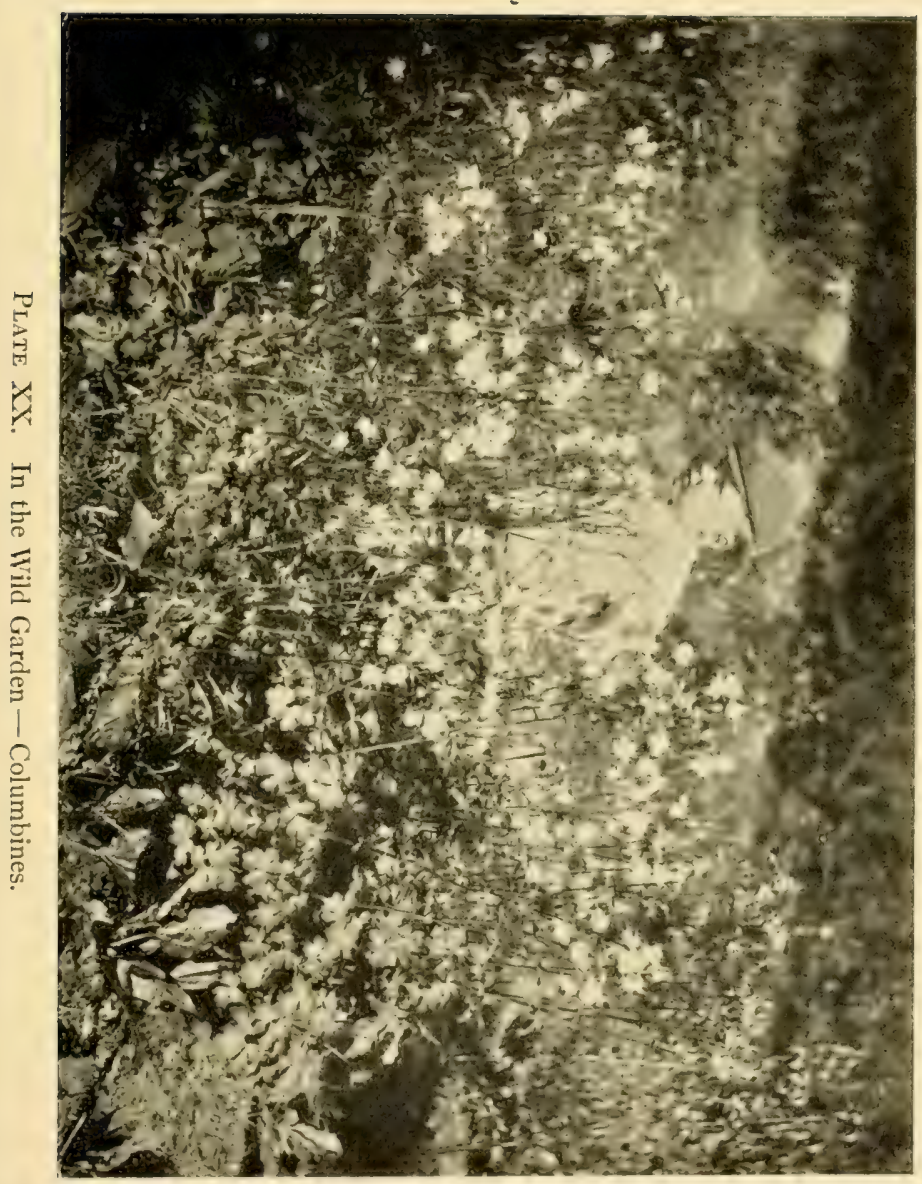





\section{Practical Directions}

placed behind the plant, so as not to be seen from the walk, and this is everywhere desirable, when it does not diminish the power of support. No stake should ever be disproportionately thick or it will appear clumsy. When one end is thicker than the other, the thick end must be inserted in the ground. And it ought to be remembered, too, that the higher any stake stands out of the ground, the greater will be the power of leverage upon it, and the deeper it should descend into the earth.

In applying stakes to plants, the time when their roots are bare and before they are covered in with soil should be chosen for placing the stake in its right position, that it may not injure any of the roots. If driven down at random after the roots are all buried, it will most probably damage or sever some of the more valuable of them. The nearer it can be placed to the stem of the plant, consistently with safety, the more power it will possess, and the less distinctly will it be visible. The tree should in all cases be fastened as firmly as possible to the stake, always providing that it has room to expand itself for two or three years.

II. Sodding Lawns. - Where good turf can be had without much trouble or expense, it will be more immediately beautiful and satisfying to sod a lawn than to sow it down with fresh seeds. And even if it be too serious an item under any circumstances, the edgings of walks and the outlines of beds should be everywhere defined by a strip of old turf at least a foot in width. This will prevent the seeds from being scattered on the walks or borders, and make the edging firmer and less ragged for several years. Indeed, it is impossible to make a sound and satisfactory edging, except with old turf.

Sods should always be chosen from an old pasture, and one where sheep have been accustomed to graze will be best. 
The autumn months offer decidedly the fittest season for laying them down, as they will then at once take ho $\mathrm{d}$ of the ground, without the danger of their separating and curling up at the edges during the succeeding summer. But any mild weather throughout the winter or a showery time up to a late period in the spring may be selected for the operation, if more convenient. The soil should always be well stirred as the sods are laid, and if there is any chance of their suffering from drought or if the grass is not sufficiently fine, a little light soil mixed with lime may be strewn over them after they are laid, and swept into their interstices with a scrubby broom. A few of the finer grass seeds may be added, if it be in spring. Sods ought always to be laid lengthwise up and down steep slopes or at right angles with a line. of walk as the edgings will then remain firmer, and may be cut truer.

12. Seeding Lawns. - For sowing grass seeds the ground should be lightly dug over about the first week in April or the first of September, and the seeds sown immediately after. It will be advisable to scatter them rather thickly, then tread and rake them well in and give the ground a thorough rolling. Care must be exercised to make up the ground by the edgings already laid to the level of the top of those edgings, in order that, when the young grass springs up, all may be on the same level and there may not be a break or dip between the old and the new. After the grass has vegetated, it will simply require to be kept free from weeds until it is strong enough to be mown. A dry day in a showery season will of course be best for sowing grass, as it is for all other seeds. And it ought not to be forgotten that, on the evenness with which the ground is dug, leveled, and raked, will hereafter depend the beauty and smoothness of the lawn. 
In sowing small lawns it will be best to buy a so-called lawn mixture from some thoroughly reliable nurseryman. In other cases it is well to stick pretty close to blue grass or June grass, Rhode Island bent grass, meadow fescue, and white clover.

13. Special Situations. - Certain situations are so unfavorable to some kinds of regetation that they are only capable of bringing a few plants to perfection. And as it is generally better to grow a few things well than to have a more ample collection of indifferently cultivated plants, the knowledge of what will flourish in a given district will be of great use to guide the planter in his selection. While I cannot pretend, then, to furnish extended lists, which would demand a familiar local acquaintance with the entire country, it may perhaps be suggestive at least of what can be done, if I advert to a few common kinds of climatic peculiarities and mention some of the most ornamental plants that are calculated to suit them.

Gardens in the neighborhood of the sea are much afflicted with gales which are of such violence and carry such a quantity of saline matter with them that the leaves and young shoots of some plants are frequently destroyed. Dense planting on ground that has been perfectly drained and prepared will be some slight preservative against such winds; and it will be useful to gather the plants together in masses to a greater extent than would otherwise be required, that they may help to sustain and shelter one another. Single plants, or thin strips of them, are always most scourgerl and cut to pieces by such gales. Still there are some plants which will endure a prodigious amount of blowing without material damage. And of these the sycamore maple and other maples, some elms (especially the Wych elm), hirches, if planted young; beech, when likewise planted in a small state; 
the common alder, the mountain ash, and several services; and the Scotch fir, Austrian pine, Pinus laricio, montana, and pinaster, if a little sheltered, will make excellent trees for the seaside. Poplars and willows will be valuable for temporary shelter, as they will grow rapidly and tall, and thus protect the others till they become strong, after which they should by degrees be almost entirely weeded out.

Among dwarf seaside plants, the dogwoods, the Ribes sanguineum and aureum and grossulariafolium, the deciduous viburnums, the symphorias, the elders, the tamarisk, some of the spiræas, particularly salicifolia, the common fly honeysuckle, and the berberries are particularly hardy for deciduous shrubs; while all the hollies are valuable as evergreens, and the common rhododendrons and heaths (when planted young), evergreen berberries, will, with privet, which is almost evergreen, be useful in rendering a seashore garden green and lively during winter. Of these, the tamarisk, the elder, and the common furze will flourish on the very margin of the sea and in the poorest sandbanks.

For hills that are more inland where there is a scanty soil and great exposure with steep or precipitous faces exhibiting little beyond the bare rock in parts, birches, pines, larches, the common ash, the common oaks, mountain ash and services, with heaths, rhododendrons if there be a little shade, common hollies, thorns, and clematis for enriching some of the jutting masses of rock, vacciniums, mountain snowberry, savin, etc., will make an excellent clothing of either a dense or a partial kind. Plants should be put in when quite small in such elevated tracts.

Of plants that will thrive in marshy places or by the sides of water courses, willows and alders will be the most significant, and the latter are decidedly ornamental. The deciduous cypress, in sheltered spots, is quite as suitable, and even 


\section{Practical Directions}

more elegant. Where there is a small raised bank, however, by the margin of a stream, oaks, beeches, sycamores, weeping birches, and thorns will form good accompaniments, though almost any other tree will grow in such a position.

Within the smoky precincts of large towns, the accumulation of soot on the leaves of plants keeps them sickly and, in conjunction with other influences, actually destroys many of them. Without doubting the potency of town gases or more substantial deposits, I am inclined to attribute some of the bad health common in town plants to the miserable earth in which they are often grown, and believe that were the soil renewed and freshened occasionally by additional deposits, the ground being duly drained and prepared in the first instance, many of our public gardens in towns would present a different aspect.

Some plants, however, unquestionably manage to endure the air of large towns better than others. Elms, planes, beeches, birches, poplars, horse chestnuts, mountain ash, lilacs, privet, Japanese quince are a few of these. Planes may be particularly mentioned as enduring the very worst of town atmospheres in the heart of London, and growing as healthily there as if they were in the open country. To enumerate more would demand an amount of space which the design of the book will not justify me in affording. Any one accustomed to walk through extensive towns might soon, by a little observation, extend and perfect this list, and with an eye also to their own locality. The principal aim in this and all other matters has chiefly been to put amateurs on the right track, and not to exhaust the subject which is too ample to be fully discussed in so short an essay.

14. Program of Work. - It may be well just to indicate, cursorily, the order in which the different operations involved in laying out a garden should be performed, as some incon- 
venience and extra work might be occasioned by having any of them done much out of the proper routine.

The first thing to be set about - whether the place be large or small - is to make a definite plan of proposed operations on a sufficiently enlarged scale. This should never be omitted since the proportions of the various parts can be judged of better on a plane surface, such as that of paper, and greater consistency and harmony can be attained. It will be advisable, also, to set out the walks, plantations, beds, etc., from this plan, by actual measurement, and not simply by the eye, to secure precisely the same easiness of lines and adjustment of parts as in the plan, only modifying any of these afterwards in such ways as an examination of the whole from the many different points of view may render necessary.

When the plan is made and the position for the house fixed upon, the soil on the spot which the house will cover, and for at least six or eight yards in width all around it, should be stripped off, and partly taken away for the plantations or kitchen garden, partly thrown up in a ridge around the stripped area to be used after the house is completed in covering such portion of the ground as may uitimately be converted into garden. Space for the builders to work and trample upon will thus be left, and there will also be room for depositing the clay or rubbish from the foundations. Beyond what will finally be wanted round the house itself, the material from the foundations should, however, be at once taken where it will be required, which will save the trouble of moving it twice.

To prevent the workmen employed in building the house and those engaged in carting materials to it from making footpaths or roads over all parts of the ground, it will be prudent as soon as the foundations for the house are excavated to cut out the principal approach, drive, or walk, and fill it with 
rough stone or gravel fit for carting and walking upon, so as to confine every one as much as possible to the use of this.

Fences of all kinds will next engage attention. It will naturally be concluded that one of the first things to do is to make the boundary fences perfect, due regard being had to the chosen points of entrance. The inner fences, such as that round the pleasure grounds, may afterwards be fixed. And where kitchen garden or other walls have to be erected, they should be begun in good time, that the builder's workmen may be got out of the way before it be necessary to commence on the ground work. In short, no trenching or leveling should be attempted in any part until the masons, bricklayers, or other artisans have fairly completed their duties.

Draining, grading, and general ground work, such as forming pieces of water, raising mounds, preparing rockeries, or any similar rough operations to throw the surface of the place into its leading shapes and outlines may then be proceeded with, always leaving space enough around the house untouched that the builders may not interfere with what is done.

While the ground is still unpolished but the general shape of everything correctly marked out, the planting should be done. It always disturbs the grass to plant after it has been laid down. And as the house will no doubt be almost finished by this time, the edgings of the walks can then be formed, which may be done by inverting sods, cut about nine inches thick, and a foot in length and breadth, along the margins, laying them so as to allow about from one to three inches to pare off at the top, and a similar piece on the sides next the walk. These sods will be found to make excellent edgings, in point of firmness; and after they are laid, the ground can be leveled to them and to the beds and plantations, ready for putting on the turf, or for sowing with grass 
seeds, either or both of which processes may follow, if it happens to be the right season. Of course, however, it is assumed that the planting, and all the other things here spoken of, will be done only at the periods of the year already recommended as most suitable.

As soon as the grass is duly laid and settled, and the workmen have left the house, the edgings of the walks can then be accurately cut, observing to pare them down quite square, and take out the soil to the very bottom of the foundation of the walk; otherwise grass and weeds will be continually rising afterwards and destroying the regularity and evenness of the lines. The edgings towards the borders or beds can be cut at the same time, or earlier if desired. The gravel may then be spread on the walks, and the whole will be completed.

But it is quite possible that workmen may be detained at the house, plastering or painting the exterior, for some time after the principal parts of the garden have been finished. In that case, it will be proper to defer leveling and sodding as much of the space adjoining the house as they are likely to trample over, and make all this good after they have been entirely removed, or much of the sod will most likely be trodden out of place or destroyed. Especially is it requisite to refrain from planting near a house until all its outer portions have received the last touches, for it is almost certain that many of the plants would otherwise be injured and broken. 


\section{N D E X}

Access to the house, 132

Accessibility, 2

Altitude, 8

Animals in parks, 199

Apparent extent, 54, 58

Approaches, 23

Appropriation, 96

Aquatic plants, 225

Arbors, 234

Architectural gardens, I 7 I

Artificial mounds, 32

Artificial ponds, 227

Aspect, I7

Association, IO2

Aviaries, 245

Banks of lakes, 229

Biographical note, xiii

Blending, 52

Boathouses, 232

Border plantings, I 5 I

Boundaries, I I

Boundary treatment, 8r

Boundary walls, 146

Bowling green, 22 I

Branching walks, IIO, II 3 , I4I

Breadth of lawn, 55

Bridges, 23 I

Building walks, 26r

Carriage turn, 138

Character, 89

Choice of a place, I

Clearings, 260

Climate, 12

Climbing plants, 186

Clumps of trees, 35

Combination of elements, $\mathrm{IO} 3$

Compactness, 49

Concealment of outbuildings, 68
Contrast, 84

Convenience, 48

Cost of maintenance, 128

Croquet grounds, 222

Curved walks, 266

Drainage, 257

Drives, 43

Eccentricities, 40

Economy, I 27

Edgings for walks, I $9 x$

Entrance features, 133,247

Evergreens, I6I

Fences, $38,59,143,47$

Fields, I 94

Fitness, 96

Flower beds, 30, I I6, I 8 , I 50

Flower beds in winter, 187

Flower garden, 202

Flowers and grass, I57

Foreground treatment, 63

Formality, 4I

Garden architecture, $\mathbf{1} 6 \mathbf{1}$

Gate lodge, 246

General principles, 46

Geometrical figures, 41

Grading, I6, 83, I2I, 268

Grading land, 196

Grading to the walk, 142

Grading walks, 57

Graduation, or transition, 53

Greenhouses, 239

Grouping, 71, 82, 183

Groups, 153

Hedges, I 88

Herbaceous plants, I 56

Historical considerations, 7

House plans, 18 
Imitation of nature, 97

Improvement of shelter belts, 36

Intricacy, 47

Kitchen garden, 44, 242

Mixed styles, 39

Monotony, 42

Mounds and banks, 176

Natural features, 95

Natural style, 123

Neighborhood environment, 5

Nursery stock, 278

Originality, 88

Overdoing, 28

Overexposure, 38

Overplanting, 34

Particular objects, 175

Perspective, 60

Picturesque style, I 24

Planting, 269

Planting out, 274

Plantings on shores, 230

Playgrounds, 219

Poverty of expression, 92

Practical considerations, i 27

Practical directions, 257

Preface to American edition, $x$

Preface to first edition, $v$

Preparations for planting, 269

Program of work, 287

Protectors for trees, 148

Removal of trees, 39

Repton on trees, I 80

Richness and polish, 67

Rockeries and fern gardens, 209

Rose garden, 213

Rustic work, 33

Seaside gardens, 255

Seclusion, 5o

Securing stock, 278

Seeding lawns, 284
Shadows, 184

Shady spots, I 88

Shapes of trees, 180

Shelter, $1_{3}$, I 29

Shelter plantings, I9o

Shrubbery walks, 197

Simplicity, 47

Single trees, 196

Sky lines, 152

Small matters, 175

Sodding lawns, 283

Soil, 9

Special collections, 216

Special features, 194

Special situations, 285

Specimen plants, 158

Staking trees, 280

Statuary, 237

Styles of gardening, 93, 107

Summer houses, 234

Surprises, 40

Symmetry, 53

Tennis courts, 222

Terrace plantings, I 69

Terrace treatments, I2I

The gardener, 272

The "long walk," I36

Thickets, 159

Treatment of walks, I 40

Tree belts, 34

Undergrowth, 160

Unity of parts, $5 \mathbf{I}$

Unsuitable ornaments, 40

Variety, 68

Various accessories, 234

Vases, 237

Views, 15, 76, 79

Vistas, 62

Walks, 70

Water, I 22

Water treatment, 80

What to avoid, 28

Winter garden, 2 I 8 



JAN $27 \quad 1911$ 

One copy del, to Cat. Div.

HAN 27 1911




\section{LIBRARY OF CONGRESS}

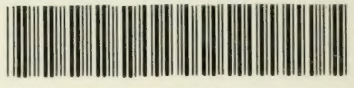

00009144985 